NATIONAL LABORATORY

MANAGED BY UT-BATTELLE

FOR THE DEPARTMENT OF ENERGY

\title{
HISTORY OF THE ENGINEERING PHYSICS AND MATHEMATICS DIVISION 1955-1993
}

J une 2001

Prepared by

BETTY F. MASKEWITZ

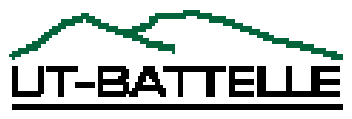




\section{DOCUMENT AVAILABILITY}

Reports produced after January 1, 1996, are generally available free via the U.S. Department of Energy (DOE) Information Bridge:

Web site: http://www.osti.gov/bridge

Reports produced before January 1,1996, may be purchased by members of the public from the following source:

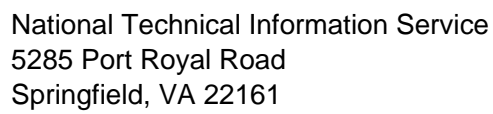

National Technical Information Service

5285 Port Royal Road

Springfield, VA 22161

Telephone: 703-605-6000 (1-800-553-6847)

TDD: 703-487-4639

Fax: 703-605-6900

E-mail: info@ntis.fedworld.gov

Web site: http://www.ntis.gov/support/ordernowabout.htm

Reports are available to DOE employees, DOE contractors, Energy Technology Data Exchange (ETDE) representatives, and International Nuclear Information System (INIS) representatives from the following source:

Office of Scientific and Technical Information

P.O. Box 62

Oak Ridge, TN 37831

Telephone: 865-576-8401

Fax: 865-576-5728

E-mail: reports@adonis.osti.gov

Web site: http://www.osti.gov/contact.html

This report was prepared as an account of work sponsored by an agency of the United States Government. Neither the United States government nor any agency thereof, nor any of their employees, makes any warranty, express or implied, or assumes any legal liability or responsibility for the accuracy, completeness, or usefulness of any information, apparatus, product, or process disclosed, or represents that its use would not infringe privately owned rights. Reference herein to any specific commercial product, process, or service by trade name, trademark, manufacturer, or otherwise, does not necessarily constitute or imply its endorsement, recommendation, or favoring by the United States Government or any agency thereof. The views and opinions of authors expressed herein do not necessarily state or reflect those of the United States Government or any agency thereof. 


\section{HISTORY OF THE ENGINEERING PHYSICS AND MATHEMATICS DIVISION 1955-1993}

\section{Compiled by Betty F. Maskewitz}

\section{ornl}

Bringing Science to Sife
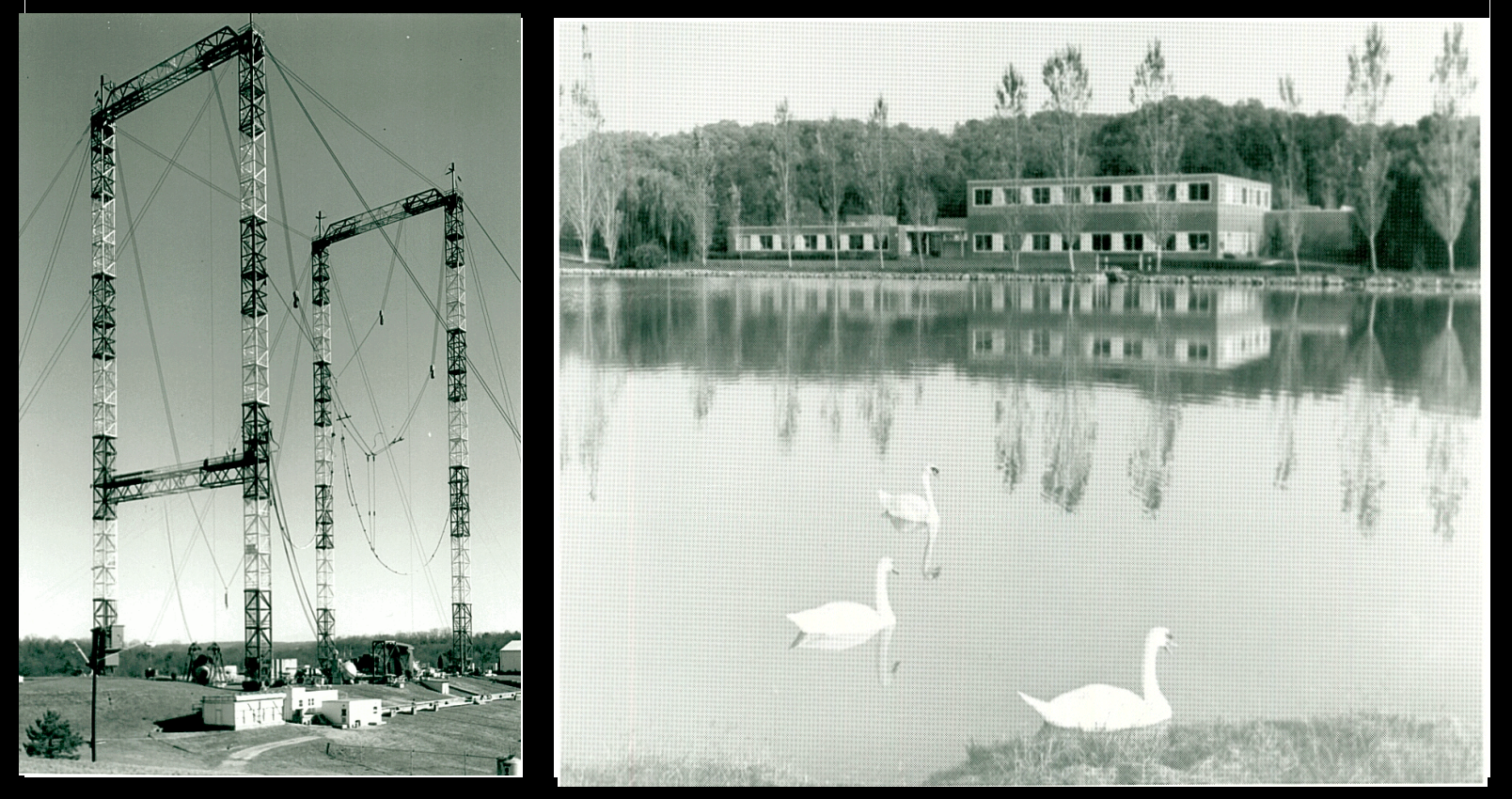



\section{FOREWORD}

A review of division progress reports noting significant events and findings of the Applied Nuclear Physics, Neutron Physics, Engineering Physics, and then Engineering Physics and Mathematics divisions from 1955 to 1993 was prepared for use in developing a history of the Oak Ridge National Laboratory in celebration of its 50th year. The research resulted in an accumulation of historic material and photographs covering 38 years of effort, and the decision was made to publish a brief history of the division.

Many division staff members, past and present, contributed to the history; some contributed written commentaries and critiques following review, and several loaned historic photographs for the publication. Many staff members reviewed specific texts and several-Daniel T. Ingersoll, Joseph Lewin, Fred C. Maienschein, Robert T. Santoro, Robert C. Ward-reviewed the manuscript and made helpful suggestions, which were implemented in the text. We also deeply appreciate the graphic design concept by Ingersoll.

The preparation of the publication in its present form could not have been possible without the expert assistance of Alice Faye Rice and her state-of-the-art word processing equipment. Her counsel on the organization of the manuscript was also invaluable. We acknowledge with appreciation the work of Lawanda E. Klobe, who spent many hours editing the text and suggesting changes in format.

The history begins with a detailed account of the founding of the Applied Nuclear Physics Division in 1955 and continues through the name change to the Neutron Physics Division in the late 1950s. The material thereafter is presented in decades - the sixties, seventies, and eighties - and ends as we enter the nineties.

Commentaries provided by:

R. G. (Tut) Alsmiller

J. Kirk Dickens

Helmut (Bill) E. Knee

Joseph Lewin

Reinhold C. Mann

Robert W. Peelle
Rebecca Rickman

David K. Trubey

Robert C. Ward

C. R. (Chuck) Weisbin

Larry Weston 


\section{CONTENTS}

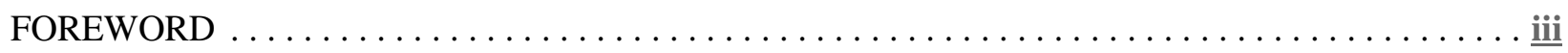

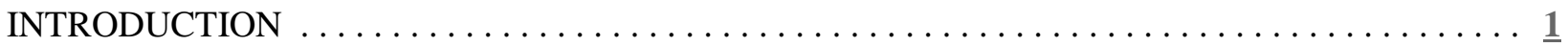

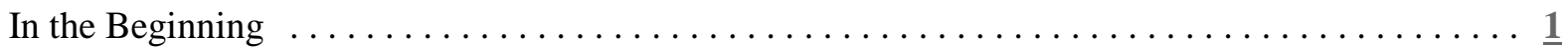

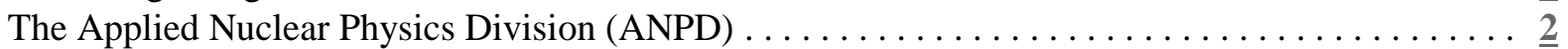

Initial Roster of ANPD Personnel (Charter Members) $\ldots \ldots \ldots \ldots \ldots \ldots \ldots \ldots \ldots \ldots$

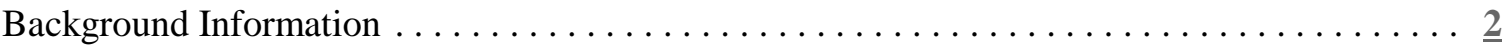

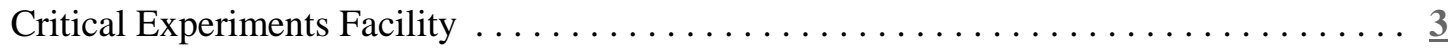

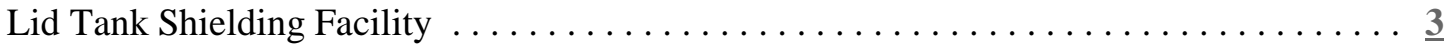

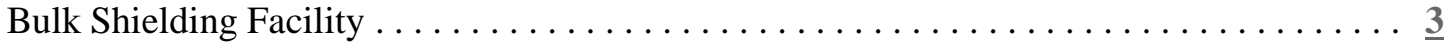

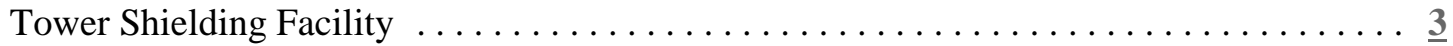

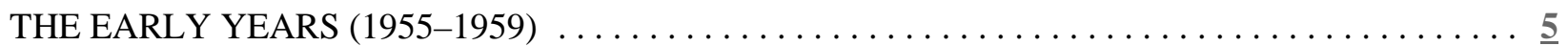

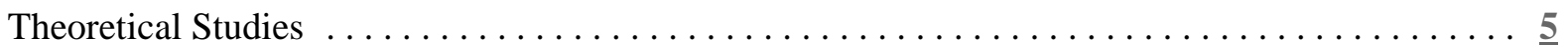

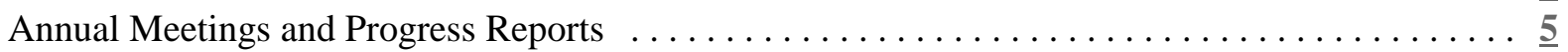

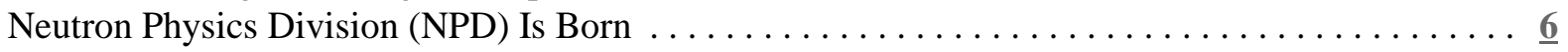

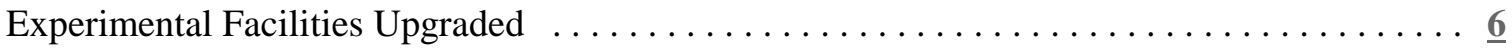

New Designs for the Bulk Shielding and Tower Shielding Reactors $\ldots \ldots \ldots \ldots \ldots \ldots$

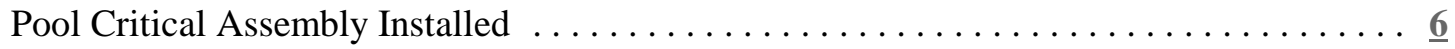

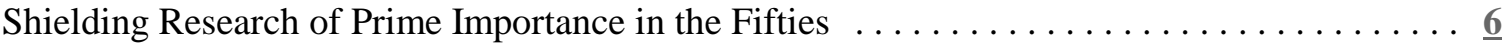

International Conferences on Reactor Shielding (ICRS) $\ldots \ldots \ldots \ldots \ldots \ldots \ldots \ldots$

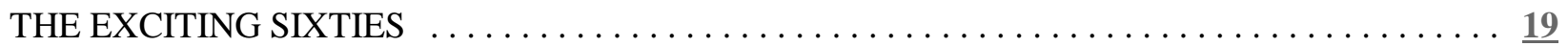

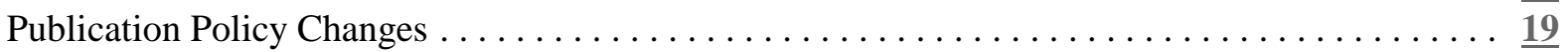

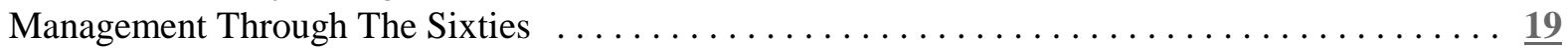

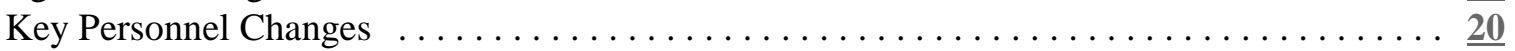

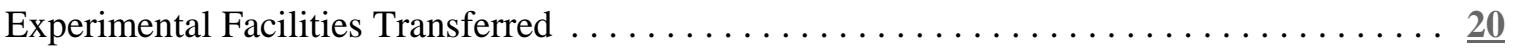

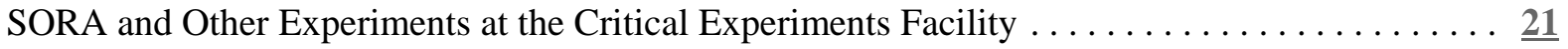

The Oak Ridge Electron Linear Accelerator (ORELA) $\ldots \ldots \ldots \ldots \ldots \ldots \ldots \ldots \ldots \ldots \ldots \ldots$

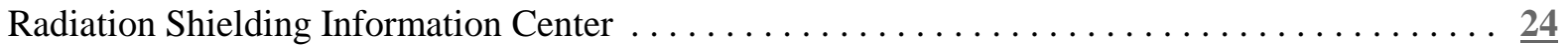

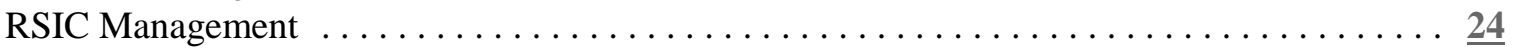

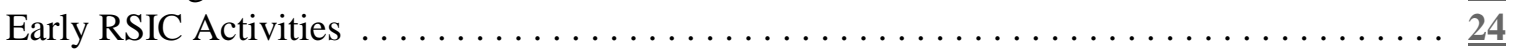

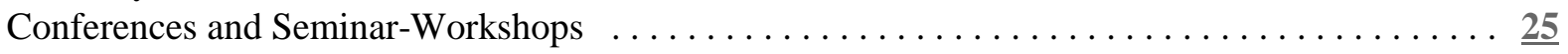

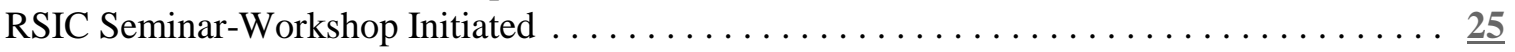

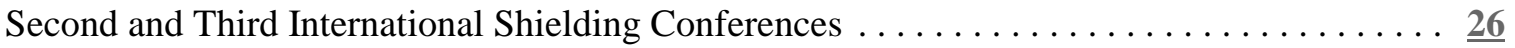

ORNL/NPD Hosts American Nuclear Society (ANS) Topical Conference . . . . . . . . 27

NPD Assists in Founding the Cross-Section Evaluation Working Group $\ldots \ldots \ldots \ldots \ldots \ldots$

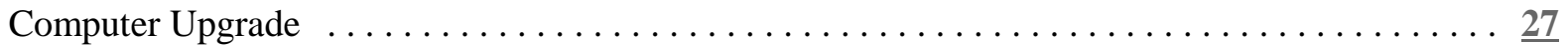

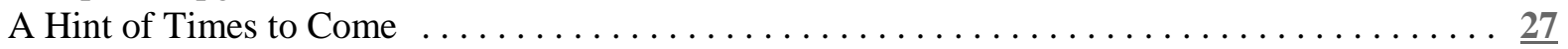

THE SEVENTIES MARK SIGNIFICANT CHANGES $\ldots \ldots \ldots \ldots \ldots \ldots \ldots \ldots \ldots \ldots \ldots$

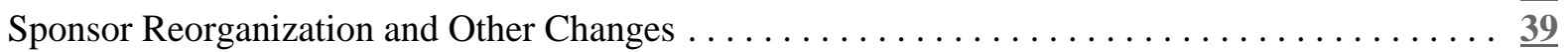

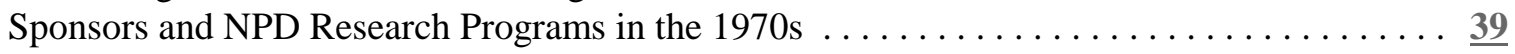

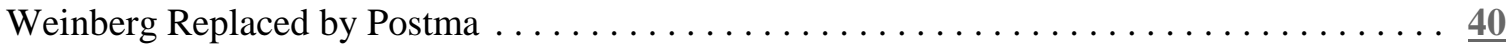


NPD Becomes Engineering Physics Division (EPD) in $1978 \ldots \ldots \ldots \ldots \ldots \ldots \ldots \ldots \ldots \ldots$

Reorganization of the Engineering Physics Division (EPD) $\ldots \ldots \ldots \ldots \ldots \ldots \ldots \ldots$

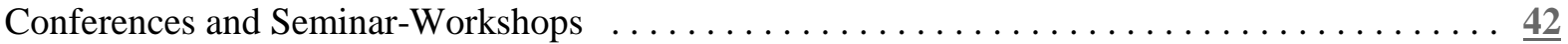

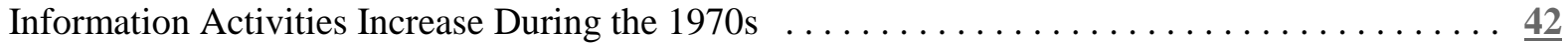

Safety Analysis Computerized Reactor Data (SACRD) $\ldots \ldots \ldots \ldots \ldots \ldots \ldots \ldots \ldots \ldots \ldots \ldots \ldots$

Central Reliability Data Organization Program (CREDO) $\ldots \ldots \ldots \ldots \ldots \ldots \ldots \ldots \ldots$

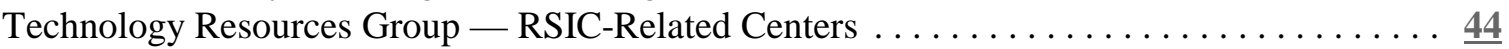

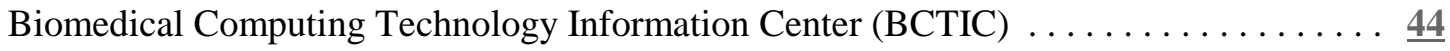

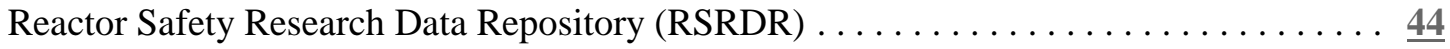

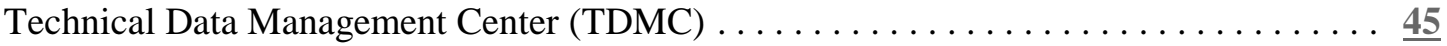

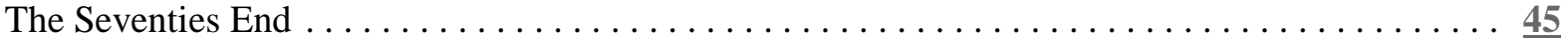

THE EIGHTIES - CHANGES AND CHALLENGES $\ldots \ldots \ldots \ldots \ldots \ldots \ldots \ldots \ldots \ldots$

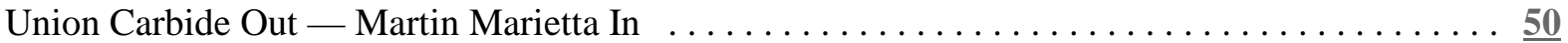

EPD Becomes Engineering Physics \& Mathematics Division $\ldots \ldots \ldots \ldots \ldots \ldots \ldots \ldots \ldots \ldots$

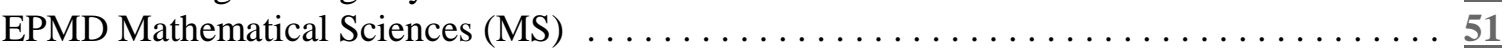

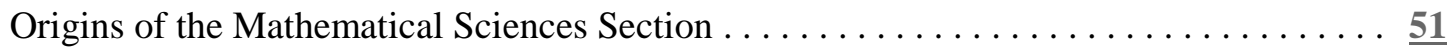

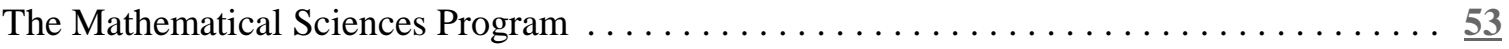

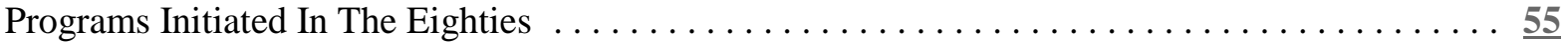

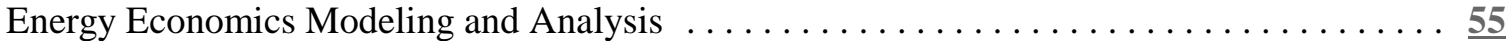

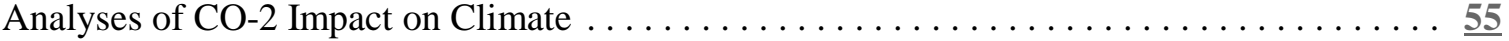

Center for Engineering Systems Advanced Research (CESAR) $\ldots \ldots \ldots \ldots \ldots \ldots \ldots \ldots \underline{\mathbf{5 6}}$

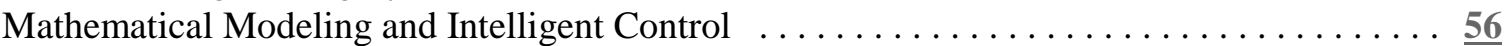

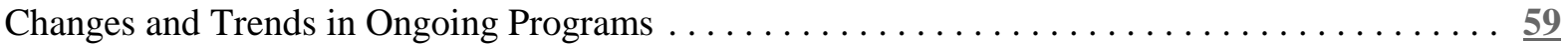

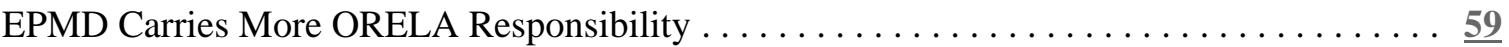

Nuclear Data Measurement and Evaluation . . . . . . . . . . . . . . . . . . . . . $5 \mathbf{5 9}$

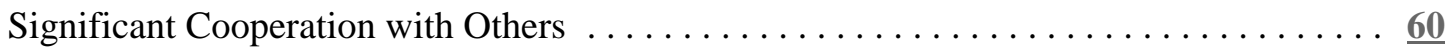

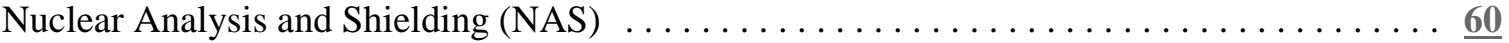

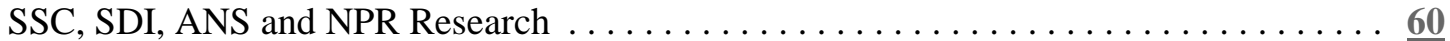

Fission Reactor Research . . . . . . . . . . . . . . . . . . . . . 61

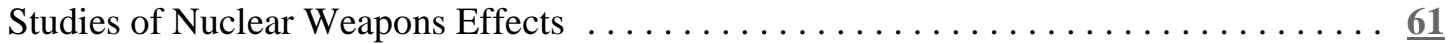

High-Energy Accelerator Shielding and Detector Research $\ldots \ldots \ldots \ldots \ldots \ldots \ldots \ldots$

Applied Physics and Fusion Reactor Analysis . . . . . . . . . . . . . . .

Nuclear Code Development .........................

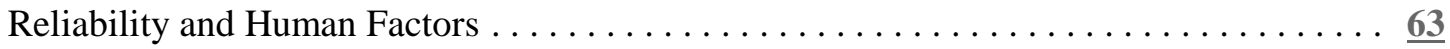

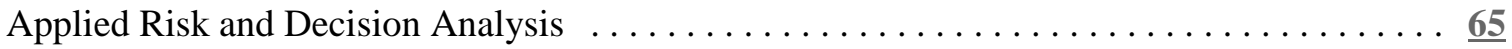

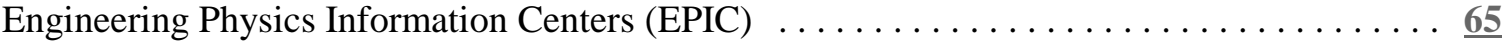

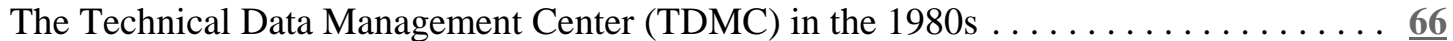

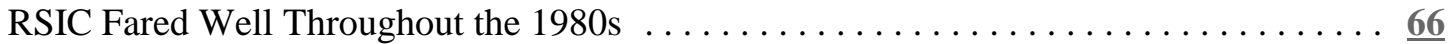

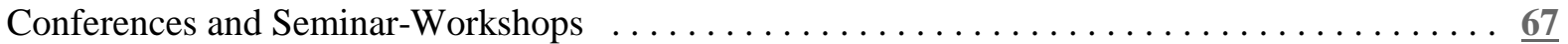

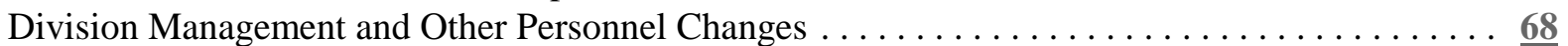

WE ENTER THE NINETIES - AND LOOK TO THE FUTURE $\ldots \ldots \ldots \ldots \ldots \ldots \ldots \ldots \ldots \underline{73}$

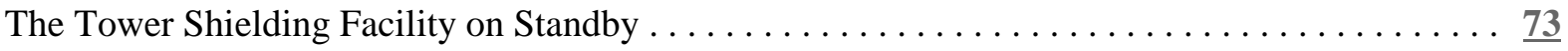

Oak Ridge Detector Center (ORDC) Established $\ldots \ldots \ldots \ldots \ldots \ldots \ldots \ldots \ldots \ldots \ldots \ldots \ldots \underline{73}$

MISSIONS, TRENDS AND BALANCES R. C. Ward, EPMD Director Looks to the Future . . . $\underline{73}$ 


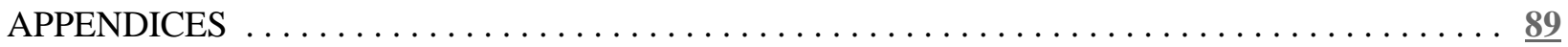

APPENDIX A DIVISION RECIPIENTS OF HONORS AND AWARDS $\ldots \ldots \ldots \ldots \ldots \ldots 91$

APPENDIX B ANPD—NPD—EPD—EPMD ADVISORY COMMITTEES 1955-1992 … 99

APPENDIX C 1993 EPMD ORGANIZATION CHART $\ldots \ldots \ldots \ldots \ldots \ldots \ldots \ldots \ldots \ldots$

\section{Commentaries}

Everitt P. Blizard, ANPD/NPD Director, was honored by the Oak Ridge Chapter of the National Secretaries Association as "Boss of the Year - 1959" for which he was nominated by his secretary,

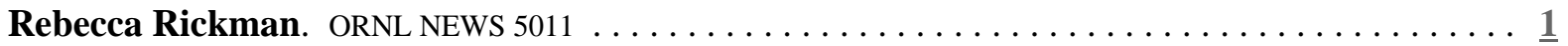

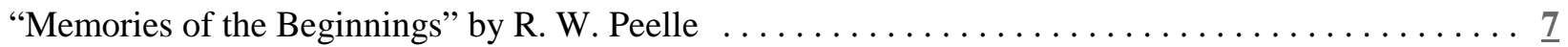

"Recollections from the Early Days" by D. K. Trubey $\ldots \ldots \ldots \ldots \ldots \ldots \ldots \ldots \ldots \ldots \ldots \ldots \ldots \ldots \ldots \ldots$

"The Division Had Many Firsts" by Rebecca Rickman $\ldots \ldots \ldots \ldots \ldots \ldots \ldots \ldots \ldots \ldots \ldots \ldots \ldots$

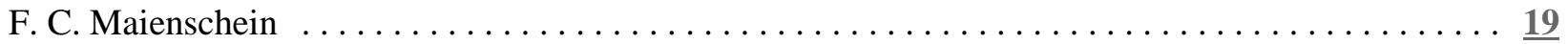

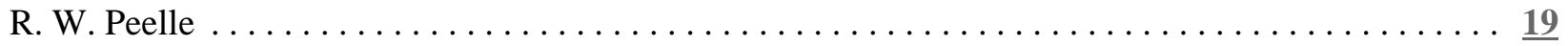

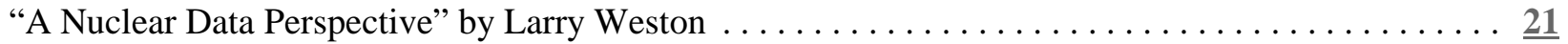

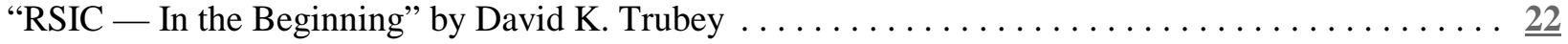

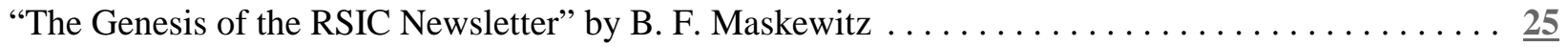

"Memories of the Neutron Physics Division" by Joseph Lewin $\ldots \ldots \ldots \ldots \ldots \ldots \ldots \ldots \ldots \ldots \ldots$

"CREDO — Sixteen Years a Research Tool" by Helmut E. (Bill) Knee . . . . . . . . . . . $\underline{43}$

"The Division Looks to the Future Through ORNL's Long Range Plan (1975-1981)" by Betty F.

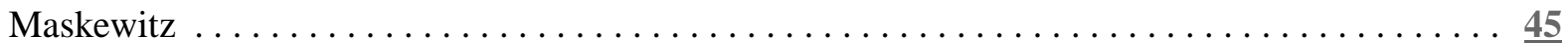

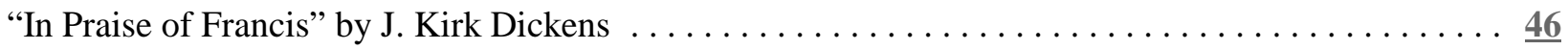

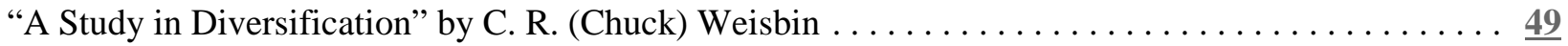

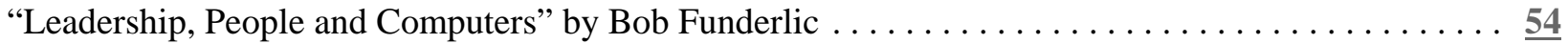

"CESAR and Intelligent Systems — A Biased Perspective" by Reinhold C. Mann . . . . . . . . . . $\underline{57}$

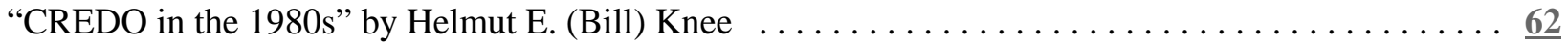

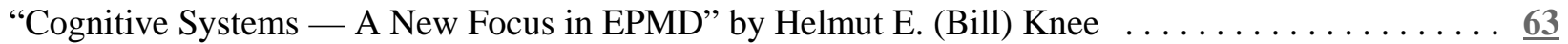

"Notes On the ORNL Applied Physics Division, Which Became the Neutron Physics Division, Which

Became the Engineering Physics Division, Which Became the Engineering Physics and Mathematics

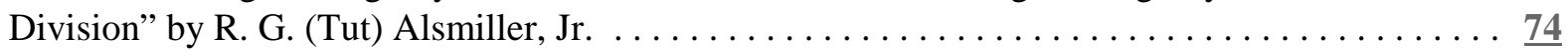

"Highlights Through the Years," by Robert W. Peelle (with contributions by others) ........ $\underline{75}$

"And, So, The Review of the Past Closes" by Betty F. Maskewitz $\ldots \ldots \ldots \ldots \ldots \ldots \ldots \ldots \ldots \underline{78}$

\section{List of Figures}

Everitt P. Blizard, ANPD/NPD Director, was honored by the Oak Ridge Chapter of the National Secretaries Association as "Boss of the Year - 1959" for which he was nominated by his secretary,

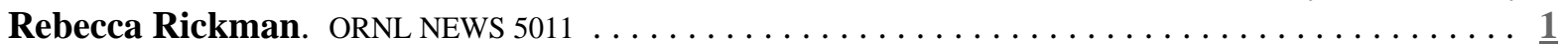

Fred C. Maienschein, NPD Director, and division secretary Rebecca Rickman at work in the new

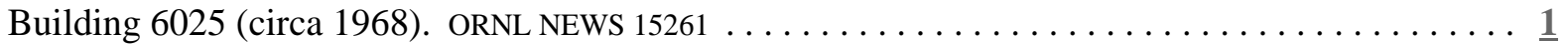

Robert C. Ward confers with Donna R. Burton, Division Secretary, as EPMD enters the 90s. ORNL 3256-93 
The ORNL Lid Tank Shielding Facility, located on the west face of the shield of the Oak Ridge X-10 Pile, was the first facility designed for experimental radiation shielding research. It operated from mid-1949 until the pile ceased operation in 1963. ORNL $8640-81 \ldots \ldots \ldots \ldots \ldots \ldots \ldots \ldots$

Elizabeth B. Johnson, ANPD experimental physicist, working at the console of the original control and safety system instrumentation of the Bulk Shielding (swimming pool) Reactor (BSR) in 1956 (left) and at the console of the newly installed BSR-II in 1957 (right). ORNL 40764 and ORNL $18172 \ldots \ldots \underline{7}$

The Pool Critical Assembly (PCA), located at the northwest corner of the BSF pool, was used to relieve the BSR of much of its low-power experiment load. ORNL $43038 \ldots \ldots \ldots \ldots \ldots \ldots \ldots \ldots$

The ORNL Lid Tank Shielding Facility, located on the west face of the shield of the Oak Ridge X-10 Pile, was the first facility designed for experimental radiation shielding research. It operated from mid-1949 until the pile ceased operation in 1963. ORNL-LR-DWG $39683 \ldots \ldots \ldots \ldots \ldots \ldots \ldots$

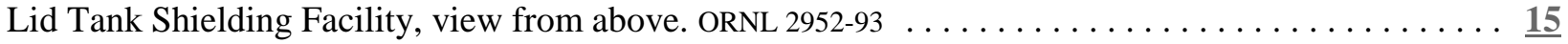

Lid Tank Shielding Facility, view from operator's desk. ORNL $2953-93 \ldots \ldots \ldots \ldots \ldots \ldots \ldots \ldots$

At the console of the Bulk Shielding Reactor (BSR-II) in the Bulk Shielding Facility (BSF), Joe Kington (left) and Keith M. Henry take data from the operating reactor, circa 1957-1958. The BSF and BSR, now permanently shut down, served many useful purposes at ORNL for 40 years. $51489 \ldots \ldots \underline{16}$

The Bulk Shielding Facility (BSF) and Bulk Shielding Reactor (BSR). ORNL $18174 \ldots \ldots \ldots \ldots$

Prof. Le Poole enjoys "hands on" the BSR controls with guidance from Fred Maineschein. ORNL 55-

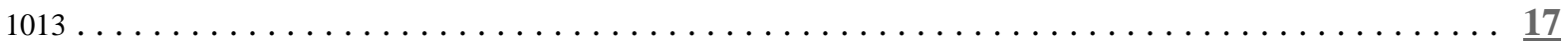

The NPD Annual Information Meeting attracted many scientists. Attending the 1958 dinner at Deane Hill Country Club in Knoxville were (left to right): A. J. Miller, C.W.J. Wende (Savannah River Laboratory), R. R. Wilson (General Atomic), R. Anderson (AEC) R. G. Doherty, Everitt P. Blizard (NPD Director), Alvin M. Weinberg (ORNL Director), L. W. Nordheim (General Atomic), and Al Simon (NPD Associate Director). Foreground (facing front, from left): Lawrence Dresner

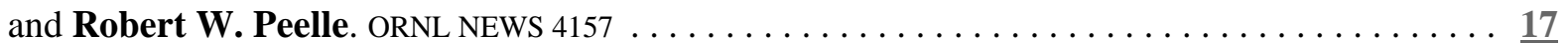

A 1958 visitor, Prof. Rossi of Italy, tours BSF and other ORNL facilities escorted by (from left); Fred

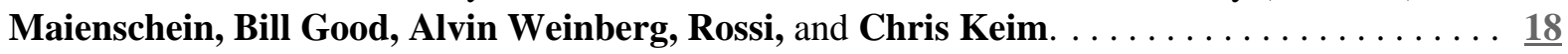

Present at the 1959 NPD Annual Information Meeting Dinner were (from left) Hal Schweinler (Solid State Division), Larry Dresner, Bob Peelle, T. K. Fowler, and Robert J. Mackin. ORNL NEWS 2627

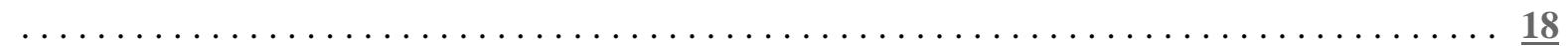

Fred Maienschein leads Nasaya Nakata of Ship Research Institute of Japan in a tour of the BSF

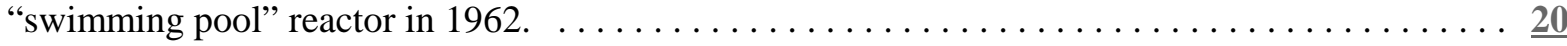

A. Dixon Callihan, Associate Director of the Neutron Physics Division, was presented the American Nuclear Society's David V.P. Williams Memorial Award in recognition of his leadership in the field of critical experimentation and the significance of his activities as editor or Nuclear Science and

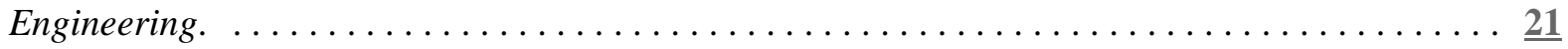

The BSF attracted many foreign visitors in the early 1960s. Right to left; Alvin Weinberg and Fred Maienschein discuss BSR experiments with Prof. Le Poole and a team from The Netherlands. ORNL

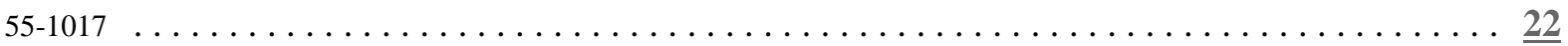

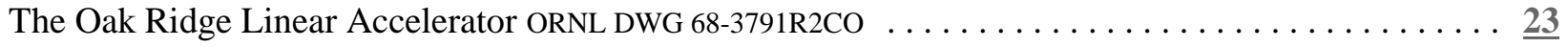
Leaders and participants of the 1965 Monte Carlo (O5R) Seminar-Workshop included (from left):

Robert Hubner (RRA/Ft. Worth), Frank H. Clark, Nancy Betz (Mathematics), Juanita Brown Wright, and Wade Selph (Lockheed/Marietta, Georgia). ORNL $13376 \ldots \ldots \ldots \ldots \ldots \ldots \ldots \ldots$

The Radiation Shielding Information Center (RSIC) staff gathers for a meeting in the late 1960s (from left): Juanita Brown Wright, Henrietta Hendrickson, Betty Maskewitz, Patti Cunningham, David Trubey, Vivian Jacobs, Hemma Francis Comolander, Mildred Landay, Wallace 
Webster, Jane Gurney, and Fritz Schmidt of the Stuttgart Technical University, Germany. ORNL

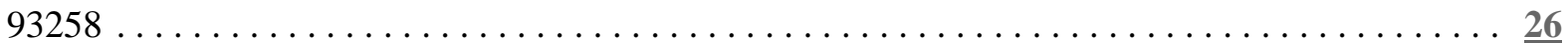

Oyama of Japan (left) is received by Fred Maienschein at the BSF in $1960 . \ldots \ldots \ldots \ldots \ldots \ldots$

The "Figure of Merit" formula is applied to a 1965 drawing related to the design of ORELA by Fred

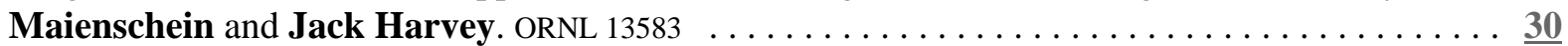

Francis Perey and John Judish test an improved klystron bunching circuit at the high-voltage terminal of the pulsed neutron source for the 3-MV Van de Graaf in building 5500, circa 1960-1962. ORNL

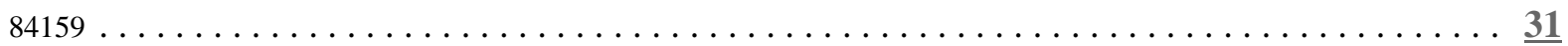

Max Dresden (University of Kansas physics professor) lectures to Frances and R. G. (Tut) Alsmiller (seated) and to A. Mertz (visitor from T-Division, Los Alamos Scientific Laboratories) circa 1967 in

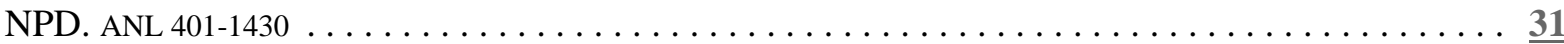

Robert W. Peelle regales an unidentified visitor, Maienschein and Philip Mittelman (MAGI, New

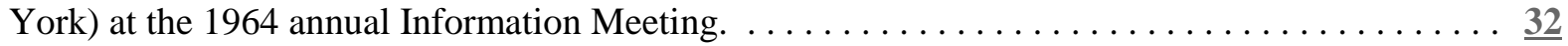

Lenna K. Lovette at the console of the ORELA PDP-4 Data Taking and Processing System. ORNL 86379

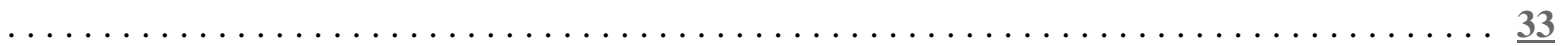

Kirk Dickens, Claire Perey, Fred Maineschein, and Francis Perey get together at the 1966 NPD

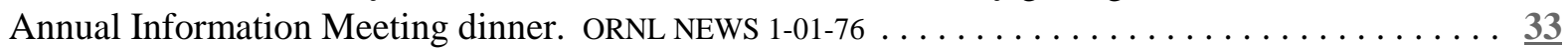

Leo Holland and Fred Maienschein share a moment with Malvin H. Kalos, member of the 1966

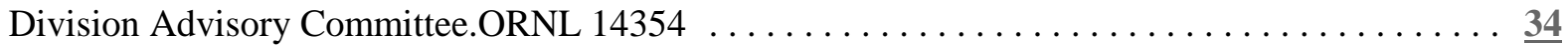
1965 O5R Seminar-Workshop participants meet for dinner (from left): Robert Coveyou, Frank Clark, Betty Maskewitz, Charles Bradshaw (Vanderbilt University), David Irving, Keith Penny, and

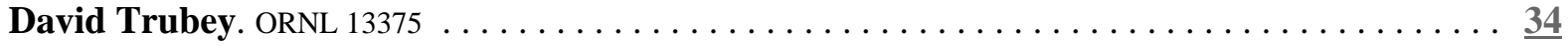
The 1967 NPD Annual Information Meeting Dinner was attended by staff members (from left): Betty F. Maskewitz, Elizabeth B. Johnson, Vivian A. Jacobs, Virginia Hamrick, Miriam Guthrie

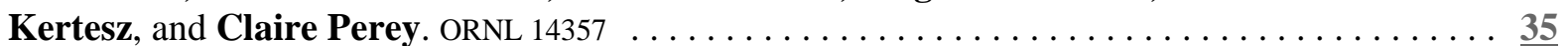

The 1969 Conference on The Effective Use of Computers in the Nuclear Industry was hosted by the University of Tennessee. Key personnel included (from left): Bill Rhyne, Noel Cramer, Betty F. Maskewitz (General Chairman), Pete Pasqua (UT/NE Professor) and Tony Buhl. ........ 35

Fred Maienschein greets the Wallace Websters and joins in the reception for attendees at the 1969 ORNL/ANS-M\&C Division conference on Effective Use of Computers in the Nuclear Industry. UT

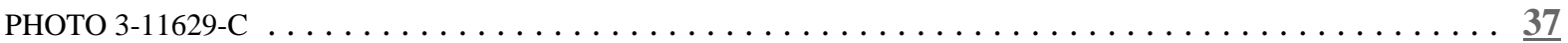

Attending a planning session for the 1969 ANS/M\&C Topical Conference on the Effective Use of Computers in the Nuclear Industry are from left: David Vondy, Henrietta Hendrickson, Betty Maskewitz, Jane Gurney, and Claude Long (Finance). ORNL $94913 \ldots \ldots \ldots \ldots \ldots \ldots \ldots$

Lorraine Abbott (center) shares a light moment with 1966 NPD annual Information Meeting participants (from left); Fred Maienschein, Lew V. Spencer (NBS and KSU), Charles E. Clifford,

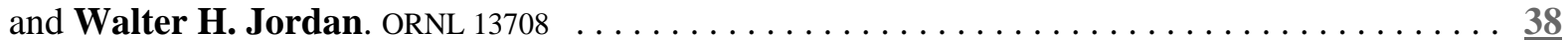

Attending the 1964 Annual Information Meeting Dinner are (from left): David K. Trubey, William E. Kreger (U.S. Naval Radiological Research Laboratory, San Francisco, later NRC staff), Betty F. Maskewitz, and A. Edward Profio (General Atomic, now at the University of California, Santa

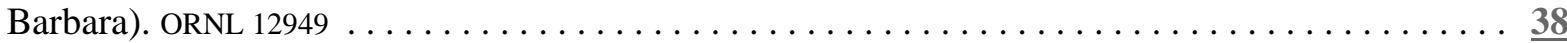

Lenna K. Lovette, secretary on experimental teams of the division, exhibits ORELAST, the ORELA Scintillator Tank designed by Ernest G. Silver and used by Gerard de Saussure circa 1969-1970.

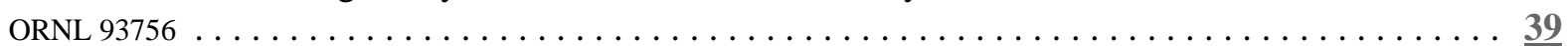

Francis "Buzz" Muckenthaler takes measurements at a mockup of SNAP Reactor Shielding at the

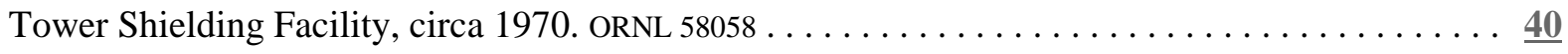
D. D. Walker (left) and Joseph Lewin working on the SNAP-TSF reactor, 1973. ORNL 1339-73 . . . . 41 
The RSIC Code Center staff review the citation and desk set received from the American Nuclear Society Shielding and Dosimetry Division for Outstanding Service-1975 (from left): Jane Gurney, Henrietta Hendrickson, Betty F. Maskewitz, David K. Trubey, Juanita Wright, and Hemma

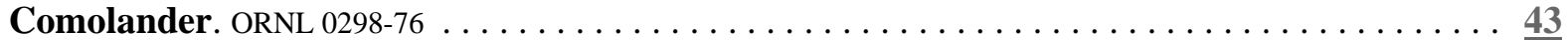

The staff of the Biomedical Computing Technology Information Center (BCTIC) check out a clinical diagnostic program (from left): William J. McClain (CSD), P. R. Bell (Consultant), Randell

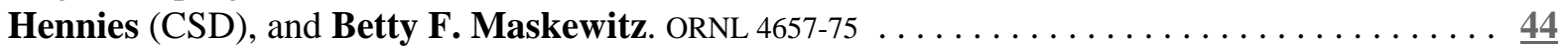

Math Panel Principals Gather at Annual Meeting Festivities in December 1976. From left: unidentified, Larry Bumgarner, Harvey P. Carter, Marje Lietzke, Art Downing, Millard Harkrider, and J.

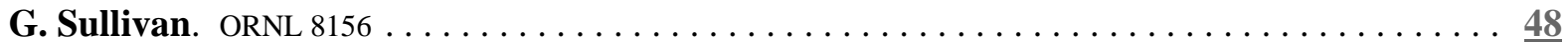

H. Clyde Claiborne and Ward W. Engle, Jr., discuss the application of the discrete ordinates method to problems in the reactor and weapons radiation shielding program (1972). ORNL 2046-71 . . . . 48

Fred Mynatt and Lorraine Abbott discuss the article on "Fuel from Accelerators" written by Abbott for the Winter 1978 ORNL Review.

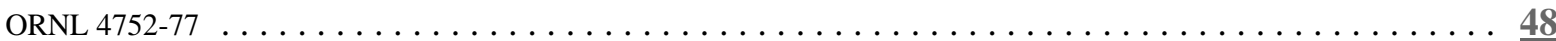

Bill Hamel (left) and Chuck Weisbin examine the HERMIES-II robot, which is used by the Center for Engineering Systems Advanced Research for concept demonstration of artificial intelligence

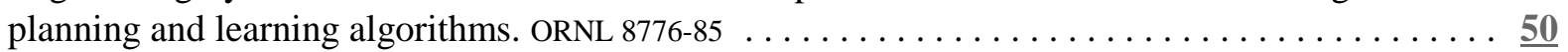

Kimiko Bowman, a research statistician, with a model that depicts solutions to the problem of the mixture of two normal probability distributions. Physical representations such as this provide insight into possible solutions to complex mathematical problems. ORNL $2999-74 \ldots \ldots \ldots \ldots \ldots \ldots \underline{\mathbf{5 2}}$

Buzz Muckenthaler, Jim Hull, and Dan Ingersoll inspect the shield mockup for the High-Temperature Gas-Cooled Reactor Coolant Channel Streaming Experiment, circa 1983. ORNL 3250-83 _.... $5 \underline{53}$

Bob Ward (left), head of EMPD Mathematical Sciences Section, discusses the ORNL Distinguished Scientist (DS) Program with Alan George, Dean and Researcher from Waterloo University in Canada, who served as UT-ORNL/DS in Computer Science 1986-1988. George, who came into the program at an early stage, was the first DS in computer Science. Upon his return to Waterloo, he was appointed Vice President and Provost of the university. ORNL $8805-87 \ldots \ldots \ldots \ldots \ldots \ldots \ldots \ldots$

David B. Reister examines HERMIES-III. ORNL $2879-91 \ldots \ldots \ldots \ldots \ldots \ldots \ldots \ldots \ldots \ldots \ldots \ldots \ldots$

Francois G. Pin removes the seven-chip fuzzy logic control system from its slot on the mobile robotic platform. The cube-shaped objects ringing the platform are acoustic sonar sensors the robot uses to

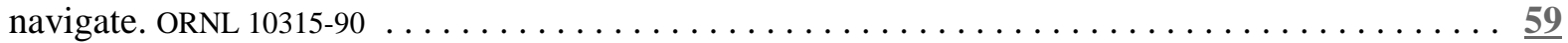

Philip F. Spelt inspects HERMIES-IIB and HERMIES-III in the CESAR laboratory. ORNL 3521-89 .. $\underline{\mathbf{6 2}}$ The RSIC staff received the American Nuclear Society's Radiation Protection and Shielding Division (RP\&S) 1987 Technical Services Award, the first such presentation to an institution in the history of the RP\&S Division. The presentation was made at the commemoraton of the 25th Anniversary of the center. The 1987 staff included (from the left, seated): Carol P. Coker, C. Marie Anthony, Ann B. Gustin, Jennifer Bartley Manneschmidt, Nancy A. Hatmaker; (standing from the left) S. Noel Cramer, Dawn C. Human, Bernadette L. Kirk, Alice F. Rice, Betty F. Maskewitz, Robert W. Roussin, Betty L. McGill, David K. Trubey, and John E. White. Plaques were also furnished to former staff members who helped to build RSICs reputation for excellence. ORNL 3344-87 . . . . 64

NPD/RSIC leadership celebrates 20 years of continuous service (1962-1982) (from left): Fred C.

Maienschein (NPD Director), David K. Trubey (shielding specialist), Betty F. Maskewitz (RSIC Director), S. Keith Penny (former RSIC Director), and Rebecca Rickman (NPD Secretary). ORNL

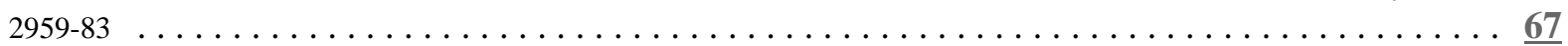

Walter N. Zobel (physicist, ANPD/NPD charter member), François Kertesz (consultant) and Joseph Lewin (long-term NPD staff member) join in celebrating RSIC's 20th anniversary in 1982. Each of 
these technical specialists made contributions to RSICs information and technology databases while

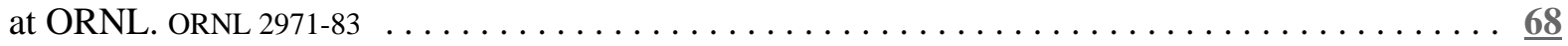

RSIC lost earliest staff members in 1980 on the retirement of (from left) Hemma Francis Comolander (codes testing), Mildred W. Landay (secretary), and Jane Gurney (SARI system maintenance).

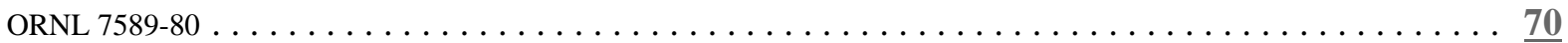

The ORELA operations staff and managers pose for 1988 photograph: (1) Ken Wallace (HPD), (2) Doug Collins, (3) Dick Green, (4) Jack Harvey, (5) Bob Spencer, (6) Ron Winters, (7) Ray Simmons, (8) Duane Larson, (9) Bob Peelle, (10) Larry Weston, (11) Gene Ziegler, (12) Brian Rooney, (13) Rex Ingle, (14) Dan Garner, (15) Roger Macklin, (16) Bob Seals, (17) S. Pendyala,, (18) John Cameron, (19) Lester Hulett, (20) Reg Gwin and (21) Jerry Schultz. ORNL 4646-88 . $\underline{70}$ Jennifer Bartley Manneschmidt, John E. White, and Bernadette L. Kirk discuss the past as they

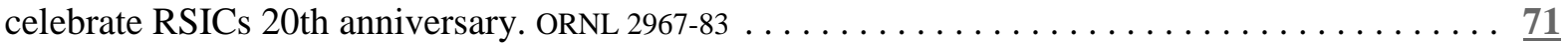

The original RSIC staff gathers to celebrate the 20th anniversary, summer 1982 (from left): Betty F. Maskewitz, M. B. "Peggy" Emmett, David K. Trubey, S. Keith Penny, and Lincoln Jung. ORNL

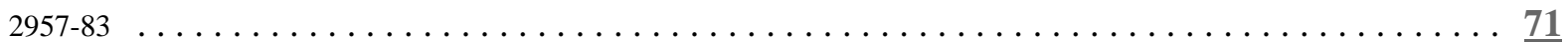

Celebrating RSIC's 20th anniversary - We covered space and high energy shielding for the RSIC literature data bank (from left): Miriam Guthrie Kertesz, Frances and R. G. "Tut" Alsmiller.

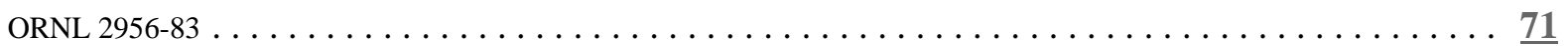

Al Geist (left) and Malcolm Stocks discuss the advantages of using the new Paragon computer for alloy

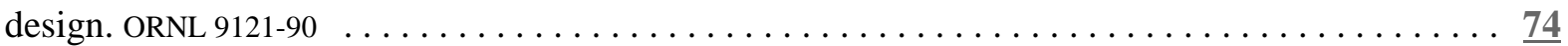

Team leader Jack Harvey (right), together with team members, Nat Hill (left) and Peter Riehs of Austria (2nd from right) pose with Al Trivelpiece (ORNL Director, 2nd from left) who presented them with a Martin Marietta Energy Systems, Inc., Technical Achievement (TA) Award for the first measurement of the neutron polarizability, June 1992. Harvey and Hill also received TA awards for being on the team led by H. Mook (Solid State Division) which observed the first evidence of phonon softening in high-temperature superconductors. Both measurements were made at ORELA.

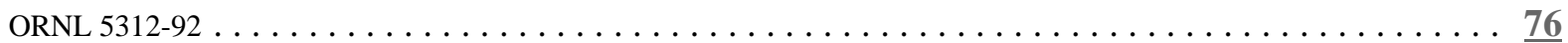

Reinhold C. Mann (left) and Edward C. Uberbacher (seated) of EMPD and Richard J. Mural, Biology Division, developed an intelligent computer system known as GRAIL (Gene Recognition \& Analysis Internet Link) to identify the genetically useful protons of DNA sequence data. They are

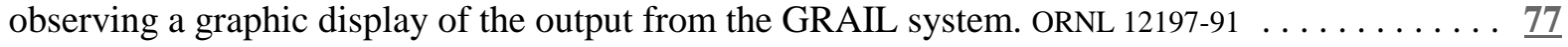

Richard Sincovec (left) and Robert C. Ward (standing) and Michael Lueze (front) inspect the Intel iPSC/2 and iPSC860 parallel computers, forerunners of the new Paragon supercomputer at ORNL.

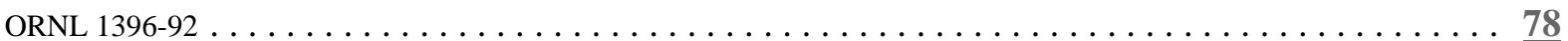

Robert. W. Roussin accompanies Alice Rice as she presents David Trubey with a special memento

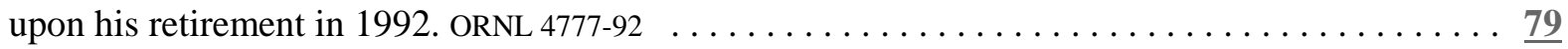

Francis “Buzz" Muckenthaler accepts a golden "Bonner Ball”from Dan Ingersoll (right), given on the occasion of his 40th anniversary (1951-1991).

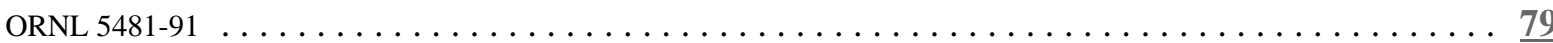

Francis G. Perey (far right) is greeted by colleagues upon his 1990 retirement. From left are Cleland Johnson (Physics), Nat Hill (I\&C), Claire Perey, Richard Macklin, and S. Raman (Physics).

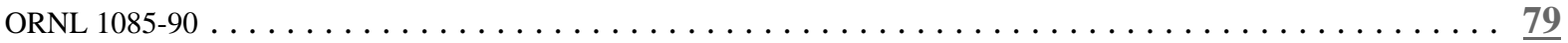

Gifts to fill his time are presented to retiree Richard L. Macklin (1956-1990) by (from left) Bob Peelle, Macklin, Jack Harvey, and Jim Johnson (Physics). ORNL $1086-90 \ldots \ldots \ldots \ldots \ldots \ldots \ldots$ ORELA operations team, 1992, seated from left, Michael Cauley and T. A. Lewis; standing from left Jerry Atchley, Dan Garner, and Don Pierce. ORNL $9587-92 \ldots \ldots \ldots \ldots \ldots \ldots \ldots$ 
ORELA staff members give a warm "send-off" to Dale Hensley as he leaves the division in 1991: 1-Jim Todd, 2-Duane Larson, 3-Ken Wallace (HPD), 4-Dave Hetrick, 5-Nancy Larson, 6-Claire Perey, 7-T. A. Lewis, 8-Jack Harvey, 9-Dale Hensley, 10-Peter Fu, 11-Francis Perey, 12-Sue Damewood, 13-Nat Hill, 14-Jack Craven, 15-Bob Peelle, 16-Rex Ingle, 17-Dick Green, 18-

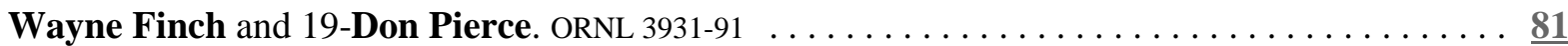

The EPMD Office staff takes time for a 1992 photo (from left, standing): Donna R. Burton (division secretary), Stephanie A. Raby (publications), Kimberly D. Barnes (finance officer), and Tamara R. Henson (operations secretary: (seated, from left) Cloyd O. Beasley (operations manager), and

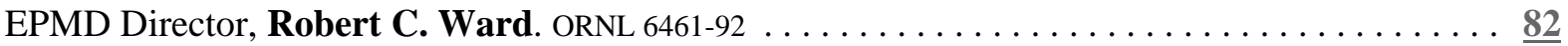
The Intelligent Systems Section sits for a portrait, circa 1992. Front row from the left, Karen S. Harber, Anita J. Alton, Susan L. Rider, Martin Beckerman, Jack C. Schryver, Judson P. Jones; Second row, James E. Baker, Xiaojun Guan, Manesh B. Shah, J. Ralph Einstein, Michelle Moulton, Sergei Petrov, Charles W. Glover; third row, Michael A. Unseren, Yutaka Watanabe, Philip F. Spelt, Edward C. Uberbacher, Reinhold C. Mann, Edward M. Oblow. ORNL-6364-92 … ․ $\underline{82}$ The Mathematical Sciences Section. In numerical order: 1-Dawn Human, 2-Marjorie Harris, 3-Judy Green, 4-?, 5-Dave Semeraro, 6-Patrick Worley, 7-Elmon Leach, 8-Rich Sincovec, 9-Gary Hartman, 10-Rick Schmoyer, 11-Tom Dunigan, 12-Len Gray, 13-Bill Lever, 14-Bill Shelton, 15-Darryl Downing, 16-Chuck Romine, 17-Tom Rowan, 18-Mark Dewing, 19-Tammy Darland, 20-Eduardo D'Azevedo, 21-Ray Flanery, 22-David Walker, 23-Ken Bateman, 24-Janice Trent, 25-Debbie Flanagan, 26-Barry Peyton, 27-Jaeyoung Choi, 28-Bruce Lowekamp, 29-Charles Leete, 30-Nick Van Goor, 31-Doug Sept, 32-June Donato, 33-George Ostrouchov, 34-Carol San Soucie, 35-John Drake, 36-Esmond Ng, 37-Toby Mitchell, 38-Max Morris. ORNL 5817-92 ․ $\underline{83}$ The Nuclear Analysis and Shielding Section: standing back: Charles Slater, Dan Ingersoll, Wayne Rhoades, Kit Haaland, Jeff Johnson, Yousry Azmy, Trent Primm, Mark Smith, Christine Parks, Barbara Bishop, Robert McNees, Sally Gaff, Shree Whitaker, Larry Williams, Angie Alford: standing front; Jim Bucholz, Joe Pace, Hamilton Hunter, Bob Spencer; seated back: Tony Gabriel, Dick Lillie, Bob Santoro, John Barnes, Sue Shriner, Dick Maerker, Vladimir Protopopescu, Jim Drischler; seated front; Fran Alsmiller, Tut Alsmiller, Brian Worley, Peggy Emmett, Patrick Brantley, Alan Smith, Tom Burns, Ward Engle. ORNL $5450-92 \ldots \ldots \ldots \underline{84}$ Giving Trubey a sendoff upon his retirement (from the left) Perry Gouge, John Miller, Lincoln Jung, Jack Taylor, Francois Kertesz, Rebecca Rickman, Harry Maggart, Trubey, Lorraine Abbott, Vivian Jacobs, Ann Gustin, Betty Clack, Van Baxter, Henrietta Hendrickson, Jane Gurney,

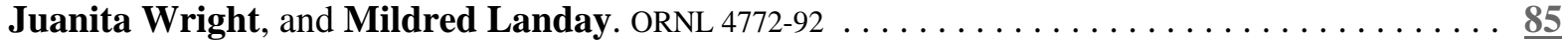
RSIC again celebrates a milestone year, its 30th anniversary, in 1992. From left standing, Jennifer B. Manneschmidt, John E. White, Betty L. McGill, Barbara J. Snow, Robert W. Roussin, Sheila V. Taylor, S. Noel Cramer; seated from left, Nancy A. Hatmaker, Bernadette L. Kirk, Carol P. Coker, Alice F. Rice, and Betty F. Maskewitz (consultant). ORNL $5734-92 \ldots \ldots \ldots \ldots \ldots$ A welcome watermelon feast relieves a hot summer day in 1992 and leads to a high level of camaraderie with the division. Larry Williams serves, assisted by Sheila Taylor, and Donna Burton. . . . . $\underline{86}$ Jack Harvey appreciates a slice of cold watermelon on a summer's day. . . . . . . . $\underline{\mathbf{8 6}}$ Staff members and students enjoy a summer treat. $\ldots \ldots \ldots \ldots \ldots \ldots \ldots \ldots \ldots \ldots \ldots \ldots \ldots \ldots$

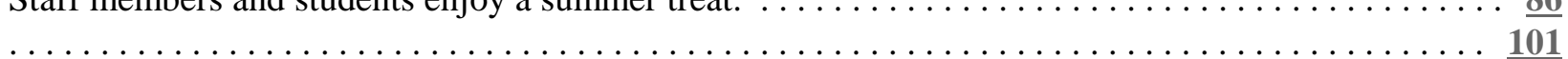




\section{INTRODUCTION}

\section{In the Beginning}

The Engineering Physics and Mathematics Division (EPMD) of the Oak Ridge National Laboratory (ORNL) was founded July 1, 1955 as the Applied Nuclear Physics Division. In the ensuing years the Division underwent several name changes. In 1958 the division leaders apparently felt that the "applied" label did not cover the ongoing research programs so the name was changed to Neutron Physics Division, a name it carried for many years. In 1978 its name was changed to Engineering Physics Division to more clearly define the Division's research environment at that time. Following the transfer of the Mathematical Sciences Group into the Division in February 1984, the name Engineering Physics and Mathematics Division (EPMD) was adopted.

The Division has been managed since its inception by three individuals: Everitt P. Blizard (1955-1966), Fred C. Maienschein (1966-1990), and Robert C. Ward (1991-....). It should also be noted that the first two division directors were served by its original secretary, Rebecca (Becky) Rickman, whose career at ORNL spanned more than thirty years. Upon her retirement in 1985 she was replaced by Donna Burton.

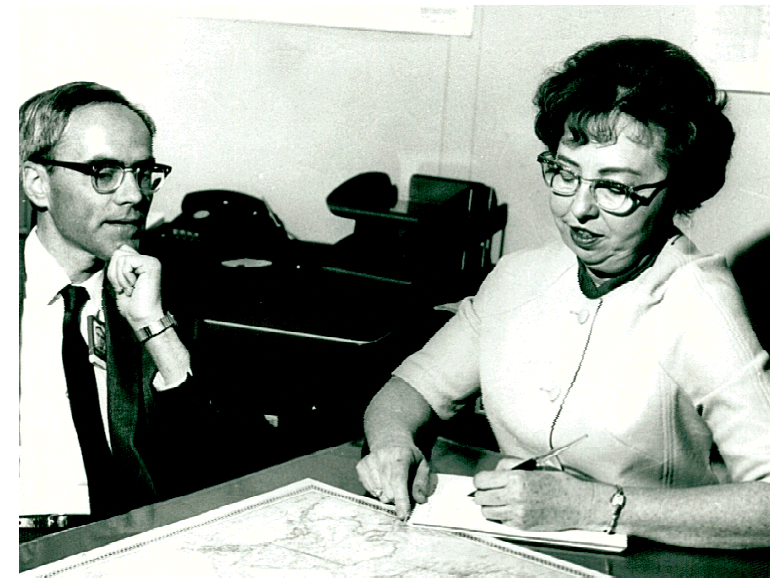

Fred C. Maienschein, NPD Director, and division sec retary Rebecca Rickman at work in the new Building 6025 (circa 1968). ORNL NEWS 15261

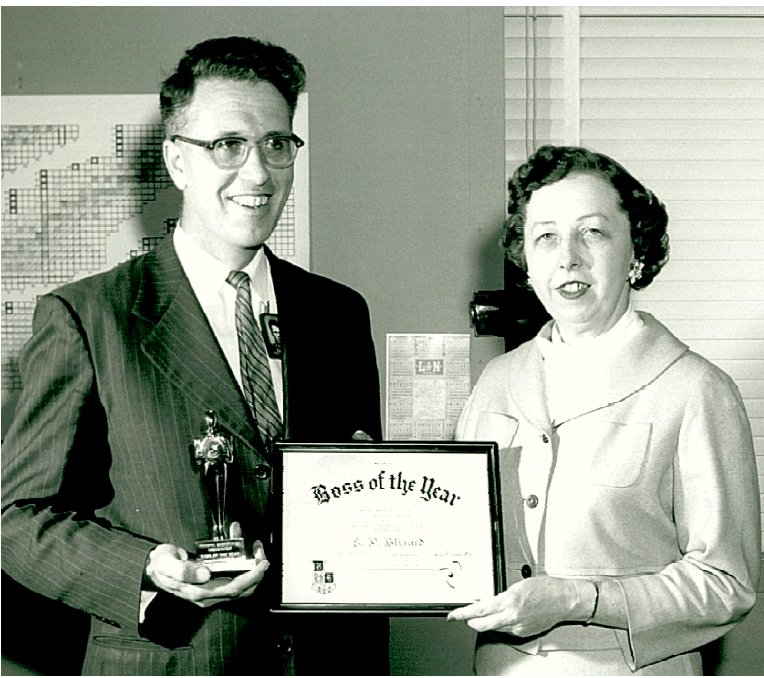

EvenittP. Blizard, ANPD/NPD Director, was honored by the Oak Ridge Chapter of the National Secretaries Association as "Boss of the Year 1959 " for which he was nominated by his sec retary, Rebecca Rickman. ORNL NEWS 5011

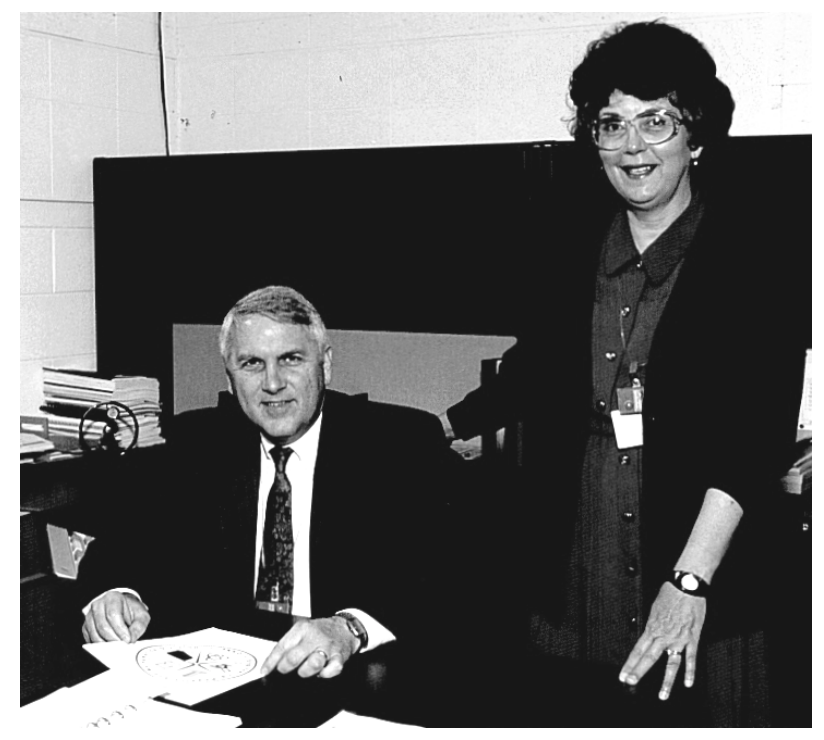

Robert C. Ward confers with Donna R. Burton, Division Secretary, as EPMD enters the 90s. ORNL 3256-93 


\section{The Applied Nuclear Physics Division (ANPD)}

The Applied Nuclear Physics Division (ANPD) was formed from those parts of the Physics Division primarily concerned with critical experiments and reactor shielding, combined with a theoretical reactor physics group transferred from the ORNL Director's Division. The stated intent was to "bring together in a single professional division a group of scientists with common interests, namely, the generation and ordering of information basic to the nuclear physics aspects of reactors."

\section{Initial Roster of ANPD Personnel (Charter Members)}

On May 27, 1955, a memo addressed to J. A. Barker of the ORNL Personnel Office was signed by E. P. Blizard with a copy to A. H. Snell, Physics Division Director:

"Effective July 1, 1955, the following personnel are to be transferred from the Physics Division to the Applied Nuclear Physics Division, Account No. 3410:

\begin{tabular}{lll} 
Lorraine S. Abbott & Lonnie W. Gilley & Robert W. Peelle \\
Mary K. Albright & Victor G. Harness & Frederick G. Prohammer \\
Everett Beckham & Mary P. Hayden & Rebecca Rickman \\
Everitt P. Blizard & Keith M. Henry & Emerson R. Rohrer \\
Theron V. Blosser & Leo B. Holland & Mary L. Rueff \\
Clarice E. Bounds & James L. Hull & Fred W. Saunders \\
A. Dixon Callihan & Elizabeth B. Johnson & Robert M. Simmons \\
George T. Chapman & Dewey J. Kirby & Albert Simon \\
Charles E. Clifford, Jr. & Temple A. Love & Jack R. Taylor \\
Robert G. Cochran & Johnie J. Lynn & James T. (Joe) Thomas \\
\multicolumn{1}{c}{ (On leave, did not return) } & Evelyn N. McBee & David K. Trubey \\
Idus D. Conner & Fred C. Maienschein & James W. Wampler \\
Daniel F. Cronin, Jr. & James H. Marable & Fritz N. Watson \\
Cleois Cross & John M. Miller & Hanover Weaver \\
James F. Ellis, Jr. & Jack N. Money & David B. F. Williams \\
Grace M. Estabrook & Francis J. Muckenthaler & Rosel N. Wright \\
James D. Flynn, Jr. & Forrest H. Murray & Clayton D. Zerby \\
John K. Fox & Richard B. Murray & Walter N. Zobel.
\end{tabular}

"Other Laboratory personnel who are to be transferred to the Applied Nuclear Physics Division, effective July 1, 1955, are the following: Robert R. Coveyou, Larry Dresner, Melvin E. LaVerne, D. W. Magnuson, M. Lewis Nelson, Richard K. Osborne."

\section{Background Information}

Much credit for creation of the ANPD is due to Everitt P. Blizard, its first director, who came to Oak Ridge in 1946 with a naval group working on the nuclear submarine project. His specific responsibility was to initiate radiation shielding studies. In November 1949 he transferred to ORNL as Group Leader, Shielding Research, Physics Division, where he continued directing the shielding work he had begun under U.S. Navy auspices., ${ }^{2,3}$ In 1954, he was made an associate director of the Physics 
Division. As the shielding programs grew in complexity and in the number of personnel involved, a separation from the Physics Division seemed indicated.

The following experimental facilities were used in support of research within the Physics Division.

\section{Critical Experiments Facility}

In 1946, a small research organization was established at the Oak Ridge Gaseous Diffusion Plant (ORGDP) under the leadership of A. Dixon Callihan to perform criticality experiments on fissile material. The research program was later transferred to ORNL, where it was known as the Critical Experiments Facility (CEF). The facility was useful in studies of critical arrays of fissionable and moderating materials. ${ }^{4}$

\section{Lid Tank Shielding Facility}

In 1947-1948, Blizard and Charles E. Clifford engaged in tests in the Core Hole of the X-10 reactor, in which problems required original thinking and subsequent changes to the testing facility. Their work eventually led to the design of the Lid Tank Shielding Facility (LTSF) that was constructed in 1948-1949. The LTSF (operating with a 28 -in.-diam. uranium converter plate as a source) was used for slab-type experiments with materials of interest to shielding. ${ }^{2}$

\section{Bulk Shielding Facility}

In November 1949, ORNL approval was secured to construct another experimental facility in which "4$\pi$ ' and 'wraparound' bulk shields could be measured. The facility consisted of a large pool of water within which a reactor and shields could be moved. Thus, the Bulk Shielding Facility (BSF), better known as the 'Swimming Pool,' was born.

The BSF encompassed work of several types. Shield mockups could be inserted in the water in which the reactor operated, and radiation penetration could be measured. The facility afforded a strong controlled radiation source for physics experiments. The reactor itself-a prototype for many research and educational reactors such as the one used at the Atoms for Peace Conference (1955-1958) in Geneva— could also be studied.

\section{Tower Shielding Facility}

The Physics Division Shielding Group realized the need for a facility to complement the BSF in which a reactor source and shield could be suspended for testing in air in relation to nuclear-powered aircraft studies. Blizard and Clifford, with calculational support by F. H. Murray and Albert Simon, evolved ideas that led to the proposal for the Tower Shielding Facility (TSF) in 1952 and its eventual operation in 1954.

The TSF, including a reactor that could be elevated $200 \mathrm{ft}$ above the ground, was to be used for those shielding experiments in which ground scattering was to be avoided. ${ }^{5,6}$

These four experimental facilities were transferred into the new division to be used in support of critical experiments and shielding studies. In addition, the ORNL Graphite Reactor was used for shielding and reactor physics experiments. 


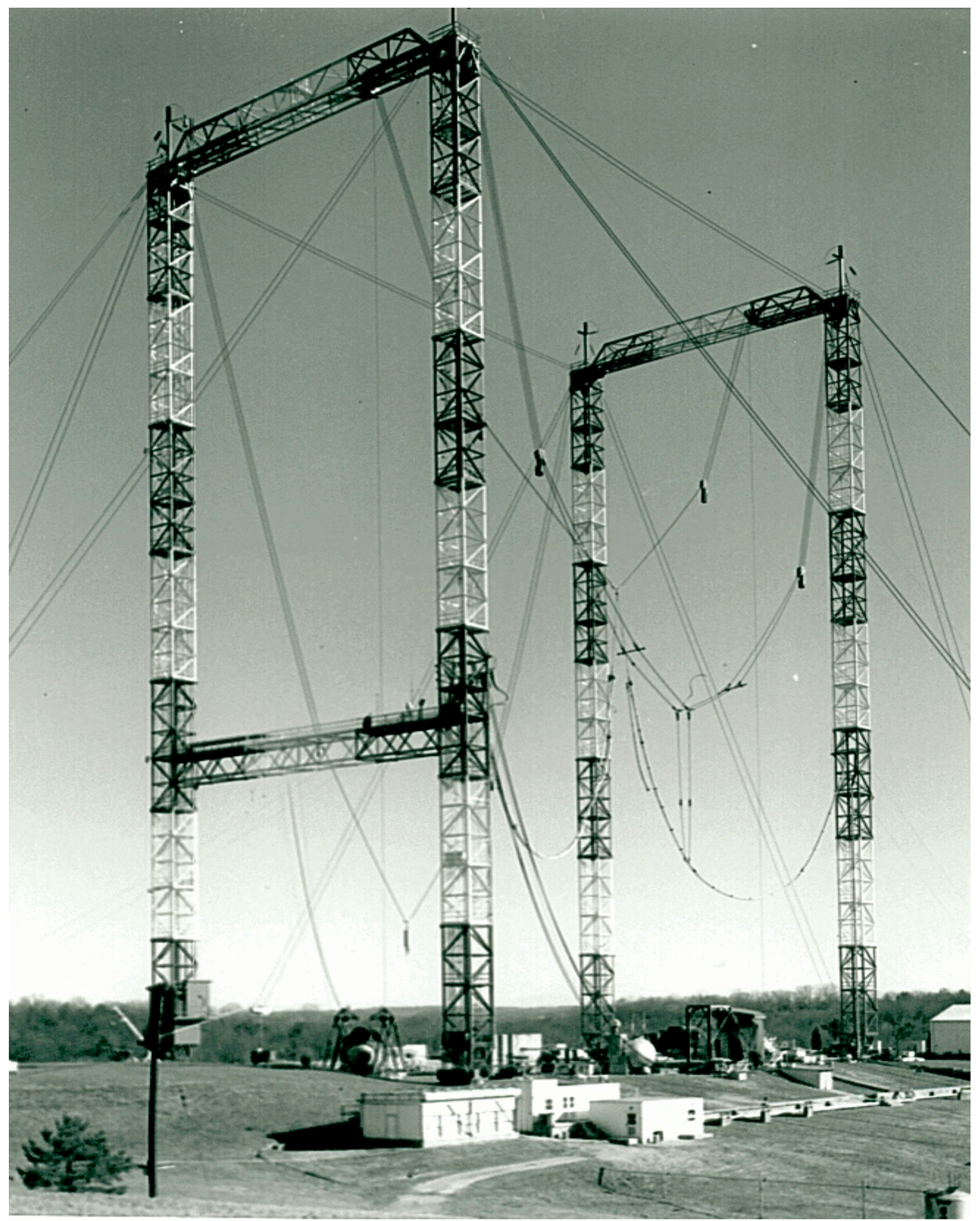

The ORNL Lid Tank Shielding Facility, located on the west face of the shield of the Oak Ridge X-10 Pile, was the first facility designed for experimental radiation shielding research. It operated from mid-1949 until the pile ceased operation in 1963.

ORNL 8640-81 


\section{THE EARLY YEARS (1955-1959)}

Division Management E. P. Blizard, the founding director, was assisted during this period by Albert Simon as associate director and four facility leaders: A. D. Callihan, Critical Experiments Facility; C. E. Clifford (1956) and Leo B. Holland (1957-1960s), Tower Shielding Facility; F. C. Maienschein, Bulk Shielding Facility; and R. W. Peelle (1956), Walter Zobel (1957) and F. J. Muckenthaler (1958-'60s), Lid Tank Shielding Facility.

Five leading experts in fields covered by the new division were selected to serve on an ANPD Advisory Committee. Appendix A is a listing of the scientists who served in this capacity through the years.

Theoretical studies of both reactor physics and radiation shielding were an essential complement to the various experiments.

\section{Theoretical Studies}

The Reactor Theory Group was concerned with both analytical and numerical methods of calculating the properties of reactors. The initial analytical work was on problems of resonance escape and capture cross sections. The numerical work was dedicated to making the greatest use of the ORNL high-speed digital computer, known as the ORACLE. Several computer codes were being developed (CORNPONE, Monte Carlo, etc.) and an associated cross-section tape was compiled. When the IBM-704 was made available in FY 1958, Coveyou, Sullivan, and others developed early versions of the Oak Ridge Random Research Reactor Routine (O5R), which eventually was used worldwide.

In the first years plans were made to undertake special experiments in the reactor physics field utilizing the Bulk Shielding Reactor (BSR), the ORNL Graphite Reactor, or an accelerator to be purchased.

\section{Annual Meetings and Progress Reports}

Everitt Blizard was a proponent of technology transfer and gave importance to an annual meeting to which leading experts and financial sponsors were invited. A progress report on the unclassified work $(\sim 50 \%)$ of ANPD was published and widely distributed. This practice was followed through the years, although the interval between reports increased beginning in 1976. Appendix B is a list of these ORNL reports (1956-1991).

The following list of the major topics under which the unclassified work was reported at the end of the first year illustrates the variety of ANPD research activities. This list includes the names of several scientists whose careers spanned the history of the division.

Research for Light-Water Moderated Reactors: K. M. Henry, E. B. Johnson, J. Kington, J. N. Anno, J. D. Flynn, W. R. Champion, and E. G. Silver

Critical Experiments: J. K. Fox, L. W. Gilley, E. L. Zimmerman, J. T. Thomas, R. Gwin, and F. G. Prohammer

Fission Physics: R. W. Peelle, W. Zobel, T. A. Love, W. W. Pratt, F. J. Muckenthaler, E. G. Silver, G. de Saussure, K. M. Henry, and M. P. Haydon 
Reactor Theory: M. L. Nelson, L. Dresner, W. E. Kinney, G. Heilborn, R. R. Coveyou, J. G. Sullivan, B. J. Garrick, R. R. Bate, J. H. Marable, J. W. Niestle, M. E. LaVerne, T. A. Welton, L. C. Biedenharn, and A. Simon

Shielding Research: T. V. Blosser, G. W. Bond, L. A. Lee, D. T. Morgan, J. F. Nichols, T.O.P. Speidel, D. W. Vroom, M. A. Welt, R. C. Reid, A. B. Reynolds, J. M. Miller, D. R. Otis, J. Smolen, D. K. Trubey, G. T. Chapman, E. Guth, G. de Saussure, R. W. Peelle, F. C. Maienschein, T. A. Love, C. D. Zerby, and S. Auslender

Radiation Detector Development: by R. B. Murray, F. J. Muckenthaler, T. A. Love, R. W. Peelle, W. Zobel and C. D. Zerby

Project Sherwood: A. Simon.

Approximately 730 copies of the first report were distributed, 131 internally. The internal distribution included, in addition to the authors above, the names of several guests and individuals who remained with the division for several years: F. L. Keller, V. R. Cain, S. H. Hanauer, D. Magnuson, J. J. Manning, H. S. Moran, R. M. Freestone, R. L. Macklin, Lincoln Jung, S. K. Penny and others.

\section{Neutron Physics Division (NPD) Is Born}

In the very busy two years of ANPD, the division's mission was gradually broadening. The change from 'Applied Nuclear Physics' to 'Neutron Physics' indicated considerable research in neutron physics as well as applications.

\section{Experimental Facilities Upgraded}

New Designs for the Bulk Shielding and Tower Shielding Reactors

The late 1950s saw progress in continuing programs as well as the initiation of new areas of work. New designs for the Bulk Shielding Reactor (BSR) and the Tower Shielding Reactor (TSR) were in process. Ernest G. Silver, Joseph Lewin, and Rafael B. Perez worked on an alternate core for the BSR, a $\mathrm{UO}_{2}-$ stainless steel reactor to be known as BSR-II. C. E. Clifford and Leo B. Holland led in the design of the spherical reactor, TSR-II (described in a later commentary by J. Lewin).

\section{Pool Critical Assembly Installed}

Elizabeth B. Johnson and Keith M. Henry were involved in work leading to the installation of a lowpower reactor facility in one end of the BSF pool. This 'Pool Critical Assembly' consisted of a lightwater-moderated and -reflected pool-type reactor intended to augment BSR and Oak Ridge Research Reactor programs by handling most of the low-power (up to $10 \mathrm{~kW}$ ) experiments for these two reactors.

\section{Shielding Research of Prime Importance in the Fifties}

The design of reactor shields and code and nuclear data development for use in shielding research were given priority. The IBM 704 computer with a Fortran Compiler, installed in the Oak Ridge Gaseous Diffusion Plant (ORGDP) Central Data Processing Facility (CDPF), was made available. Clay D. Zerby and Hubert Moran initiated a high-energy accelerator shielding code system to perform calculations of the spatial and energy distributions of high-energy particles penetrating an idealized shield. Hugo Bertini initiated research in accelerator shielding, a forerunner to the extensive intranuclear cascade calculations he performed in subsequent years. Trubey and Penny initiated gamma-ray Monte Carlo 
code development (GRINDER), and F.B.K. Kam and Henry Stern worked on analytical codes for data analysis associated with the design of shields for nuclear-powered aircraft.

Research for light-water reactors (LWRs), both theoretical and experimental, continued throughout the 1950s. A.B. Reynolds, K.M. Henry, and E.B. Johnson studied reactivity effects of large voids in the PCA reflector. Silver and Wolf Etzel (W. Germany) performed critical mass calculations for pool-type research reactors.
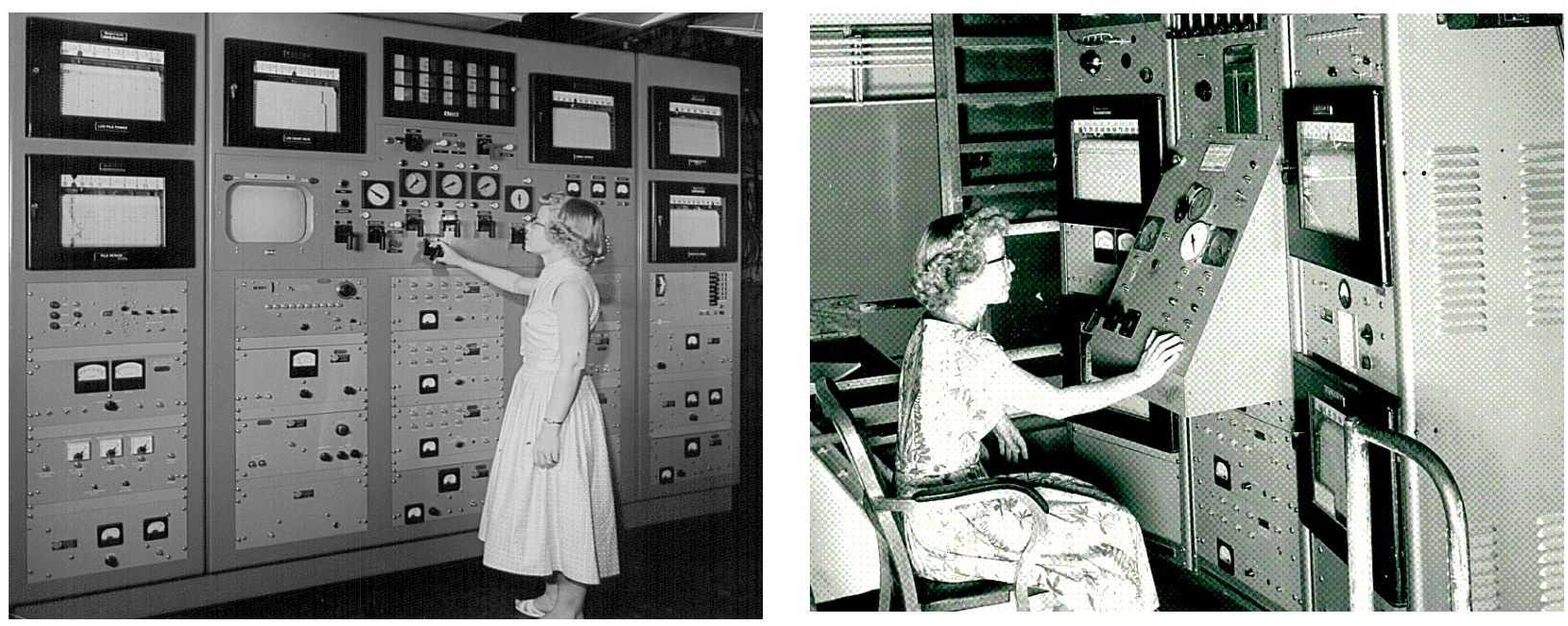

Elizabeth B. Johnson, ANPD experimental physic ist, working at the console of the original control and safety system instrumentation of the Bulk Shielding (swimming pool) Reactor (BSR) in 1956 (left) and at the console of the newly installed BSR-II in 1957 (right). ORNL 40764 and ORNL 18172

\section{International Conferences on Reactor Shielding (ICRS)}

Everitt Blizard had a wide acquaintance among the European shielding scientists and engineers with whom he cooperated and collaborated in areas of common interest. He encouraged technical information and personnel exchange and was one of the promoters of an international conference on reactor shielding.

The First International Conference on Reactor Shielding (1-ICRS) was convened in 1958 at Cambridge University with the United Kingdom Atomic Energy Authority (UKAEA) as host. Blizard and other NPD members participated, thus setting a precedent for continuing division support for the series of conferences (2-8) to follow.

\section{COMMENTARY: “Memories of the Beginnings" by R. W. Peelle}

I did not quickly gain a global view of ORNL's overall activities in reactor physics and shielding after I arrived in February 1954. Much work was classified then, but more important in maintaining my 'blinders' was my own dual focus on getting a fast start helping Maienschein and others on a difficult experiment while spending a few hours each day working on my thesis data.

The task of shielding an aircraft reactor with the knowledge at hand was formidable, and the shielding groups were alive with activity in getting the TSF experiment and analysis under way. That facility would offer hope at last of separating air and ground scattering effects - a crucial issue with the thin primary shield used in one of the leading conceptual designs. There were guests at ORNL from several consultant firms and nearly every aircraft company, and they were depended upon for a good 
share of the overall productivity. Since I knew a bit about the anisotropies observed in all cross-section experiments in the several MeV region, I was rather shocked to learn in that era that the 'latest and greatest' air scattering calculation, by Clay Zerby I think, took account of neutron scattering using only elastic scattering, and that was taken to be isotropic in the center-of-mass system. But with an ORACLE computer the best available, it was silly of me to expect more. (We were proud then of Jerry Sullivan for developing one of the first assembly languages).

Everitt Blizard and Herbert Goldstein were the men of shielding at that time. In technical meetings they would provide a large share of the discussion, both on technical points and in the traditional repartee of experimenter vs theorist. It was a good show, and we junior members of the community learned a lot from it. Other than the contributions of these leaders and a few others, the technical level of those meetings was rather low. Many of the workers had been pressed into this effort without the analytic training or nuclear physics background that would have allowed rapid development of more sophisticated approaches. How could so many bad theories be in 'satisfactory' agreement with bad experiments? I did a little classified work that turned out as bad as the rest; that helped me understand one value of the 'restricted data' stamp.

It was not surprising that the Applied Nuclear Physics Division split off from Physics. Part of the reason was that the level of activity was getting high enough, but I suspect there was another reason. While Art Snell as head of the Physics Division fully appreciated the importance of shielding, dosimetry, etc., he had great difficulty in generating any personal technical interest in the field. He wrote with bold frankness, in a review article published in The American Scientist covering the 1955 Geneva Atoms for Peace conference, that he couldn't stay awake for that part of the conference, so he took off to tour some of the areas around Geneva.

The swimming pool facility (BSF) was a weird place to work. It had been built at very low cost, but there were penalties. I remember that in the men's room the ivy planted outside the walls was growing up inside along the galvanized iron wall, having found its way through a wide crack just above floor level. The water in the pool was purified after an enormous sum was spent to seal the walls of the pool with high-quality enamel. However, lots of dirt must have washed out of the hillside with water leaks. Fred Maienschein had that fixed by pumping a zillion cubic yards of grout through holes in the floor to make an artificial mountain of hardened material. Privately, he may have been concerned about a hypothetical accident in which the hill might collapse, let all the water out, and leave the activated reactor fuel unshielded.

Prior to the white enamel job, some chemical was added to the water in the pool to reduce corrosion. It probably didn't work except to inhibit the vision needed for operations at the reactor. Afterwards, demineralized water was used and the 'blue glow' of Cerenkov radiation was very beautiful even though the reactor power was low. The emerging technology, or maybe the pretty color, attracted guests almost every day. Many of the guests were influential people, wondering, I suppose, if their countries should invest in such a device. After all, it was the only reactor around where one could see something. The BSR was not only beautiful and accessible, but rather friendly as its fission counter clicked over the PA system as a substitute for having an operator at the console. Twenty or so times a year Maienschein appeared in a photo just under the headline of the ORNL News, greeting some scientific or political dignitary from far away.

Doses measured in the water at the BSF were shielding benchmarks, and lots of effort went into obtaining a valid reactor power calibration over a large dynamic range as well as neutron and gamma 
doses. I remember a huge wall chart pasted up from large sheets of semilog graph paper. I don't recall how many cycles were required, but it was easy to see the neutron dose from photoneutrons generated in the water. Research centered on 'fast neutron removal cross sections' observed in the Lid Tank and elsewhere, and data bases relied on these values rather than real energy-and angle-dependent cross sections. What a contrast with the picture now, or even in 1975!

In those days there was great excitement about the work, even if it was not all well founded. In part this attitude was fueled by cold-war fervor; many expected a major conflict within a few years. While we didn't know very well the scientific basis of what we were doing, we did try very hard to do better. From reports that I heard, not all laboratories shared that excitement and level of effort; if so, I suppose that is why we did a little better than some. Averaged over the whole period of reactor and shielding physics development up to perhaps 1980, I think it was generally true that the field was carried forward by a strong urge toward excellence that went beyond the minimum requirements of the sponsors, who were a part of that drive and deserve lots of credit for their attitude.

Everitt Blizard would now and then become interested in possible topics for a PhD. thesis for himself. In about 1957 he considered doing one using our gamma-ray spectrometry equipment. However, the breadth of his daily contacts and his feelings of personal responsibility for all shielding problems were far too demanding for him to take off a year to work on a narrow topic. All of his 'spare' time went into review articles intended to raise the general level of understanding of shielding. So he continued just as well without a PhD, a feat that was easier then than it would be now. He was a hard-working and hard-thinking extrovert, who worked toward solutions to all

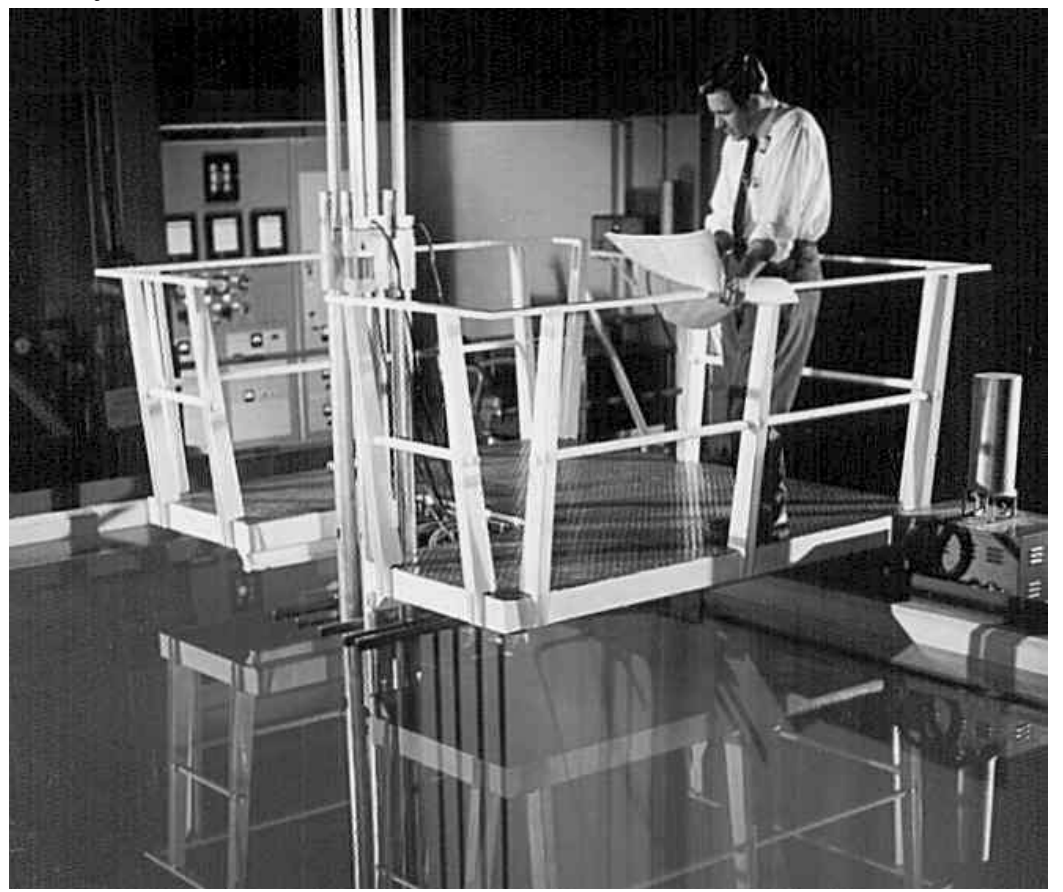

The Pool Critical Assembly (PCA), loc ated at the northwest comer of the BSF pool, was used to relieve the BSR of much of its lowpower experiment load. ORNL 43038 sorts of shielding problems as he ceaselessly sharpened his pocket knife on the oilstone he kept at his desk. I never saw him cut anything with it. (NOTE: Fred Maienschein and Lorraine Abbott knew 'Bliz' far better than I, and might have cause to disagree with some of the above.)

One of Maienschein's long-term efforts was to bring the whole division to one area so that interactions could occur. The result was helpful, but the areas of interest have become rather dispersed and therefore less advantage accrues to the consolidation than would have originally been the case. 


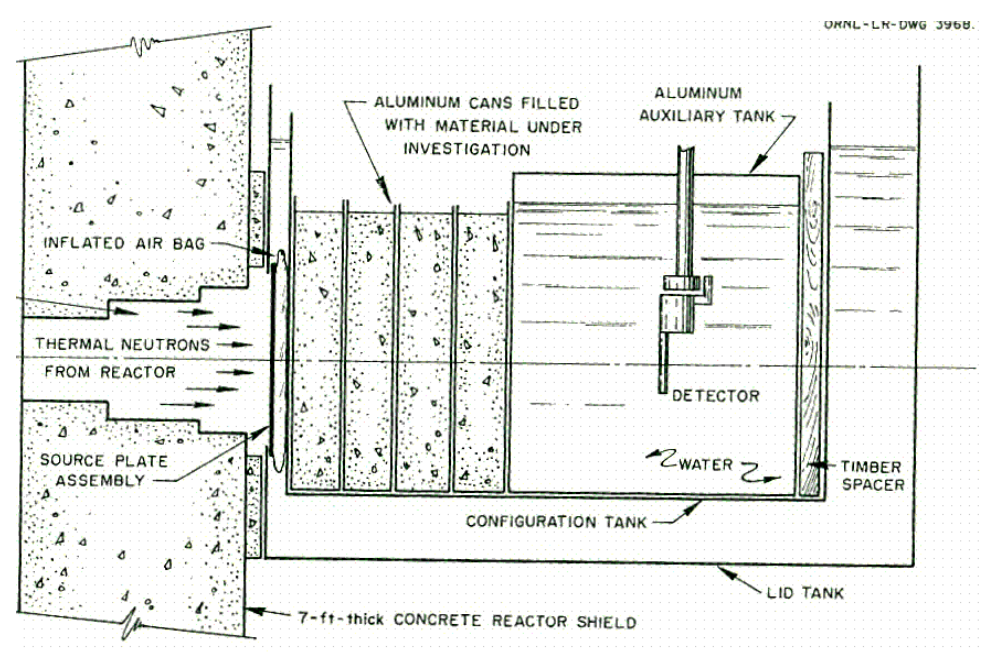

The ORNL Lid Tank Shielding Facility, located on the west face of the shield of the Oak Ridge X-10 Pile, was the first facility designed for experimental radiation shielding research. It operated from mid-1949 until the pile ceased operation in 1963. ORNLLR-DWG 39683

Schematic Drawing of Lid Tonk Geometry.

\section{COMMENTARY: “Recollections from the Early Days” by D. K. Trubey}

After graduation from college with a degree in Physics in June 1953, I was invited to Oak Ridge National Laboratory for an interview with Everitt P. Blizard, leader of the ORNL Physics Division Shielding Group. I met Art Snell, director, and Harry Maggart, administrative assistant, and 'Becky' Rickman, Blizard's secretary. I had lunch with Blizard and Herbert Goldstein of Columbia University, who was in Oak Ridge to attend what was called the "Summer Shielding Session."

I returned to ORNL in September 1953, after receiving security clearance, to work under Blizard in the Physics Division (PD). I was assigned to the Lid Tank Shielding Facility (LTSF) to work in a group led by Charles (Chuck) Storrs, a loanee from General Electric. Other LTSF staff members included George Chapman, John Miller, and Fritz Norman Watson. The four of us, called "engineers," were responsible for the Lid Tank shielding experiments, all related to the Aircraft Nuclear Propulsion (ANP) Program, working under Storr's supervision. The technicians included Jack Money, Jack Taylor, Jim Wampler, Everett Beckham, and electronics technicians Jim Sellers and Dalton Smiddy.

The Lid Tank was located on the west face of the ORNL Graphite Reactor. A channel through the shield allowed thermal neutrons from the reactor core to come to the source plate of the Lid Tank, which generated about 6 watts of fission power. As a source of radiation, it was used to determine the shielding effectiveness of the samples (such as lead and steel) placed in the Lid Tank. The samples were lowered into the water tank and measurements were taken in the water behind the slab samples.

Prior to the building of the Lid Tank, the 'core hole' was used as a source of neutrons from the reactor for shielding measurements, which I understand were carried out by Charlie Clifford and others. There was scattering and leakage around the samples in the 'core hole, 'so these experiments were not very satisfactory and the tank was installed to alter the geometry of the experiments.

I was involved in two experiments during my year at LTSF: (1) a comparison of the secondary gamma-ray effectiveness of lead vs bismuth, and (2) a measurement in sugar water. It had been proposed that, due to the lower thermal neutron cross section, bismuth might be a better shield than lead and 
would result in producing fewer secondary gamma rays. The experiment showed no essential difference. I gave a paper on the results at a classified ANP meeting at Knolls Atomic Power Laboratory in 1954.

The second experiment required that we carry 10,000 pounds of sugar up the stairs at the side of the tank and dump it into a secondary tank placed inside the Lid Tank. I suspect it was Goldstein who suggested that sugar water would provide a medium for carbon to be distributed uniformly throughout a water medium. The experiment allowed us to measure the removal cross section of carbon in a continuous medium as opposed to being in a slab followed by water, as most removal cross sections had been determined. Removal cross sections were the main products of LTSF and they were eagerly sought by the shielding engineers of that era. The removal cross section gave an indication of the effectiveness of a particular material embedded in a hydrogenous medium. The theory required that any material should be followed by material containing hydrogen, such as water. There were other hydrogenous media proposed, such as zirconium or titanium hydrides, but they were very expensive.

Blizard sent me to the Oak Ridge School of Reactor Technology (ORSORT) in the summer of 1954. Since there were no nuclear engineering courses taught in the universities at this early stage, students came from everywhere for ORSORT training. There were two categories of students: employees sent to ORSORT at company expense, and newly graduated students who received fellowships to attend. $S$.

Keith Penny and Ernest G. Silver came on fellowships and later joined the new Applied Nuclear Physics Division (ANPD).

The ORSORT faculty included Bob Meghreblian, who later turned his lecture notes into a textbook, and Jim Marable, who taught reactor analysis. Blizard taught shielding; Lewis Nelson lectured on mathematics; and Larry Dresner, Bob Charpie, and others gave topical lectures. During this summer we were organized into groups to study particular reactor concepts with ORNL staff members providing guidance. Alvin Weinberg was the mentor of my group, which actually met at Y-12. Like many of Weinberg's concepts, it was a fluid fuel system.

The ANPD was formed in 1955 while I was in ORSORT. When my course was completed, Penny and I were assigned to a new shield design group led by Leo Holland which replaced the Pratt \& Whitney shield design team whose members were recalled. We took on as our first assignment an evaluation of a particular reactor concept to determine the shield weight. The shield design group, as such, appeared to be in a constant state of flux. Fred Keller came in as group leader and was promptly sent to Mexico. Richard (Dick) Maerker headed the group for a short time, then he was sent to France for a year's assignment in the CEA/CEN/Fontenay-aux-Roses Shielding Laboratory. By this time, we were moved into the attic of Bldg. $4500 N$ with two young Air Force officers from Wright Field, Bill Dunn and Raymond Lessig.

Realizing that no one was going to direct our efforts, I initiated some research projects in collaboration with Dunn and Lessig. Clay Zerby and Sid Auslander (Pratt \& Whitney) had developed a Monte Carlo gamma-ray transport code for the ORACLE; Auslander, before he left ORNL, showed me how to operate the program. I used it for gamma-ray transport calculations and directed Dunn and Lessig in other studies such as leakage of radiation from the Bulk Shielding Reactor.

Keith Penny and I eventually shared an office in $4500 \mathrm{~N}$ and began a collaboration on developing a gamma-ray transport code in parallel with Bob Coveyou and his group's development of O5R for neutron transport. Quite a few of the ideas for $O 5 R$ were incorporated into what later became known as OGRE. 
In 1960, Blizard asked me to understudy his ORSORT shielding lectures in order to fill in when he was absent. As time passed, I was giving more and more of the lectures and all of them by the end of the course. Then I took over completely and gave all the lectures through 1961 and 1962.

There were two projects in which I was involved in the late 1950s that I remember well. The first one began, as I recall, when Blizard came into my office to interrupt my work "for a few weeks." It turned out to be a number of months.

Weinberg and Wigner were finishing up their book on nuclear chain reactors at this time, and Weinberg was aware of the LTSF measurements of the thermal neutron flux distribution which could be transformed to a point source in water. The information could be used to predict the non-leakage probability of an aqueous homogeneous reactor, and Weinberg would find it useful in completing the theoretical description of the reactor for the book. I became involved in computing the function (buckling), which has to do with the shape of the thermal neutron flux in a reactor near its outer edge. It would, therefore, give the leakage or non-leakage probabilities. Reginald Gwin was also involved because of his background related to critical facility experiments where a number of aqueous homogeneous spheres had been taken to criticality.

The result of the above work was summarized in the book, a publication that Frank Clark always called "V\&V" for "Vineberg \& Vigner." I remember that on one occasion when Weinberg called me into his office, Wigner was there. As the work was being discussed, Weinberg left the room leaving me alone with Wigner. I was awed in the presence of such a famous man. Of course, both Weinberg and Wigner are very gracious and humble people, and I really had nothing to fear. The work also resulted in a paper authored by Weinberg, Gwin, and Trubey that was presented at the 1958 Geneva Conference by Gwin.

The other well-remembered project, related to the Fermi age of neutrons in water, was one in which I collaborated with $\boldsymbol{T}$. $\boldsymbol{V}$. Blosser. There was a well-known discrepancy between the measured age and the theoretical ages based on calculations, and Herb Goldstein, I believe, was behind the pursuit of this discrepancy. The thermal neutron attenuation curve in water from the Lid Tank was essentially unknown close to the source for various reasons. The source had rather large dimensions, and what was wanted was the unperturbed flux from a theoretical point source. The original LTSF source was an array of slugs from the graphite reactor. The second source, aluminum with a uranium-aluminum alloy plate as the 'meat' of the sandwich designed by George Chapman, was a better source. The power was measured by comparing heat from electrical heaters in the plate to fission heat. The power level was known better than it had been with the original source, but because of the detectors and the size of the fission plate, flux depression was present, and the shape of the curve near the source was really quite unknown. I recall making attempts to predict what the shape should be near the source based on other information. Goldstein showed interest and was doubtful of my success. So we took another 'tack'; Blosser to make measurements in the thermal column located on top of the graphite reactor. This column consisted of a tunnel through the shield on top of the reactor so that neutrons could come up through the graphite, becoming highly thermalized on arrival at the end of the tunnel. Blosser had various kinds and sizes of fission foils to simulate a point source, and indium foils to measure the thermal neutrons by using cadmium covers which would effectively block the thermal neutrons. By subtraction, the data could be interpreted in terms of just the thermal neutron flux. Of course, the fission foils and detector foils were not point sources or point detectors, and I attempted, by mathematical techniques using the ORACLE, to transform the data from a disk source-disk detector to that of a point source-point detector. I recall that 
Blizard expressed skepticism of my methodology; he consulted Coveyou who stated that what I was doing was reasonable. The ORACLE was difficult to use compared to today's computers in terms of programming arithmetic with real numbers. I invented schemes using integer arithmetic which would renormalize whenever getting out of range with real numbers.

Blosser's experiments resulted in publications, mainly in division progress reports and probably nowhere else. This problem, however, was being addressed by other researchers and their work was cited in a number of Nuclear Science \& Engineering articles.

The problem of flux depression arises from perturbation of the flux by the detector. One would like to have what Frank Clark called a "non-perturbing detector." And so we did a series of measurements with foils of different thicknesses to be able to extrapolate to a zero-thickness detector. This work was suddenly interrupted by an accident, an explosion at the pilot plant next door to the graphite reactor building that had been used by the Chemical Technology Division to develop pilot chemical separation processes. The explosion in one of the cells of the pilot plant deposited contamination all over the area, throughout the graphite building, and around outside. The graphite reactor was shut down for a cleanup operation that took a number of months. Blosser and I each got involved in other things and we did not resume the project. One thing that did come out of this work was that Goldstein became convinced that the Fermi age discrepancy between measurements and theory was due to the fact that these correction factors had not been taken into account.

I recall an incident that happened while Blosser and I were involved in the above project. We were working on top of the graphite reactor ( 1960) when Adlai Stevenson, who was running for President, came to visit what was to become a national historic landmark. I had to stifle an urge to spit down upon Stevenson's shiny bald head, which was directly below us.

\section{COMMENTARY: “The Division Had Many Firsts” by Rebecca Rickman}

The Applied Neutron Physics Division was organized in July 1955 by bringing together a large number of the original staff members from the Physics Division (The Bulk Shielding Facility, The Lid Tank Facility, The Tower Shielding Facility, and the Critical Experiments Facility) and the Director's Division (a number of theorists and mathematicians). A total of $~ 60$ staff members, including technicians at the various experimental facilities and clerical and administrative staff, made up the ANPD.

At the time of the organization, Everitt P. Blizard, the first division director, was deluged with applicants for the position of Administrative Assistant. Lorraine Abbott, Reports Editor, and I, Rebecca Rickman, the division director's secretary, approached Blizard with the idea that the two of us could handle the duties of administrative assistant along with our other duties. It was suggested that Abbott would handle the budget and that I would handle personnel matters. Blizard bought the idea and as a result we became the first division at ORNL to operate without an administrative assistant. So far as I know, this practice has continued in the division until the present time.

Two or three years later, when Work for Others money became evident, Blizard asked for part-time assistance from the ORNL Budget Office. Thus, Joe Carr became the first finance officer to be assigned to a division. Carr was followed by Claude Long, Charles Watson, John Hickey, John Gann, Myra Rose, and, currently, Kimberly Barnes.

Blizard was the first division director at ORNL to acquire Work for Others funds of any substance (from NASA and the U.S. Navy). Approximately \$1 million was obtained from these sources. At that time, 
it was a very simple procedure - Alvin Weinberg's office called to say, "we have a letter we think you should see." Blizard literally ran from his office at the west end of 4500N, second floor, to Weinberg's office at the east end. He came back running and waving and telling anyone within earshot, "I've got a million-dollar letter!” Paperwork was so simple at that time!

The division maintained a small clerical support staff for approximately 20 years. We were cited on successive years for having the smallest clerical staff per professional staff and the highest number of publications per professional staff. (This was before the Computer Age.) Reports, journal articles, and other documents were typed and edited in the division; equations were handwritten for the most part. Although this publication record was maintained until circa 1980, the clerical staff began increasing in the mid-1970s.

The original secretarial support staff included Mary Lou Rueff, Critical Experiments Facility (CEF); Clarice Bounds, Bulk Shielding Facility (BSF); Evelyn McBee, Tower Shielding Facility (TSF); and Rebecca Rickman, secretary to E. P. Blizard. Virginia Glidewell was employed in the Reports Office by Lorraine Abbott. Very soon, Helen Daggett Cook replaced Clarice Bounds at BSF and shortly thereafter Jane Patterson was added to the BSF staff. Thus, the staff of 7 persons giving clerical support remained basically the same for approximately 10 years. At some point, Beth Christian was added to assist Blizard with his duties as Editor of Nuclear Science and Engineering. Mildred Landay came on board in the late 1960s and served 15 years as RSIC Secretary.

This small clerical staff was able to produce the enormous amount of paper generated by a technical staff of approximately 70 plus loanees, subcontractors, and other guests. Of course, reorganization, budgetary deficiencies, and resignations caused shifting of and additions to the secretarial staff. However, the early team of secretaries were dedicated and outstanding workers who helped to make the division thrive and gain world-wide recognition.

Some of those subsequently added to the secretarial staff who made outstanding contributions included Erma (Steve) Howe, first at TSF and later as secretary to C. R. Weisbin, CESAR Section; Coralee Zeigler, secretary to R. G. Alsmiller, Jr.; Lenna Lovett, secretary to R. W. Peelle; and Lindy Norris, secretary to $\boldsymbol{C}$. $\boldsymbol{E}$. Clifford.

In the ensuing years, a number of secretaries passed through the division, but the Computer Age changed things drastically. Technical staff members began typing their reports on personal computers and electronic mail was introduced. Secretarial responsibilities changed as well.

The division was among the first to have guest assignments from other countries (Pakistan, Turkey, Germany, Japan) as well as other organizations in the United States (Pratt \& Whitney, General Electric, Boeing), to name a few of the early participants.

The division seemed to be a melting pot for individuals who were somewhat misfits in their current jobs. Blizard was an expert at hiring individuals and finding a niche which made them happy and productive staff members. However, the early team of secretaries were dedicated and outstanding workers who helped to make the division thrive and gain world-wide recognition. 


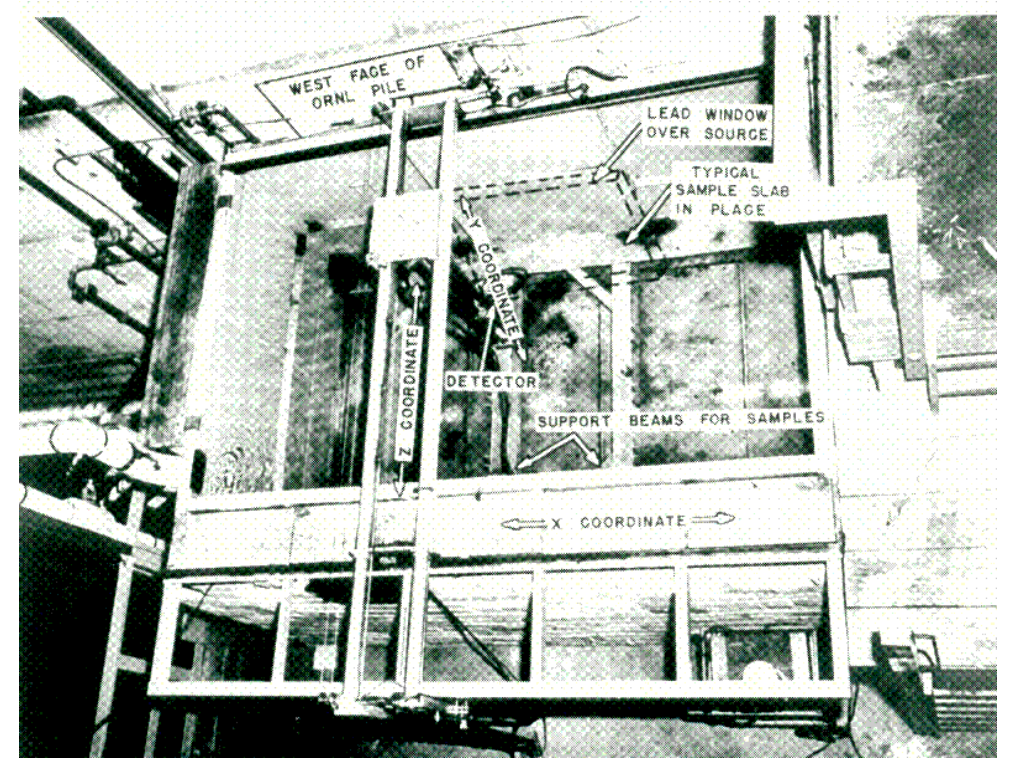

Lid Tank Shielding Fac ility, view from a bove. ORNL 2952-93

Lid Tank Shield ing Facility, view from opera tor's desk. ORNL 2953-93

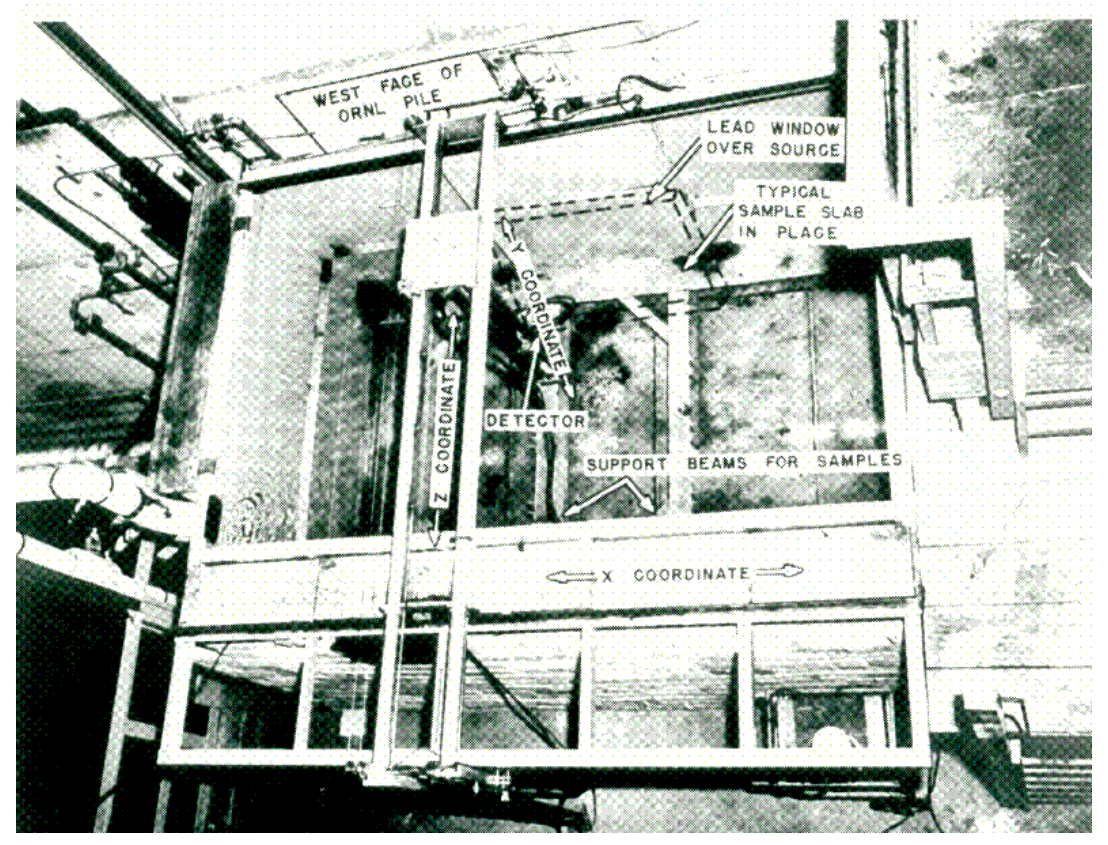




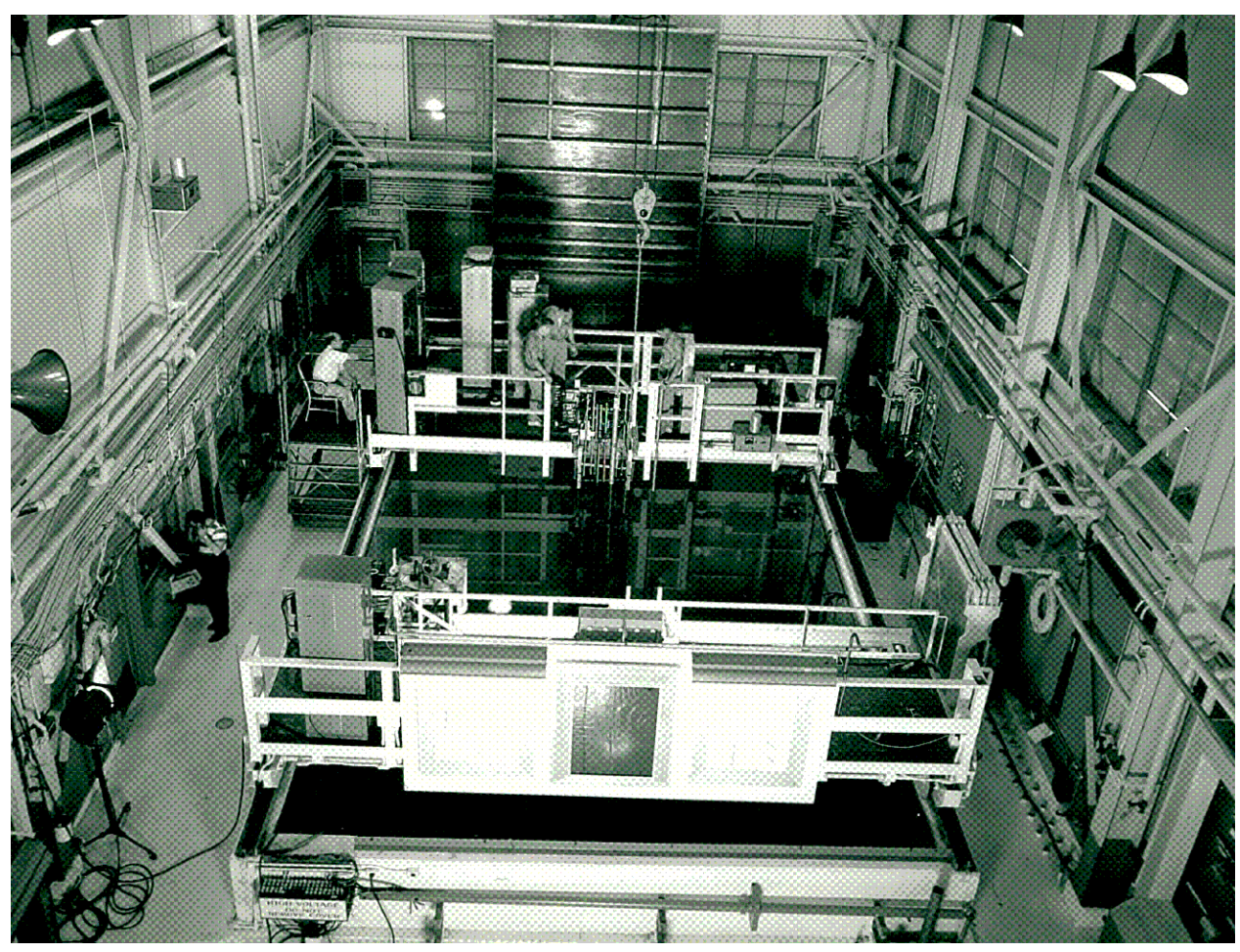

The Bulk Shielding Facility (BSF) and Bulk Shielding Rea ctor (BSR). ORNL 18174

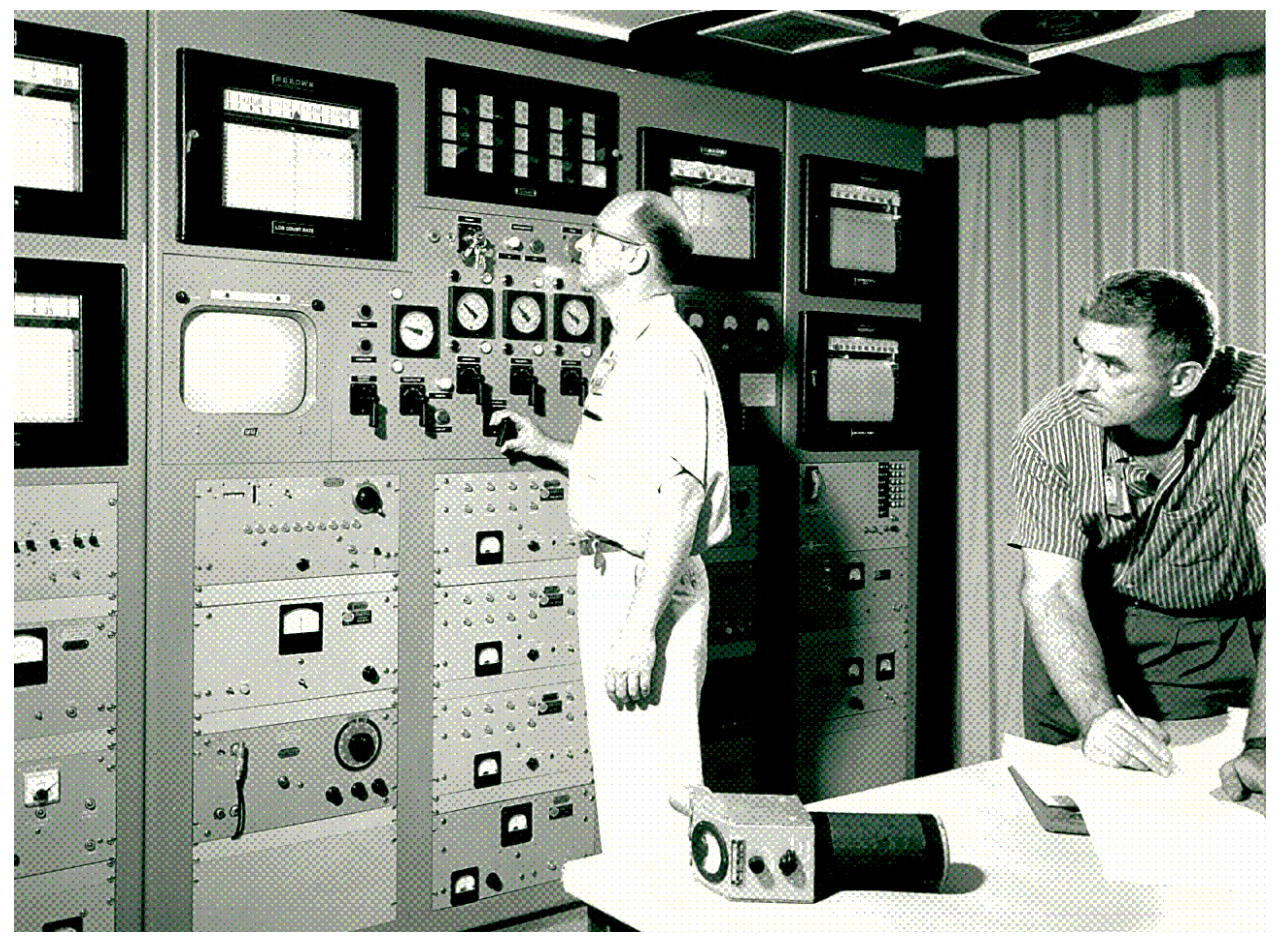

At the console of the Bulk Shielding Reactor (BSR-II) in the Bulk Shield ing Facility (BSF), Joe Kington (left) and Keith M. Henry take data from the operating reactor, circa 1957-1958. The BSF and BSR, now permanently shut down, served many useful purposes at ORNL for 40 years. 51489 


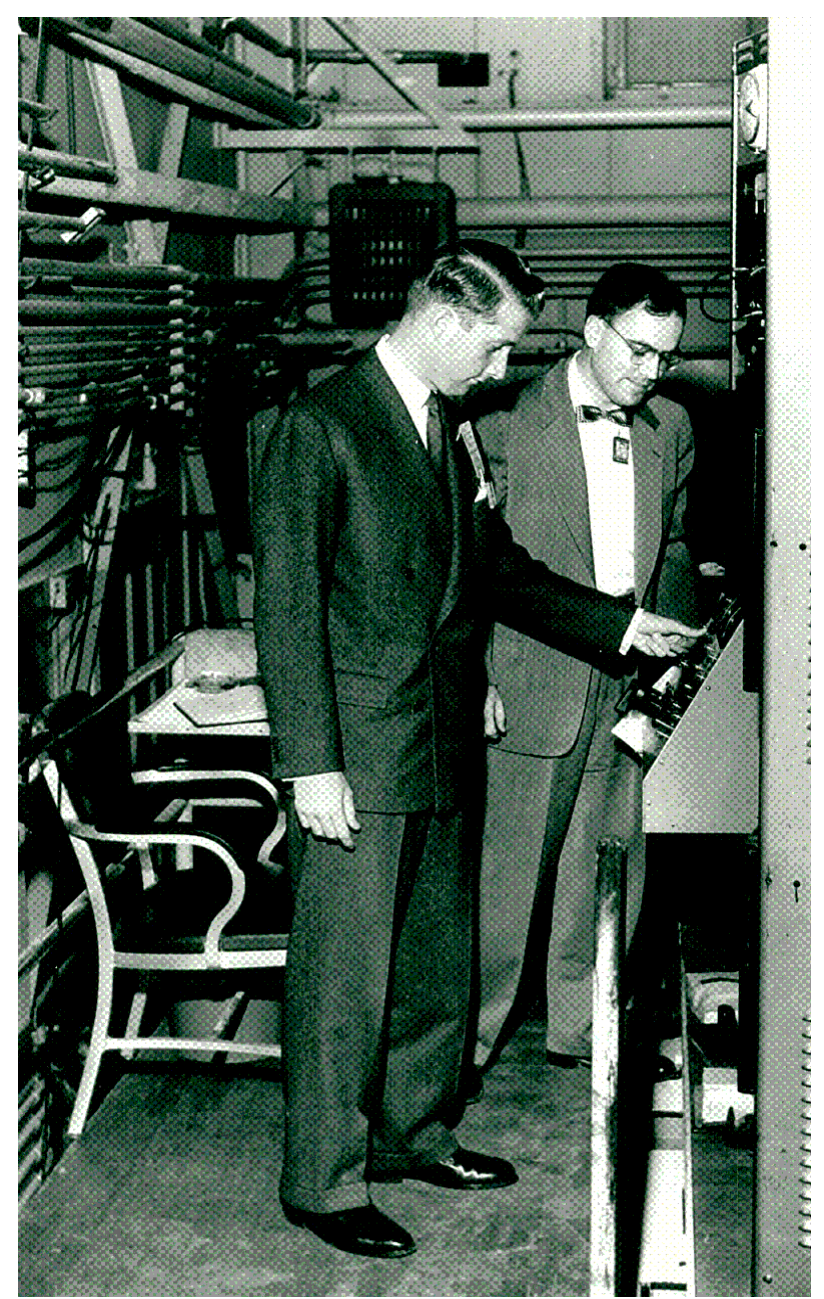

Prof. Le Poole enjoys "hands on" the BSR controls with guidance from Fred Maineschein. ORNL 55-1013

The NPD Annual Information Meeting attracted many scientists. Attending the 1958 dinner at Deane Hill Country Club in Knoxville were (left to right): A. J. Miller, C.W.J.

Wende (Savannah River Laboratory) R. R. Wilson (General Atomic), R. Anderson (AEC) R. G. Doherty, Everitt P. Blizard (NPD Director), Alvin M. Weinberg (ORNL Director), L W. Nordheim (General Atomic), and Al Simon (NPD Assoc iate Director). Foreground (facing front, from left): Lawrence Dresnerand

Robert W. Peelle. ORNL NEWS 4157

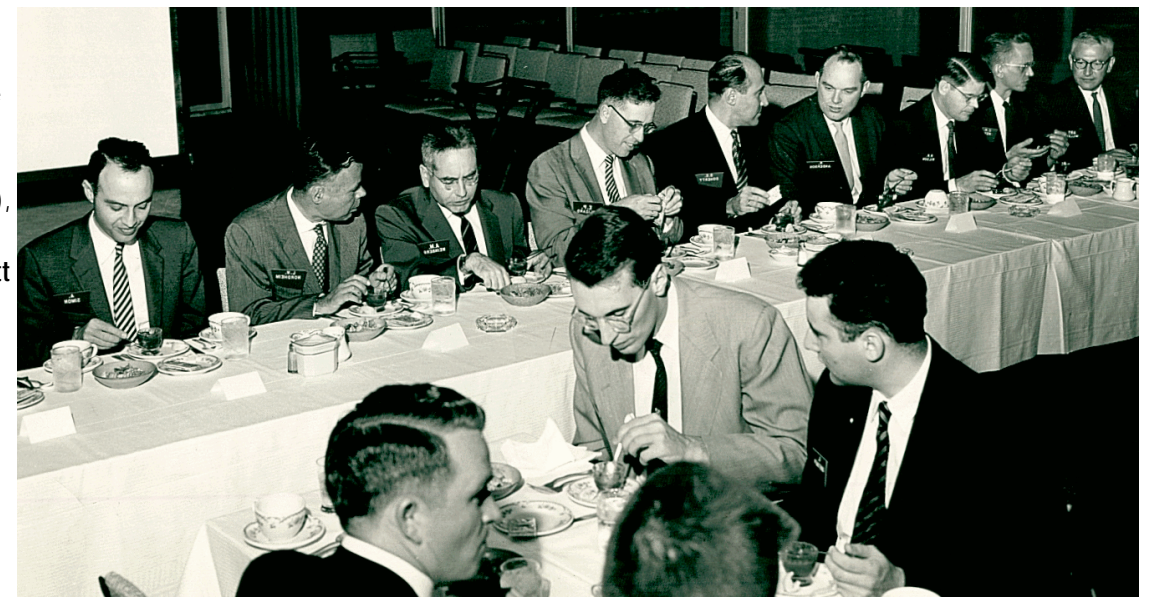




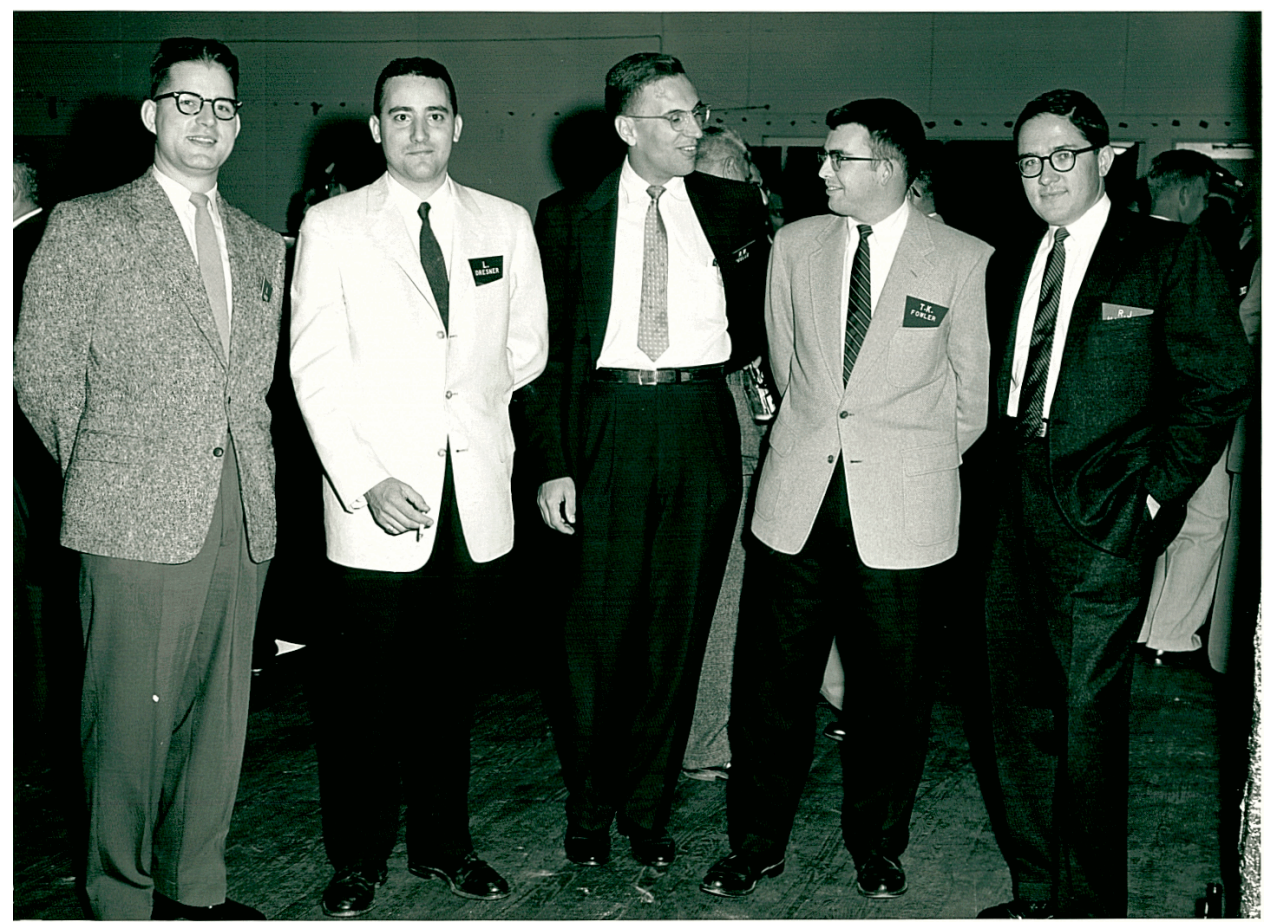

Present at the 1959 NPD Annual Information Meeting Dinner were (from left) Hal Schweinler (So lid Sta te Division), Lamy Dresner, Bob Peelle, T. K. Fowler, and RobertJ. Mackin. ORNL NEWS 2627

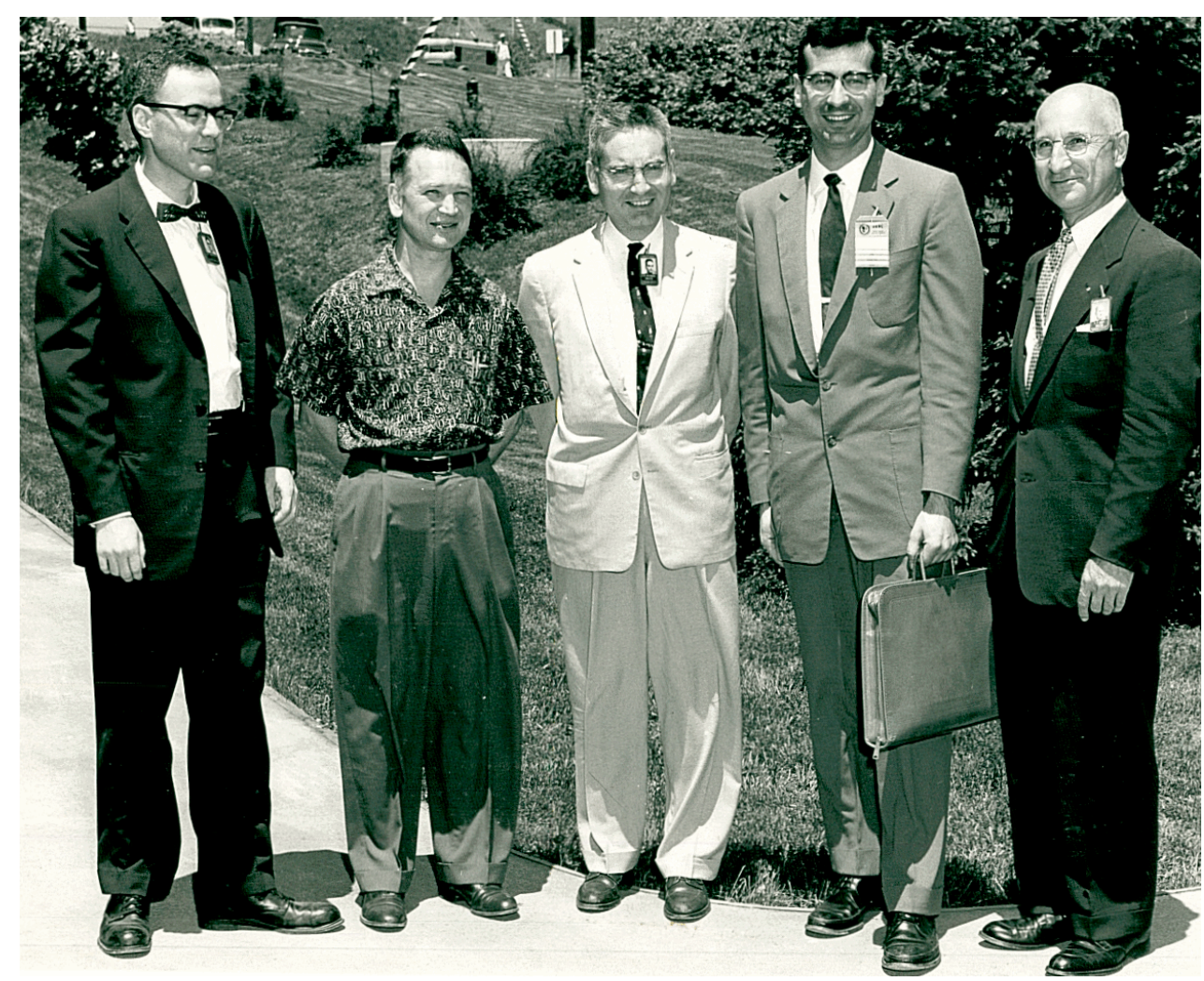

A 1958 visitor, Prof. Rossi of Ita ly, tours BSF and other ORNL facilities esc orted by (from left); Fred Maiensc hein, Bill Good, Alvin Weinberg, Rossi, and Chris Keim. 


\section{THE EXCITING SIXTIES}

The pace and momentum of the 1950s continued into the early 1960s as Blizard's enthusiasm generated high morale throughout NPD with striking results and applications. The programs included a strong mix of research and experiments related to LWRs, radiation detectors, and nuclear and reactor physics. BSR-II and TSR-II were completed and used in NPD research programs. New technical programs were introduced through which there was collaboration and cooperation with other divisions, for example, shelter shielding (civil defense) and thermonuclear and desalting research. The Radiation Shielding Information Center (RSIC) was established, and other changes occurred.

There were also depressing happenings. The Kennedy assassination was followed by the declining health and subsequent death of Everitt Blizard.

\section{Publication Policy Changes}

An observation was made that emphasis on the annual progress reports resulted in some research not being reported elsewhere. It was noted that individual papers in the NPD progress reports were not being treated specifically by information centers or otherwise collated into organized scientific literature. The decision was made to limit each paper in the progress report to the length of either an abstract or a summary in order to give the authors more time to spend on 'topical' reports. It was expected that the abstract would cover prior publication with the summary to cover work initiated but not yet completed, and thus not yet ready for publication.

\section{COMMENTARY: $F$. C. Maienschein}

In response to the comment, "We hit some kind of climax in FY 1963 - or so it seems to me" (BFM), the response was "You are right, a climax in stupidity. We were wasting scarce resources in publishing in obscure progress reports what belonged in the open literature."

\section{COMMENTARY: $R$. W. Peelle}

Maskewitz quoted Maienschein (above) on the division's overcommitment to progress reports. He didn't overstate the problem. We all spent much of each year writing those reports, but only the few readers closely tied to the same projects would ever see any of the results. They were certainly up to date, but included lots of work that never reached fruition. By contrast, the information meetings included many guests from out of town who often contributed significantly to the discussions.

This philosophy resulted in a vigorous adherence thereafter to publishing the division's research results in the open scientific literature.

\section{Management Through The Sixties}

The mid-1960s were years of management transition. When Simon left ORNL, Callihan and Maienschein were appointed associate directors (FY-1960) and began to carry an increasingly larger share of division management. Blizard, exercising oversight while assisting Eugene Wigner in establishing a civil defense program at ORNL, became ill. 
Everitt P. Blizard's illness required hospitalization for several months during the fiscal year, ending in his death February 22, 1966. The RSIC Newsletter No. 16, March 17, 1966 carried this item:

"The shielding world has suffered a great loss in the passing of Everitt P. Blizard. He was truly a giant in the field, and the force of his personality and direction will long be remembered. His service in shielding dates back to the infancy of the field and his accomplishments are widely recognized."

The ANS Journal, Nuclear Science \& Engineering 27:2 (Feb. 1967) was published as a memorial to Blizard who served as editor during the period 1960-1965. The first article (pp.145-50) was a moving eulogy and tribute written by Professor Herbert Goldstein of Columbia University.

Fred C. Maienschein, who served as acting director during Blizard's illness, became NPD Director and A. Dixon Callihan remained Associate Director. Three technical group leaders were selected, each with specific responsibility: C. E. Clifford, Reactor and Weapons Radiation Shielding; R.G. Alsmiller, Jr., Theoretical Space and High-Energy Accelerator Shielding; and R. W. Peelle, Experimental Space and High-Energy Accelerator Shielding.

\section{Key Personnel Changes}

There were key personnel changes throughout the decade. Clay Zerby and Keith Penny transferred to the Union Carbide Research Institute in New York, but Penny returned some years later. Frank H. S. Clark, a contributor to several NPD programs, including RSIC where he organized and chaired the

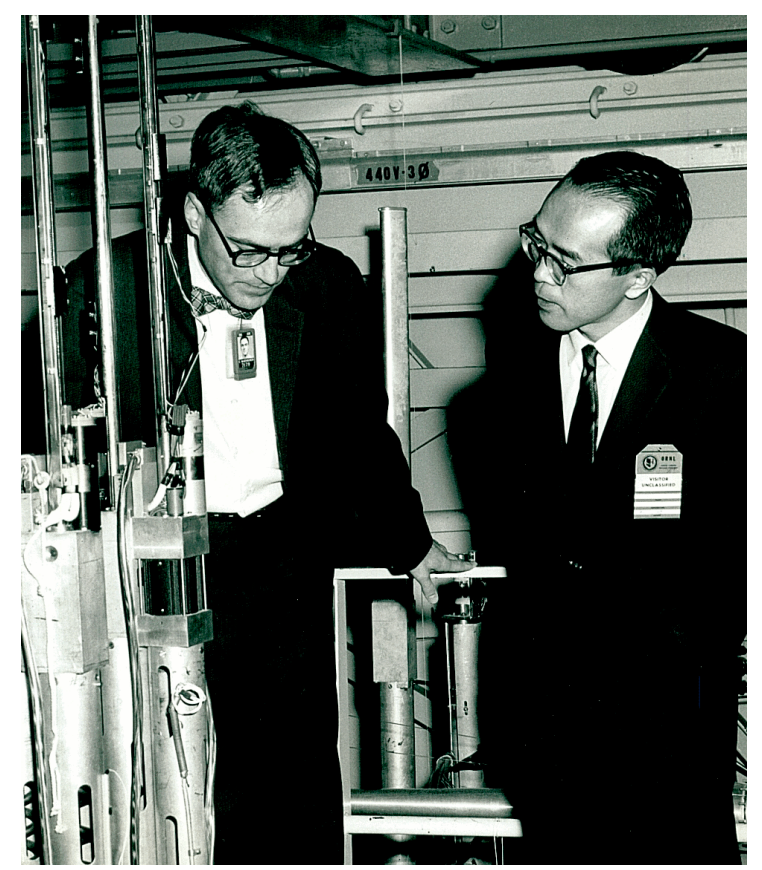

Fred Maienschein leads Nasaya Nakata of Ship Research Institute of J apan in a tour of the BSF "swimming pool" reactor in 1962.
CSEWG Shielding Committee in FY 1968, transferred to the I\&C Division. New staff members included Edward A. Straker and Jack Yost. The ORGDP/CDPF team handling RSIC's codes operations transferred into NPD in FY 1968 with Hemma Francis Comolander, Henrietta Hendrickson, Jane Gurney, and Juanita Brown Wright joining other newcomers, Ann Gustin, Vivian Jacobs, and Mildred Landay, in RSIC activities.

Following the transfer of Callihan from the Division in FY 1969, Alsmiller, Clifford and Peelle were appointed associate directors to assist Maienschein in administration of the Division.

\section{Experimental Facilities Transferred}

The Bulk Shielding Facility (BSF), which includes the 2-MW Bulk Shielding Reactor (BSR-II), and the adjacent Pool Critical Assembly (PCA), was used as a source for radiation shielding and related experiments from 1951 through 1963. It was transferred out of the division in FY 1964 and the BSR-II began serving as a general-purpose research reactor. This reactor and the

PCA were used to train generations of nuclear engineers. In September 1991, DOE ordered that the 40year-old facility be permanently shut down due to "insufficient funding to support reactor operations." 


\section{SORA and Other Experiments at the Critical Experiments Facility}

The Critical Experiments Facility was utilized throughout the early 1960s. Experiments by Callihan and others included an important series of measurements with well-understood solutions.

A program of critical experiments was performed in cooperation with EURATOM, in supporting the design of the Sorgente Rapida (SORA), a fast neutron, NaK-cooled, repetitively pulsed nuclear reactor. Gustav Kistner (EURATOM) joined John T. Mihalczo in studies on the critical experiment mock-up in which results substantiated the nuclear design of SORA.

In FY 1969 Callihan was transferred, with the Critical Facility he headed, to Y-12 Plant management.

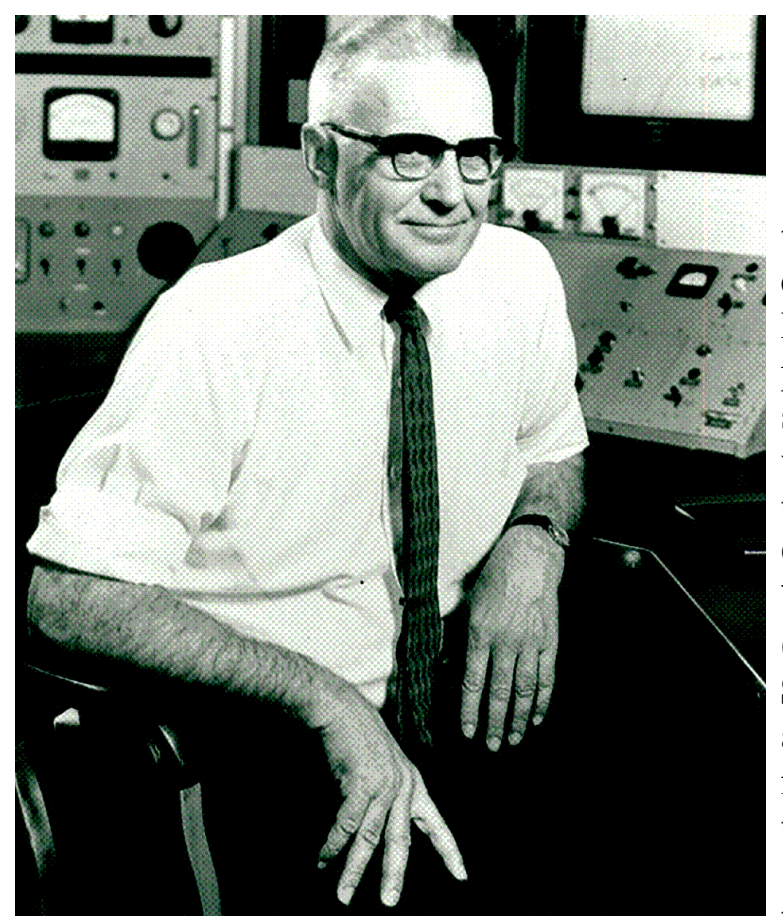

A. Dixon Callihan, Associate Director of the Neutron Physics Division, was presented the Americ an Nuclear Soc iety's David V.P. Williams Memorial Award in recognition of his leadership in the field of critic al experimentation and the signific ance of his a c tivities as ed itor or Nuclear Science and Engineering.

\section{The Oak Ridge Electron Linear Accelerator (ORELA)}

Beginning in the late 1950s, Maienschein led a team of planners and designers towards the establishment of a new research facility. The Oak Ridge Electron Linear Accelerator (ORELAL), whose pulsed neutrons were to be used for making crosssection measurements by the time-of-flight technique, was completed by the end of the 1960s. The design team included Ross Burrus, R. Gwin, G. de Saussure, Victor Verbinski, and L. W. Weston of NPD, and Robert C. Block, J. A. Harvey (program codirector), and Macklin, Miller, and Slaughter of the ORNL Physics Division. They were assisted by A. L. Boch, Construction Project Director from the Director's Division, and J. A. Murray from the General Engineering and Construction Division.

ORELA was to be operated jointly by NPD and the Physics Division to provide a versatile source of the electrons, photons, and neutrons expected to be useful in studies of electron scattering, photonuclear reactions, and radiation effects. Accepted from the manufacturer in August 1969, the accelerator was effectively used for cross-section measurements thereafter.

\section{COMMENTARY: “A Nuclear Data Perspective” by Larry Weston}

The thread of the NPD nuclear data program is as follows. In the 1950s, fission gamma-ray measurements were made by Maienschein, Chapman and Peelle. After that ( 1959) came the eta measurements of de Saussure, Macklin, and others, which were encouraged by ORNL Director Alvin Weinberg. About 1961, there were capture and fission cross-section measurements at the 3-MeV Van deGraaff by de Saussure and Weston. Commencing in 1963, and continuing until ORELA was 
operational in 1969, there were measurements of capture and fission cross sections by de Saussure, Weston, and Gwin at the Rensselaer Linac. There was also a measurement program at the General Atomic Linac in 1964. The NPD nuclear data experience greatly influenced the approval given for ORELA.

Construction of ORELA was completed in 1968, and it immediately became a world-class producer of nuclear data under the operational management of Peelle and Harvey. Many division members have done experiments at ORELA over the years, including Zane Bell, T.V. Blosser, John Dabbs, Gerard de Saussure, George Chapman, Kirk Dickens, Reg Gwin, Jack Harvey, Bill Kinney, Temple Love, Duane Larson, Dick Macklin, George Morgan, Dave Olson, Bob Peelle, Francis Perey, Raphael Perez, Ernie Silver, Bob Spencer, and Larry Weston.

\section{COMMENTARY: “RSIC - In the Beginning” by David K. Trubey}

I first learned of plans for a shielding information center from Phil Hemmig of the USAEC Reactor Physics Branch, who was attending the FY 1962 Annual Information Meeting. Blizard appointed

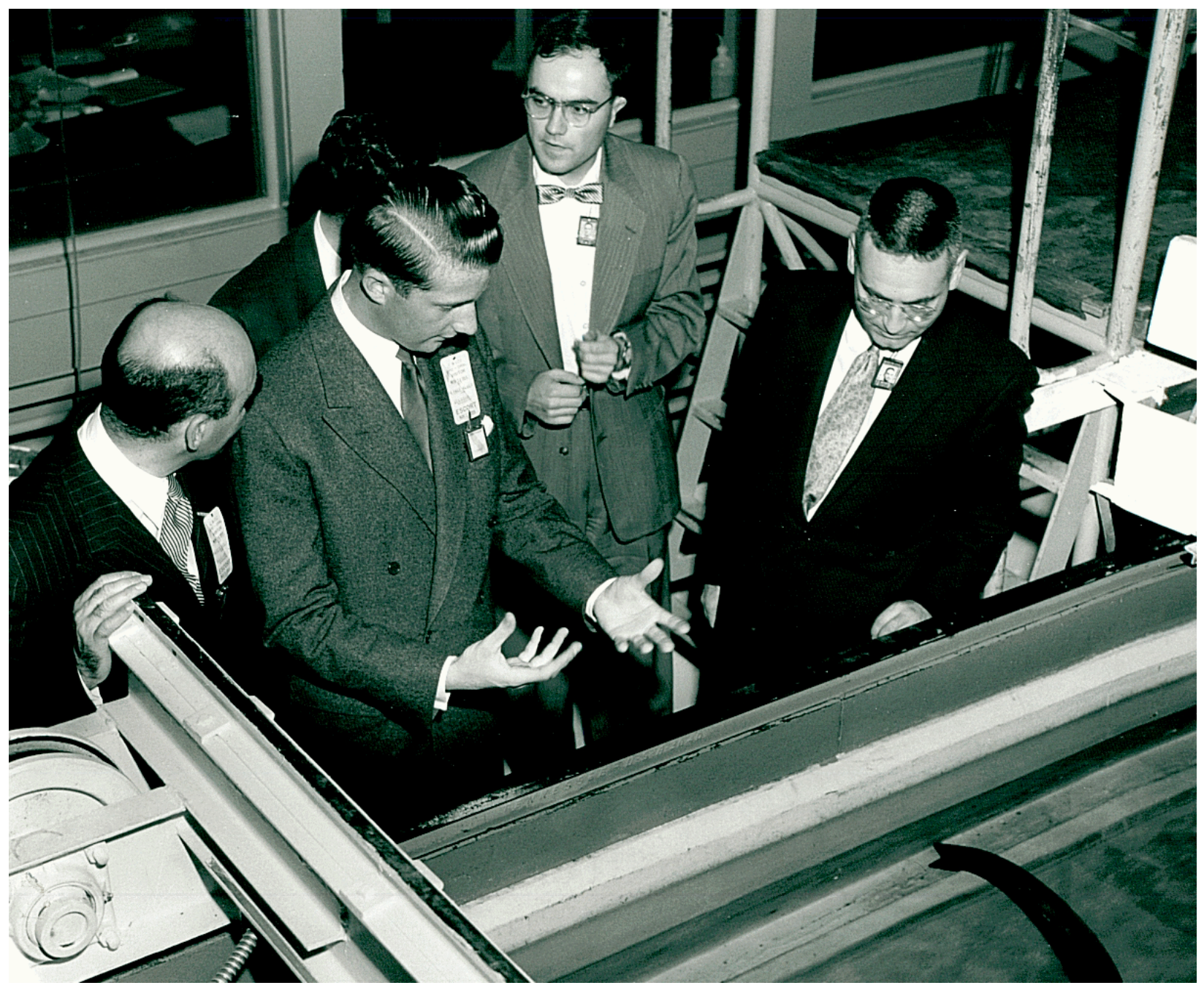

The BSF attracted many foreign visitors in the ea lly 1960s. Right to left; Alvin Weinberg and Fred Maienschein disc uss BSR experiments with Prof. Le Poole and a team from The Netherlands. ORNL 55-1017 
S. Keith Penny to head the proposed center, which eventually became the Radiation Shielding Information Center (RSIC). Keith and I, sharing the same office, began to make plans. There seemed to be two immediate tasks: (1) the development of a computer-based information retrieval system, and (2) the collection and testing of shielding software.

Francois Kertesz organized an orientation visit to Battelle Memorial Institute's established information centers for Bill Cottrell, Phil Baker, Penny, and me, through which we hoped to gain insight for establishing our own centers at ORNL. I remember well the detailed work involved in the manual indexing and extracting of key information from selected literature specimens. When we asked Battelle staff members whether the use of computers would be helpful, they responded that they would access computers if they could think of a way to use them! When we returned to ORNL, Penny and I immediately began the design of what would become the RSIC Storage and Retrieval Information System (SARIS). Peggy Emmett of the ORNL Math Division, who worked with us in developing OGRE, did the programming of what was, I believe, the first computer-based information system at Oak Ridge.

Penny and I were aware of computing technology development within shielding groups nationwide. We had obtained some codes such as NIOBE and RENUPAK (moments method) from United Nuclear and MODRIC (diffusion theory) from the ORGDP/CDPF. Working with Betty Maskewitz, and others at ORGDP, we implemented the codes on the CDPF computers and used them in various applications. For example, I attempted to reproduce Lid Tank measurements by using RENUPAK coupled with MODRIC, a coupling of transport theory and diffusion theory in a process I termed 'Transfusion.'

In programming OGRE, we worked in parallel with and closely followed the work of the team that was developing O5R. When Frank Clark came into the division, I remember his perceptive observation that all Monte Carlo neutron transport at ORNL was O5R by definition. Everybody had a collection of subroutines; and these altogether comprised O5R. In the beginning it was called Oak Ridge Random Reactor Research Routine, and subsequently shortened, probably by Lorraine Abbott, to O5R.

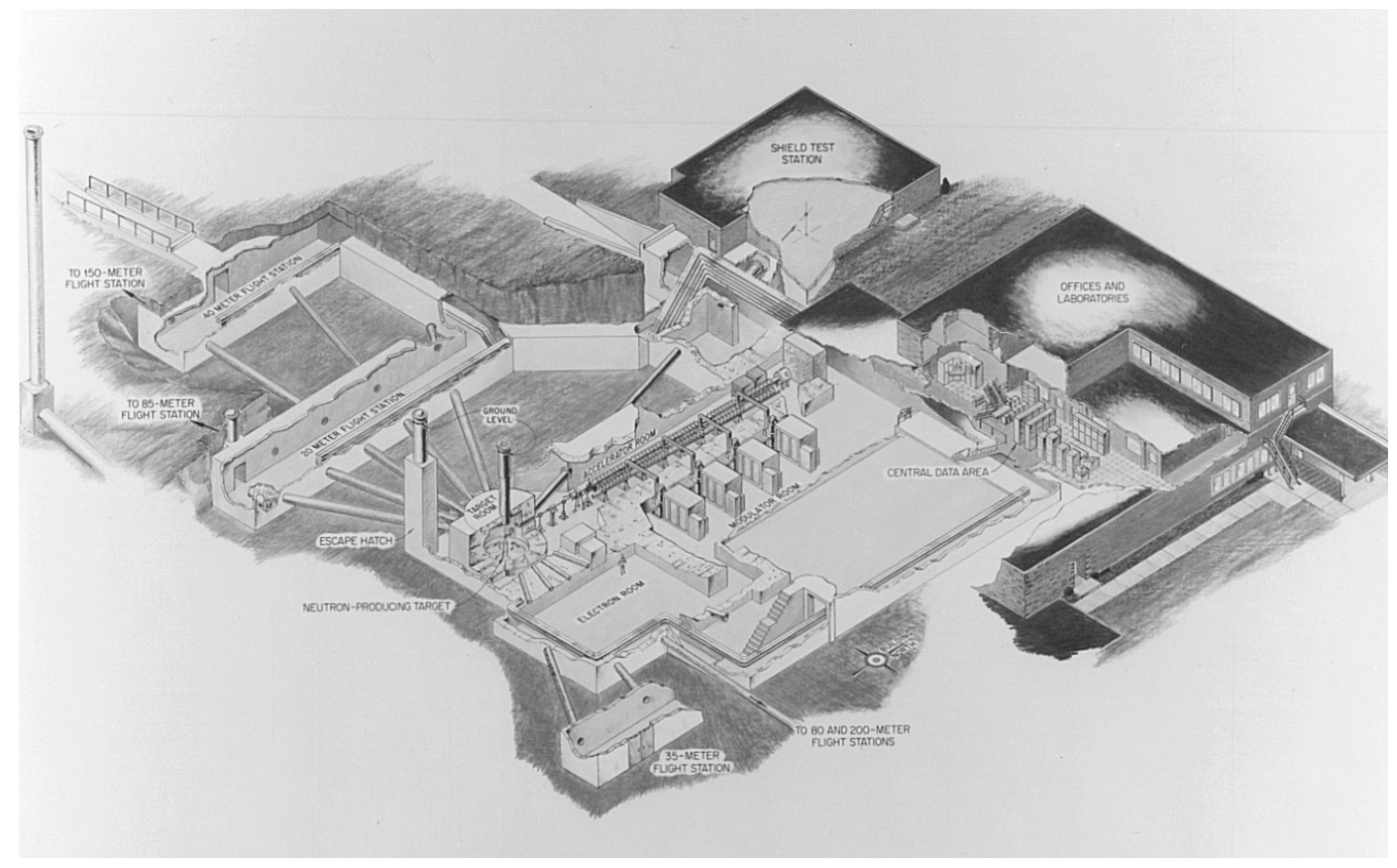

The Oak Rid ge Linear Accelerator ORNL DWG 68-3791R2CO 
In early 1963, Blizard invited Betty Maskewitz to join with us as the RSIC Codes Coordinator. Space was at a premium in $4500 \mathrm{~N}$ and I remember that she was assigned to the office that Blizard called 'Baker Street Irregulars,' based on the Sherlock Holmes youngsters who provided him with a variety of information. The 'youngsters' included Bob Coveyou, Jerry Sullivan, Dave Irving, Bill Kinney, and Maskewitz. A well-remembered incident: General Electric Company shipped all of its shielding codes in a great wooden box addressed to Betty. When the box arrived in her absence, the 'Irregulars' had the box set upon her desk where it completely covered the desk for weeks before it was opened.

Incidentally, RSIC was first called Shielding Information Center (SIC), but we soon thought of the ambiguity there would be in regard to electromagnetic shielding. We added the word 'radiation' to SIC and it became RSIC.

Division technology transfer was accelerated during the sixties following the establishment of an information analysis center.

\section{Radiation Shielding Information Center}

The Radiation Shielding Information Center (RSIC) was established in FY 1963 by the U. S. Atomic Energy Commission (AEC) to collect, organize, evaluate, and disseminate information on shielding against radiation from nuclear reactor and other low-energy radiation sources. The information initially covered was in the form of published literature and computer codes. Ira Zartman, head of the AEC Reactor Physics Branch, was the founder. Philip Hemmig, a physicist on his staff at the time, has served RSIC in a special relationship (monitor, technical advisor) and has supported the RSIC mission throughout its 31-year existence (1962-1993).

The RSIC information coverage included radiation from reactors, radioisotopes, weapons, accelerators, and both natural and manmade radiation in space. The Defense Atomic Support Agency (DASA, later DNA) and the National Aeronautics \& Space Administration (NASA) joined AEC in support of the Center at an early stage.

\section{RSIC Management}

S. K. Penny served as RSIC's first director, assisted by D. K. Trubey, shielding specialist. Betty F. Maskewitz transferred from the ORGDP/CDPF to initiate the computer codes and computer-related data activities. Penny left ORNL in FY 1967 and Trubey served as RSIC Manager 1967-1970. He, in turn, was replaced by Maskewitz, who served throughout the 1970s and early 1980s. Robert W. Roussin is the current director.

\section{Early RSIC Activities}

No commercial software for the storage and retrieval of titles and abstracts of literature existed in the early 1960s. Penny and Trubey, with Peggy Emmett as programmer, designed and implemented the RSIC Storage and Retrieval Information System (SARIS).

The radiation transport and shielding computing technology (codes and data) developed in the defunct Aircraft Nuclear Propulsion Program was transmitted to RSIC in 1963 via the General Electric Company Nuclear Materials and Propulsion Operation. These kernel integration and Monte Carlo codes, programmed in machine language for the IBM 704, were tested for operability on the IBM 7090-7094 
and packaged as CCC-1 through CCC-4 as the beginning of the RSIC Computer Codes Collection. The Data Library Collection was initiated with Hugo Bertini's low-energy intranuclear cascade results, packaged as DLC-1/LEP.

At the end of the decade, the computer code collection contained 60 tested code packages and a book of abstracts of the collection was published as ORNL/RSIC-13.

\section{COMMENTARY: “The Genesis of the RSIC Newsletter” by B. F. Maskewitz}

RSIC published its first newsletter June 1, 1963. The newsletter announced the establishment of the center, described its program and services, and requested shielding information.

A Board of Volunteer Coordinators was listed in the newsletter: 47 scientists and engineers who represented a cross section of the international shielding community. The RSIC staff met with the Coordinators for the first time at the 1963 summer meeting of the American Nuclear Society in Salt Lake City, Utah. The groundwork was laid for cooperation throughout the nuclear industry.

It was not until January 1965 that the second newsletter was published, and that was due to pressure from the Coordinators! It was published on a monthly basis thereafter.

Leaders and participants of the 1965 Monte Carlo (O5R) Seminar-Workshop included (from left): Robert Hubner (RRA/Ft. Worth), Frank H. Clark, Nancy Betz (Mathematic s), J uanita Brown Wright, and Wade Selph (Lockheed/Marietta, Georgia). ORNL 13376

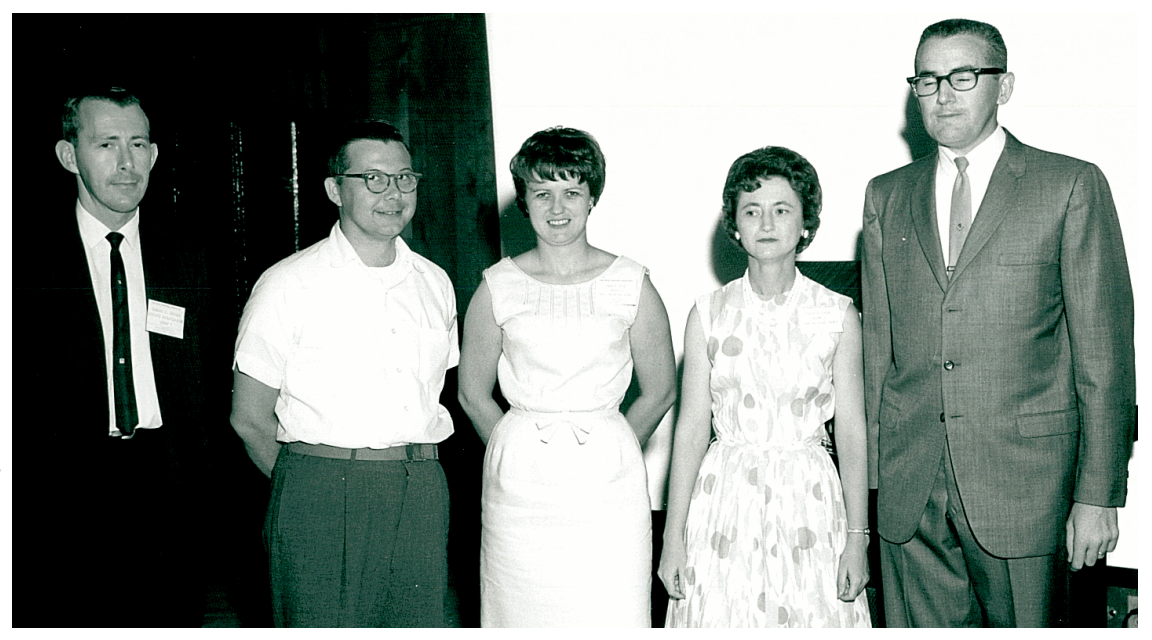

\section{Conferences and Seminar-Workshops}

\section{RSIC Seminar-Workshop Initiated}

The development of the O5R Monte Carlo code system had reached a point where it was being requested by other institutions. The NPD developers and users joined in an RSIC-sponsored seminarworkshop wherein the theory, operating mechanics, data preparation, and applications were discussed. The participants were able to have hands-on access to run their own problems and carry home the complete code package.

The O5R Seminar Workshop, held July 27-28, 1965, drew 80 participants, representing 45 different institutions in the United States, France, and West Germany.

At the invitation of the European Nuclear Energy Agency (ENEA), Maskewitz implemented the O5R and OGRE (Monte Carlo) and SDC (kernel integration) code systems on the IBM 7090 in the EURATOM Establishment at Ispra, Italy, and she and Penny led a seminar-workshop (April 26-29, 1966) under the sponsorship of the ENEA Computer Programme Library. The leading computing 
technology in use within the European shielding community was contributed to RSIC as a result of discussions and meetings which followed.

The philosophy that the seminar-workshop was a practical technique to disseminate a large amount of information to many requesters at a given time became RSIC operating practice in the years to follow. The experts in a given calculational method were invited to discuss theory and application of the methodology in the seminar portion, following which a workshop on a code system selected to represent the method was conducted by the specific code developers. The seminar papers were published as a stateof-the-art report on that methodology.

Other seminar-workshops followed through the sixties:

Kernel Integration, featuring LASL's QAD code system (1967)

Discrete Ordinates (1-d), featuring ORNL's ANISN (1967); ORNL/RSIC-19

Electron Transport Theory, featuring NBS's ETRAN (1969)

Discrete Ordinates (2-d), featuring ORNL's DOT-II (1969)

Multigroup Cross Section Preparation - Theory, Techniques and Computer Codes, featuring ORNL's SUPERTOG and XSDRN (1969); ORNL/RSIC-27

\section{Second and Third International Shielding Conferences}

The second in the conference series (2-ICRS), convened in Studsvik, Sweden, in FY 1962, was attended by Blizard and Clifford. The third (3-ICRS), held in Oxford University in 1967 with UKAEA/Harwell as host, was covered by Trubey and many other U.S. shielders. The USSR participated through a small delegation led by Armen Abagyan from the PPEI/Obninsk fast reactor shielding group. Abagyan was host for the first RSIC orientation visit to the USSR (1969, Maskewitz).

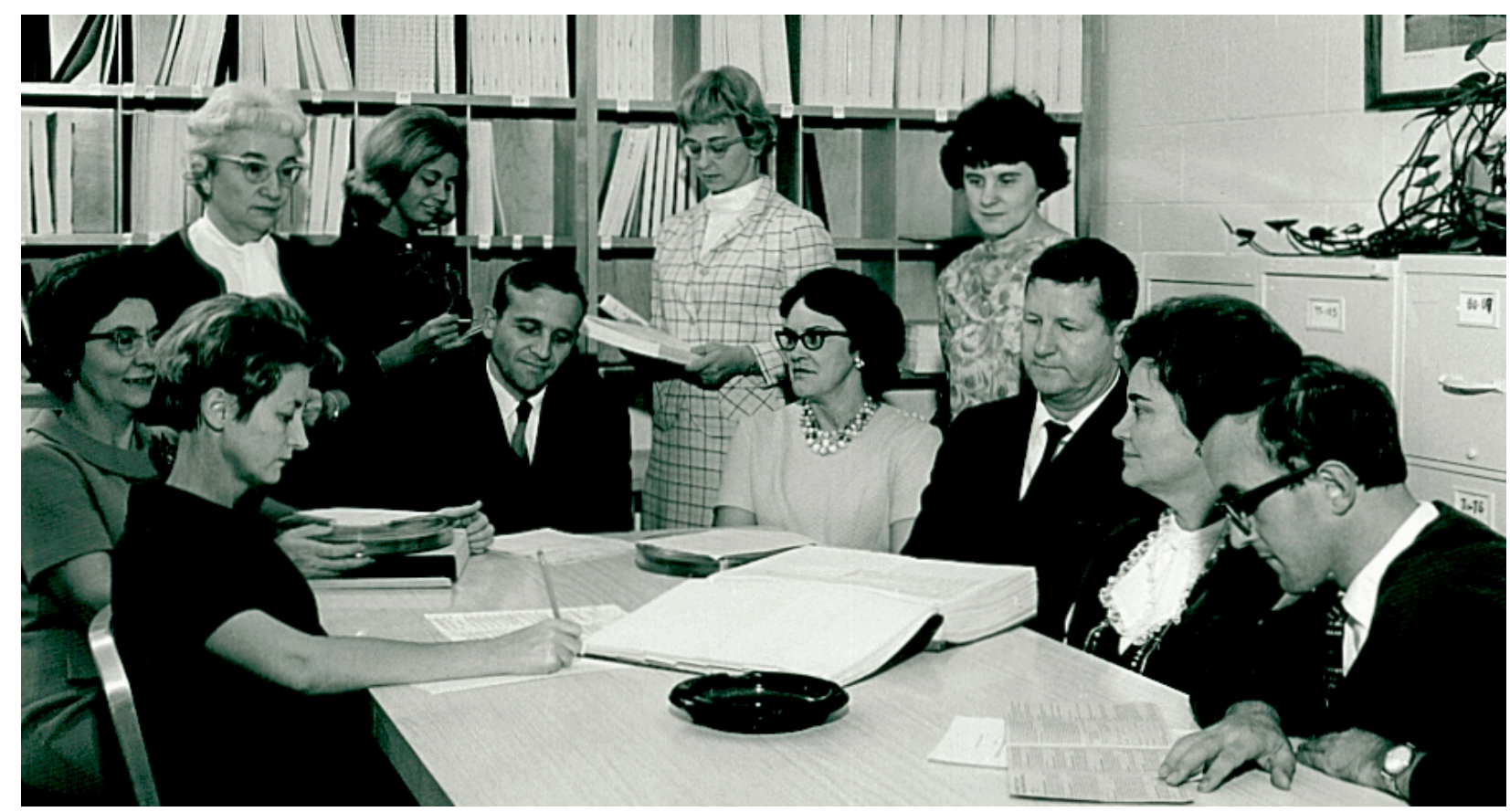

The Radiation Shield ing Information Center (RSIC) staff gathers for a meeting in the late 1960s (from left): J uanita Brown Wright, Henrietta Hendrickson, Betty Maskewitz, Patti Cunningham, David Trubey, Vivian J acobs, Hemma Franc is Comolander, Mildred Landay, Wallace Webster, Jane Gumey, and Fritz Schmidtof the Stuttga rt Technic al University, Germany. ORNL 93258 


\section{ORNL/NPD Hosts American Nuclear Society (ANS) Topical Conference}

A topical conference, sponsored by the ANS Mathematics and Computation Division and ORNL, on "Effective Use of Computers in the Nuclear Industry" was hosted by ORNL/NPD in the University of Tennessee's Conference Center April 20-23, 1969 with Betty F. Maskewitz as general chairman.

\section{NPD Assists in Founding the Cross-Section Evaluation Working Group}

Henry (Hank) Honeck, while a staff member at Brookhaven National Laboratory (BNL), dreamed of organizing an effort to bring order and standardization in measuring and evaluating cross sections for use in the nuclear industry. He managed to get assigned to the USAEC Division of Reactor Development in order to secure the necessary funds to turn his theories into actual practice.

On June 9-10, 1966, Honeck called a meeting at BNL with the stated purpose of organizing a set of tasks leading to "development of a set of basic data which can be used to accurately predict the behavior of neutrons in a nuclear reactor." - (RSIC Newsletter)

An informal group had been working with Honeck for some time, and computing machine formats were identified such as the Evaluated Nuclear Data Files (ENDF-A \& B). Several ORNL NPD and Reactor Division (RD) personnel formed a working group, and C. W. (Pete) Craven (RD) represented ORNL's interest in this first formal meeting of the USAEC Cross Section Evaluation Working Group (CSEWG). Each of the AEC laboratories and several contractors voluntarily supported CSEWG in this effort. Several NPD staff members were involved in leadership roles from the beginning and continue to support CSEWG.

\section{Computer Upgrade}

The local computer facilities were upgraded (CDC-1604, IBM-7090, IBM-360/75/91, etc.) during the 1960s. Division research scientists, aided by computer programmers from both ORGDP/CDPF and the ORNL Mathematics Division, were enabled to advance the state of the art of computing methodology to solve important problems in both low-energy and high-energy physics.

\section{A Hint of Times to Come}

The ORNL director spoke of the late 1960s as a "time of trial for science in the United States with AEC retrenchment and the ORNL staff reduced by 3\%." "The Laboratory experienced overall financial retrenchments in 1969. It was said to be "the year of the environment," a political issue, with subsequent restrictions on the nuclear industry. ${ }^{8}$ NPD programs were little affected directly, but there were rapid changes to come in the 1970s. 


\section{COMMENTARY: “Memories of the Neutron Physics Division” by Joseph Lewin"}

In 1956, when I first worked in the ORNL Engineering Division in venerable Building 1000, the Neutron Physics Division was led by Everitt P. Blizard, a man of formidable presence, of outstanding scientific reputation, and of great administrative ability. I was awed by his nuclear-Navy background and by his knowledge of both the theoretical and the experimental in this exotic field that promised and threatened so much of life on Earth.

He was also a courteous, pleasant gentleman. There was at that time a general ambiance of pleasant courtesy - something of the common feeling of unity in an important human mission - exploration of the possibilities inherent in the fissioning of heavy elements and the fusing of light ones; something residual of the feeling of unity that had been generated by World War II, and was now enhanced by the presence of a new military, technological, and pseudo-ideological adversary in a 'Cold War.'

Fred C. Maienschein of Indiana was leader of the Bulk Shielding Facility in 1956 (Associate Division Director in 1959 and Division Director in 1966). I was fascinated by the cosmopolitan nature of the people within the division, and for that matter, within most of ORNL. People who had originated in all corners of the United States, as well as throughout the western world, were there. That is why I still recall that Maienschein was a 'Hoosier'; that Charlie Clifford, the mercurial leader of experimental shielding research, was from Oklahoma; that Leo B. Holland, director of the Tower Shielding Facility (TSF), was from Pennsylvania by way of the Pacific Theater of War; that Keith Henry, operator of the Bulk Shielding Facility (BSF) and assertive master of all related trades, was a native of our neighbor city-Knoxville, Tennessee; and that Robert Peelle, head of basic physics research, was a PhD graduate of Princeton University.

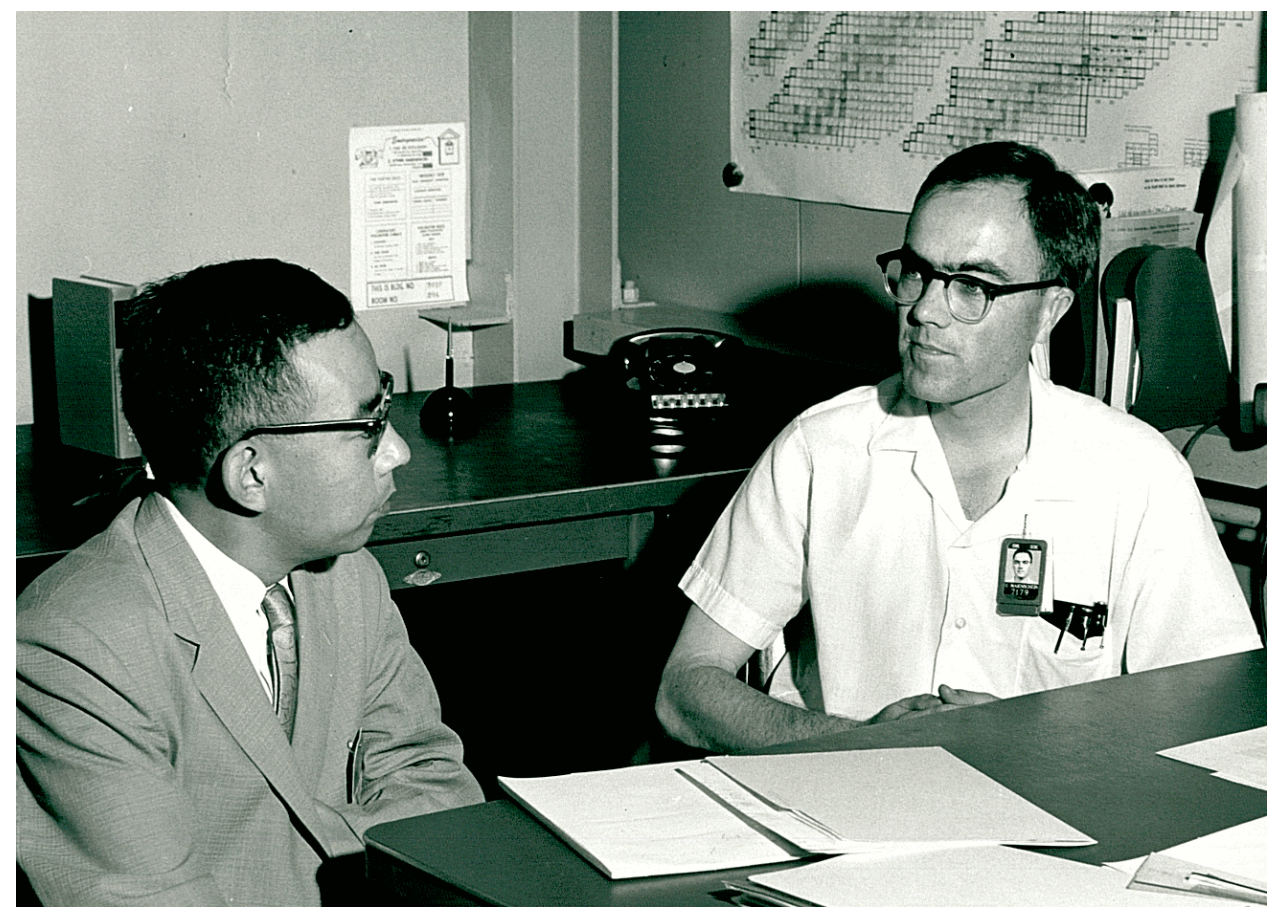

Oyama of Japan (left) is received by Fred Maienschein at the BSF in 1960.

"Staff member of the ORNL Engineering Division 1956-1957; NPD 1958-1985. 
The personality of the division was indelibly and pleasantly tinted by the presence of Becky Rickman and Lorraine Abbott, both of whom worked with Blizard from the inception of the division.

I was an engineer who had taken courses on some aspects of 'the nuclear business,' both at an aircraft company and at the Oak Ridge School of Reactor Technology (ORSORT), and had been placed at ORNL as a loanee/trainee for the nuclear-powered aircraft program - one of the romantic extrapolations of the nuclear euphoria of the 1940s and 1950s. Everything and almost everyone I saw and heard at ORNL impressed me, and the Neutron Physics Division seemed like a 'temple of the occult,' standing squarely at the leading edge of physics and engineering applications to create the postwar nuclear age.

When the First Geneva Conference on Peaceful Uses of Atomic Energy was held in 1955, people from Oak Ridge, and in particular from NPD, had represented a significant part of the United States contribution. The 'swimming pool'-type reactor from Oak Ridge (dubbed 'The Geneva Reactor') was the only operating reactor there and was built and demonstrated by persons such as Leo Holland and others from NPD, Instrumentation and Controls $(I \& C)$, Plant and Equipment $(P \& E)$, and other ORNL divisions.

The Second Geneva Conference (held in 1958) established a sequence of cautious meetings and 'exchanges' with the Russian-Soviet nuclear community in which NPD staff members participated. In addition, the influence of the new nuclear age was made evident by the meeting in Geneva of President Eisenhower with Bulganin, Malenkov, and Krushchev—the interim triumvirate ruling Russia and associated 'republics.'

The Bulk Shielding Reactor (BSR-II) project, begun in 1956-1957, involved the construction of an all-stainless steel core for the Bulk Shielding Facility. Ernest Silver, originally from Germany and Boston, was a leading physicist in this effort, although, as usual, many others from NPD and other divisions participated. Outstanding among these were I\&C Division staff members Elbert P. Epler, Lester C. Oakes, Steve Ditto, John Anderson, and others.

I recall Elizabeth (Libby) Johnson and Dixon Callihan, who were working at the NPD Critical Assemblies Facility in an isolated and well-guarded site between X-10 and Y-12, consulting on the possible hazards of the new BSR-II core. The elements in the stainless steel that was to form the cladding and structural members of the BSR-II has considerably higher capture cross sections for neutrons than the aluminum of the BSR-I, and thus the rate at which power output could rise in the new core exceeded that of the BSR-I core. This required a faster-acting shutdown system, and the safety rods had to be spring loaded in order to insert them more rapidly than was possible under the action of gravity alone. A test stand to measure the speeds of insertion in water was built at the I\&C Division, and tests on various modifications were run for several months until Maienschein, Clifford, Peelle, Epler, Silver, and many others were satisfied. They were a tough group to please, as scientific integrity demanded.

Since 1954 the Tower Shielding Facility (TSF) has been the only facility for investigating radiation propagation in air. (NOTE: For a relatively short time, a small swimming pool-type reactor was flown around Texas in a B-36 bomber, but that could not match the versatility and safety of the TSF.)

The reactor core of the Tower Shielding Reactor (TSR-I) had been a copy of BSR-I but immersed in a large 'pot' that held the water necessary for moderation, cooling, and some of the shielding as the entire assembly could be raised about $200 \mathrm{ft}$ above ground level to simulate some aspects of an airborne nuclear propulsion source. A better geometrical simulation of an Aircraft Nuclear Propulsion installation was needed, and Alvin M. Weinberg and Blizard concluded that the geometry of the reactor should be spherical so as to provide as nearly an isotropic source of neutron and gamma-ray radiation 
as possible. Charlie Clifford and Leo Holland, in consultation with many others, worked out the basic configuration of the core, its cooling system, and the control and safety elements. Paul E. Oliver, an energetic and congenial engineer with whom I shared memories of military service in Europe, first suggested the symmetrically arranged boron-carbide-loaded plates that moved radially within a central spherical volume in the core.

It was a unique and successful design that required months of fabrication by the skilled shops at ORNL and months of testing in a rig designed by a group, including engineering physicist Vic Cain and engineer Donald Ward.

The TSR-II installation at TSF required much testing and preparation of the site and auxiliary equipment. Francis J. (Buzz) Muckenthaler was the chief TSF experimentalist. He prepared the installations of spectrometers, dosimeters, and collimated angular distribution detectors that made the spherical geometry of the core meaningful for comparison of experimental results with the results calculated by the several sophisticated methods under development in NPD.

A most interesting episode in TSF and NPD history was the installation of a Space Nuclear Auxiliary Power (SNAP)-10A Reactor on a specially designed rig at the facility (after some modifications to improve safety and operability in air). This was a

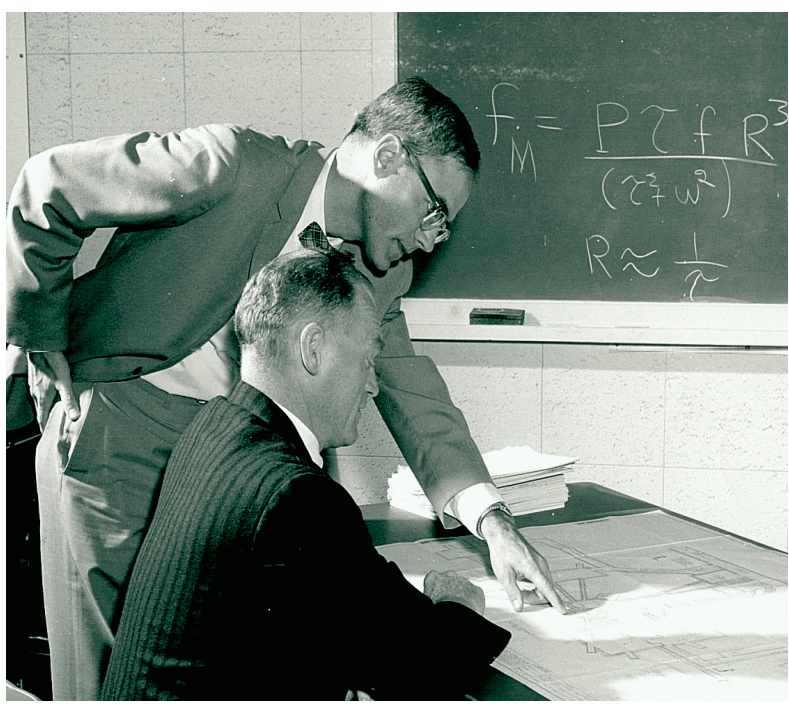

The "Figure of Merit" formula is applied to a 1965 drawing related to the design of ORELA by Fred Maiensc hein a nd Jack Harvey. ORNL 13583 compact, uranium hydride-fueled, NaK-cooled reactor capable of producing a few kilowatts of thermal power that was ejected to the atmosphere through a strange-looking heat exchanger that was mounted like some weird ribbed 'antlers' over the welded stainless steel 'can' that contained the NaK and the fuel. Control was achieved entirely by varying the reflection of neutrons by rotating beryllium semi-cylinders in and out of the beryllium reflector that surrounded the core. In addition, a stainless steel rod acted as an emergency shutdown device. Everyone at TSF and many from other divisions worked under the able leadership of Leo B. Holland to make the facility a unique contributor to the development of nuclear science and engineering.

The TSF operating crew epitomized the composition and evolution of ORNL personnel.

John Manning was a native Tennessean and of Navy service; Jim Hull was from Alabama; Don Ward, a Californian; Keith Henry of Knoxville; Jim Wallace from LaFollette; Fred Richardson from Kentucky; Jack Money from nearby Kingston; and others to whom I apologize for a poor memory. I do recall a man everyone called 'Rags' (I believe his family name was Stevens, but my deepest apologies if I am wrong). He was the always-cheerful custodian of the TSF underground quarters - 'underground' in the sense that they were completely shielded from the radiation of the TSF reactors by concrete walls and ceiling, covered with at least 6 ft of Tennessee loam. Roy Clark of the Health Physics Division periodically checked the entire facility for contamination and radiation leakage through the shielding.

The 1960s were years of national controversy, and the controversies were reflected quite clearly among the people who shared whole days in these unusual quarters. 
The NPD, however, was not just a group of experimental facilities. The theoretical and analytical group, supported by many experts in mathematics and computerization, outnumbered the reactor groups. Measurement of the probabilities of the interactions of neutrons at all energies, with all possible materials and their elements (neutron cross sections) was done within the division at the Oak Ridge Electron Linear Accelerator (ORELA) under Jack Harvey, and the wealth of information, of innovative solutions of radiation transport problems, made necessary a large correlation and informationprocessing effort. This was epitomized in the Radiation Shielding Information Center (RSIC), which operated within NPD. Organized and led by persons who became known throughout the world - Keith Penny, David Trubey, Betty Maskewitz, Bob Roussin, and many others - the Center attracted people from around the globe and was instrumental in the gradual growth of scientific communications that tended to break down the isolation of countries and favor the evolution of a universal scientific community.

With fond memories of

\author{
General M. Argo \\ Everitt P. Blizard \\ George T. Chapman \\ Frank H. Clark \\ Helen Cook
}

Gerard de Saussure

Robert (Bob) Freestone

Keith M. Henry

William E. (Bill) Kinney

Temple A . Love

and all the others who served with the Neutron Physics Division.

Franc is Perey and John J udish test a n improved klystron bunching circ uit at the high-voltage teminal of the pulsed neutron source for the 3-MV Van de Graaf in building 5500, circa 1960-1962. ORNL 84159

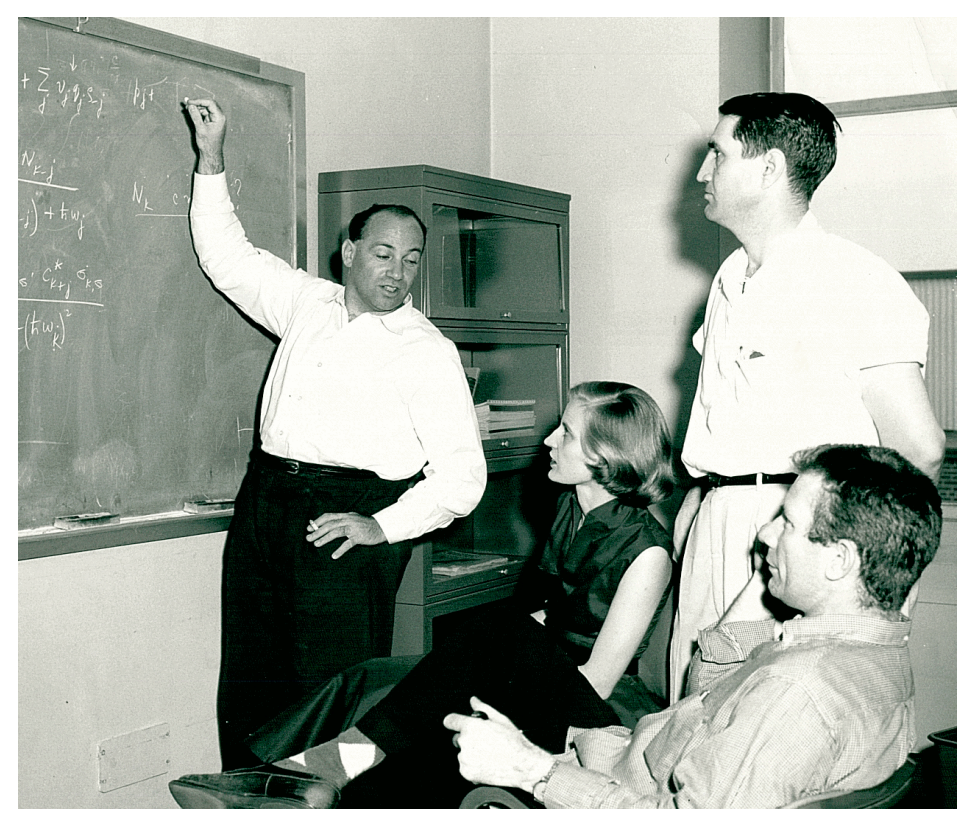

Max Dresden (University of Kansa s physic s professor) lectures to Frances and R. G. (Tut) Alsmiller(seated) and to A. Mertz (visitor from T-Division, Los Alamos Sc ientific Laboratories) circa 1967 in NPD. ANL 401-1430

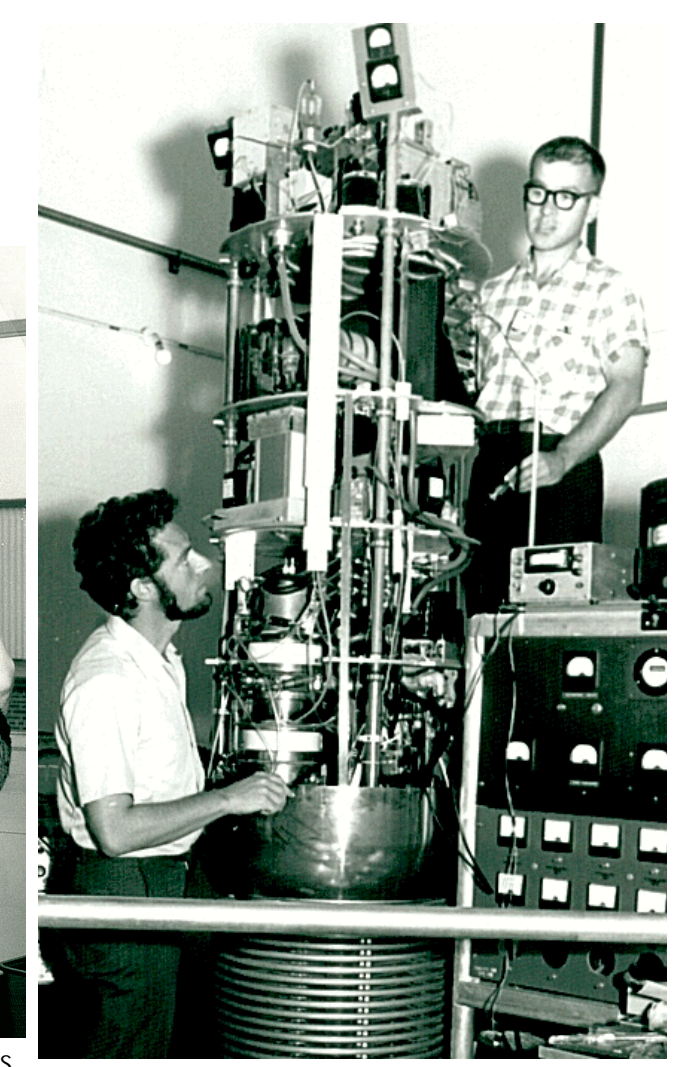



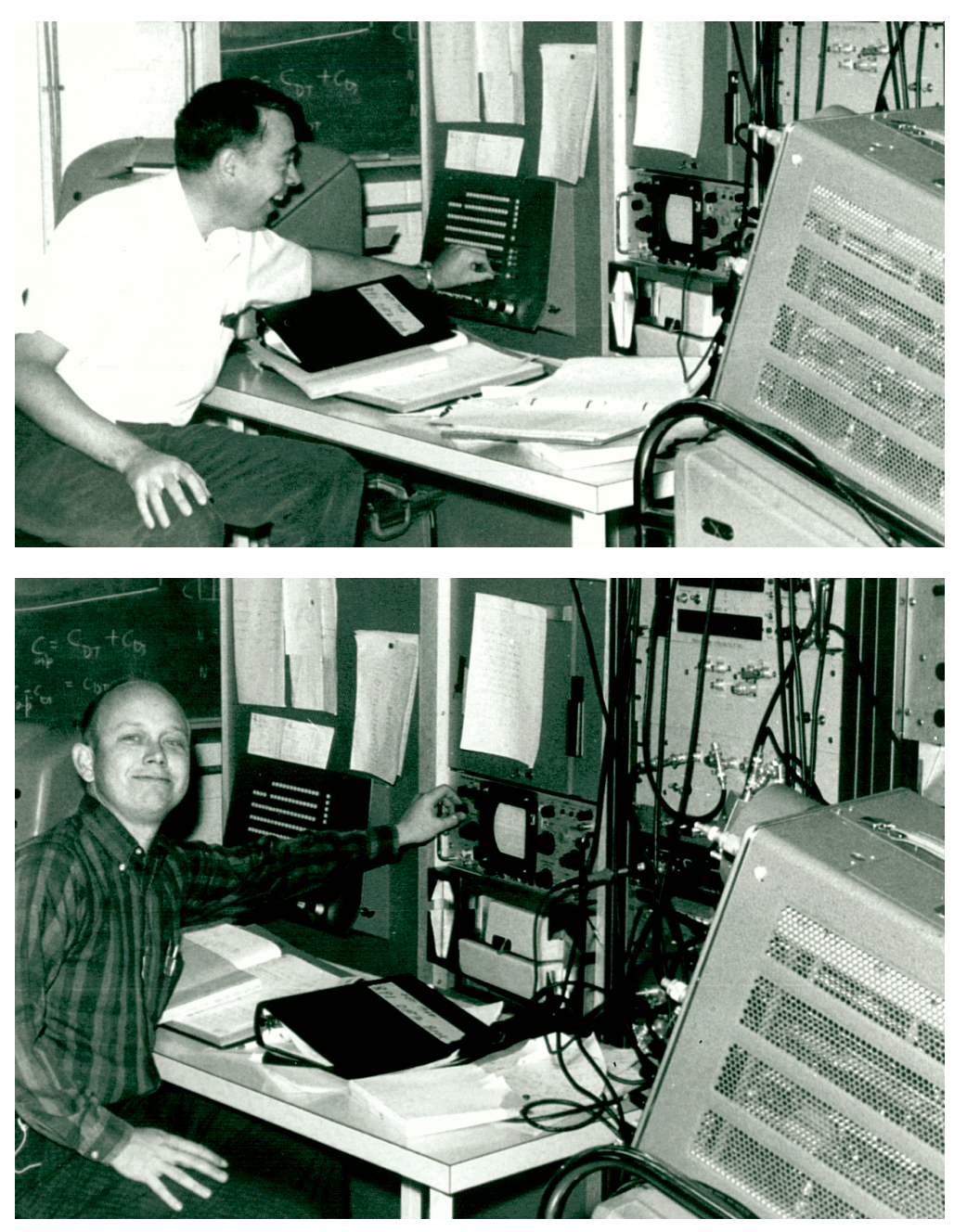

Reginald Gwin (top) and Larry Weston (bottom) work with an early 1963 system (PDP-4 and related instrumentation) designed to take and process data from an experiment which they performed on the Linac at Rensselaer Polytechnic Institute. At the time, the system was the first of its kind.
Robert W. Peelle

regalesan

unidentified visitor,

Maienschein and

Philip Mittelman

(MAGI, New York) at the 1964 a nnual Information Meeting.

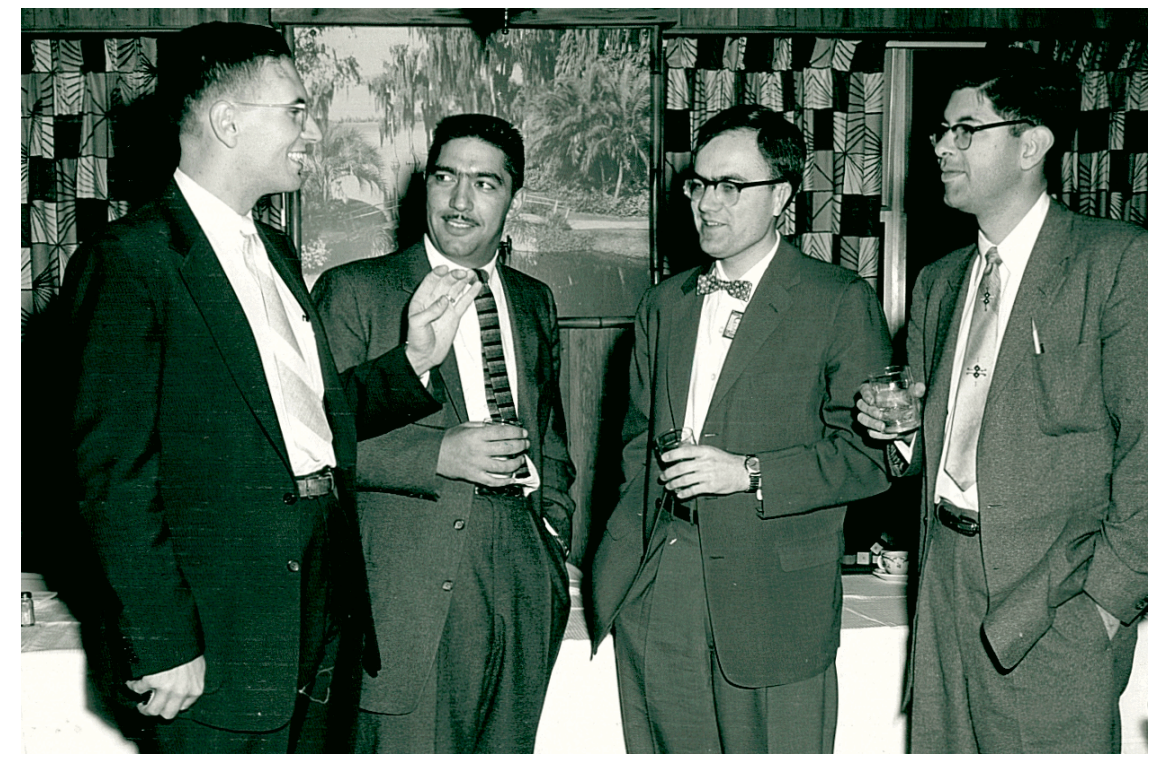




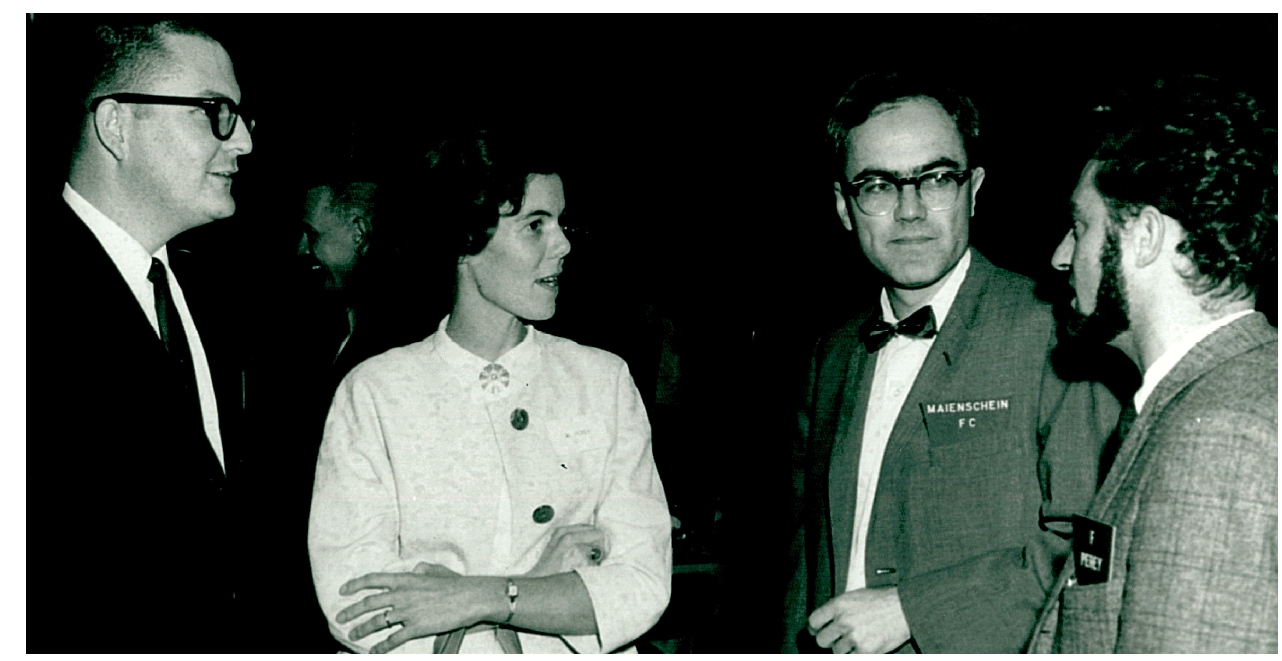

Kirk Dickens, Claire Perey, Fred Maineschein, and Franc is Perey get together at the 1966 NPD Annual Info mation Meeting dinner. ORNL NEWS 1-01-76

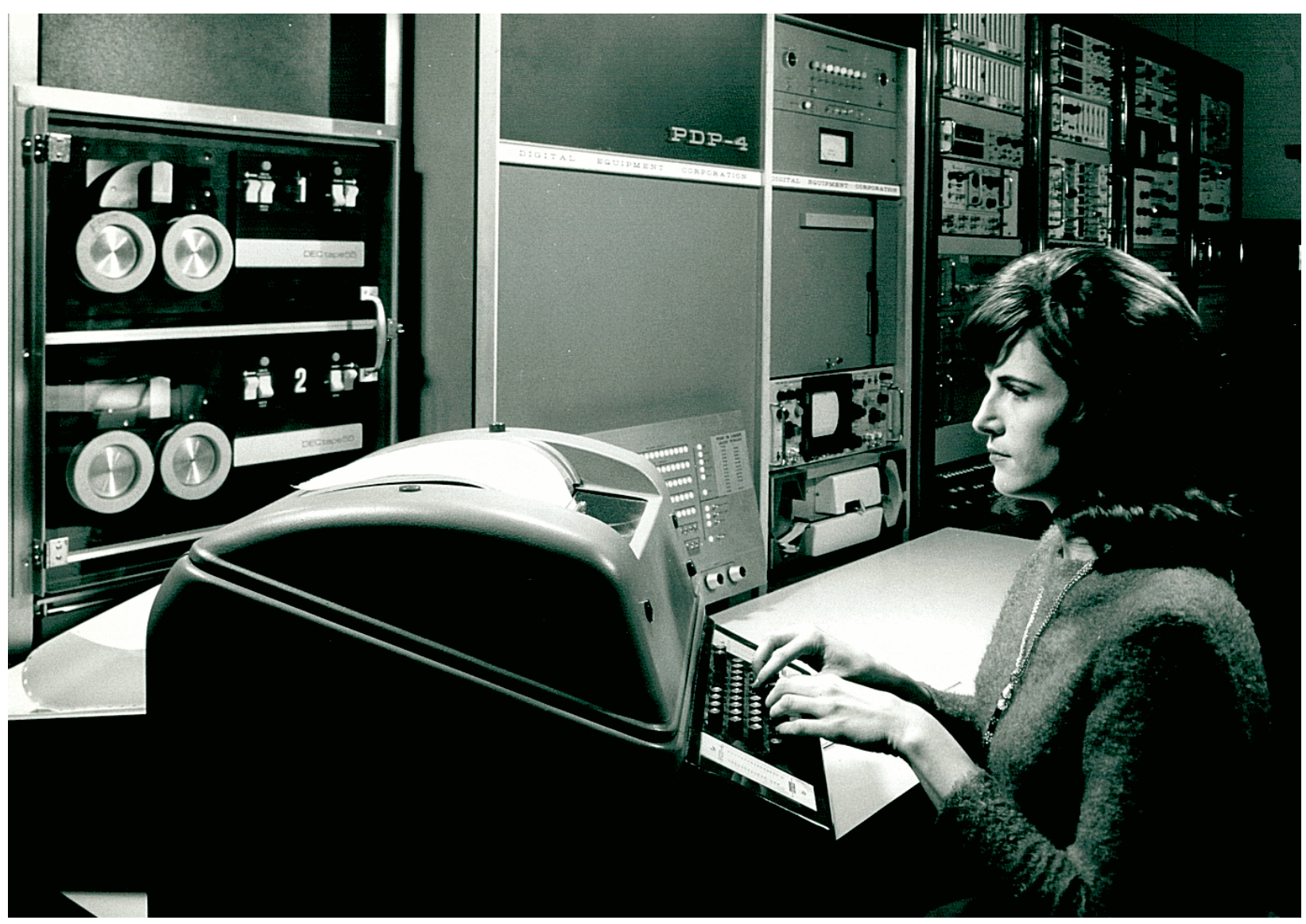

Lenna K. Lovette at the console of the ORELA PDP-4 Data Taking and Processing System. ORNL 86379 


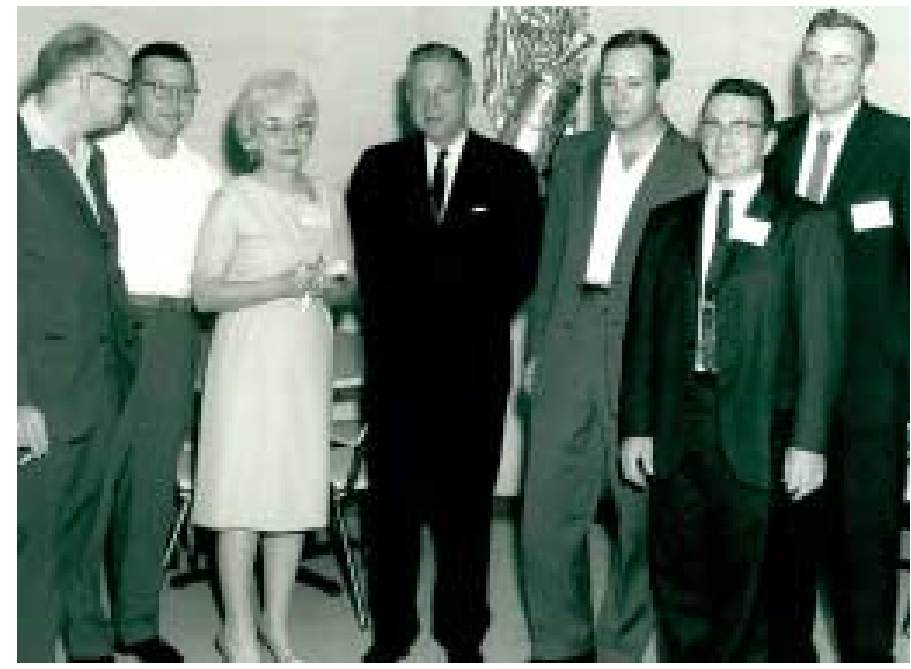

1965 O5R Seminar-

Workshop participants

meet for dinner (from left):

Robert Coveyou, Frank

Clark, Betty Maskewitz,

Charles Bradshaw

(Vanderbilt University),

David Inving, Keith Penny,

and David Trubey. ORNL

13375

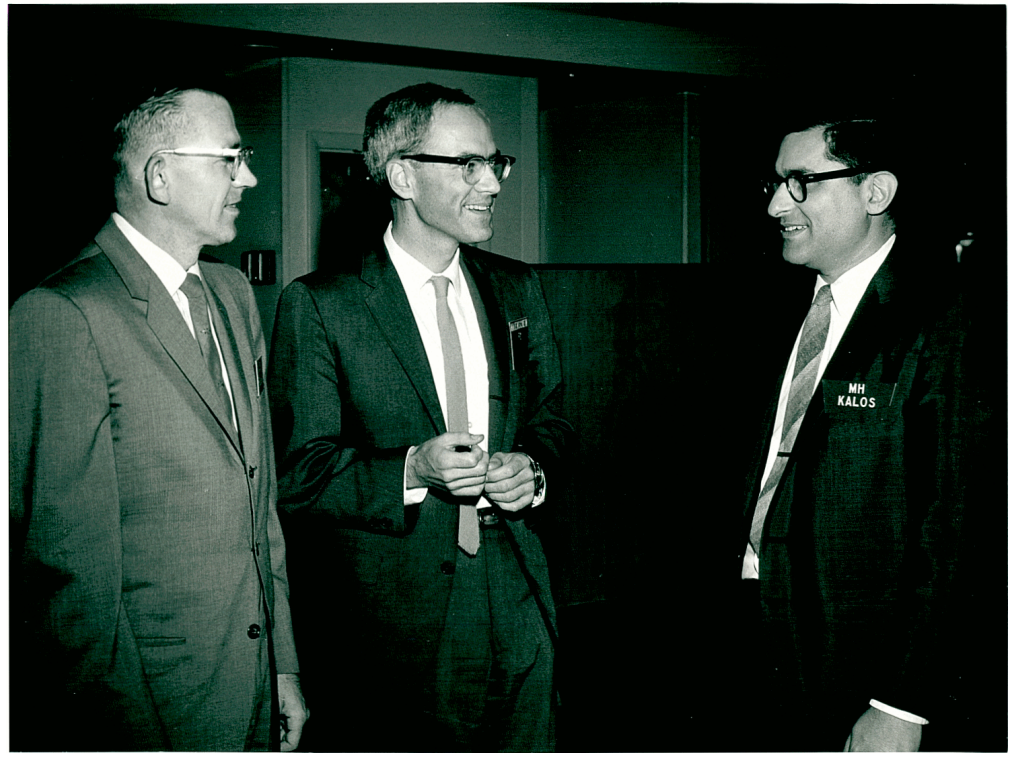

Leo Holland and Fred Maienschein share a moment with Malvin H. Kalos, member of the 1966 Division Advisory

Committee.ORNL 14354 


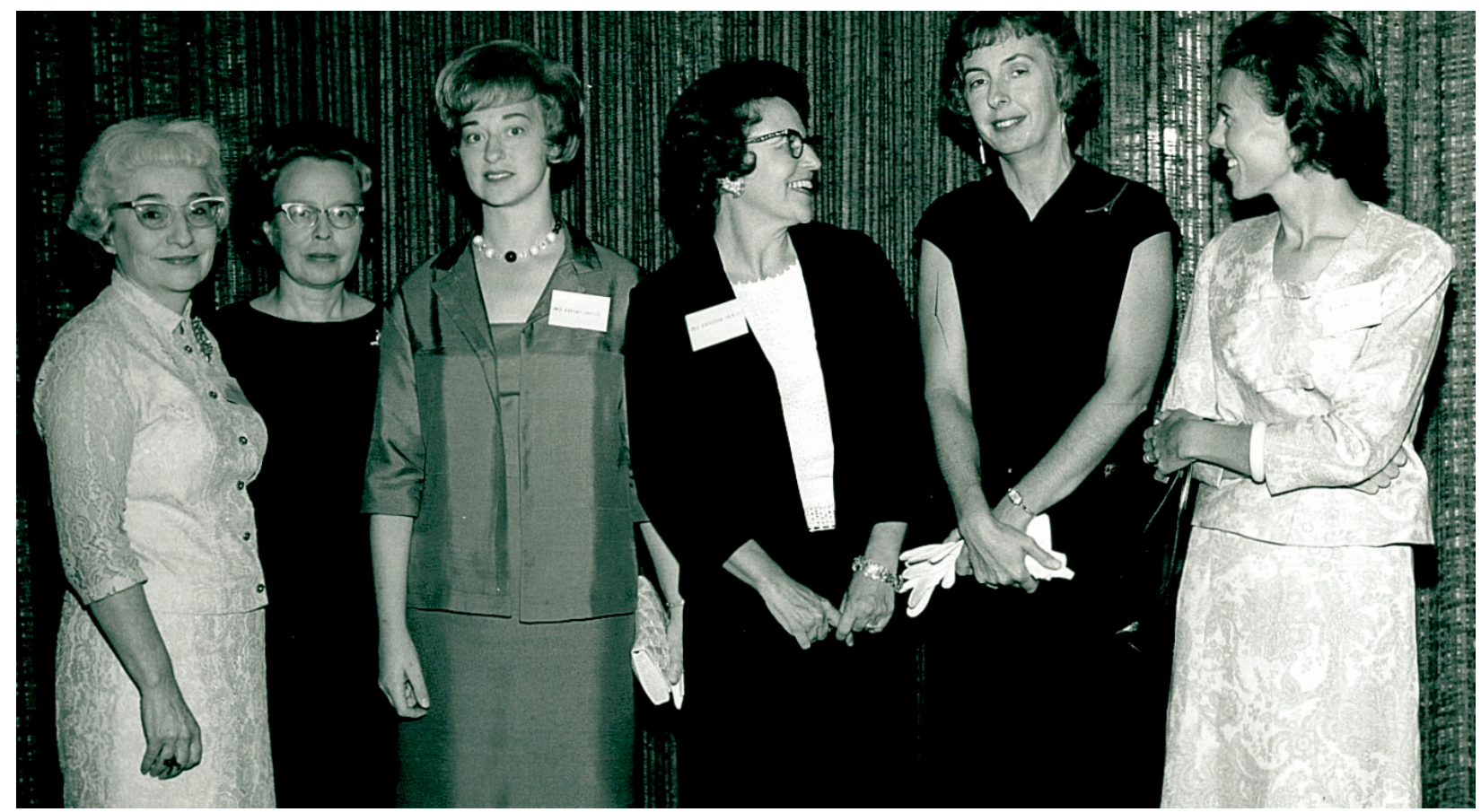

The 1967 NPD Annual Information Meeting Dinner was attended by staff members (from left): Betty F. Maskewitz, Elizabeth B. Johnson, Vivian A. Jacobs, Virginia Hamrick, Miriam Guthrie Kertesz and Claire Perey. ORNL 14357

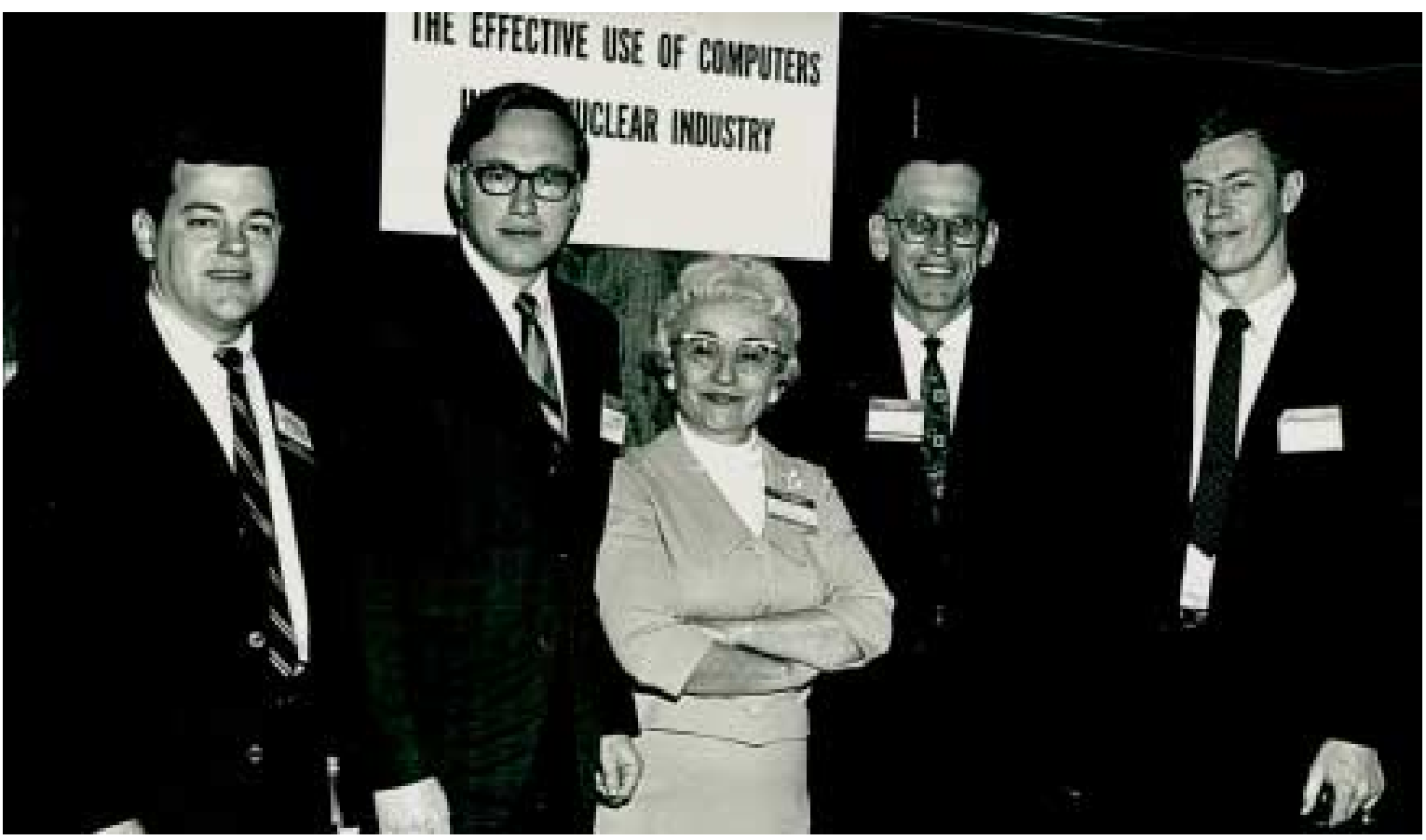

The 1969 Conference on The Effective Use of Computers in the Nuclear Industry was hosted by the University of Tennessee. Key personnel included (from left): Bill Rhyne, Noel Cramer, Betty F. Maskewitz (General Chaiman), Pete Pasqua (UT/NE Professor) and Tony Buhl. 
Organizers and leaders of the 1967 ANISN Seminar-

Workshop take a rest (from left): G. Elliott Whitesides,

Betty F. Maskewitz, Mildred Landay, Ward Engle. From below left: Juanita Brown Wright, Henrietta Hendrickson, Hemma Francis Comolander, Maskewitz, Charles Slater (1967 RSIC/ORAU Summer Participant), Landay and David Trubey. ORNL 14895 and ORNL 14896

The experts in discrete ordinates methodology review the state of the art in the 1967 SeminarWorkshop (from left): Kaye D. Lathrop and Bengt Carlson of Los Alamos Scientific Laboratory and Fred Mynatt of Union Carbide Nuclear Division. The workshop team (DOT code system) included Computer Science Division personnel (bottom, left to right): Mynatt, Dick Rogers, Ward Engle, Elliott Whitesides, Larry Williams, Maurice Greene, and Eddie Ford, III. ORNL 14899 and ORNL 14897
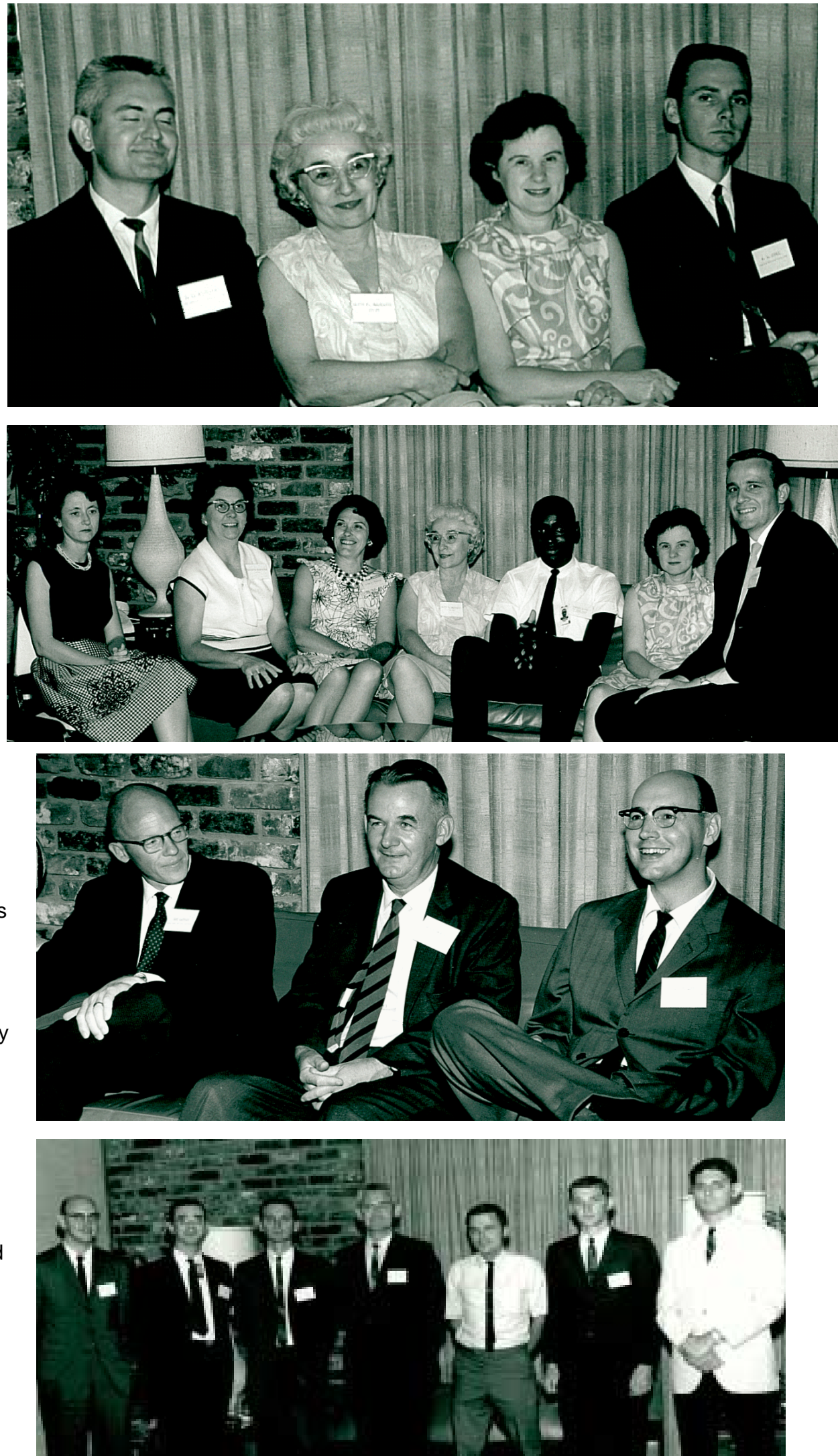


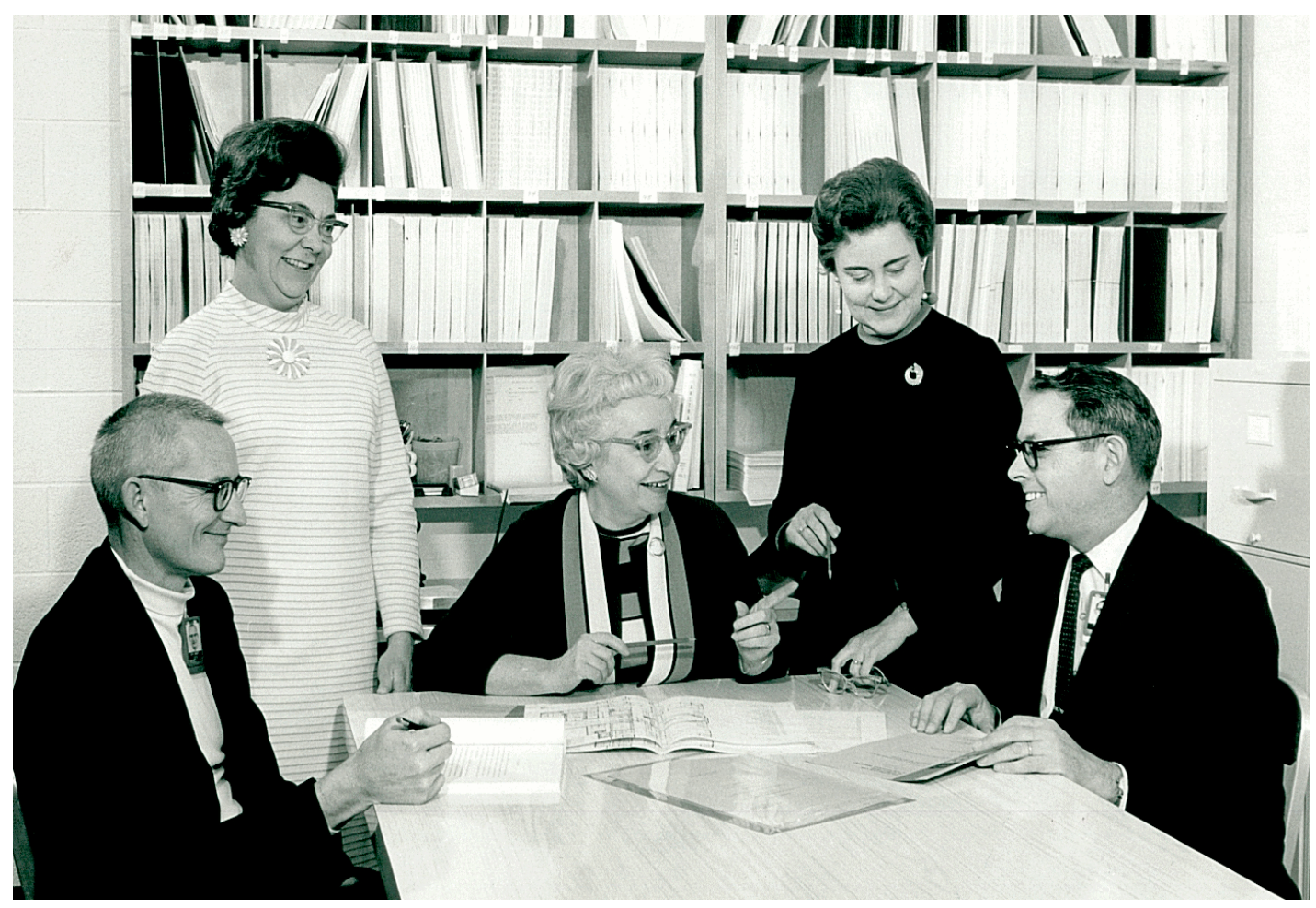

Attending a planning session for the 1969 ANS/M\&C Topical C onference on the Effective Use of Computers in the Nuc lear Industry a re from left: David Vondy, Henrietta Hendrickson, Betty Maskewitz, Jane Gumey, and Claude Long (Finance). ORNL 94913

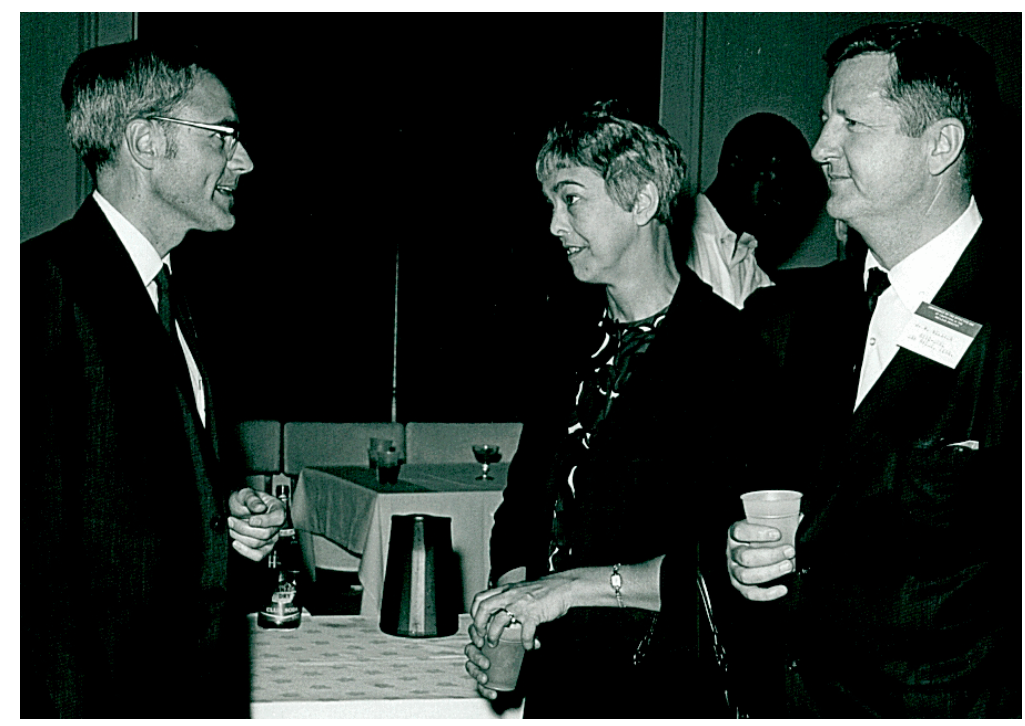

Fred Maienschein greets the Wallace Websters and jo ins in the reception for attendees at the 1969 ORNL/ANS-M\&C Division conference on Effective Use of Computers in the Nuclear Industry. UTРНО 3 -11629-C 


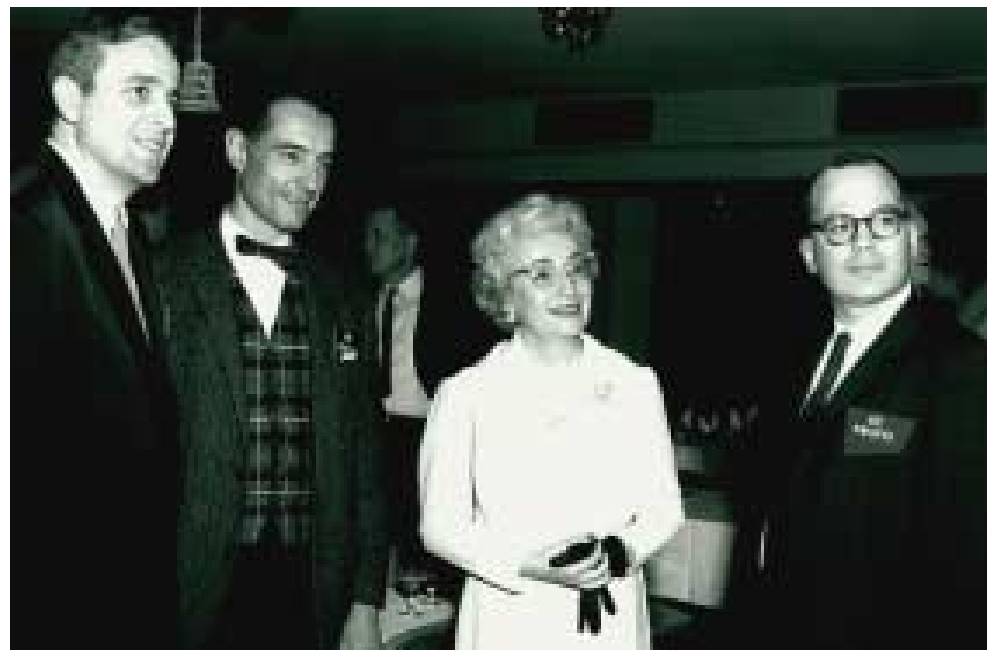

Attending the 1964 Annual Information Meeting Dinner a re (from left): David K. Trubey, William E. Kreger(U.S. Naval Radiological Research La boratory, San Franc isco, later NRC sta ff), Betty F. Maskewitz, and A. Edward Profio (General Atomic, now at the University of Califomia, Santa Barbara). ORNL 12949

Lomaine Abbott(center) sharesa light moment with 1966 NPD annual Information Meeting partic ipants (from left); Fred Maienschein, Lew $\mathbf{V}$. Spencer (NBS and KSU), Charles E Clifford, and Walter H. Jordan.

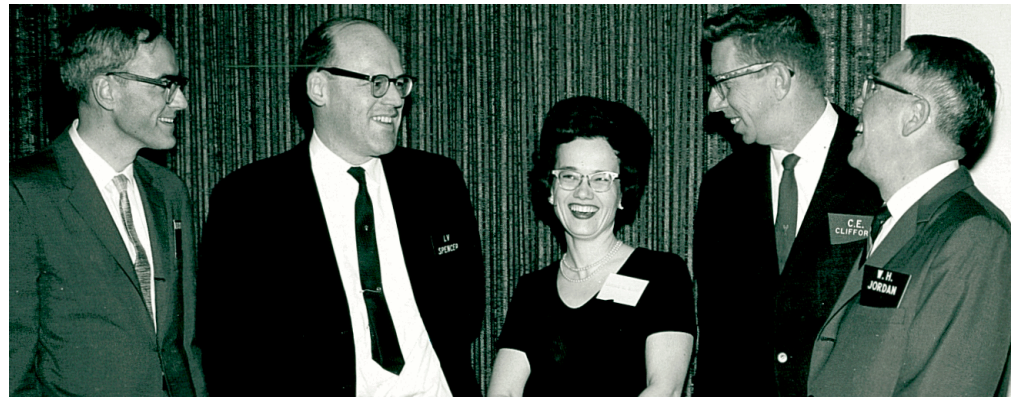




\section{THE SEVENTIES MARK SIGNIFICANT CHANGES}

The 1970s witnessed many changes in ORNL and the NPD work environment. The Arab oil embargo, the Three Mile Island accident, and a rapidly growing concern for the environment led to nonnuclear activities to replace the diminishing nuclear programs. The NASA space shielding program decelerated as a result of decreased emphasis on space missions. Division staff members sought ways to diversify gradually into new areas of research. Cooperation and collaboration with other ORNL divisions increased with shared activities in nonnuclear programs related to energy and the environment.

The liquid metal fast breeder reactor (LMFBR) program, which had become the major reactor shielding program within NPD as we entered the 1970s, began to decelerate as we entered the 1980s.

\section{Sponsor Reorganization and Other Changes}

In October 1974, the AEC was reorganized into the Energy Research and Development Administration (ERDA) and the Nuclear Regulatory Commission (NRC). ERDA lasted only three years; it was renamed Department of Energy (DOE) in 1977.

\section{Sponsors and NPD Research Programs in the 1970s}

ERDA/DOE Division of Reactor Development and Demonstration:

Cross-section measurements, evaluations, uncertainty studies and processing; core analysis, shield

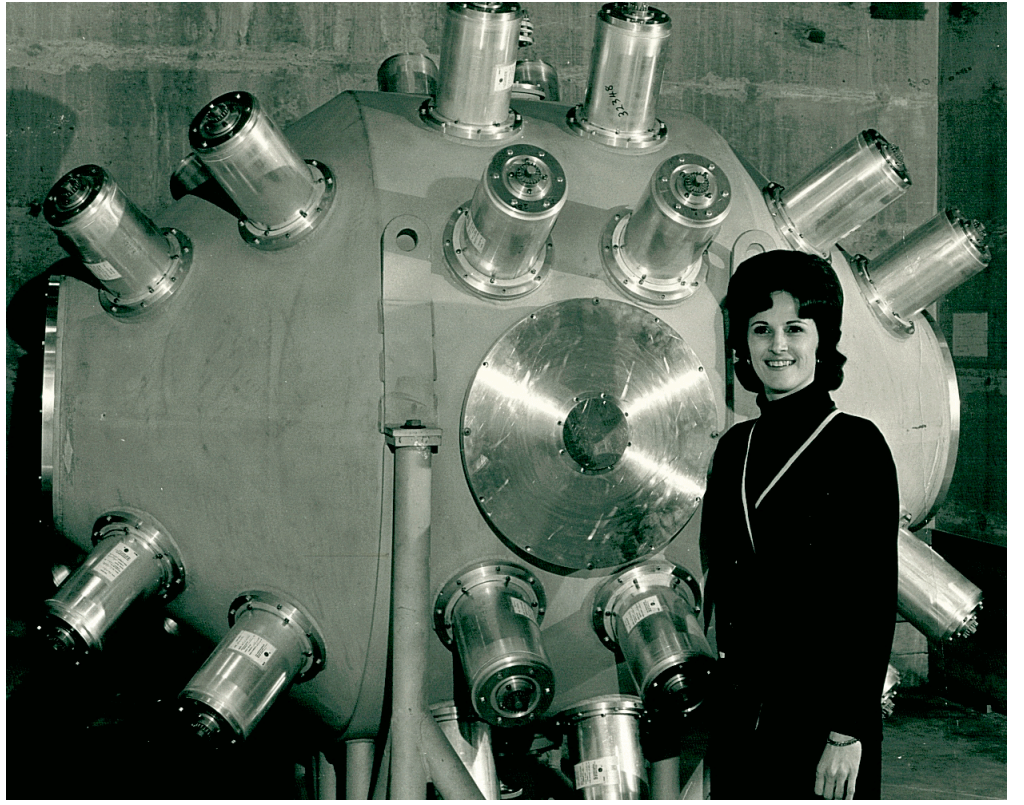

Lenna $\mathbf{K}$. Lovette, sec retary on experimental tea ms of the division, exhibits ORELAST, the ORELA Sc intillator Tank designed by Emest G. Silver and used by Gerard de Saussure circ a 1969-1970. ORNL 93756 analysis, and sensitivity analysis

methods development; core neutronics studies for fast reactors; shielding experiments and analyses; shielding analysis for FFTF and CRBR; waste management studies; Nuclear Safety Data Base; and RSICLMFBR studies.

ERDA/DOE Division of Nuclear Research and Application:

GCFR shielding experiments and analyses; analysis of GCFR shield designs; thorium assessment studies; thorium and uranium fuel cycles in fast breeder reactors.

ERDA/DOE Division of Nuclear Fuel Cycle and Production:

Gas-cooled reactor and thorium utilization studies; safeguards and actinide transmutation calculations. 
ERDA/DOE Division of Magnetic Fusion Energy:

Plasma modeling; neutronics studies for EPR, TNS, DPR, and EBT; MFE integral shielding experiments and analyses; RSIC-MFE activities.

ERDA/DOE Division of Physical Research:

Transport calculations for high-energy particles; ionization calorimeter design; accelerator breeding studies; cross-section measurements and evaluations for fusion and fission reactors; studies of neutron capture in actinide wastes; and ORELA operation and improvements.

ERDA/DOE Division of Biomedical and Environmental Research with HEW/FDA Bureau of Radiological Health and Society of Nuclear Medicine:

Biomedical Computing Technology Information Center.

Nuclear Regulatory Commission:

Fission-product decay heat studies and transport calculations - UO-2 fragmentation calculations; RSIC-NRC activities.

Defense Nuclear Agency:

Cross-section measurements, evaluations, processing and data library development; radiation transport code maintenance; integral experiment analysis; transport calculations; and RSIC-DNA activities.

Other Studies:

RSIC survey of shielding needs of the nuclear power industry for EPRI; cross-section sensitivity analyses of thermal reactors for EPRI; TFTR neutronics calculations for Princeton University; improvement of a tank modeling code for US Army/BRL; and an ORNL Exploratory Studies Program related to atmospheric diffusion of particles released at low altitudes and advanced fuels sensitivity studies.

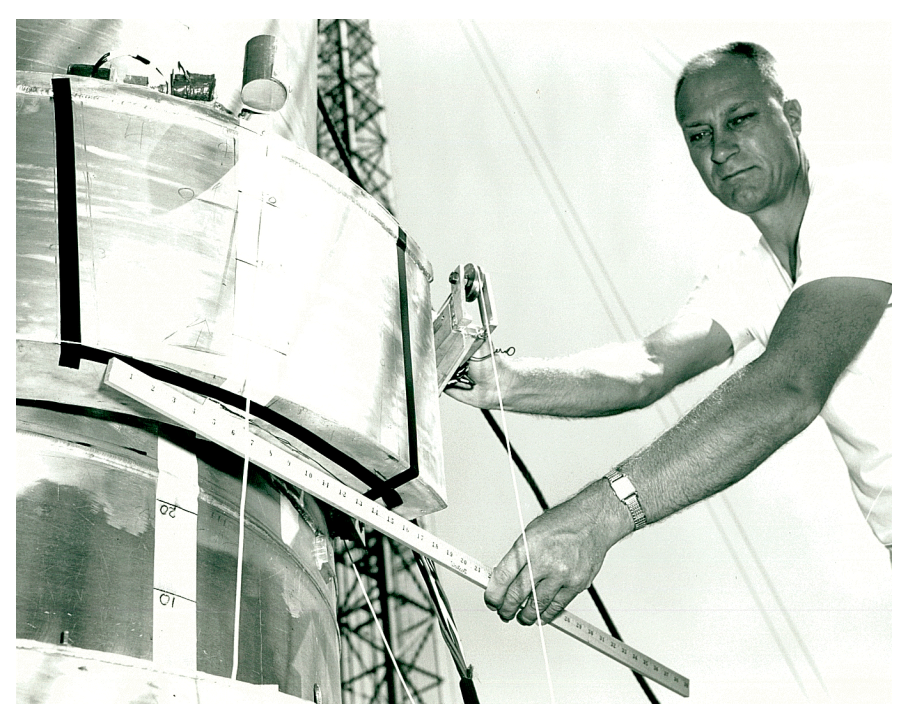

Franc is "Buzz" Muckenthalertakes mea surements at a mockup of SNAP Reactor Shield ing at the Tower Shielding Facility, circa 1970. ORNL 58058
ORELA was the only experimental facility for which NPD retained operational responsibility. Operation of TSR-II and HPRR was assumed by the ORNL Operations Division and BSF by the Solid State Division during the mid-1970s. The changes in operation did not affect the division experimental program at the TSF.

\section{Weinberg Replaced by Postma}

ORNL Director Alvin Weinberg was replaced by Herman Postma in FY 1974, with subsequent changes in management philosophy. The Associate Division Director position was eliminated in favor of an overall management team consisting of the director and managers of division organizational units, i.e., sections and programs. 


\section{NPD Becomes Engineering Physics Division (EPD) in 1978}

In light of the above and other changes, the division attempted to redirect activities from reactor physics into adjacent areas in which it appeared to have particular or potential competence. It was felt that the name 'Neutron Physics' was no longer appropriate. The analysis of complex systems that involve detailed mathematical modeling and intensive computer use was considered to be the right direction for an extension of the division's work. Therefore, the name 'Engineering Physics' was selected as an appropriate name for the Division.

\section{Reorganization of the Engineering Physics Division (EPD)}

The most important change in EPD organization included splitting the Nuclear Engineering Analysis Section into three groups and combining all experimental programs into one section. The latter change was forced in part by the reduced pace of TSF operations. Integration of the integral experiments for fission-reactor shielding at TSF and those for fusion-reactor shielding in Building 6025 was introduced. For example, shielding materials (which were expensive) were shared between the two facilities. It was also felt that sharing personnel and instruments would be cost effective and give added value to the overall program.

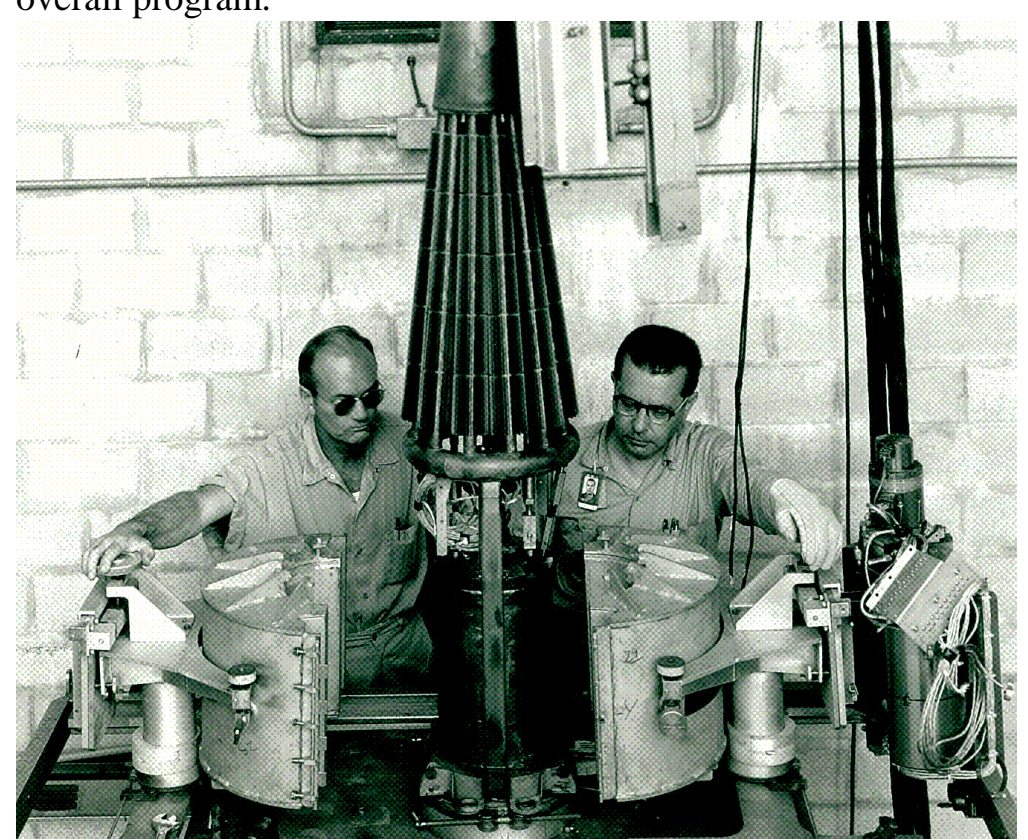

D. D. Walker (left) and Joseph lewin working on the SNAP-TSF reactor, 1973. ORNL1339-73
Division of the analytical section into two groups allowed the concentration of new efforts by one group upon the extension of activities into reactor safety and reliability and into risk-benefit analysis for energy systems. The other group expanded its analysis of thermal-reactor systems to include the pebble-bed gas-cooled reactor.

Table I best illustrates the trends in work areas within the division over a 6-year period (FY 1974-FY 1979).

The introduction of the many changes made the 1970 s basically a milestone period in the history of the Division. It, therefore, seems appropriate to look at EPD manpower distribution. EPD included six organizational units in the mid-1970s, staffed as follows:

Electron Linear Accelerator (R. W. Peelle + 16 EPD, 5 I\&C, 3 CSD, and 1 guest)

Neutron Cross Sections (F. G. Perey +8 EPD and 1 Physics Division (PD))

Reactor Shielding Experiments (C. E. Clifford ${ }^{*}+12$ EPD, and 4 UT)

${ }^{*}$ Clifford, a charter member of the division, retired from ORNL in 1977 with 34 years (1943-1977) of service. 
Shielding Analysis and Reactor Physics (F. R. Mynatt* + 22 EPD, 10 CSD, 1 GA Tech, 1 GE, and 4 UT)

Radiation Shielding Information Center (B. F. Maskewitz + 13 EPD)

High and Medium Energy Radiation Transport (R. G. Alsmiller + 4 EPD and 2 CSD)

\section{Conferences and Seminar-Workshops}

The Fourth International Conference on Reactor Shielding (4-ICRS) was convened in Paris in October 1972 under French CEA, IAEA, and OECD/NEA sponsorship. Division members served on the program committee and Clifford, Lewin, Maskewitz, and Roussin participated in the conference. The fifth conference (5-ICRS) of the series was convened in Knoxville in April 1977 under IAEA, ANS and ORNL sponsorship. D. K. Trubey served as general chairman with full NPD support.

Seminar-Workshops continued to be effective in NPD/EPD-led technology transfer during the decade.

Monte Carlo Methodology, featuring MAGI's ANTE and ORNL's MORSE (1970); ORNL/RSIC-29

Radiation Transport in Air, featuring SAI's ATR and AFWL's SMAUG (1971); ORNL/RSIC-33

Radiation Energy Spectra Unfolding Techniques, featuring ORNL's FERDOR and University of Illinois'FORIST (1976); ORNL/RSIC-40

Neutron Spectrum Adjustment, IAEA-sponsored status review, featuring ORNL's STAY'SL (1977); IAEA-TECDOC-221

Multigroup Nuclear Cross-Section Data Preparation and Data Library Manipulation Techniques, featuring ORNL's AMPX and CCCC-formats (1978); ORNL/RSIC-41

Theory and Applications of Sensitivity and Uncertainty Analysis, featuring ORNL's FORSS (1978); ORNL/RSIC-42

\section{Information Activities Increase During the 1970s}

During the 1970s the Division became known as a promoter of information activities, and new centers were established. Two of these, SACRD and CREDO, were managed under the Reactor Analysis, Safety and Reliability program.

\section{Safety Analysis Computerized Reactor Data (SACRD)}

SACRD, a nuclear safety data base, was established in FY 1975 to meet the need for input for various fast reactor analysis codes. Sponsored by DOE, SACRD functioned throughout the decade and was closed down with the demise of the LMFBR program.

*Mynatt, who had served division programs since 1965, first on loan from ORGDP/CDPF, and as a staff member since 1970, left in FY 1978 to manage ORNL/NRC programs. The responsibilities carried by Mynatt were reorganized into new units headed by Bartine, Flanagan, and Weisbin. 


\section{Central Reliability Data Organization Program (CREDO)}

A new data base program, CREDO, began operating in FY 1978. The CREDO task was to compile statistics on the reliability of various nuclear plant components as determined from experience with operating reactors.

\section{COMMENTARY: “CREDO — Sixteen Years a Research Tool” by Helmut E. (Bill) Knee}

The Centralized Reliability Data Organization (CREDO) was established in the mid-1970s as a data base and data analysis center for reliability, maintainability and availability data on liquid metal reactor components and systems from U.S. liquid metal research facilities: Fast Flux Test Facility (FFTF), Experimental Breeder Reactor-II (EBR-II), Rockwell's Energy Technology Engineering Center, Westinghouse's Advanced Reactor Systems Division, and General Electric's Advanced Reactor Division. Also included were Japanese test facilities (JOYO and other facilities at the O-arai Engineering Center) operated by The Power Reactor and Nuclear Fuel Development Corporation (PNC).

The original idea for CREDO came from DOE in 1975 in response to a need to utilize probabilistic risk assessment data in the design of the Clinch River Breeder Reactor. At ORNL, George F. Flanagan was one of the original supporters. In 1976, Paul M. Haas joined NPD to bring the concept to reality. In 1977, the first funding for data collection activities was received and a number of individuals began work on the project, including N. Maurice Greene, Terry F. Bott, Mike Woodside, Gary Johnson and Rounisi Morteza. DOE/NE supporters of the CREDO program included Harry Alter (program monitor),

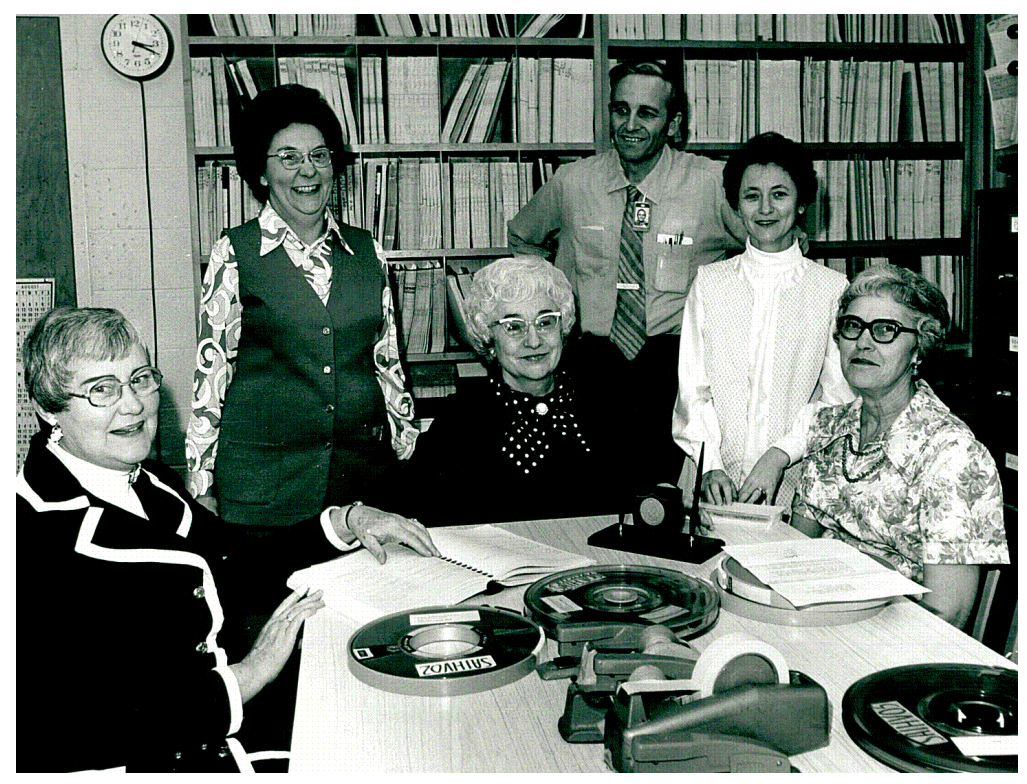

The RSIC Code Center staff review the citation and desk set received from the American Nuclear Society Shield ing and Dosimetry Division for Outstanding Service-1975 (from left): Jane Gumey, Henrietta Hendrickson, Betty F. Maskewitz, David K. Trubey, J uanita Wright, and Hemma Comolander. ORNL 0298-76
Francis X. Gavigan, Robert

Neuhold, and Wade Carroll.

The CREDO system

architecture, data base management system, and data collection forms and protocols were designed between 1978 and 1980. In addition to personnel mentioned above, others involved in the effort included John J. Manning, G. W. Cunningham, Virginia $M$. Forsberg, Knee, and Steve D. Hudson. The first Co-op and summer students, who provided reliability data processing services, included Paul F. Seagle, Scott L. Painter, Mark Anderson, and Clarence Reynolds.

Data collection activities were initiated at EBR-II in 1978. Analyses of these data pointed toward a high degree of human errors, or errors

that were propagated via human involvement. These preliminary findings prompted Haas and Bott to 
convince the Nuclear Regulatory Commission to fund a study on safety-related operator actions. This experiment-based program was extremely significant for a number of reasons. It was the first human factors study in the Division, and it led to formation of the Reliability and Human Factors (R\&HF) Group. It also resulted in a NUREG/CR report that proclaimed that, for certain reactor events, control room operators may not have sufficient time to respond appropriately. The NUREG/CR report was published 6 weeks prior to the Three-Mile Island accident.

CREDO was expected to expand in the 1980s under the joint U.S./Japanese program.

\section{Technology Resources Group — RSIC-Related Centers}

RSIC's reputation for effective technology transfer, especially in technical activities related to computer code and data exchange, led to requests for spin-off activities. Three additional information centers were initiated during the decade. These centers were managed under an umbrella initially entitled Technology Resources Group. The name of the group was changed to Engineering Physics Information Centers (EPIC) in the late 1970s in conformity with the new name of the Division.

\section{Biomedical Computing Technology Information Center (BCTIC)}

As a result of cooperative efforts that began in 1971 between ORNL and members of the Society of Nuclear Medicine, the ERDA Division of Biomedical and Environmental Research established BCTIC within NPD in 1975. The Center was chartered to collect, organize, evaluate, and disseminate information on computing technology among those engaged in biomedicine in general and nuclear medicine in particular and to serve as a central focus for exchange of such information. W. J. McClain and R. L. Henne (CSD) gave technical support to BCTIC, and P. R. Bell and Frank Clark served as consultants.

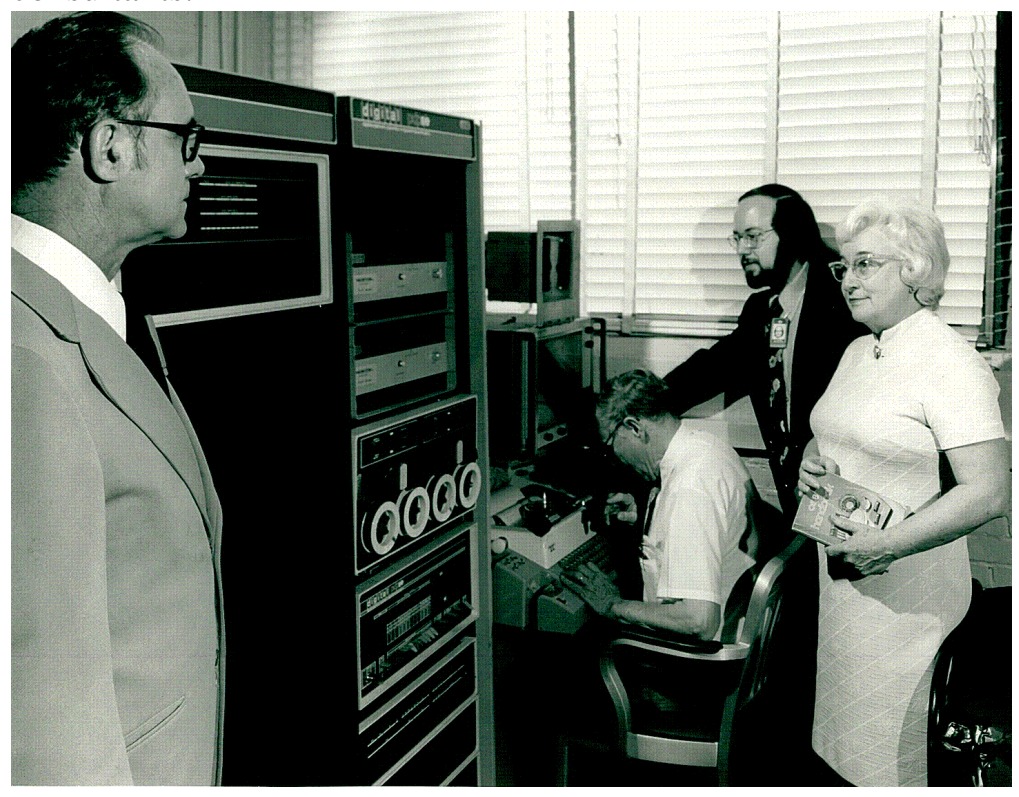

The staff of the Biomedic al Computing Technology Information Center (BC TIC) check out a clinical diagnostic program (from left): William J . Mc Clain (CSD), P. R. Bell (Consultant), Randell Hennies (CSD), a nd Betty F. Maskewitz ORNL 4657-75

The holdings were transferred to INEL in the early 1980s.
Within 5 years, BCTIC was developed into a successful prototype. The Center was transferred into a medical research environment at Vanderbilt University in 1980.

\section{Reactor Safety Research Data} Repository (RSRDR)

A repository and distribution center for reactor safety research data, sponsored by the NRC Office of Nuclear Regulatory Research, was established in EPD/EPIC in FY 1978. RSRDR served as the archival repository and response center of the NRC/Reactor Safety Research Data Bank System located at the Idaho National Engineering Laboratory (INEL). RSRDR functioned within EPIC until after the Three Mile Island accident when there was a lessened interest in this specific area of data. 
Technical Data Management Center (TDMC)

TDMC was established in 1976 to serve NRC licensing and regulation programs. TDMC objectives were to define, develop, and maintain a center for acquiring, analyzing, packaging, documenting, and disseminating computing technology for use by NRC staff, licensees, and contractors. Initial efforts were related to radiological assessment codes, the Standardized Computing Analysis for Licensing Evaluation (SCALE) System, and meteorological evaluation of effluent release from nuclear power plants.

\section{The Seventies End}

Joining the staff early in the decade were Fred Mynatt, Ward W. Engle and Larry Williams (FY 1971) who were formerly on loan from CSD; Edward Oblow (FY 1972); A. R. (Tony) Buhl, G. L. Morgan, C. R. (Chuck) Weisbin, George F. Flanagan, David B. Simpson, R.A. Lillie and S.N. Cramer (FY 1973); Charles Slater (FY 1975); D.R. Vondy and T.B. Fowler (FY 1975); and Daniel T. Ingersoll (FY 1977).

The 1970s ended with significantly changed programs from those of the 1960s and early 1970s. The DOE LMFBR and the DNA programs had gradually and consistently diminished in funding. By the end of the decade some key EPD technical leaders were gone: Edward D. Straker, Wayne A. Coleman, Milo Solomito, Buhl, M. L. Gritzner, T. J. Hoffman, V. R. Cain, Walter Zobel, Tony W. Armstrong, Morgan, Mynatt and Clifford.

A large fraction of the EPD programs $(\sim 50 \%)$ were carried out by subcontractors and by loanees from the Computer Sciences, Physics, and Instrumentation and Controls divisions

\section{COMMENTARY: “The Division Looks to the Future Through ORNL's Long Range Plan (1975-1981)” by Betty F. Maskewitz}

On September 20, 1974, the ORNL staff issued the first of a series of long-range plans with the stated aim "to give the ORNL research staff and service groups a view into the directions, related emphases, and important programs at the Laboratory and to reorient whenever changes appeared wise." The series was also aimed at acquainting government sponsors with the interrelatedness and essential nature of a multipurpose laboratory addressing national objectives.

The 1975-1981 plan stated the objectives and major thrusts of ORNL programs, policies and constraints, and program goals (fission, fusion, coal and other systems, energy systems, physical sciences, and life sciences). NPD/EPD research programs are obviously stated in the areas of fission, fusion, and the physical sciences.

The strongest ORNL focus for these 5 years was to center on activities to help ensure the acceptability of and to accelerate the deployment of nuclear power. In the fission energy area, strongest attention was to be given to the nuclear fuel cycle, nuclear safety, and special aspects of reactor technology in which NPD/EPD's special aspect was shielding studies. The TSF reactor was cited as "the only reactor designed for shielding studies and also for capabilities related to cross-section measurements and shielding analysis." Computer codes, developed for reactor shielding design calculations, were to be verified through benchmark and shielding configuration experiments at the TSF.

The Division's reactor technology program included the determination of neutron cross sections of fertile and fissile materials and neutron scattering and gamma-ray production cross sections for LMFBR core and shield design needs. A rapidly growing effort was expected on shielding studies for the GCFR, which was said to have enhanced shielding problems arising from the low-density coolant. 
Division plans are also featured in aspects of program goals. GCFBR shielding requirements included design and optimization of radial and axial shields, application of sensitivity analysis to determine uncertainties in shield design and data requirements, and confirmation of analysis with TSR experiments. Fusion reactor technology programs included studies of neutronics and fusion reactor design problems.

Specific inclusion of Division plans are obvious in the discussion of the goals of the physical sciences. Reactor physics, mentioned as an important discipline for core and shield design, was expected to play a significant role in the design of fuel reprocessing plants for breeders. Major effort was expected in the area of neutron cross-section measurement and evaluation for both fission and fusion studies; on development and maintenance of computer codes and data for fast reactor shield analysis, design and optimization, for military systems analysis and for high-energy transport for accelerators. Radiation shielding experiments at TSF and ORELA were expected to continue.

The Radiation Shielding Information Center (RSIC) was specifically cited for serving its sponsors as a national technology resource for radiation interaction and transport information and technology. RSIC's technology transfer functions were expected to grow with increased emphasis on commercial nuclear power plants and CTR systems. The special relationship with DNA and DOE/DCTR nuclear data programs was expected to continue in the years ahead. The plan suggested that "appreciable expansion of RSIC's role would be cost effective."

The above excerpts from the 1975-1981 ORNL plan hint at the Division's expectations for the years ahead. A historical review of the progress reported through the intervening years reveals how subtly changes creep into 'the best laid plans.'

\section{COMMENTARY: “In Praise of Francis” by J. Kirk Dickens}

A review of the history gives me a good feeling for the beginning 6 years of the Division before I came to ORNL. The success of the Division has been, of course, the result of the efforts of a hundred or more people at any given time in our history. One aspect I have observed is that our Division has almost always been a happy division; people of diverse interests and backgrounds have found sufficient commonality to work together. To a considerable extent, I am sure, this characteristic was due to our management, first Blizard and then Maienschein. Both managed division personnel firmly while being fair.

If Blizard and Maienschein were the heart of the Division, Francis Perey was certainly its technical soul, at least during the 1960s and 1970s. Francis was hired in 1960 as an experimentalist, but before he was thirty he made his national reputation (1962) with a theoretical work coauthored by Brian Buck. Within a few years he was giving invited papers and became a Fellow of the American Physical Society. It is known, of course, that he built up and headed a very active experimental group, but less well known are his interactions with other parts of the Division. He was a 'consultant' to anyone who had a problem. This enthusiasm for a problem was, and still is, infectious. He certainly was at the experimental forefront of our kind of research.

When I joined Francis in 1962, he and Bob Silva had already developed a charged-particle detection system at least 2 years ahead of the rest of the world. While Gwin and Weston should be credited locally for using a small computer in an experimental setup, it was Francis who grabbed onto this concept, making our system in Building 5500 the envy of all who watched us take data using it. I remember one day Weinberg came to call. Francis soon had him seated at the console and was instructing our ORNL 
Director on how to reduce the data to cross sections! Weinberg wielded a light pen that day, probably for the first time in his professional life.

Francis did not invent the pulsed-neutron generating systems in Building 5500, but he certainly made maximal use of them. Bill Kinney's Ph.D. dissertation was one happy result of those experiments. I don't know what influence Francis had on the design of ORELA, but his enthusiasm for doing experiments here was evident even before the machine was completed. He was involved in at least three experiments within the first year. By that time, he was also deeply involved in evaluation efforts for what was to be ENDF/B-3, and he began thinking about techniques to analyze the large bodies of data beginning to come out of ORELA experiments.

I could go on! My hope is that the above sentiments can somehow weave into the NPD/EPD/EPMD history the strong influence of the Division's only Corporate Fellow.

\begin{tabular}{|c|c|c|c|c|c|c|}
\hline \multirow{2}{*}{ Program $^{a}$} & \multicolumn{6}{|c|}{ Fiscal year (in \% of total) } \\
\hline & 1974 & 1975 & 1976 & 1977 & 1978 & 1979 \\
\hline LMFBR Physics (Including shielding) & 50 & 38 & 34 & 28 & 25 & 18 \\
\hline LMFBR Safety & - & 1 & 5 & 9 & 10 & 7 \\
\hline CRBR & - & 12 & 10 & 9 & 8 & 5 \\
\hline GCFR & 1 & 4 & 2 & 3 & 6 & 7 \\
\hline Total Breeder Reactors & 51 & 55 & 51 & 49 & 49 & 37 \\
\hline Alternate Reactors & 2 & 2 & 4 & 8 & 11 & 10 \\
\hline NRC & - & 5 & 5 & 5 & 5 & 16 \\
\hline Total Fission & 53 & 62 & 60 & 62 & 65 & 63 \\
\hline Fusion & 2 & 4 & 4 & 6 & 7 & 6 \\
\hline BES and HEP & 21 & 20 & 23 & 22 & 21 & 19 \\
\hline DNA & 18 & 13 & 9 & 7 & 5 & 5 \\
\hline EPRI & - & - & 2 & 1 & 1 & 5 \\
\hline Miscellaneous & 6 & 1 & 2 & 2 & 1 & 2 \\
\hline TOTAL (\%) & 100 & 100 & 100 & 100 & 100 & 100 \\
\hline Subcontracts & 3 & 2 & 1 & 1 & 6 & 11 \\
\hline $\begin{array}{l}{ }^{a} \text { LMFBR }=\text { Liquid-Metal Fast Breeder Rea } \\
\text { Fast Breeder Reactor; NRC }=\text { Nuclear Regu } \\
\text { Energy Physics; DNA = Defense Nuclear A }\end{array}$ & $\begin{array}{l}\text { Clincl } \\
\text { ission; } \\
=\text { Elec }\end{array}$ & $\begin{array}{l}\text { iver } \mathrm{B} \\
\mathrm{ES}=\mathrm{B} \\
\mathrm{c} \text { Powe }\end{array}$ & $\begin{array}{l}\text { der Re } \\
\text { ic Ener } \\
\text { Researc }\end{array}$ & $\begin{array}{l}\text { tor; GC } \\
\text { Science } \\
\text { Institute }\end{array}$ & $\begin{array}{l}\mathrm{R}=\mathrm{Ga} \\
\mathrm{s} ; \mathrm{HEP}\end{array}$ & $\begin{array}{l}\text { ooled } \\
\text { igh- }\end{array}$ \\
\hline
\end{tabular}




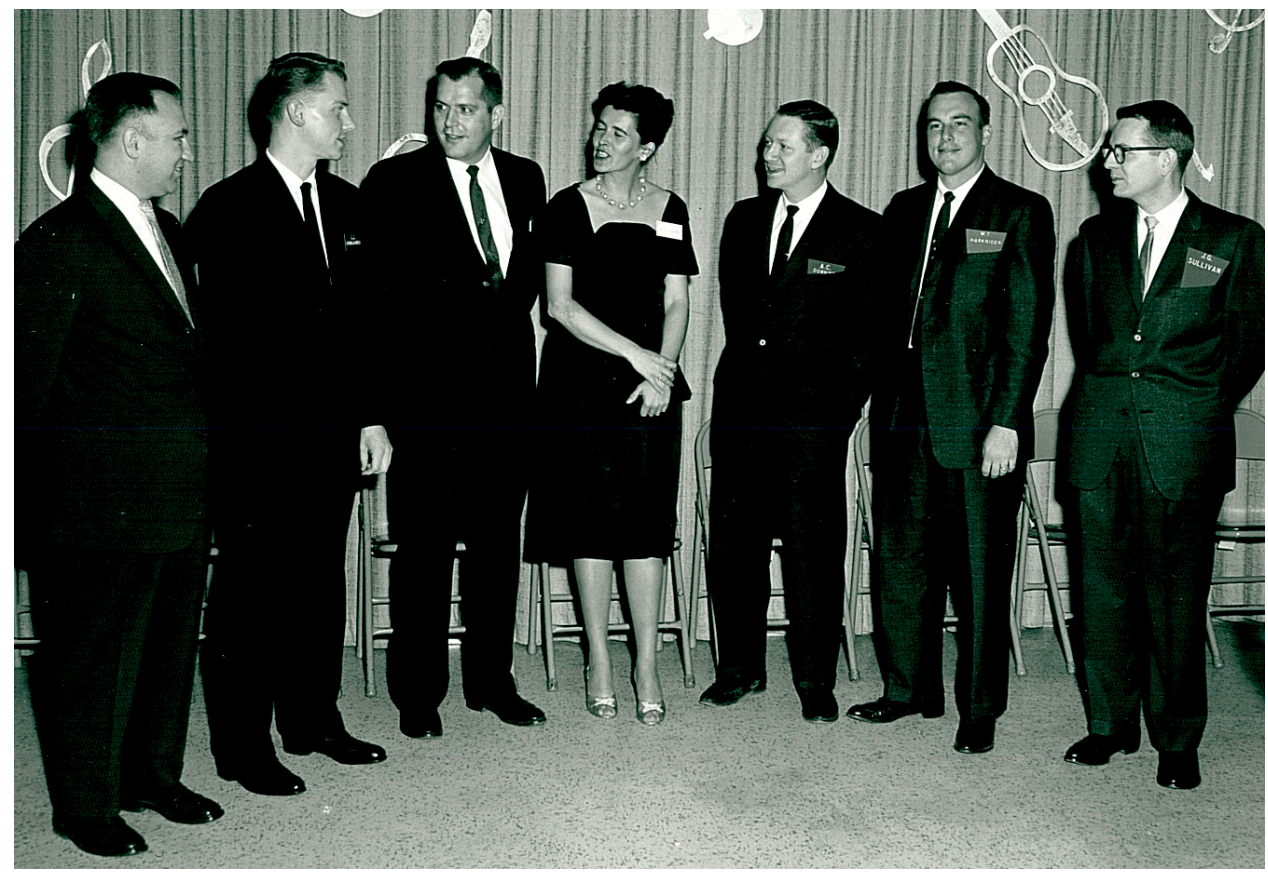

Math Panel Principals Gather at Annual Meeting Festivities in December 1976. From left: unidentified, Lamy Bumgamer, Harvey $\mathbf{P}$. Carter, Marje Lietzke, Art Downing, Millard Harknider, and J. G. Sullivan. ORNL 8156

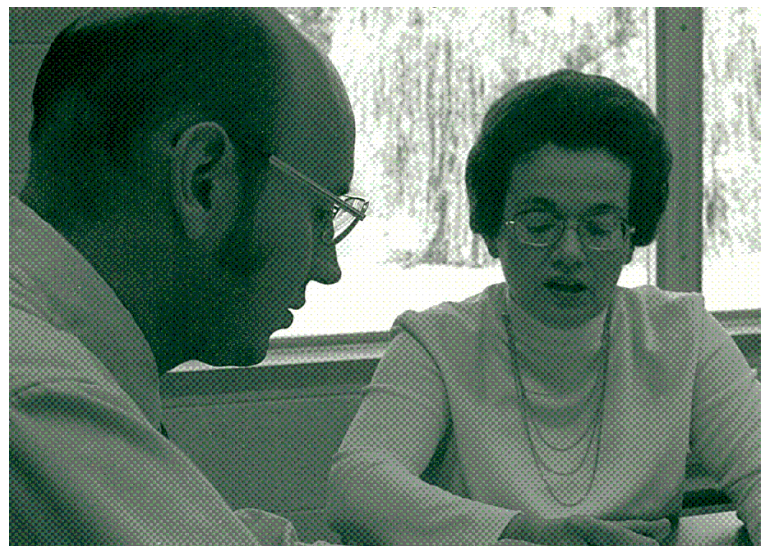

Fred Mynattand Lomaine Abbottd isc uss the artic le on "Fuel from Accelerators" written by Abbott for the Winter 1978 ORNL Review. ORNL 4752-77

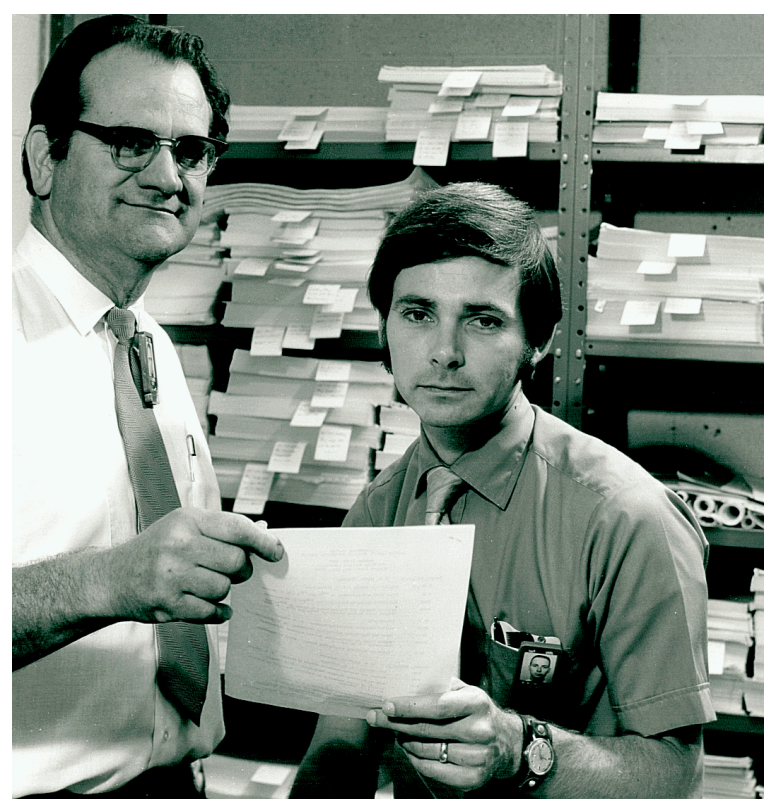

H. Clyde Claibome and Ward W. Engle, Jr., disc uss the application of the discrete ordinates method to problems in the reactor and weapons radiation shielding program (1972). ORNL 2046-71 


\section{THE EIGHTIES — CHANGES AND CHALLENGES}

As we entered the 1980s, EPD programs continued to reflect a long, slow trend away from neutronics studies on which the Division was founded in 1955. In particular, a major trend was away from experimental and calculational methods development for performing neutronics studies and toward application of those methods to a variety of projects.

New areas of research that required different approaches and techniques were given attention: for example, fission reactor work was broadened to include risk analysis and human factors studies to support the safe and reliable operation of reactors. Research was initiated in intelligent control systems that represented an application of broader physical and mathematical techniques to problems of energy systems.

\section{COMMENTARY: “A Study in Diversification” by C. R. (Chuck) Weisbin”}

In the early 1970s, the Neutron Physics Division was generously supported by several federal agencies, including the Defense Nuclear Agency, and the divisions of Reactor Research and Development and Basic Energy Sciences of the Atomic Energy Commission (AEC). This resulted in a coherent, world-recognized program including measurement, evaluation, processing, testing, analysis, and dissemination of nuclear data with emphasis on neutron transport theory associated with the problems of reactor shielding. Group charters were relatively clear and, on the whole, various group activities seemed to complement each other quite well. To some of us, however, core physics analysis was more interesting. Many of the heavy nuclide cross sections were measured and distributed by ORNL, but the charter for reactor analysis clearly was the purview of ANL. By pushing heavily in the area of reactor physics sensitivity analysis, leading the community into quantitative uncertainty analysis, and leading the CSEWG data testing activity, ORNL/NPD developed a strong position in both reactor and shield analysis.

However, in the late 1970s, as President Carter put a stop to nuclear fuel reprocessing and the prominence of nuclear research declined with mounting safety and waste disposal concerns, it was clear that at least part of the Division had to diversify to survive.

AEC passed to ERDA, which passed to DOE, and a broader view of energy extending outside our traditional nuclear domain seemed necessary. One approach was to involve ourselves in energyeconomy model validation. Although we had no formal training in 'supply-demand' modeling, members of the ORNL Energy Division had relevant domain experience, and we offered considerable expertise in methodologies to understand the validity of the output of highly complex models. It should be noted that experimental validation of future relative trends (e.g., barrels of oil generated in the year 2010 using improved oil recovery techniques relative to oil imports) was simply not possible. Among the many lessons we learned from this experience were the difficulties associated with rapidly establishing peer recognition in a new field, and the extreme importance of coal and nuclear power to the electricity generation capability of the United States.

We already knew something about nuclear power, and with coal as the major competitor it was time to look carefully at some of the difficulties associated with coal utilization, particularly the 'greenhouse

${ }^{*}$ Currently at Jet Propulsion Laboratory. 
problem.' We offered the U.S. Department of Energy our experience in information analysis (RSIC, CSEWG) to establish a Carbon Dioxide Information Center (CDIC) intended to follow in the spirit of Alvin Weinberg's information analysis center paradigm. This was our second attempt at expanding our scope to domains in which we admittedly had little disciplinary experience. Among some of the lessons learned here were the enormity of scope associated with $\mathrm{CO}-2$ analysis, and the very limited data base actually available to make confident scientific predictions.

Finally, in the early 1980s, the DOE/BES Office of Engineering solicited new initiatives in Engineering Science. Not knowing fully what 'Engineering Science' truly was, we developed a proposal for research in intelligent machines with first efforts to focus on autonomous robotics. We wanted to cross-cut the frontiers of artificial intelligence, parallel computing, and sensor fusion. This was the third example of our 'Chutzpah' since once again we lacked tangible disciplinary experience and had no reputation in the robotics field. However, with significant effort by many, we were able to pass peer

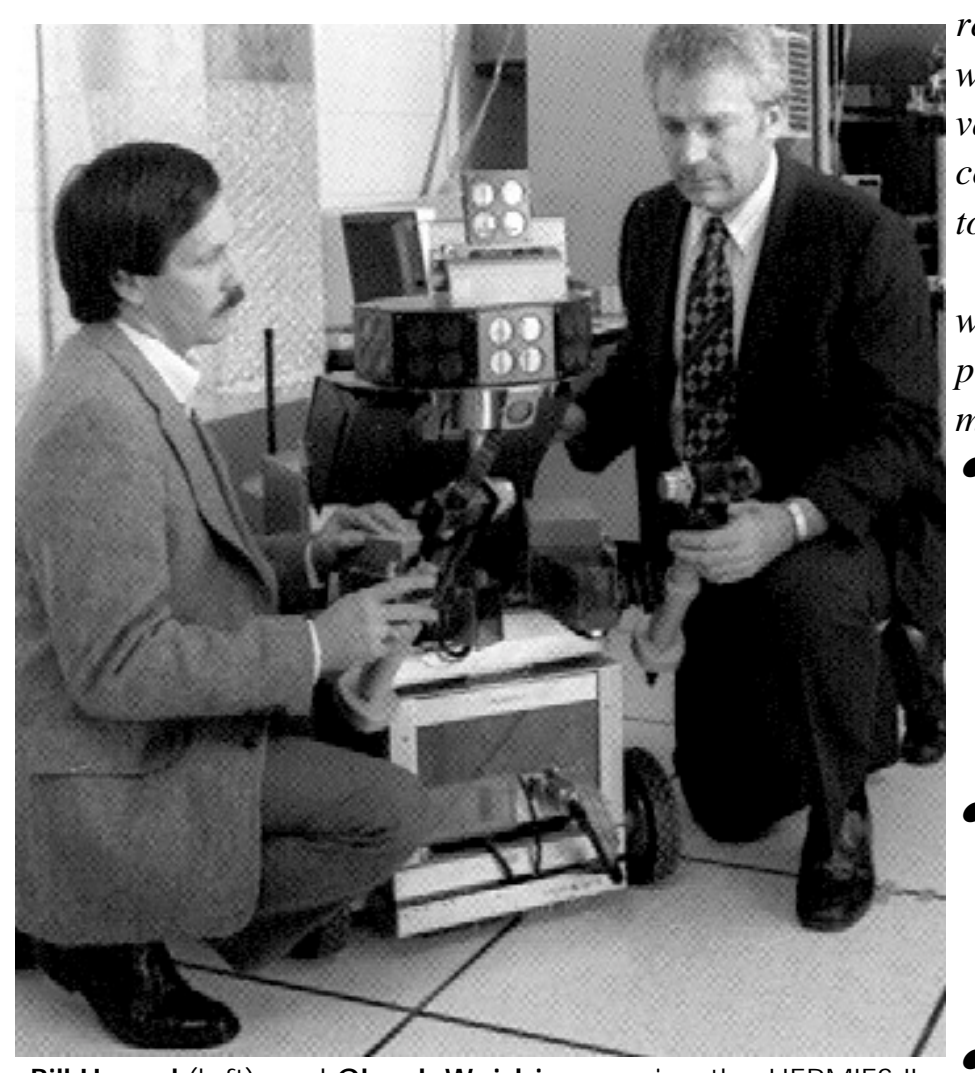

Bill Hamel (left) and Chuck Weisbin exa mine the HERMIES-II robot, which is used by the Center for Engineening Systems Advanced Research for concept demonstration of a rtific ial intelligence planning and leaming a lgorithms. ORNL 8776-85 review and ultimately our CESAR center was funded. This effort was particularly valuable because it was supported with consistency and hardware tests were able to measure the worth of our contributions.

Although it is difficult to summarize what has been learned from all this, I'll point to a few observations which by no means will be widely accepted.

- Diversification is exciting and the learning curve is steep, but it is frustrating to some to regress from world recognition to "Who are you? We haven't seen you contributing to our field!" Breaking into new things is truly challenging.

- Diversification made the Division much less coherent than it was in the early 1970s, and one of our earliest and most unique strengths of group interaction suffered.

Truly important to success were the people! This old cliche is well worn but really true.

\section{Union Carbide Out - Martin Marietta In}

On April 1, 1984 Martin Marietta Energy Systems replaced Union Carbide Nuclear Division as operator of the DOE Oak Ridge, Paducah, and Portsmouth nuclear facilities. Some adjustment was needed at ORNL to conform to the new management style, but in general Division programs were not affected by the change. 


\section{EPD Becomes Engineering Physics \& Mathematics Division}

The Division again made changes in direction in the early 1980s. The major change resulted from transfer of the former CSD/Mathematical Sciences Department into the Division on February 1, 1984. This transfer prompted the name change to Engineering Physics and Mathematics Division (EPMD) and added three new research areas: applied mathematics, computer science, and statistics.

\section{EPMD Mathematical Sciences (MS)}

\section{Origins of the Mathematical Sciences Section}

For many years, mathematics and statistics research was sponsored in Oak Ridge by the Office of Basic Energy Sciences. This research had its beginnings in the ORNL Mathematics Panel organized by Alston S. Householder in 1948. Householder attracted a number of mathematicians and statisticians to his staff and by 1956 he had formed mathematics and statistics sections. The early Math Panel had a relatively small staff, and studies evolved around the ORACLE (Oak Ridge Analog Computer and Logical Engine), built at Argonne National Laboratory (ANL) by ANL and ORNL engineers and installed at ORNL in 1953. The ORACLE was phased out in the early 1960s, replaced by the early IBM and CDC computers at ORNL and K-25.

The 1959 organization chart of the Mathematics Panel indicated a dual role for Householder, Panel Director and leader of mathematics research, with R. P. Kawal and Walter Gautschi as research staff members. A. W. Kimball led statistics research, with Donald A. Gardiner, Marvin A. Kastenbaum, George Atta and Elmon Leach. A Programming and Computation Section was headed by Art Downing, with A. A. Grau, Nancy M. Dismuke, and Harvey P. Carter as technical staff members. Ed C. Long was responsible for Computer Operations. H. H. Bottenbrauch joined the Mathematics Research Section later that year.

In 1961, Gardiner became Statistics Section Leader with M. M. Goff, Atta, Leach, and Kastenbaum headed a Biometrics Section (1961-1966) with D. G. Gosslee and J. E. Parham.

The Mathematics Panel, a familiar name in the 1950s, ceased to exist in mid-1962. With reorganization came a change in name to Mathematics, an ORNL division. Two major departments were organized: Services and Operations (Harvey P. Carter, head) and Research (Mathematics, Programming, Biometrics, Statistics) with group leaders reporting directly to Householder.

Downing left ORNL in 1964, and Carter was appointed assistant director to Householder while continuing to manage services and operations. Several technical staff members were added to his section in the early 1960s: M. Feliciano, C. W. Nestor, Atta, M. T. Harkrider, R. L. Shively, R. P. Rannie, A. M. Craig and H. Katzan (Programming Services); J. G. Sullivan (Systems); Charles S. Williams, assisted by J. E. Parham (Computer Services). In 1966, Feliciano, Sullivan, and Williams were appointed Section Leaders of Programming, Systems, and Computer Services respectively.

Householder continued to manage the three research programs through the 1960s: Mathematics and Programming (G. K. Haeuslein, L. L. Bumgarner, W. B. Gragg, and Paul Nelson); Biometrics (Kastenbaum, Gosslee, and V.R.R. Uppuluri); and Statistics (Gardiner, Uppuluri, F. L. Miller and T. L. Hebble).

Householder retired in 1969 and was succeeded by Carter as Director of the ORNL Mathematics Division, which continued to provide research activities, computer operations and systems, and a growing body of applications programmers.

In the late 1960s Kastenbaum left ORNL and the mathematics and statistics research programs were merged into one section headed by Gardiner. The areas of research expanded during the early 1970s, requiring additions to the research and technical staff. Mathematicians and statisticians were added, 


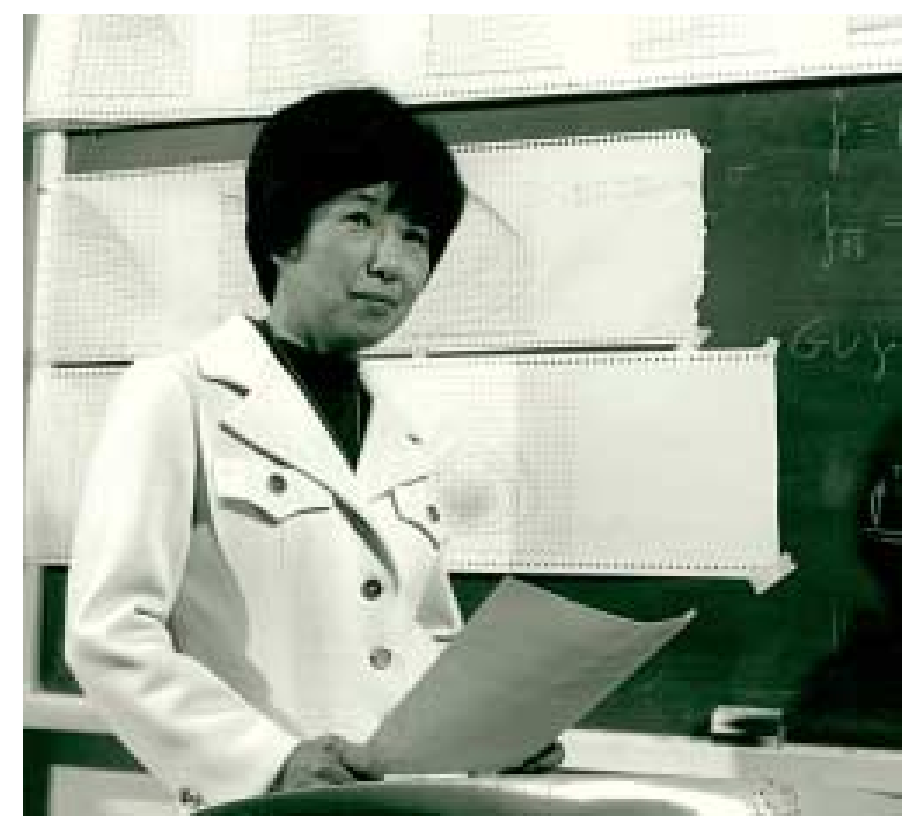

Kimiko Bowman, a research statistician, with a model that depicts solutions to the problem of the mixture of two nomal probability distributions. Physical representations such as this provide insight into possible solutions to complex mathematic al problems. ORNL 2999-74 including Claudia and William Lever, John Beauchamp, Toby Mitchell, Charles Bayne, Alan D. Solomon, Robert C. Ward, and others. The research team was divided into two groups headed by Ward (Mathematics) and Gosslee (Statistics). A Computing Support Group, headed by George Wilson, included technical staff members and technicians.

The ORNL Mathematics Division staff was more than doubled in 1970 with the transfer from the ORGDP/CDPF of a large body of computer applications programmers headed by Alfred A. Brooks. The division was reorganized by Carter, who set up three departments: Technical Applications under Brooks, Systems under Sullivan, and Mathematics and Statistics under Gardiner. Robert Funderlic (who had headed a small mathematics development group in CDPF since the early 1960s, Michael T. Heath, and Kimiko Bowman transferred into mathematics and statistics research. A

Computing Applications Section under Elliot Whitesides (and later Michael Westfall) was housed adjacent to division buildings ( $6025 \& 6010)$ to accommodate the personnel who provided applications support to EPD. As time passed, several staff members transferred into EPD, including Fred R. Mynatt, Ward W. Engle, Larry Williams, David Bartine, Joseph Pace, Douglas Selby, S. Noel Cramer, and others.

In 1973, all UCND computer operations and related research and services were organizationally centralized in a new unit called UCND Computer Sciences Division (CSD) headed by Harvey P. Carter. Computer Facilities were managed by Charles Allen, Management Information Systems by Robert Tanner, Technical Applications by Brooks, Computer Systems by Sullivan, and Mathematics and Statistics Research by Gardiner. Carter (1973-1984) reported to Alton Elkins and later to Paul Vanstrum.

The 1981 organization chart of Mathematics and Statistics Research indicated that Gardiner managed four working groups: Computing Support led by Wilson with Leach, N. J. Price, and C. A. Serbin ; Mathematics led by Ward with S. J. Chang, Funderlic, L. J. Gray, Heath, and Solomon; Statistics A, led by Gosslee with Beauchamp, E. L. Frome, V. E. Kane, T. J. Mitchell, M. D. Morris and R. L. Schmoyer; and Statistics B, led by Lever with Bayne, Bowman, Hebble, S. A. McGuire, Uppuluri and T. Wright.

A further CSD reorganization, which included centralization of telecommunications, occurred with the coming of Martin Marietta Energy Systems in 1984. The resulting new Energy Systems organizational unit, Computing and Telecommunications Division (C\&TD), was headed by Ronald Leinius with Carter as assistant director.

Through the early 1980s, C\&TD carried responsibility for a broad spectrum of duties ranging from fundamental research in the mathematical sciences to maintenance of local computer facilities and telecommunications. 
Upon the retirement of Gardiner, Robert C. Ward was appointed head of the Mathematics and Statistics Research Section. The section served as the research arm of C\&TD until it became the EPMD Mathematical Sciences Section February 1, 1984. The Section, currently led by Richard Sincovec, functions through four groups: Mathematics under Leonard J. Gray, Computer Science under George A. Geist, Statistics under Darryl J. Downing, and an Advanced Visualization Laboratory managed by Michael R. Leuze.

In 1992, Carter transferred to an Energy Systems staff position

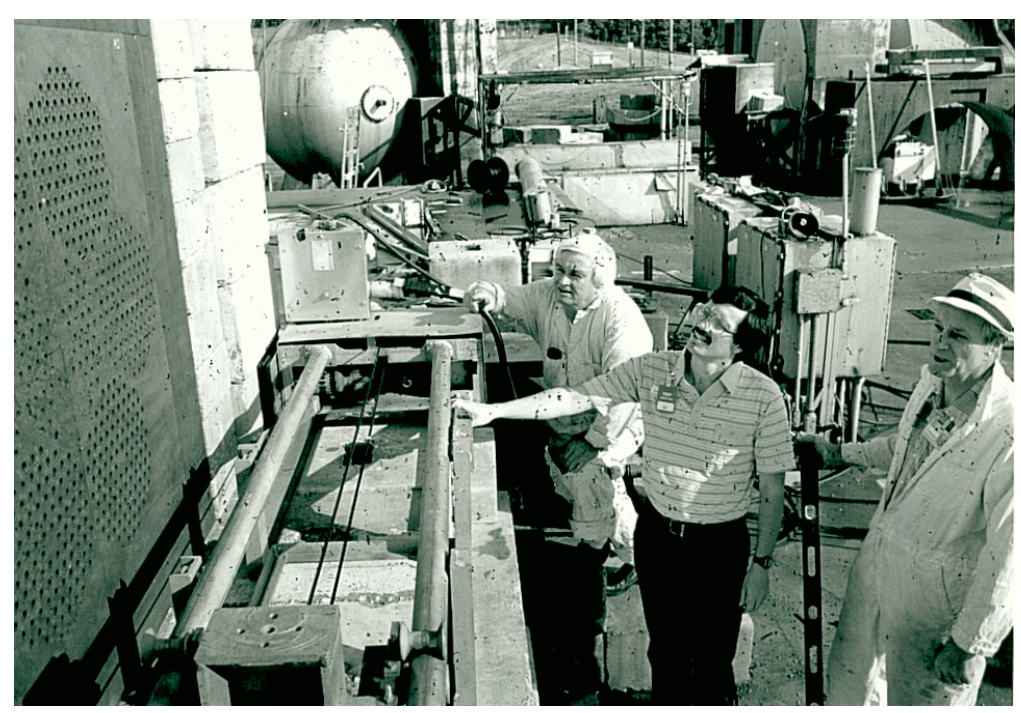

Buzz Muckenthaler, J im Hull, a nd Dan Ingersoll inspect the shield mockup for the High-Temperature Gas-Cooled Reactor Coolant Channel Streaming Experiment, circ a 1983. ORNL 3250-83

\section{The Mathematical Sciences Program}

In their mission the Mathematical Sciences (MS) Section stated three main objectives: (1) to perform research in applied mathematics, statistics, and computer science germane to the solution of the nation's energy problems; (2) to consult and collaborate with other scientists working on these problems; and (3) to provide for the technical development and growth of its personnel in advanced and leading-edge mathematical, statistical, and computer science technology.

The MS Section received $\sim 45 \%$ of its financial support from staff-generated basic research proposals; the remaining 55\% came from consulting activities. Sponsors of the basic research included the DOE Applied Mathematical Sciences Program, the DOE Office of Health and Environmental Research, the Air Force Office of Scientific Research (AFOSR) Computational Mathematics Program, the NASA Marshall Space Flight Center Materials Processing Program, ORNL divisions (Biology, Energy, Engineering Technology, Environmental Sciences, Health and Safety Research, and Solid State), Martin Marietta Aerospace, TVA, and ORNL Exploratory Studies.

The focus of the research program in computer science was on parallel computing. Research in mathematics emphasized moving boundary problems. In the late 1980s, a new research project in statistics was initiated; design and analysis of computational experiments to join existing projects in computational statistics and biostatistics.

Activities in this section featured increased and broadened interactions with the University of Tennessee; for example, the Numerical Linear Algebra Year and establishment of the Advanced Computing Laboratory. A collaboration with Cornell University resulted in development of a fractureanalysis system based on a new boundary-element technique.

The MS Research Computing Facility was improved by the addition of an Intel iPSC/d6 in 1985 and a Sequent Balance 8000 in 1986. 


\section{COMMENTARY: “Leadership, People and Computers” by Bob Funderlic}

For me the inseparability and excellence of leadership, people and computers embodies the history of the Mathematical Sciences Section. Its leadership can best be thought of as progressing from Alston Householder to Rich Sincovec via Don Gardiner and Bob Ward. Their excellence in research has probably been key to their excellence in recruiting, which has also been enhanced by their continual organization of timely professional meetings at both the national and local level. Along with their local symposia have been a steady stream of distinguished visitors. These visitors and the many student programs, including the recent Householder postdoctoral fellowship, have led to extraordinary synergism with staff.

And oh what a staff! It started with Householder and continues with Jack Dongarra, who followed Alan George in the ORNL/UTK Distinguished scientist program. In my most recent chat with Rich Sincovec, he remarked how the best thing about the section was the excellence of the staff, and he added that they were wonderful human beings as well. Indeed, there seems to have always been a special spirit of enthusiasm and selflessness within the section. Among the reasons for the talented staff are interesting scientific problems at ORNL, exciting research goals, and the availability of cutting edge high performance computers. Oak Ridge's wide variety of stimulating scientific applications have often inspired related scientific computing research and development. The need to solve high energy physics eigenvalue problems led to efficient computer algorithms, other computing research has been driven by, e.g., materials simulation, environmental and ecological problems, centrifuge development and reactor design.

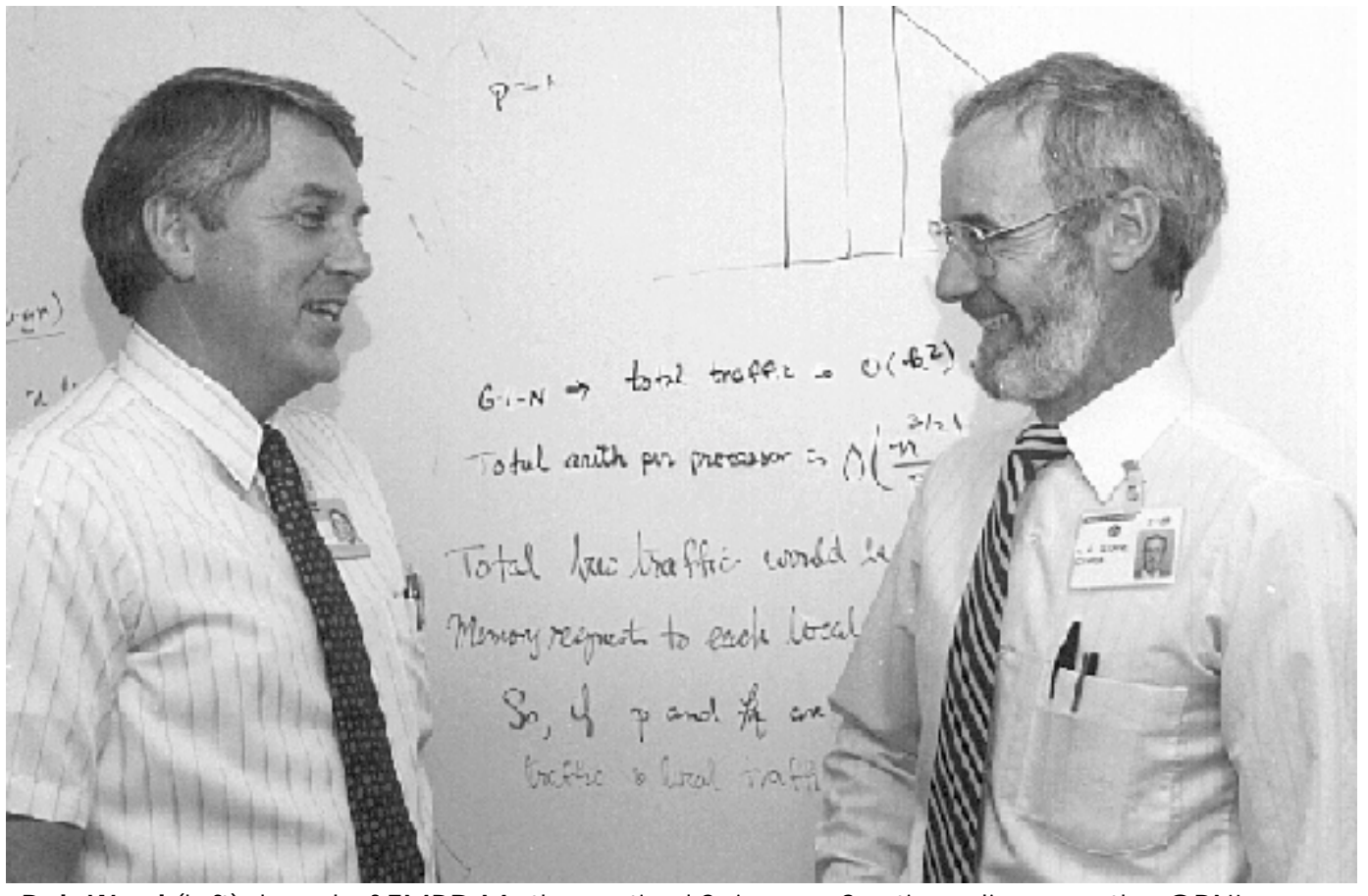

Bob Ward (left), head of EMPD Mathematic al Sciences Section, disc usses the ORNL Distinguished Scientist (DS) Program with Alan George, Dean and Researcher from Waterloo University in Canada, who served as UT-ORNL/DS in Computer Sc ience 1986-1988. George, who came into the program at an early stage, was the first DS in computer Science. Upon his retum to Waterloo, he was appointed Vice President and Provost of the university. ORNL 8805-87 
Providing an important impetus to staff enhancement and recruiting has been the availability of computers that were mostly state of the art.

It started with the ORACLE in the 1950's, built specifically for ORNL, and followed swiftly by the best IBM scientific computers of their time (650, 704 and 7090) at K-25, but used extensively by mathematicians and other scientists at ORNL. ORNL then obtained the best Control Data Corporation computer, a 1604, which was followed by the IBM 360 model 50 - for which ORNL wrote the operating system! The switch from CDC to IBM was considered a big political struggle. So even those simpler times were accompanied by emotional political problems, and in that case, a prominent computing scientist quit and went to work for CDC! Other important computers followed including a CRAY.

Probably the most important related computing leadership decision was to come in the early 1980's. The section made the definite and decisive commitment to strongly concentrate in research in parallel computing, They have been a world leader ever since. ORNL received Intel's first 64-node hypercube off their assembly line, local hypercube and other parallel computing conferences were organized, excellent researchers were recruited, and high performance computing research became synonymous with ORNL and the Mathematical Sciences Section. At every national conference related to scientific computing, section researchers are cited for their innovative computing research. Perhaps the most exciting recent project that is making history is the Parallel Virtual Machine (PVM) system. This system can use a heterogeneous group of machines at diverse locations as one general-purpose concurrent computing resource.

Those of us who have been associated with Mathematical Sciences and the related computing research and development have been truly fortunate.

\section{Programs Initiated In The Eighties}

\section{Energy Economics Modeling and Analysis}

This program, initiated in the early 1980s by Weisbin and others with support from the DOE Energy Information Administration, continued under the sponsorship of the DOE Office of Fossil Energy. The goal was to reduce U.S. vulnerability to disruptions that could follow a large reduction in the supply of petroleum or an increase in its cost. The EPD effort included developing quantitative assessment models of liquid and gaseous fuel supplies, performing sensitivity and uncertainty analyses, developing decisionmaking methodology, contingency planning, and providing DOE/OFE with a 'public sector' home for computer models and analyses [Center of Model Evaluation Technology (COMET)].

EPD principals involved included Weisbin, Oblow, Alsmiller, Jacob Barhen, Drischler, J. R.

Einstein, and Perey. CSD staff members J. E. Horwedel and J. L. Lucius provided computing support. The program, vigorously pursued through the mid-1980s, was closed out by the end of the decade.

\section{Analyses of CO-2 Impact on Climate}

Initiated in the late 1970s, the Division's CO-2 research program expanded into studies of climatic effects while continuing sensitivity analyses. M.C.G. Hall and Cacuci performed a study aimed at the physical interpretation of the adjoint functions for sensitivity analysis of atmospheric models. The DOE Carbon Dioxide Research Division ended the EPMD's CO-2 research program in FY 1985. 


\section{Center for Engineering Systems Advanced Research (CESAR)}

CESAR was established by DOE during the 1980s under the leadership of Weisbin. Its stated mission was to address long-range energy-related research in intelligent control systems. Emphasis was to be on interdisciplinary research for large-scale distributed processes applicable to many energy-related technologies.

Following the resignation of C. R. Weisbin, who served 16 years (1973-1989) in the Division, Reinhold Mann assumed leadership of a reorganized Intelligent Systems Section, which encompassed the Autonomous Robotic Systems Group under F. G. Pin and the Cognitive Systems and Human Factors Group under Knee. In the reorganization, activities were concentrated on research in a broad spectrum of areas ranging from intelligent interfaces between humans and complex systems to autonomous mobile robots, as well as biomedical applications of advanced pattern-recognition systems.

\section{Mathematical Modeling and Intelligent Control}

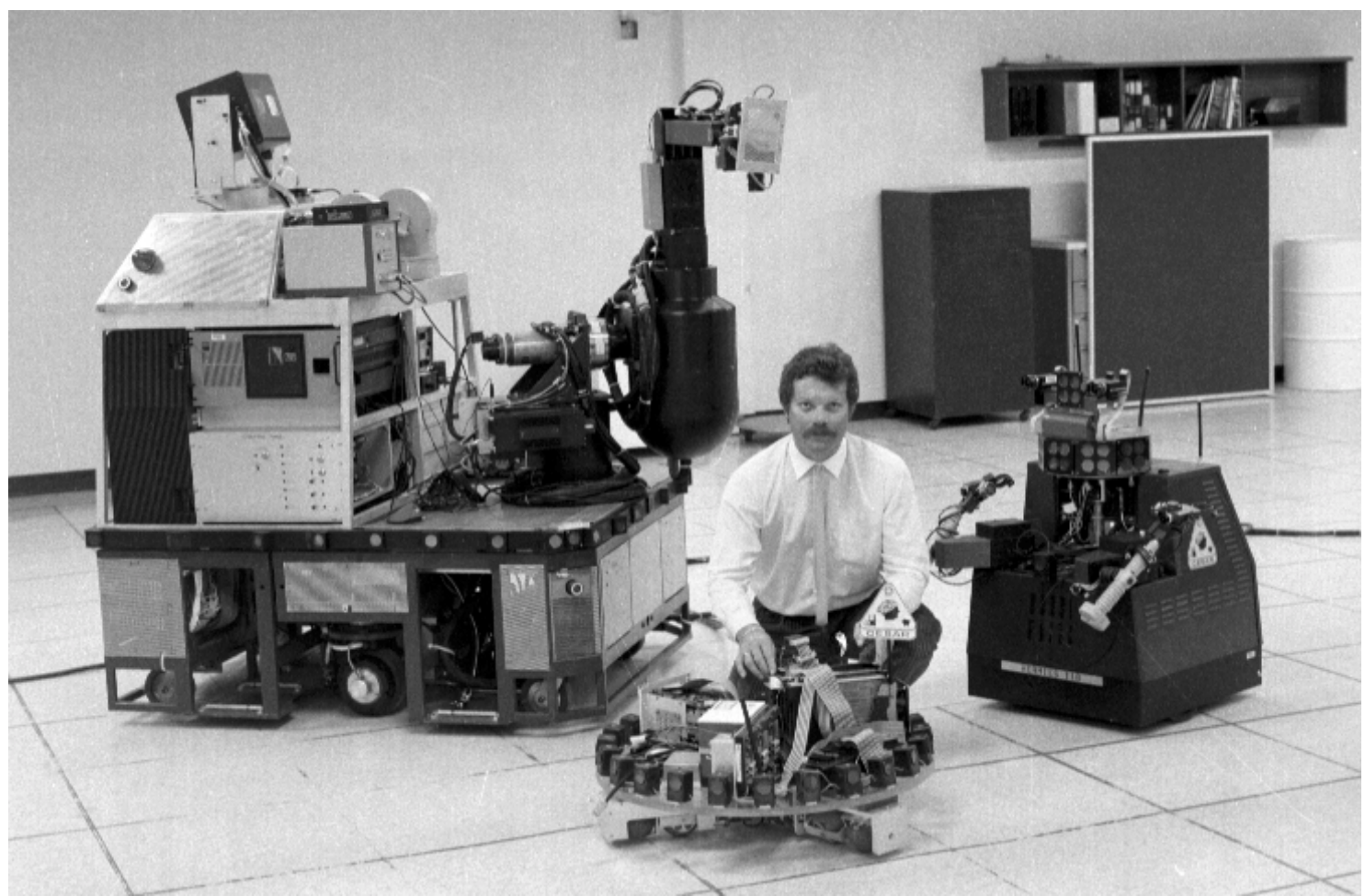

Francois G. Pin is shown with three operational robots in CESAR: HERMIES-III, HERMIES-IIB, and orthogonal French Wheel platform (OFWP, patent pend ing). Experiments with HERMIES-IIB stopped in FY 1992. ORNL 4022-91

The CESAR Mathematical Modeling and Intelligent Control program attracted attention in the artificial intelligence and robotics communities. Development of a series of mobile robots for autonomous operation centered on the self-powered robot prototypes, HERMIES I, II, and III.

The mathematical modeling and performance assessment research covered several areas in which analytical methods were developed and mathematical models used to predict and evaluate the behavior of dynamic systems. These programs included calculations of the fluences of neutrons inside LWR pressure vessels under Electric Power Research Institute sponsorship, some mathematical modeling for the DOE 
Waste Management Programs and the Civilian Radioactive Waste Management Office, and continuing energy-economic modeling analysis for fossil fuel systems.

This research included mechanisms, dynamics, and controls; concurrent computation and neural net vision and multisensor integration; and world modeling and man-machine symbiosis.

The Section also participated in the ORNL Robotics and Intelligence Systems Programs, including cooperative research with ORNL Fuel Recycle, I\&C, and Engineering divisions. At the end of the decade cooperation was initiated with four universities (Florida, Michigan, Tennessee, Texas).

\section{COMMENTARY: “CESAR and Intelligent Systems - A Biased Perspective” by Reinhold C. Mann}

I joined CESAR and Chuck Weisbin's section in August 1986. The section was then called Mathematical Modeling and Automated Methods, which I never quite understood. The mathematicians who (I suspected) were best qualified to do the modeling were in a different section, and to have the 'Automated Methods' in the name just because of the sensitivity analysis work seemed bizarre to me. Neither could I understand what a Roman emperor (Caesar) and the Greek gods' messenger (Hermes) had to do with intelligent machines, until I realized that somebody must have gone through great agony to omit an ' $a$ ' from the emperor's name and to add an 'I' to the messenger's name in order to come up with acronyms that make some sense when they are spelled out [Center for Engineering Systems Advanced Research (CESAR) and Hostile Environment Robotic Machine Intelligence Experiment Series (HERMIES)] and at the same time are easily remembered by a broad number of people.

When I joined, the Section was in a period of transition from what can be better explained by my predecessor to what we are doing now, which is basic and also applied research in intelligent systems including those that have humans 'in the loop.' Our work involves a substantial experimental component. We make mobile robots do things that may sometimes appear rather elementary, such as getting from $A$ to B without bumping into things or people, learning from examples, manipulating simple control panels, cleaning up simulated spills on the floor, performing surface contamination assessment on 55-gallon storage containers, and so forth. It turns out that these tasks represent substantial challenges when one tries to execute them reliably with an intelligent robot. These machines need to 'see' and understand their surroundings, make decisions, move about, and use manipulators ('robotize' for arms) to do useful things. At the same time they need to keep their human supervisors (and, upon request, operators) tuned in to what they are doing. For human operators we build mental models of complicated systems such as a nuclear power plant, and we strive to verify these models by using sophisticated equipment with which we can do things like tracking a subject's eye movements during a complicated cognitive process. There is definitely no shortage of difficult problems at various levels of inquiry, from basic research in several so-called 'enabling' technologies such as multisensor fusion, embedded parallel computing, adaptive control, machine learning, redundant mobile manipulator systems, human-machine interfaces, and many others, to issues in integration of these technologies into reliably working prototype machines.

My highest respect goes to the initiators of this research effort and to the inventors of the corresponding acronyms. Their vision, clairvoyance, and relentless enthusiasm and perseverance were truly exceptional. New programs and developments within DOE during the past three years have shown that basic research in intelligent machines and robotics is an important part of the agency's mission. How else will we be able to continue to meet in the long term the "safer, faster, cheaper" objectives in solving energy-related problems (e.g., nuclear power, environmental restoration and waste management). 
Long before robotics and intelligent systems became an important activity for DOE, CESAR research focused on the very topics that now appear in robotics technology development plans: a high degree of automation, unstructured or incompletely known workspaces, handling of unexpected events and emergencies, and man-robot synergy. Long before education and relations between national laboratories and universities became priority agenda items, CESAR was collaborating with universities, forming a consortium with the universities of Florida, Michigan, Tennessee, and Texas, proving the first successful research experience to many undergraduate students and hosting postgraduate students and research faculty from the United States, Europe, Japan, and South Korea.

Why has there not been growth of the CESAR basic research commensurate with these new priorities? To elaborate on the many reasons would be beyond the scope of this exposition. They include formidable competitors within the DOE complex, conflicting and also overlapping agendas at ORNL, and many others. In the 'new culture' parlance, a 'root cause,' however, can be summarized concisely as shortsightedness in the decision process that leads to research priorities and to the corresponding allocation of funds. I will not go into details on how Japanese and European programs were initiated in the mid-1980s with charters that could have been copied from early 1983 CESAR planning documents. Enough 'sour grapes'!

The fact is that we have in the Intelligent Systems Section a splendid assembly of interdisciplinary talent that has been cooperating successfully on many challenging fundamental research problems. The long-term, peer-reviewed CESAR program has enabled us to build an infrastructure that permits us to continue to tackle new and exciting problems such as multiple cooperating robots. We have also started to expand our intelligent systems and parallel computing work into applications that originate in the

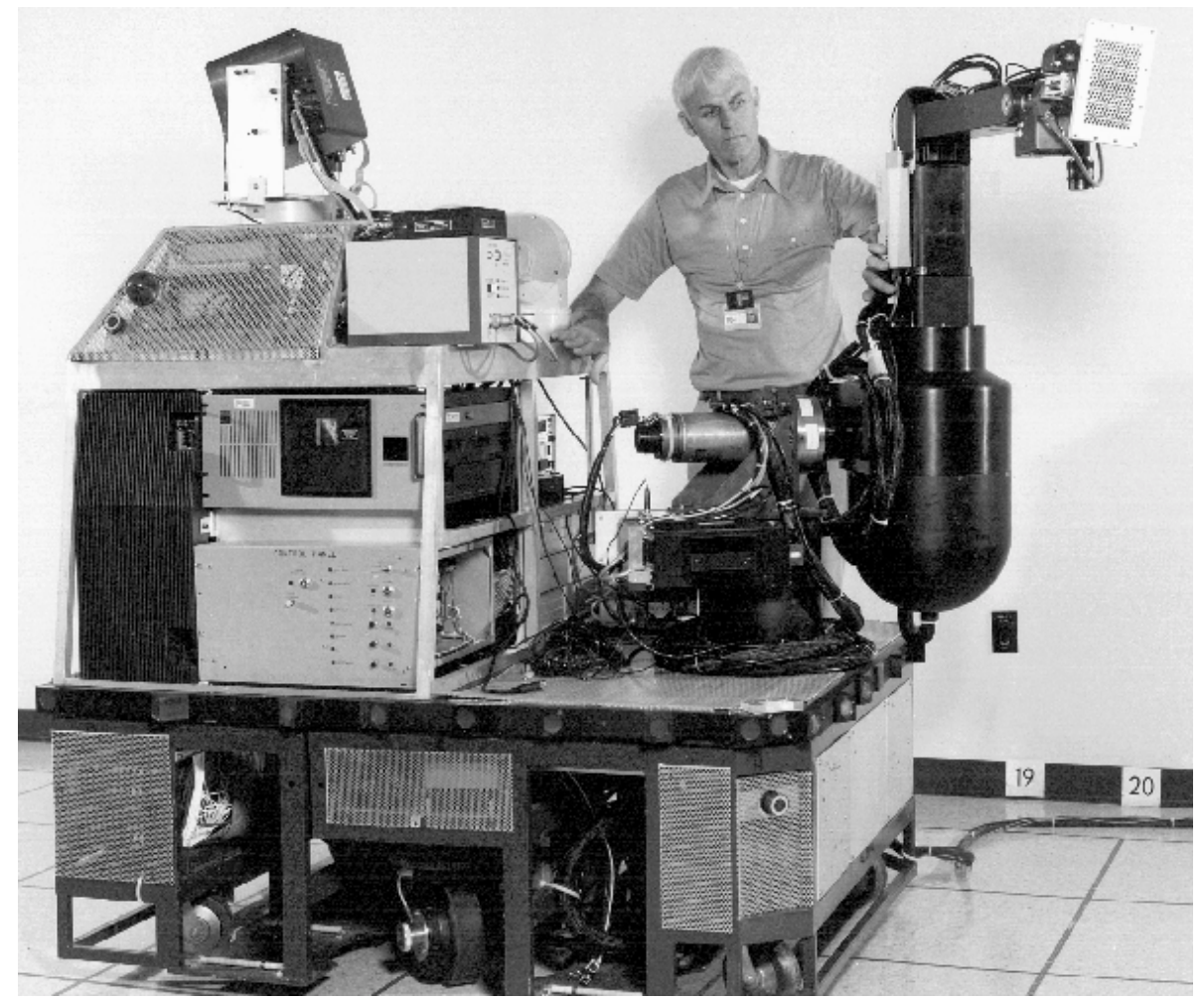

David B. Reisterexa mines HERMIES-III. ORNL 2879-91 
biomedical arena (pattern recognition for the Human Genome Program), and in high-energy physics (neural network algorithms for accelerator detector systems).

I mentioned that Chuck Weisbin's section was in a period of transition in the early- to mid-1980s, implying that we have completed the transition. This is true in the sense that work related to the pre-1983 era is no longer pursued in the Section. However, other transitions are constantly taking place. The Section's scientists and engineers shape our effort. We move on as we solve problems, discover new concepts, and create new opportunities.

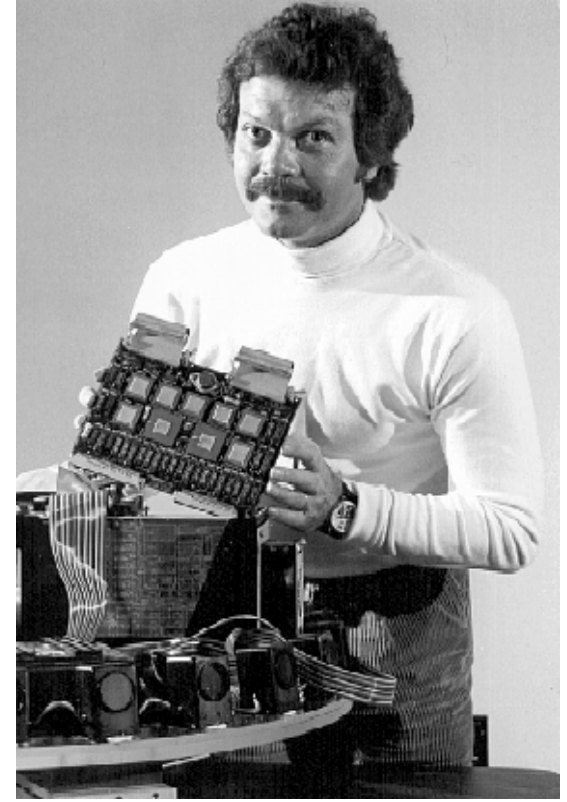

Francois G. Pin removes the sevenchip fuzzy logic control system from its slot on the mobile robotic platform. The cube-shaped objects ringing the platform are acoustic sonar sensors the robot uses to na vigate. ORNL 10315-90

\section{Changes and Trends in Ongoing Programs}

Several EPMD programs suffered financial constraints during the decade, but in all cases work continued as feasible. Brief descriptions of the programs and trends in each of the research areas follow.

\section{EPMD Carries More ORELA Responsibility}

The research performed at ORELA over the years was split evenly between the ORNL Physics Division (PD) and NPD/EPD, the former emphasizing studies of nuclear structure and neutron reaction mechanisms and the latter devoting more effort towards obtaining the cross sections needed for nuclear energy programs. Over the years the emphasis had shifted towards practical needs. In the fall of 1982, more than half of the ORELA research being reported through PD was transferred to EPD, including the transfer of ORELA Co-Director, Jack A. Harvey.

ORELA, said to be the prime nuclear data facility in the world, was used in this time period by collaborators from UKAEA/Harwell, the University of Vienna (Austria), CEA/CEN/Cadarache (France), and the National Institute of Science and Technology (NIST, formerly NBS).

\section{Nuclear Data Measurement and Evaluation}

The Nuclear Data Measurement and Evaluation Section under Peelle was responsible for one of the Division's older programs of research performed primarily at ORELA. The program was said to have retained "an admirable continuity even as the level of support decreased owing to dramatic changes in the U.S. fission reactor program." With the transfer of responsibility for nuclear data research from the DOE Office of Nuclear Energy Fast Reactor Program to the Office of Energy Research Basic Energy Sciences Program, the research program at ORELA suffered an overall loss of about $25 \%$ of its funding in a 2-year span.

The surge in operating costs associated in part with increasingly complex environment, safety, and health procedures had also resulted in loss of staff and precluded hiring replacement scientists and engineers for the future. However, ORELA continued to be used for data measurements, and staff members continued to improve the theoretical model codes, to analyze new data, and to perform research to refine and improve existing evaluated data. 
The Section played an important role in the effort to assemble the sixth version of the evaluated nuclear data file (ENDF/B-VI). This data file, derived from experiment and theory, was designed to provide the input data needed to compute nuclear system behavior. The data file was released worldwide in 1990. A large share ( $60 \%)$ of the data measurement and evaluation work to make this improved release possible can be attributed to EPMD staff members.

\section{Significant Cooperation with Others}

Much of the work related to nuclear data included efforts of many visiting scientists from universities and national laboratories in the United States and foreign countries. As noted throughout this historical record, EPD staff members joined in cooperative efforts to produce and refine needed nuclear data. Division leadership in these efforts was apparent from the beginning of the Cross Section Evaluation Working Group (CSEWG) of the BNL National Neutron Data Center. Members of the Division began to take an active role in the OECD Nuclear Energy Agency Nuclear Data Committee, an international cooperative effort established in 1982.

The transfer or retirement of key scientists and engineers from the ORELA program was a severe setback. The scientific strength of the Section was thought to have been reduced. The illness and later death of long-term staff member Gerard de Saussure was keenly felt throughout the Division. Section head Peelle (Division charter member) announced his intent to retire at the end of CY 1991, and D. C. Larson was selected as his replacement.

\section{Nuclear Analysis and Shielding (NAS)}

The Nuclear Analysis and Shielding Section was involved in a diversity of programs through the 1980s. Under successive leaders D. E. Bartine, D. G. Cacuci, and D. T. Ingersoll, NAS also included one of the oldest programs in the Division: development and testing of transport methods and crosssection data for application to the design of reactor shields. The TSF experimental phase of the program was said to have been undersupported, but shielding studies at TSF were revived through a joint program with Japan. The work reported on reactor core analysis was said to "reflect the past rather than the future due to curtailment of U.S. fission reactor programs."

NAS research areas included radiation transport methods (MORSE, MCNP, KENO-V) and data; radiation shielding applications; reactor analysis; analysis of reactor operating data; studies of nuclear weapons effects; and mathematical physics. New staff members included C. M. Haaland (nuclear weapons effects) and V. Protopopescu (mathematical physics).

During the 1980s the radiation transport and shielding activities devoted to advanced nuclear reactors such as liquid metal reactors for civilian applications focused on the joint U.S./Japanese TSF experiments and further development of TORT (3-D discrete ordinates) code system. Studies also continued for diverse nuclear and other systems.

\section{SSC, SDI, ANS and NPR Research}

The scope of the high-energy transport code (HETC) was extended to include energy ranges up to 20 $\mathrm{TeV}$ for use in future shielding and detector design calculations for the proposed Superconducting Super Collider (SSC).

Considerable progress was made on work in support of the Strategic Defense Initiative (SDI) such as development of improved hydrocode methods and algorithms for calculating the penetration of hypervelocity projectiles in solid and layered shield assemblies.

NAS supported the design of the Advanced Neutron Source (ANS) by performing neutronics calculations and developing a cross-section data library for use in ANS analyses. New applications 
included the New Production Reactor (NPR) and application of high-energy physics analysis to detectors planned for SSC.

\section{Fission Reactor Research}

Reactor shielding research during this period was largely associated with high temperature graphite reactors (HTGRs) and with LMFBRs to a lesser extent. There was renewed interest in the use of reactors in space applications. Another interest was in shielding data and methods available for designing shields for fuel reprocessing centers. In the latter cases it was not clear whether long-term funding would be available.

\section{Studies of Nuclear Weapons Effects}

The Division continued to study radiation transport through the atmosphere in problems related to assessing the doses received by victims of Hiroshima and Nagasaki. With Defense Nuclear Agency support, a team led by Bartine and Joseph V. Pace III joined with others in the U.S. Dose Assessment Program. NAS participation centered on calculations of radiation transport in an air-over-ground environment. A spin-off of these studies was further development of the three-dimensional discrete ordinates code system (TORT) by Wayne Rhoades.

\section{High-Energy Accelerator Shielding and Detector Research}

Work related to high-energy accelerator shielding and detector research continued to be performed at the request of outside groups. During this period, shielding calculations were carried out to aid in design of a proposed neutron oscillation experiment at the Oak Ridge Research Reactor and design of a neutrino experiment at the Rutherford Laboratory in England. Other calculations of the transport of high-energy particles supported a variety of research activities.

\section{Applied Physics and Fusion Reactor Analysis}

The Applied Physics and Fusion Reactor Analysis Group under Alsmiller pursued fusion reactor research and continuing research related to high-energy particle accelerators. Several fusion-related experiments were performed, but the program was reoriented when financial restraints caused integral experiments to be discontinued. Efforts to expand the high-energy work were not successful.

The Division's magnetic fusion energy program included integral experiments and their analyses, neutronics calculations in support of radiation damage studies and tritium recovery, and a variety of other design calculations. Principal investigators included Alsmiller, Robert Santoro, Chapman, Dick Lillie, Tony Gabriel, Tom Burns, and a number of cooperating individuals from the ORNL Fusion Energy and other divisions, and guests.

A 174-neutron-group activation cross-section data library (ORACT) was developed for fusion and fission reactor design studies.

\section{Nuclear Code Development}

There was some code development and use in various applications. VENTURE/DEPTH-CHARGE was used in sensitivity problems, and LEPRICON was improved and validated. E. M. Oblow released Version B of GRESS, a gradient-enhanced software system for performing sensitivity analyses. FERDO and FERD, unfolding codes used within Division experimental groups for several years, were documented and placed in the public domain. Dave Vondy and Tom Fowler continued implementation of a modular system of computer codes for nuclear reactor core analysis. 
COMMENTARY: “CREDO in the 1980s” by Helmut E. (Bill) Knee

In 1980, Knee became manager of the CREDO system and developed the basis for many of the computer-based reliability analyses methods used within the system. Knee and Alter, interested in expanding the data collection base beyond FFTF and EBR-II, met with PNC in Japan (primarily with Akira Watanabe) to discuss CREDO support of their liquid metal reactor component/system data needs for design of the MONJU reactor. In 1985, PNC and DOE entered into a 4-year memorandum of agreement wherein (1) DOE would give a version of CREDO, including all CREDO data, to PNC, and (2) PNC would collect data from their liquid metal facilities and share these data with DOE, and would provide $\$ 1.25 M$ of funding over the life of the agreement.

The CREDO staff remained relatively constant during the 1980s. Jay F. Manneschmidt completed and optimized the data base management system; Jim D. Drischler implemented a number of CREDO software packages; and Janice Arwood aided in archiving and management of various versions of the CREDO data 'store.' Jonathan Haire, of the ORNL Fuel Recycle Division led a number of reliability, maintainability, and availability studies using CREDO data. These studies were carried out by Brett $\mathbf{L}$. Humphrys, Karen H. Koger and Phillip Leonetti, Co-op Student supporters of CREDO in the late 1980s.

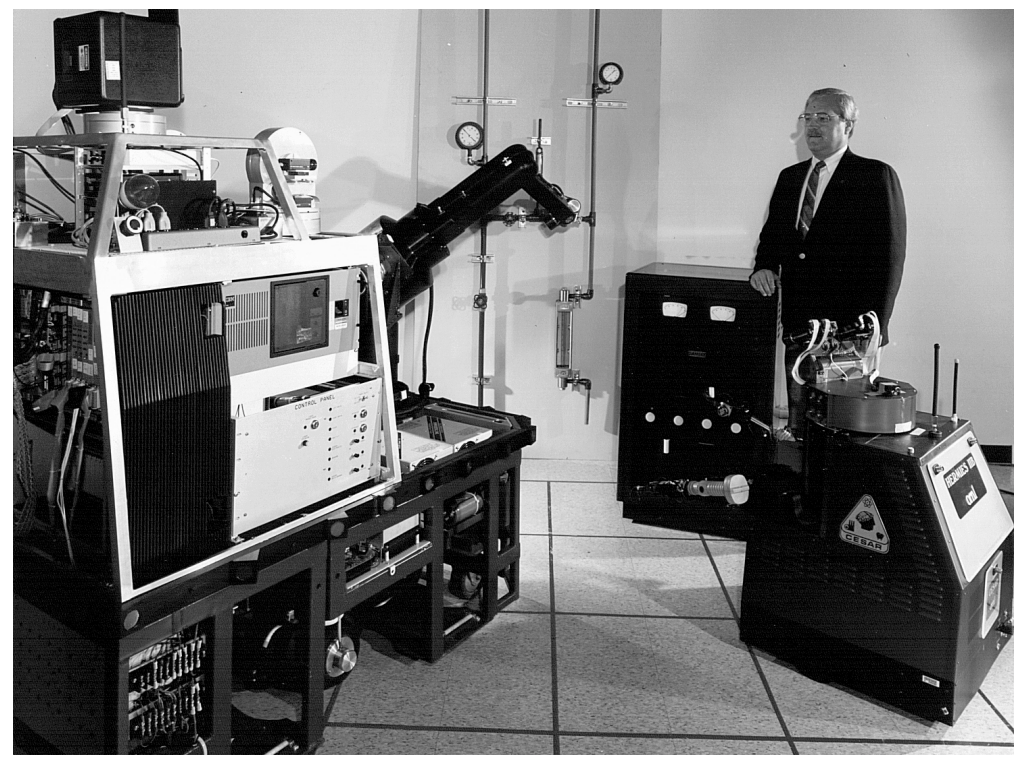

Philip F. Speltinsp ec ts HERMIES-IIB and HERMIES-III in the CESAR laboratory. ORNL 3521-89
ORNL program managers, involved with CREDO throughout its history, included Bill Harms, Mario Fontana, Uri Gat, John Wantland, and John E. Jones, Jr. PNC also sent staff members to ORNL, each for at least a 1-year assignment, to assist in the CREDO effort. These included Keiichi Setoguchi, Eiji Komori, and Kenichi Kurisaka.

In 1989, Mark S. Smith was appointed CREDO program manager. Smith and Knee renegotiated a 4-year follow-on memorandum of agreement between DOE and PNC. This agreement, based on the original terms, included \$2 M of new CREDO funding for 1989-1992. During this time period, CREDO also provided data and analyses to support the probabilistic risk assessments being conducted for FFTF, EBR-II, and the SP-100 space reactor.

In Japan, CREDO data were successfully utilized to support the design of PNC's MONJU liquid metal reactor. In 1992, the last year of the agreement between DOE and PNC, MONJU was approaching power operations.

The CREDO system was archived in 1993 after having been developed successfully and run at ORNL for more than 16 years. 


\section{Reliability and Human Factors}

The Reliability and Human Factors Group continued work initiated in the late 1970s, although NRC was de-emphasizing research in these areas. The Safety-Related Operator Action (SROA) Program was established in FY 1983 to provide a data base to support development of criteria for safety-related actions by power plant operators. Other activities included development of a Maintenance Personnel Performance Simulator (MAPPS).

The Group, led by Knee in the late 1980s, was renamed 'Cognitive Systems and Human Factors' and moved from NAS into the Mathematical Modeling and Intelligent Control Program.

\section{COMMENTARY: “Cognitive Systems - A New Focus in EPMD” by Helmut E. (Bill) Knee}

The origins of cognitive systems and human factors research in EPMD can be traced to the late 1970s when analyses of CREDO data indicated that a significant portion of the events involved either human error or were propagated by human involvement. The NRC sponsored a program whose results indicated that operators may not have sufficient time to adequately respond to certain reactor events. The report of this finding, published shortly before the Three Mile Island accident, prompted the NRC to provide additional funds to study human performance in nuclear facilities through collection of human performance data from various nuclear training simulators. This influx of new work underwrote establishment of the Reliability and Human Factors Group, which encompassed both CREDO and the NRC human factors work.

The Safety-Related Operator Action (SROA) program formed the initial focus of human factors research. The program (1978-1986) collected human performance data from operators going through exercises at various $P W R$ and BWR training simulators. The database created by this research was significant; is still referenced in terms of supporting the identification of skill-based, rule-based and knowledge-based behavior and utilization of symptom-based, as opposed to event-based, procedures. The SROA program introduced the use of task analyses and adapted the military's instructional system development/systems approach to training for use in the nuclear industry. Howard Gray was hired to manage the program. Other staff members supporting the SROA work included Chuck J. Jorgenson (the Division's first psychologist) and Bill Hensley.

Because SROA data were plentiful and related to the performance of human operators, an NRCsponsored effort to develop a predictive model of human performance was initiated. This relatively simple model, entitled OPPS (Operations Personnel Performance Simulation), provided the basis for more than a decade of human modeling research that followed. Knee, CREDO program manager, was also the principal investigator in the first major SROA spinoff project. The project involved modeling team performance in nuclear maintenance activities to generate human error probabilities for use in probabilistic risk assessment studies. A significant result of the project (1980-1985) was the development of MAPPS. Human factors work (1980-1985) focused primarily on training-related research and behavioral modeling and was supported almost exclusively by the NRC. During this period, psychologists Paul A. Krois and Richard J. Carter were hired to conduct training-related research. 
In 1985, the NRC Human Factors Branch was dissolved, necessitating a significant effort to realign the funding base for the research. Two government agencies were successfully approached: the Department of Defense (initially the U.S. Air Force (USAF)) and the DOE Advanced Controls Program. The USAF contract involved research in support of a hazardous waste and materials training program. The DOE project required development of a human cognition model for operators working in the control room of an advanced reactor. Jack $\boldsymbol{C}$. Schryver joined the team and became the principal architect of a model entitled INTEROPS (Integrated Reactor Operator/System), a tool for studying the allocation of function issues in control room design.

In the mid-1980s, psychologist Michele Terranova was hired to conduct research for the U.S. Navy. Paul Haas, founder of the R\&HF Group, left ORNL in early 1987, and Bill Knee assumed leadership responsibilities.

The R\&HF Group was initially established as an independent entity within the Division. It did not fit well with the traditional shielding/neutronics research of the Division and worked independently of other organizational units for several years. In 1988 the group was administratively placed in the Nuclear Analysis and Shielding Section (NAS), headed by Caccuci at that time. In 1989, the group was again moved - this time into the Mathematical Modeling and Intelligent Control Section headed by Weisbin. The group name was changed to Cognitive Science and Human Factors (CS\&HF) to emphasize a focus on the cognitive sciences and to de-emphasize their reliability roots. For the first time, the group was able to focus solely on human factors research. Also in the late 1980s, Philip F. Spelt, a psychologist on leave from Wabash College to perform robotics-related research at ORNL, was invited to join the group. When Weisbin left ORNL in late 1989, Reinhold C. Mann was appointed Section Leader. The organizational change gave a new flavor to the human factors research, which involved a move towards

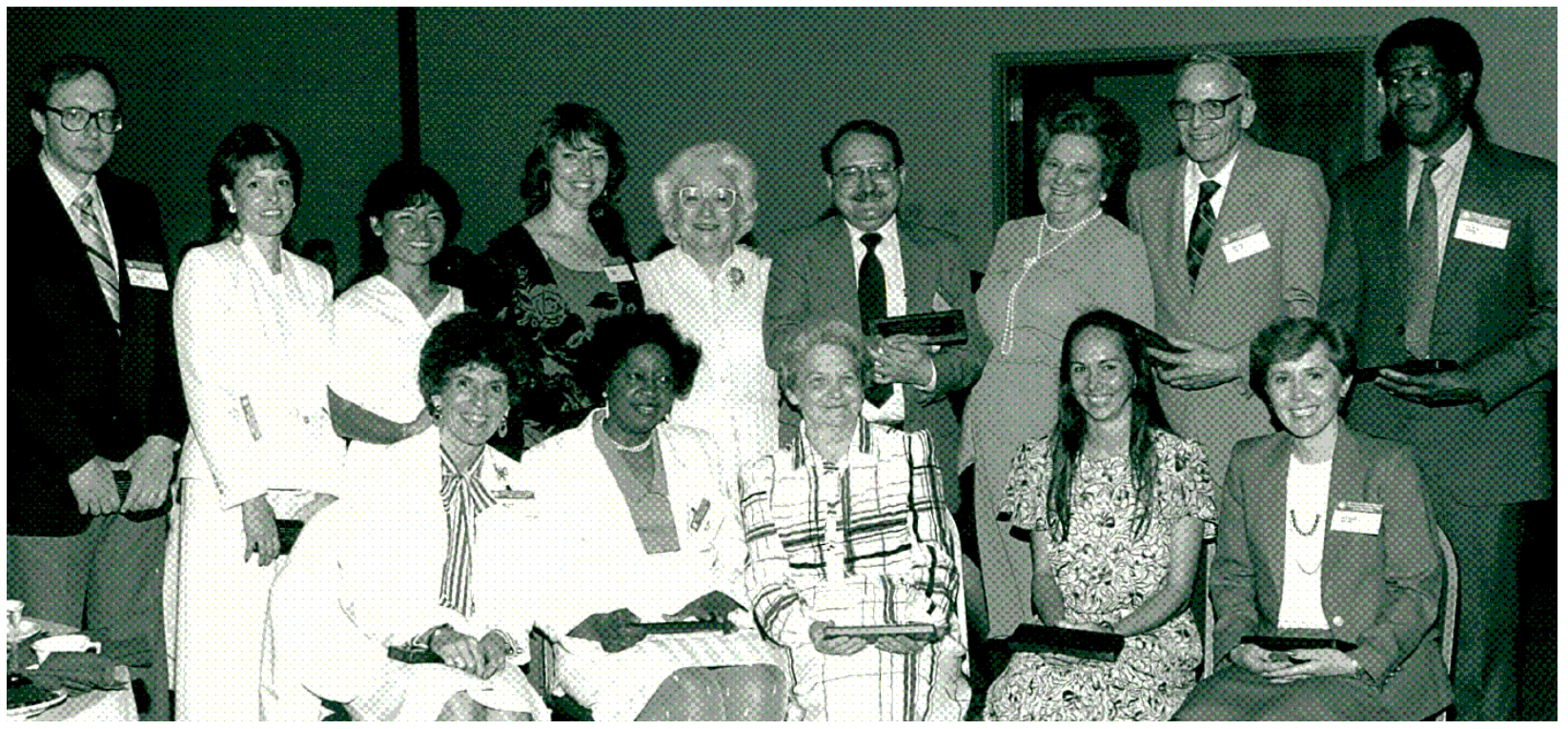

The RSIC staff received the Americ an Nuclear Society's Radiation Protection and Shielding Division (RP\&S) 1987 Technic al Services Award, the first such presentation to an institution in the history of the RP\&SDivision. The presentation was made at the commemoraton of the 25th Anniversary of the center. The 1987 staff included (from the left, seated): Carol P. Coker, C. Marie Anthony, Ann B.

Gustin, Jennifer Bartley Mannesc hmidt, Nancy A. Hatmaker, (stand ing from the left) S. Noel Cramer, Dawn C. Human, Bemadette L Kirk, Alice F. Rice, Betty F. Maskewitz, Robert W. Roussin, Betty L Mc Gill, David K. Trubey, and John E White. Pla ques were also fumished to former staff members who helped to build RSIC s reputation for exc ellence.

ORNL 3344-87 
artificial intelligence (AI) technologies. The group's name was again changed - to Cognitive Systems and Human Factors.

The change in emphasis attracted new research staff members. Ed Oblow and Chuck W. Glover initiated research in the machine learning area. Gunar E. Liepins transferred from the Energy Division to support machine learning research and to pursue genetic algorithm research. Pedro Otaduy, a former Wigner Fellow, brought expertise in the area of supervisory control.

Research in the late 1980s and early 1990s moved toward experimental research. One unique area of research funded by DOE is concerned with the utilization of eye-gaze data (where a computer user is looking on a CRT screen, pupil dilation, transition rates, etc.) for interface control. This research involves prediction of an operator's interface control intent from clues within the eye-gaze data set. This work is being pursued by Schryver, and was carried out by Joseph E. Goldberg while on sabbatical from Penn State University.

As nuclear-related research declined in the early 1990s, the U.S. Department of Transportation became a major sponsor of a study of human performance in advanced vehicles and training in advanced traffic management centers. Another significant effort, initiated in the early 1990s, was human factors engineering design support for the Advanced Neutron Source.

The following students have supported the human factors research within the group: Jill A. George, Colleen Thornton, Diane Hartley, Inga Treitler, Kent Van Cleave, Bob Timmerman, Leonard Palko, Brett Humphreys, Rupy Sawhney, Julie Davis, Eric Saltzen, and N. R. Desa. University staff members also made contributions to the human factors research: Bruce Coury (University of Massachusetts), Wayne Jones (Memphis State University), and Stephen Hockaday (California Polytechnic State University).

\section{Applied Risk and Decision Analysis}

The program of the Applied Risk and Decision Analysis Section led by Flanagan was largely funded by NRC to study various risks to nuclear power plants (e.g., risk posed by floods, fires, accidents, etc). Most of this work was performed by subcontractors under Division management. The program was phased out when Flanagan left the Division.

\section{Engineering Physics Information Centers (EPIC)}

The EPIC management umbrella covered five centers at the end of the 1970s: RSIC, TDMC, CDIC, COMET, and BCTIC. CDIC, sponsored by the DOE Office of Basic Energy Sciences Carbon Dioxide Research Division, was transferred in FY 1984 into the ORNL Environmental Sciences Division, where it continues to be supported by DOE. Work in COMET was suspended with the phaseout of the energymodeling program. BCTIC was transferred into a clinical environment at Vanderbilt Medical Center in Nashville, Tennessee.

EPIC work in the 1980s focused on efforts to improve communications on a worldwide basis through use of new technology (e.g., electronic mail, telex, data base services, and floppy disk transmittal). The in-house computer (DG Eclypse) was upgraded from S/130 to MV/4000. In conformance with trends in computer usage, EPIC began collecting and packaging computer codes designed to run on personal computers.

EPIC NRC-sponsored programs 'waxed and waned' during the 1980s. The RSRDR database was returned to INEL in Idaho, while the TDMC effort lasted throughout the decade. 


\section{The Technical Data Management Center (TDMC) in the 1980s}

The NRC TDMC program was established in 1976 to perform the following subtasks: (a) technical data management in the "open code/data package" concept; (b) enhancement, development of new options and extensions, standardization, and documentation of selected computing technology; (c) technical data generation, validation, and documentation; and (d) publications in support of TDMC tasks and other NRC technical data management programs.

Several code systems and newly developed routines were implemented on NRC computers, documented and made generally available during TDMC operations. The subtask (c) to generate gammaray attenuation coefficients and buildup factors for engineering materials was completed. Following technical review, the data package was accepted as a standard (ANS-6.4.3).

As a result of an NRC internal reorganization in the late 1980s, TDMC was discontinued after more than 10 years of operation. At the conclusion of this program in 1988, John E. White, who had carried much of the TDMC work, was appointed RSIC Data Coordinator.

\section{RSIC Fared Well Throughout the 1980s}

Through the decade, RSIC gradually comprised an increasingly larger fraction of the Division's shielding program and served the international scientific community as a technical institute for shielding design and analysis. This was recognized on the occasion of RSIC's 20th anniversary (FY 1983). It was celebrated locally, nationally, and internationally at a gala luncheon in RSIC's honor during the Sixth International Conference on Radiation Shielding (ICRS) held in Tokyo May 16-20, 1983.

RSIC's quarter century of effort was recognized by the American Nuclear Society through its 1987 Radiation Protection and Shielding Division Technical Service Award, the first presentation to an institution. Each RSIC staff member received an ANS Technical Service Award certificate.

RSIC data activities included continuing support of the Cross-Section Evaluation Working Group (CSEWG) in which RSIC Director Roussin chaired the Methods and Formats Committee.

\section{RSIC Gains New Sponsors}

RSIC gained new sponsors during the 1980s: (1) the DOE Office of Military Affairs (OMA) for coverage of SDI reactors and space systems; (2) the DOE Office of Waste Management; and (3) the DOE Office of Naval Reactors. RSIC's coverage of the information and technology needs of the weapons laboratories (Los Alamos, Lawrence Livermore, and Sandia) was funded (1983-1986) directly by these institutions. In FY 1987 blanket coverage by DOE/OMA was given directly at the request of the weapons laboratories.

In FY 1990 RSIC received the largest number of requests in its history (3832), 12\% higher than in FY 1989. This increase was attributed largely to environment, safety, health, and defense programs within the user community.

\section{International Activities}

RSIC's long-term cooperation with and service to the international radiation transport and shielding community was assuming increasing importance. Reciprocity had become real; the major part of incoming information and technology in the 1980s was from foreign contributors, with France and Japan in the lead.

Collection of information and technology and promotion of technical information exchange remained the prime purpose of the RSIC “orientation" visit. During the early years, RSIC leaders focused on the United States and western European nuclear research institutions; in the 1980s focus was on Eastern Europe and the Far East, where several orientation visits were made to nuclear research institutions during the 1980s and early 1990s: Japan, South Korea and Taiwan (1980); Japan (1983); Peoples 
Republic of China (1983, 1986, 1987 and 1990); South Africa (1988); Poland, USSR, Bulgaria, and Greece (1989); Bangladesh, China and Japan (1989); Japan and the Philippines (1990); USSR (1990); and Russia (1991 and 1992).

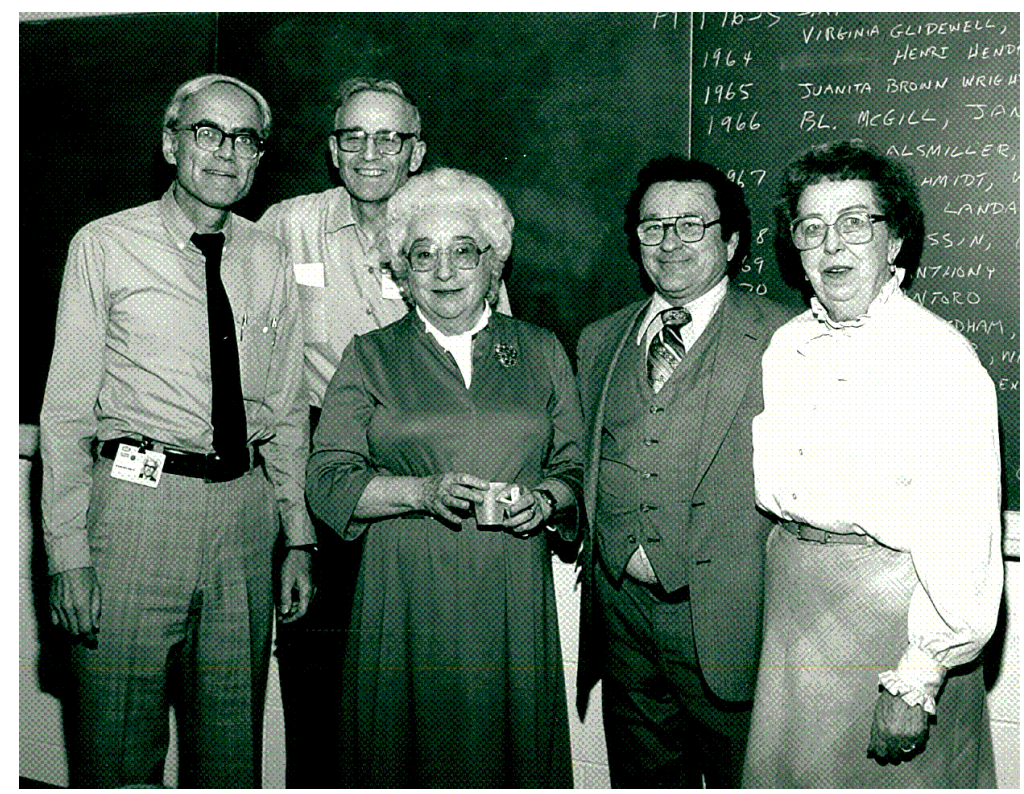

NPD/RSIC leadership c elebrates 20 years of continuous service (1962-1982) (from left): Fred C. Maienschein (NPD Director), David K. Trubey (shield ing specia list), Betty F. Maskewitz (RSIC Director), S. Keith Penny (former RSIC Director), and Rebecca Rickman (NPD Secretary). ORNL 2959-83

RSIC Staff Changes - Several long-term staff members retired during the 1980s, requiring several adjustments in information analysis operations: Comolander, Gurney, and Landay (1980), Hendrickson (1985), Maskewitz (1988), and Gustin (1989). John White joined the staff in 1981 and S. Noel Cramer in 1986.

In 1988 two foreign guests were assigned to RSIC: T.Y. Lee, Korean Atomic Energy Research Institute, 1-year; and IAEA Fellow, Mafiqur Rahman from Bangladesh, 6-months.

\section{Conferences and Seminar-Workshops}

The Sixth International Conference on Radiation Shielding (ICRS) was convened in Tokyo, Japan May 16-20, 1983 with RSIC and other EPD participation. Current trends in shielding research led to a broadened technical program and a slight change in the name of the series; the word "Reactor" was replaced with the word "Radiation." Roussin and Maskewitz attended the 7th-ICRS in Bournemouth, England in September 1988. Planning was initiated for the 8th-ICRS to be held in the United States in 1994 in Arlington, Texas.

RSIC organized three seminar-workshops during the 1980s:

Theory and Applications of Monte Carlo Methods featuring TRIPOLI, cosponsored by the French CEA/CEN/Saclay April 1980; ORNL/RSIC-44

MORSE-CGA Workshop, cosponsored by EPD and CSD staff members, June 17-29, 1985

Modular Code System for Performing Standardized Analysis for Licensing

Evaluation, SCALE, Cosponsored by ORNL/C\&TD and the USNRC, April 1986. 


\section{Division Management and Other Personnel Changes}

December 1, 1990 Robert C. Ward became EPMD Director when Fred C. Maienschein retired after having served ORNL programs for 40 years including 25 years as NPD/EPD/EPMD director. R.F. Sincovec replaced Ward as Mathematical Sciences Section manager.

R.C. Mann was appointed manager of Intelligent Systems replacing Weisbin, who resigned IN 1989. Roussin, RSIC Director since 1983, had assumed all EPIC administrative responsibilities upon the retirement of Maskewitz.

Bartine left the Division during the decade; Cacuci replaced him and, in turn, was replaced by Ingersoll as leader of Nuclear Analysis and Shielding. Haas led the Reliability and Human Factors area in the early 1980s and was replaced by Knee near the end of the decade. Ward, who had joined the management team as a section head, was elevated to Associate Director September 29, 1989.

Cloyd O. Beasley joined the Division as Operations Manager with primary responsibility for overseeing environmental, safety and health compliance. Establishment of this position followed the October-November 1990 Tiger Team audit, after which it was expected that emphasis on these issues would continue to increase.

In November 1987 James L. Lucius died. A 32-year CSD employee, Lucius worked on NPD/EPD/EPMD programs, particularly in development of AMPX and FORSS. Also noted is the death in 1988 of Division charter member James H. Marable, who retired in 1983.

The March 1992 Division roster included 128 individuals as EPMD staff members, a number which has changed little through the years. The Personnel Changes section of ORNL-6682 lists 18 new additions to the scientific staff (mainly in Mathematical Sciences) and 8 additions to the administrative and technical support staff.

Four Division charter members retired after more than 30 years of service: Maienschein, Abbott, Chapman, and Trubey. Other members of the long-term scientific staff who retired included: $\mathbf{O}$.W. Christian, Gwin, Macklin, Maskewitz, Perey, and Uppuluri. Administrative and technical support staff losses included retirees Marie Anthony, 'Steve' Howe and L.C. Whitman.

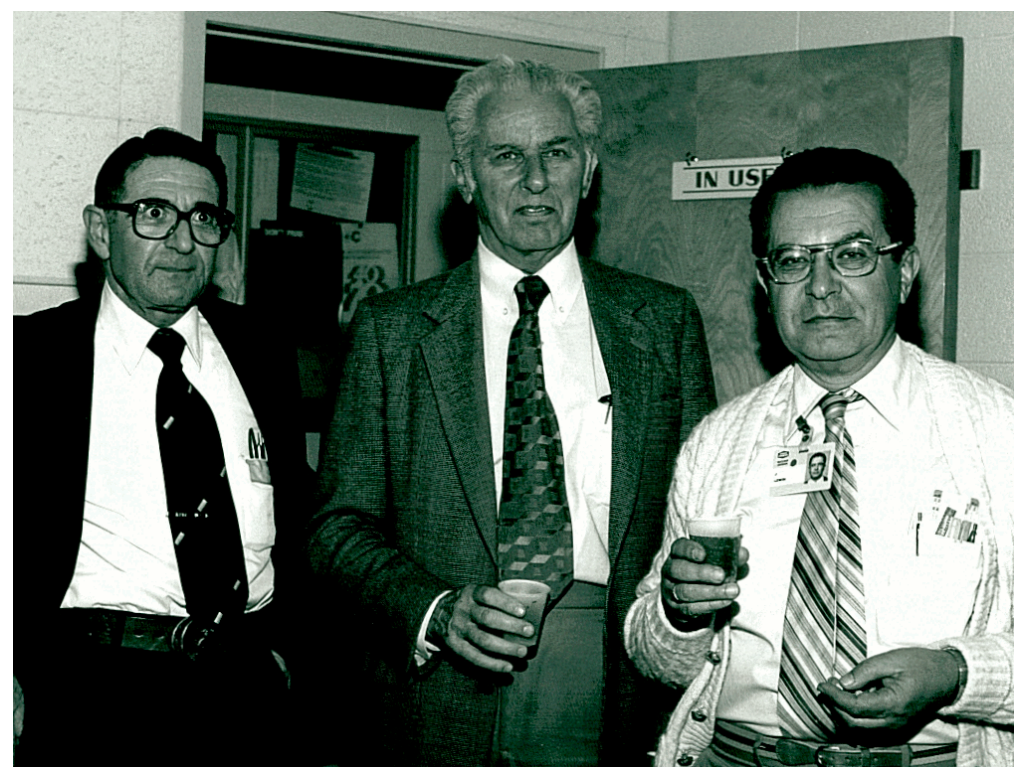

Walter N. Zobel (physic ist, ANPD/NPD c harter member), François Kertesz (consultant) and Joseph Lewin (long-term NPD staff member) join in celebrating RSIC's 20th anniversary in 1982. Each of these technical specialists ma de contributions to RSICs information and technology data bases while at ORNL ORNL 2971-83

A surprising number of individuals received guest and short-term appointments (116), and many others participated in division programs and projects as follows: graduate students (31), ORAU Programs 
(49), Teacher Research Program (2), UT Postdoctoral and other programs (5), NSF Undergraduate Research Program (2), One U.S. Military Service Academy Research Associate, and various student programs (11). It is obvious that the Division's outreach extends far beyond the local facilities.

\section{Other Changes and Challenges}

-Alvin W. Trivelpiece replaced Herman Postma as ORNL Director near the end of the decade with no observable impact on the Division. However, other changes did make a difference.

Some unusual challenges strongly affected the Division's work. The continued wait for the restart of the Tower Shielding Facility (TSF), closed since March 1987, delayed JASPER, the joint U.S./Japan reactor-shielding program. The overriding DOE-wide concern with environmental, safety, and health problems, which required increasing expenditure of division resources (funds and staff time), was considered to have significantly reduced EPMD research productivity. The housing of the Mathematical Sciences Section at the remote site at Y-12 caused increasing difficulties. A new building at ORNL, planned to ease this situation, was completed and occupied in the early 1990s. 


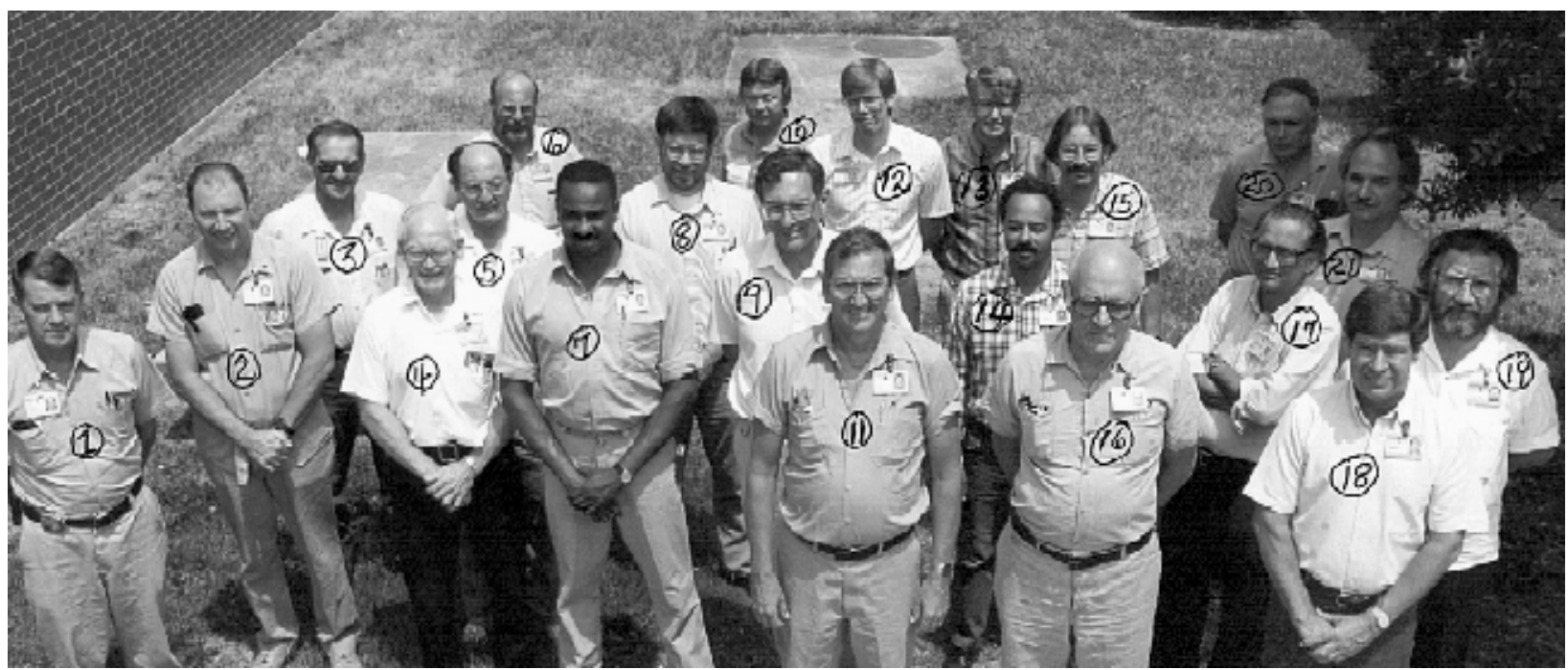

The ORELA operations staff and managers pose for 1988 photograph: (1) Ken Wallace (HPD), (2) Doug Collins, (3) Dick Green, (4) Jack Harvey, (5) Bob Spencer, (6) Ron Winters (7) Ray Simmons, (8) Duane Larson, (9) Bob Peelle, (10) Lany Weston, (11) Gene Zegler, (12) Brian Rooney, (13) Rex Ingle, (14) Dan Gamer, (15) Roger Macklin, (16) Bob Seals, (17) S. Pendyala, (18) John Cameron, (19) Lester Hulett, (20) Reg Gwin and (21) Jemy Schultz. ORNL 4646-88

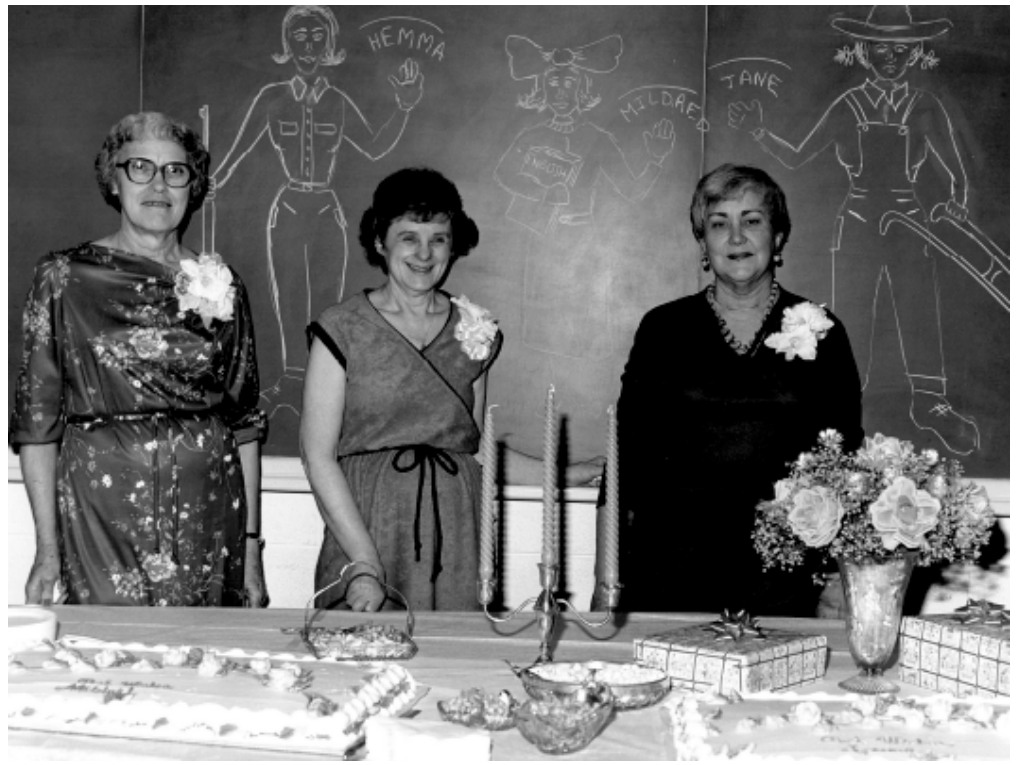

RSIC lost ea rliest staff members in 1980 on the retirement of (from left) Hemma Francis

Comolander (codes testing), Mildred W. Landay (sec retary), and Jane Gumey (SARI system ma intenance). ORNL 7589-80 
The original RSIC staff gathers to celebrate the 20th a nniversary, summer 1982 (from left): Betty F. Maskewitz, M. B. "Peggy" Emmett, David K. Trubey, S. Keith Penny, and Linc oln J ung. ORNL 2957-83
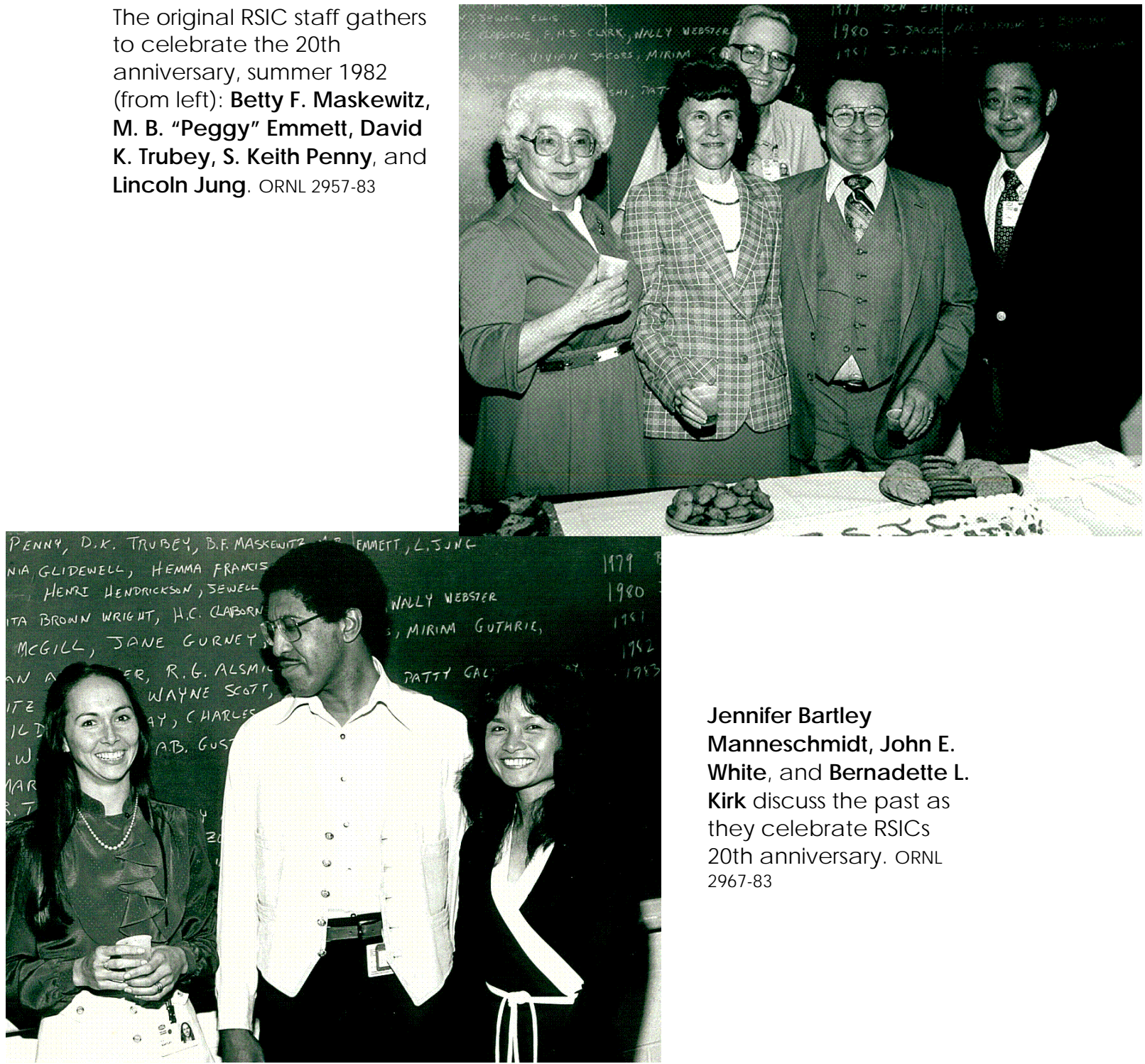

J ennifer Bartley

Manneschmidt, J ohn E

White, and Bemadette $\mathbf{L}$

Kirk disc uss the past as

they celebrate RSICs

20th a nniversary. ORNL 2967-83

Celebrating RSIC's 20th a nniversary - We covered space and high energy shield ing for the RSIC litera ture data bank (from left): Miniam Guthrie Kertesz, Frances and R. G. "Tut" Alsmiller. ORNL 2956-83

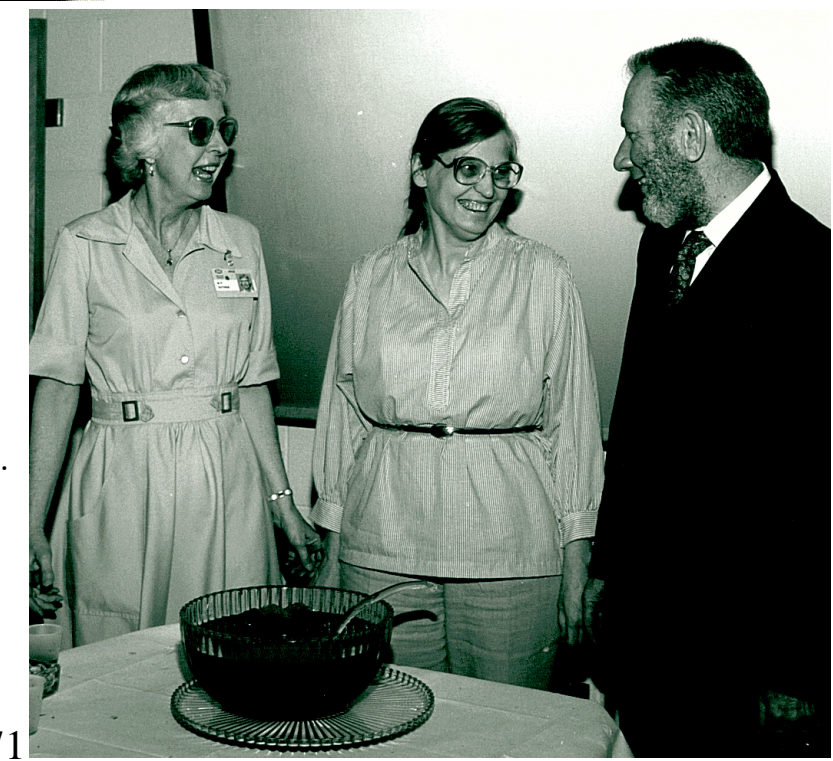




\section{WE ENTER THE NINETIES - AND LOOK TO THE FUTURE}

\section{The Tower Shielding Facility on Standby}

For the past 40 years the Tower Shielding Facility was home to specialized research projects involving radiation shielding. That role apparently has come to an end with the conclusion of the Japanese-American Shielding Program of Experimental Research (JASPER) in December 1992; DOE decreed that the facility be closed. TSF is currently on standby, awaiting final instructions for its demise.

It seems fitting that the last TSF experimental program was a jointly funded effort by DOE and Japan's Power Reactor and Nuclear Fuel Development Corporation. Begun in 1985, the joint program explored shielding challenges presented by sodium-cooled power reactors. At least one Japanese scientist/engineer was assigned to EPMD at all times over the 7-year project.

The TSF, with its Tower Shielding Reactor (TSR-II), is a shielding research facility that continues to be unique in the world. The TSF experimental programs have, for the past several years, been administered through the EPMD Nuclear Analysis and Shielding Section under Ingersoll, Holland, and Muckenthaler, and an operational team on the site deserve much credit for the many contributions to the knowledge base of radiation transport and shielding, both in the air and earthbound.

\section{Oak Ridge Detector Center (ORDC) Established}

An Oak Ridge Detector Center was established in January 1990 (T. A. Gabriel, Director) to facilitate ORNL involvement in development, design, and engineering of physics detectors for the Superconducting Super Collider. ORDC, operating in conjunction with other southeastern laboratories and universities, coordinates basic research support of general high-energy detection systems and specific development support for the Solenoidal Detector Collaboration and the L* Collaboration.

\section{MISSIONS, TRENDS AND BALANCES R. C. Ward, EPMD Director Looks to the Future}

Engineering Physics and Mathematics Division managers recently met to discuss and set near-term goals for the Division. They adopted the following as the Division's mission and driving forces.

The primary mission of the Engineering Physics and Mathematics Division is to develop and apply in concert the principles, methods, and data of the engineering, nuclear, mathematical, computational, and cognitive sciences to complex research problems of national importance. Partnerships with industry and universities are sought to develop and transfer technology that will improve the nation's competitiveness.

In the choice of projects, the Division seeks research and development activities that are technically interesting, fundable, relevant to ORNL's mission, and in which our contributions will be "world class." Tasks are favored that will produce hard scientific results, utilize unique 
ORNL resources, require cooperative multidisciplinary approaches, lead to publication in respected journals, and develop technology of interest to American industry.

For the most part, the above statement could have served as the mission of the Division for the past several decades. The major difference has been, and will continue to be, the areas receiving the emphasis. Certainly the nuclear sciences dominated the research interests of the Division until the 1980s when nuclear energy began to lose public support. Since that time, the engineering and computational sciences have experienced great growth and have become major research foci of EPMD. This trend is expected to continue for at least the next 4 or 5 years. But the nuclear sciences are expected to make a comeback at the turn of the century as alternative energy sources fade and environmental concerns are addressed.

During recent years Division staff members have been active participants in defining, planning, and implementing DOE's role in 4 Presidential initiatives: global change, high performance computing and communications, biotechnology, and advanced manufacturing. These initiatives rely very heavily upon the engineering and computational sciences. Strong emphasis on these national issues will be evident in our future research programs.

In addition, considerable effort will be extended toward transferring technology developed in our division to the industrial sector when appropriate. Cooperative research and development agreements (CRADAs) will become a significant activity and source of funding support.

Our vision for EPMD includes maintaining international leadership in our core competencies and

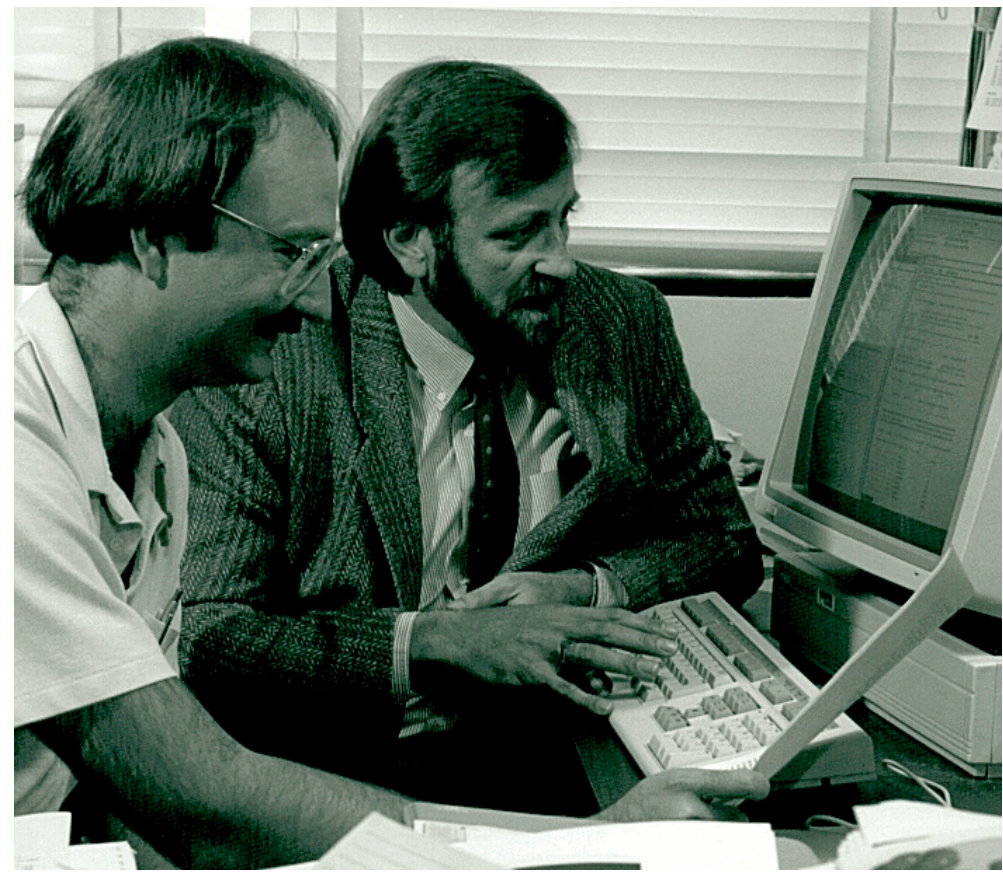

Al Geist (left) and Malcolm Stocks disc uss the advantages of using the new Paragon computer for a lloy design. ORNL 9121-90 forming interdisciplinary teams to produce unique capabilities for innovative approaches to complex problems of scientific and technical importance in cooperation with both industry and universities where possible. We want every researcher in the engineering, nuclear, mathematical, computational and cognitive sciences to feel that his or her career is not complete without research experience in EPMD.

COMMENTARY: "Notes On the ORNL Applied Physics Division, Which Became the Neutron Physics Division, Which Became the Engineering Physics Division, Which Became the Engineering Physics and Mathematics Division" by R. G. (Tut) Alsmiller, Jr.

Bliz's (E. P. Blizard) decision that the fields of high-energy shielding and space shielding were ripe for exploitation, and his and Clay Zerby's success in getting funding for programs in both fields was a milestone for the Division. The high-energy shielding program has continued for more than 30 years and is still continuing. The Division has had a significant part in the shield design of every major accelerator constructed in the United States in the past 30 years. Of course, accelerator shielding methods have 
improved enormously over the years, and many of the advancements resulted from the work of the Division. If the SSC continues to be funded, the high-energy calorimeter design program, which up to now has been part of the high-energy shielding program, promises to become a very large program.

Space shielding did not last as long as accelerator shielding, but the work culminated in production of a Space Shielding Handbook, published as ORNL/RSIC-35, that is still in use today. The fact that there was an experimental component of the space shielding program was due to Bliz's influence and made the work of the Division unique among space shielding groups in the United States.

Bliz's death had a profound influence on the Division because the entire Division was of his making; without taking anything from later management, the Division without Bliz was never the same.

The construction of ORELA provided the Division with a neutron source that was unique at the time and enabled the Division to be in the forefront of cross-section development for many years.

Our efforts in the "War on Cancer" was a direct result of our high-energy particle transport work and provided interesting work for several members of my group for several years.

Alvin Weinberg's retirement as ORNL Director was very significant for both the Laboratory and the Division. It was due to external circumstances as well as to Weinberg's retirement, but in many respects the Laboratory and the Division have never been the same as in the earlier years when they were being influenced by Weinberg.

The retirement of Walt Jordan and Art Snell also had lasting effects on the Division since they were both good friends of the Division and able administrators.

I personally had little to do with FFTF work, but it was very important work and certainly aided in giving the Division an international reputation.

Some years later, when Fred Maienschein and I were trying hard to obtain work in the shielding of fusion devices, our success in obtaining the Fusion Integral Experiment Program was a direct result of EPD work on the FFTF. I was told that the people in Washington who had seen the EPD work on the FFTF wanted the Division to "do the same thing for the fusion program."

The demise of the Clinch River Breeder Reactor (CRBR) and the decline of the nuclear power program in the United States meant that what had been a major element of the work of the Division for many years would be greatly reduced. However, the New Production Reactor and Advanced Neutron Source programs may mean that once again the Division will have a goodly amount of work in reactor design and shielding.

Some comment on the briefforay of the Division into economic modeling is in order. The work was creditable, but after it was over, I, and I think the Division administration, felt that the Division should in the future avoid straying quite so far from physics and nuclear engineering.

With the retirement of Fred Maienschein and a new division director and with extensive programs in applied mathematics, robots, and artificial intelligence, the Division is quite different from what it was in past years, but it will, I am sure, continue to do outstanding work and be a vital part of the Laboratory.

\section{COMMENTARY: “Highlights Through the Years,” by Robert W. Peelle (with contributions by others)}

Division history should include a set of highlights - developments that really made a difference to the Division, ORNL, and perhaps to global development of science and technology. I'm not sure that I

have the breadth of view to do that, particularly because communication across the world was always 
strong enough that major activities at ORNL mirrored to some extent developments in all leading laboratories. However, I'll start a list to which others may add, recognizing that the degree of uniqueness of divisional achievements is variable, and that no major project can go far unless its value is broadly recognized.

The following developments are highlighted:

- The imagination that led to development of the LTSF, BSF, and TSF as integral shield test facilities to challenge and guide the findings of analysis. These integral shielding facilities always seemed to be the most productive. (Peelle and Ingersoll)

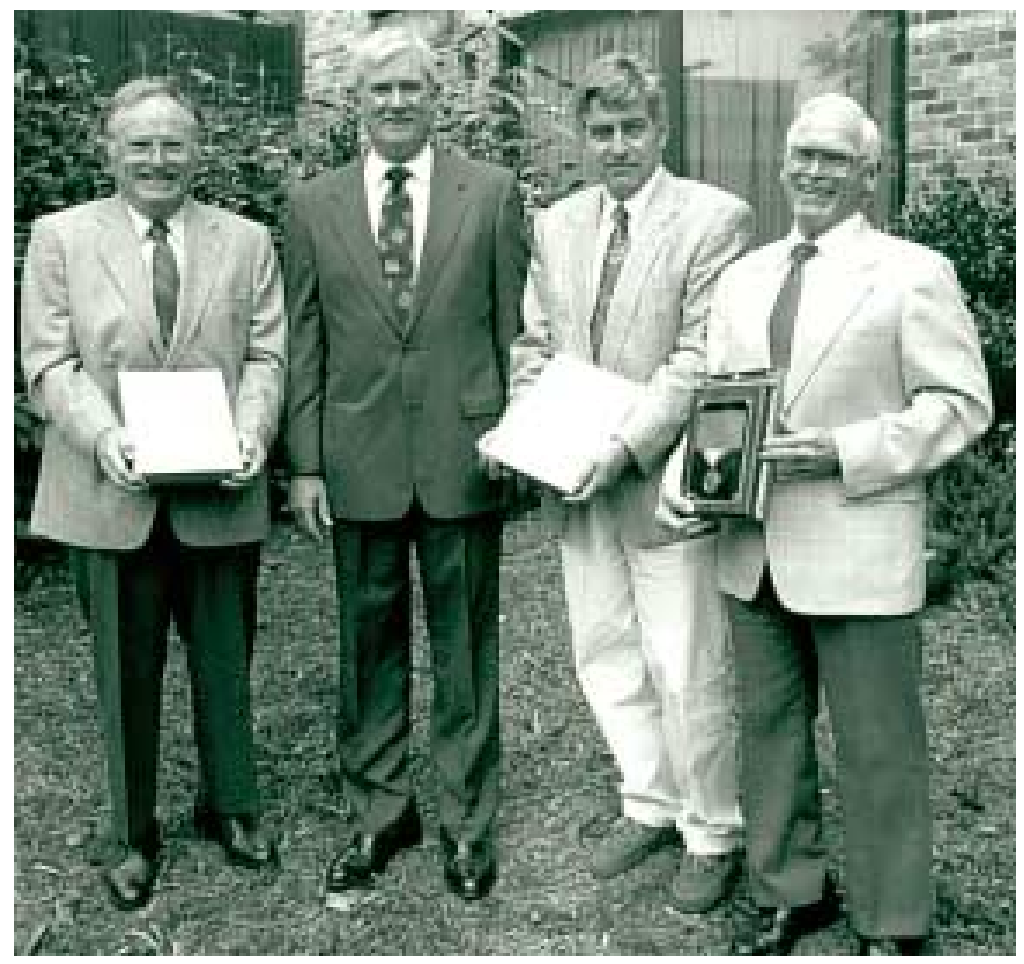

Team lea der Jack Havey (right), together with team members, Nat Hill (left) and Peter Riehs of Austria (2nd from right) pose with Al Tivelpiece (ORNL Director, 2nd from left) who presented them with a Martin Marietta Energy Systems, Inc., Tec hnic al Achievement (TA) Award for the first mea surement of the neutron polariza bility, J une 1992. Harvey and Hill also received TA awards for being on the team led by H. Mook (Solid State Division) which observed the first evidence of phonon softening in high-temperature superconductors. Both mea surements were made at ORELA. ORNL 5312-92

- Establishment of the Critical Experiment Facility that provided benchmark-quality results. Note that the Gwin-Magnusson series of critical $\mathrm{U}-\mathrm{H}_{2} \mathrm{O}$ solutions continue to challenge reactor physicists. (Peelle)

- Serious Math Panel efforts initiated by Householder to grapple with efficient numerical analysis methods as digital computers gradually became available. (Peelle)

- Robert R. Coveyou's development of random number generation for Monte Carlo and other methodology (1950-1960s); Coveyou's emphasis on computer generation of pseudo-random numbers, coupled with David Irving's programmed algorithms, developed technology still in use today. (Dickens and Cramer)

- Development of Monte Carlo and discrete ordinates techniques capable of handling shield analysis problems, and learning how to study the results of these analyses. While we had an early role in Monte Carlo, our later work on discrete ordinates resulted in computer codes that became world standards. (Peelle and Ingersoll)

- Theoretical and experimental work in the 1960s by Perey and others, which elucidated and verified the optical model of nuclear scattering. (Dickens) 
- Measurements at the Oak Ridge Isochronous Cyclotron (1960s) by Peelle, Bertrand and others, from which were first identified the giant quadrupole resonances. (Dickens)

- Development of neutron cross-section efforts at the ORNL High Voltage Facility, which together with facilities at Aldermaston, Argonne, Los Alamos, Duke, and elsewhere generated a tradition that credible fast neutron data measurements are possible and worthwhile. When initial efforts lagged, our neutron reaction group with Perey, Kinney, Dickens, and others, picked up. (Peelle)

- The vision of knowledge-sharpening and sharing that launched the Radiation Shielding Information Center. (Peelle)

- Broadening shield design analysis to accelerator and space projects, leading to diversity, breadth of viewpoint, and capabilities. (Peelle and Ingersoll)

- Founding ORELA, on the shoulders of earlier electron Linac efforts at Saclay and Harwell. "Let's take this nuclear data business seriously and develop adequate facilities." The effort was shared with the ORNL Physics Division. Again, "good" sponsors get lots of credit. (Peelle)

- Division staff contributions to ENDF formulation and extensions (e.g., covariances) through the years. (Dickens)

- Decay heat measurements (mid-1970s) which have been the de facto benchmark data for calculations ever since and are still state of the art; these measurements have impacted essentially all power reactor operations. (Dickens)

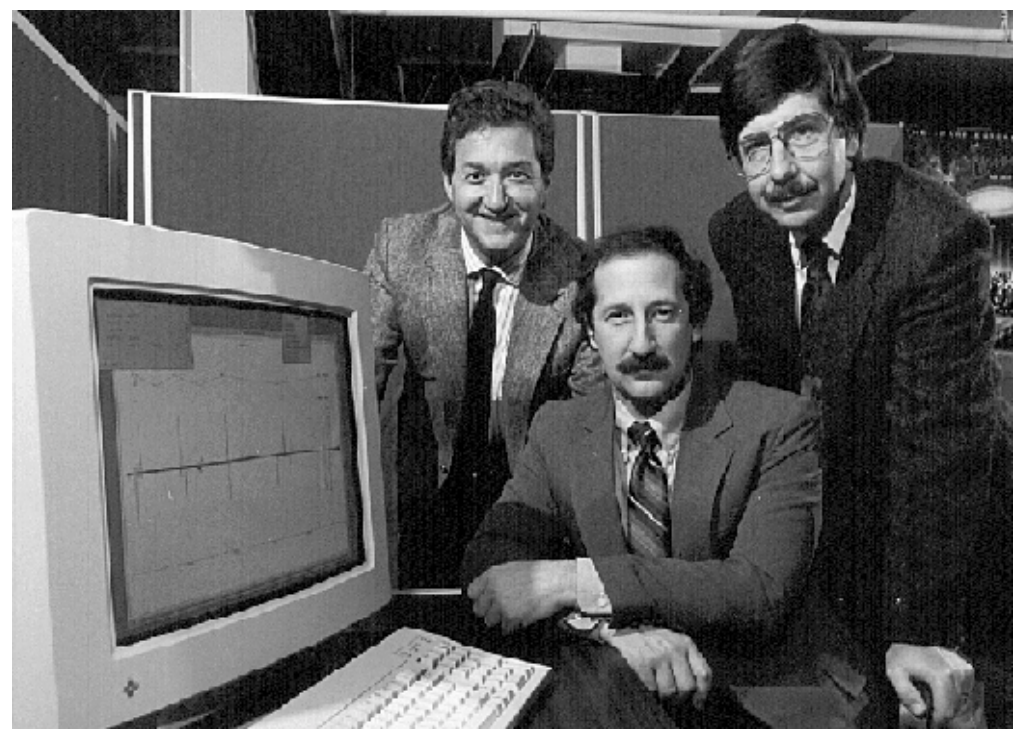

Reinhold C. Mann (left) and Edward C. Uberbacher (seated) of EMPD and Richard J. Mural, Biology Division, developed an intelligent computer system known as GRAIL (Gene Recognition \& Analysis Intemet Link) to identify the genetically useful protons of DNA sequence data. They are observing a graphic display of the output from the GRAIL system. ORNL $12197-91$

- Sub-threshold fission experiments at ORELA in the late 1970s by de Saussure and others, the double and triple fission barrier concepts, important for reactor design and theory (Dickens)

- Work by Chia-Yao (Peter) Fu, Nancy and Duane Larson, which resulted in substantial improvements in evaluation techniques and experimental data analysis. (Dickens)

- Development of practical techniques for global sensitivity and uncertainty analysis. (Peelle)

- Inclusion of intelligent systems research, to be attacked on the highest level of abstraction but with enough robotic device tests to keep thinking honest. (Peelle)

- Bringing Mathematical Sciences under the Division's wing, allowing ORNL at last to be a leader in computation capability under the large-scale multiple processor rubric. (Roussin) 
- The aggressive movement of Mathematical Sciences into parallel computing, which led to creation of the Center for Computational Sciences (CCS) and acquisition of one of the most powerful parallel computers in the world. (Sincovec)

- The Informatics effort, initiated in 1991, which led to the development of GRAIL (Gene Recognition and Analysis Internet Link), a multisensor/neural network pattern-recognition system for finding genes in DNA sequences. The system, now used by more than 600 laboratories worldwide to find genes, won a 1992 RD100 Award (E. C. Uberbacher, and R. C. Mann (EPMD), and $\boldsymbol{R}$. J. Mural of the ORNL Biology Division. (Mann)

- And just maybe, if things work out, extension of the multidisciplinary capability to include the human who labors with machines to increase productivity, and application of the advanced techniques to cope with understanding biological complexity. (Peelle)

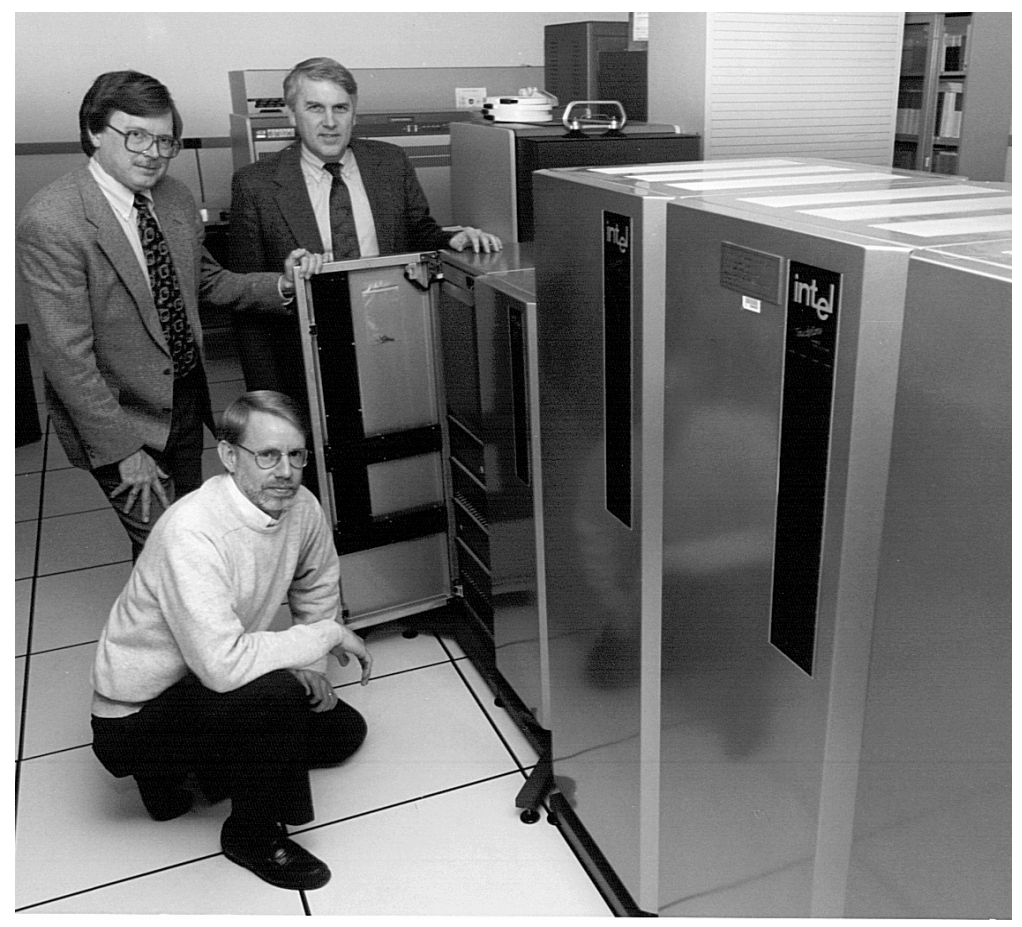

Richard Sincovec (left) and Robert C. Ward (standing) and Michael Lueze (front) inspect the Intel iPSC / 2 and iPSC 860 parallel computers, forenunners of the new Paragon supercomputer at ORNL. ORNL 1396-92

\section{COMMENTARY: “And, So, The Review of the Past Closes” by Betty F. Maskewitz}

As of July 1, 1993, the Division will be 38 years of age. It came into being in an environment largely dominated by research related to the atomic nucleus. The years have brought a gradual change towards the nonnuclear as can be seen clearly in the periodic progress reports. There is a nostalgic note in some of the commentaries - there was a lot of enthusiasm and 'Gung-Ho' job satisfaction among early NPD staff members.

The observation of 50 years of accomplishments in the various research programs at the Oak Ridge National Laboratory may prove to be cathartic for 'Old-Timers.' We can count our blessings for the work we enjoyed and the colleagues with whom we shared some challenging years. The Division has attracted some gifted people to deal with the present, and they will bring their imagination, enthusiasm, and technical skills to the research problems and programs of the future. 
Robert W. Roussin a c compa nies Alice Rice as she presents David Trubey with a special memento upon his retirement in 1992. ORNL 4777-92
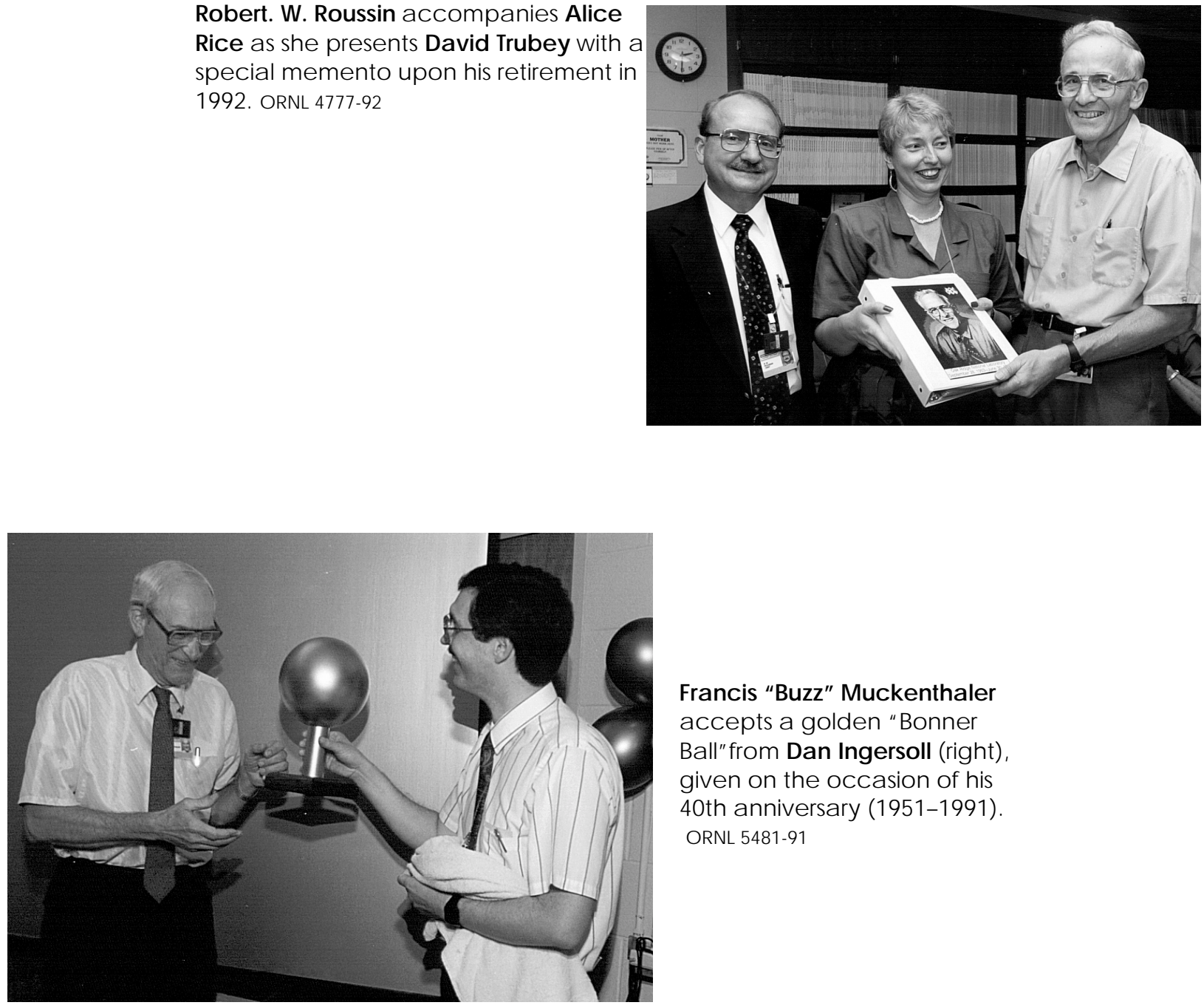

Franc is "Buzz" Muckenthaler accepts a golden "Bonner Ba ll"from Dan Ingersoll (right), given on the occasion of his 40th a nniversa ry (1951-1991). ORNL 5481-91

Franc is G. Perey (far right) is greeted by colleagues upon his 1990 retirement. From left a re Cleland Johnson (Physics), Nat Hill (I\&C), Claire Perey, Richard Macklin, and $\mathbf{S}$. Raman (Physic S). ORNL 1085-90

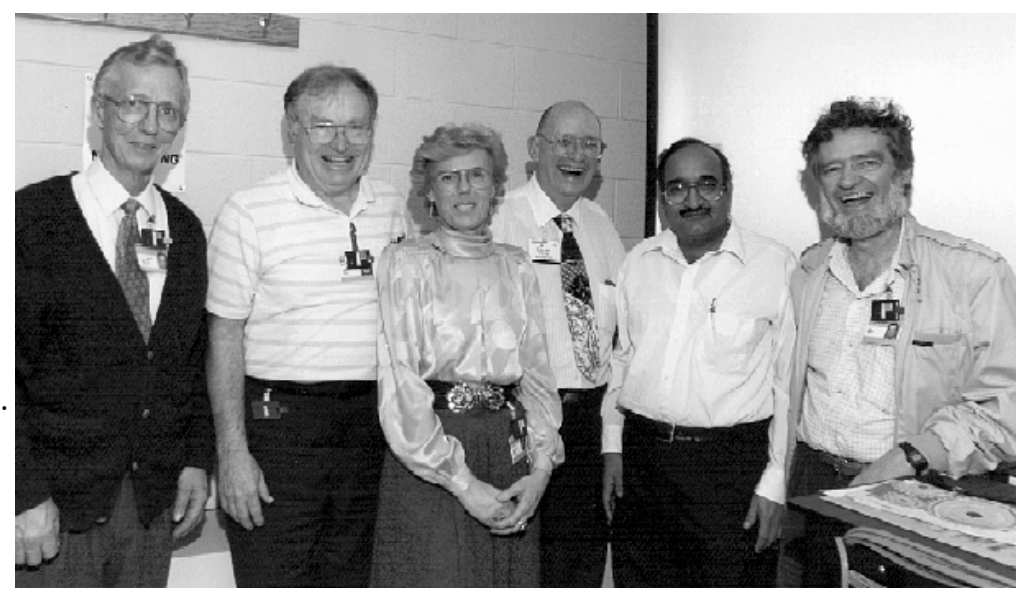




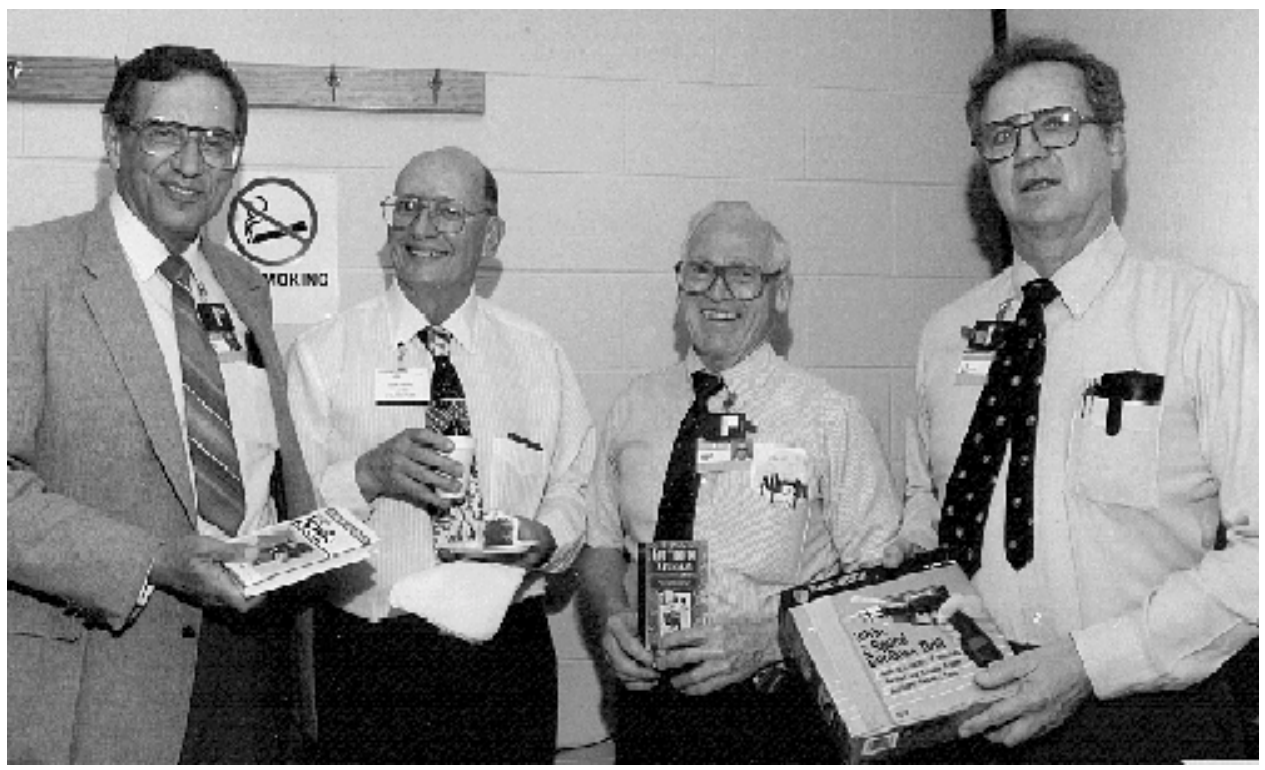

Gifts to fill his time are presented to retiree Richard L Macklin (1956-1990) by (from left) Bob Peelle, Macklin, Jack Harvey, and J im Johnson (Physics). ORNL 108690

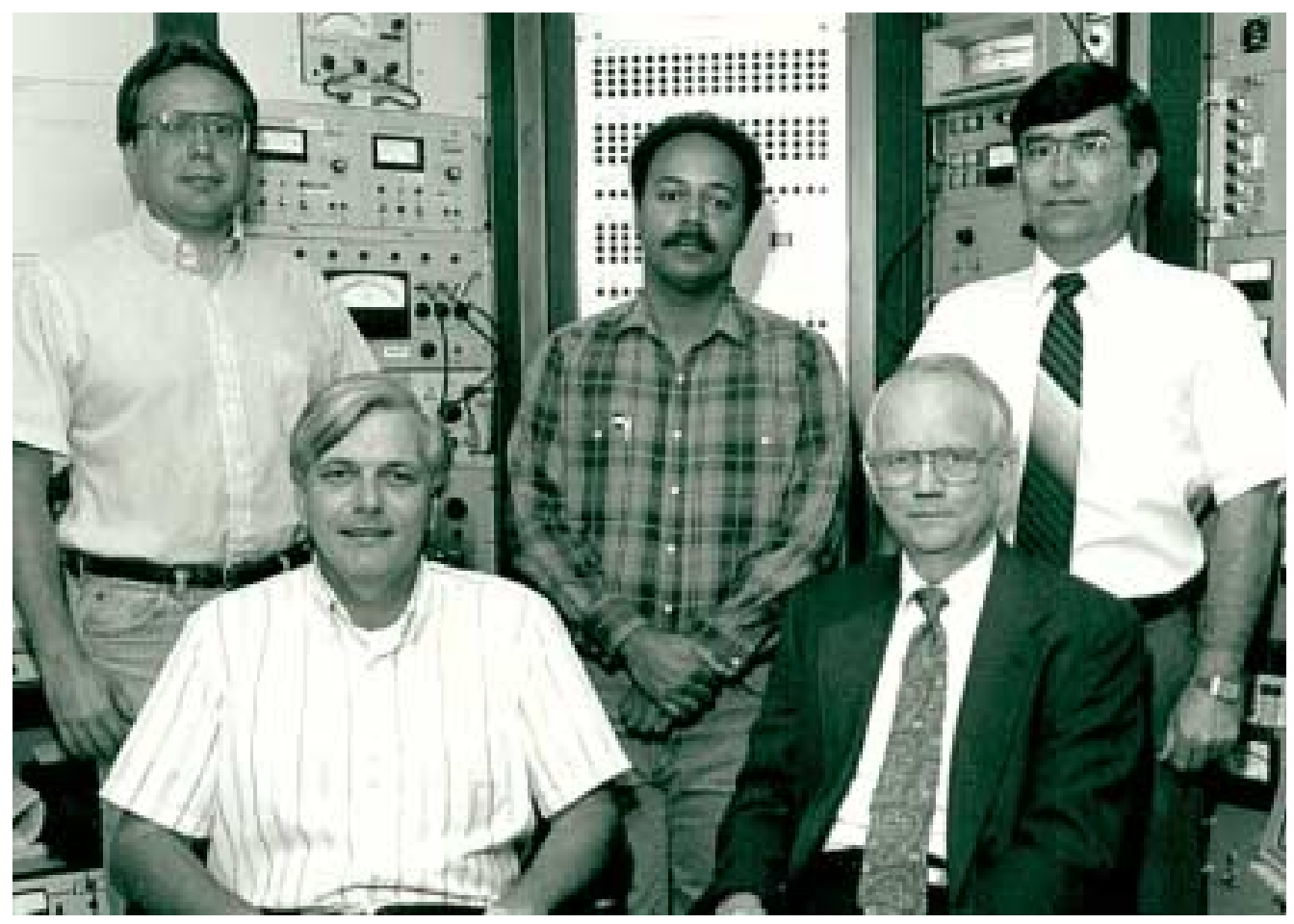

ORELA operations team, 1992, seated from left, Michael Cauley and T. A. Lewis; standing from left Jemy Atchley, Dan Gamer, and Don Pierce. ORNL 9587-92 


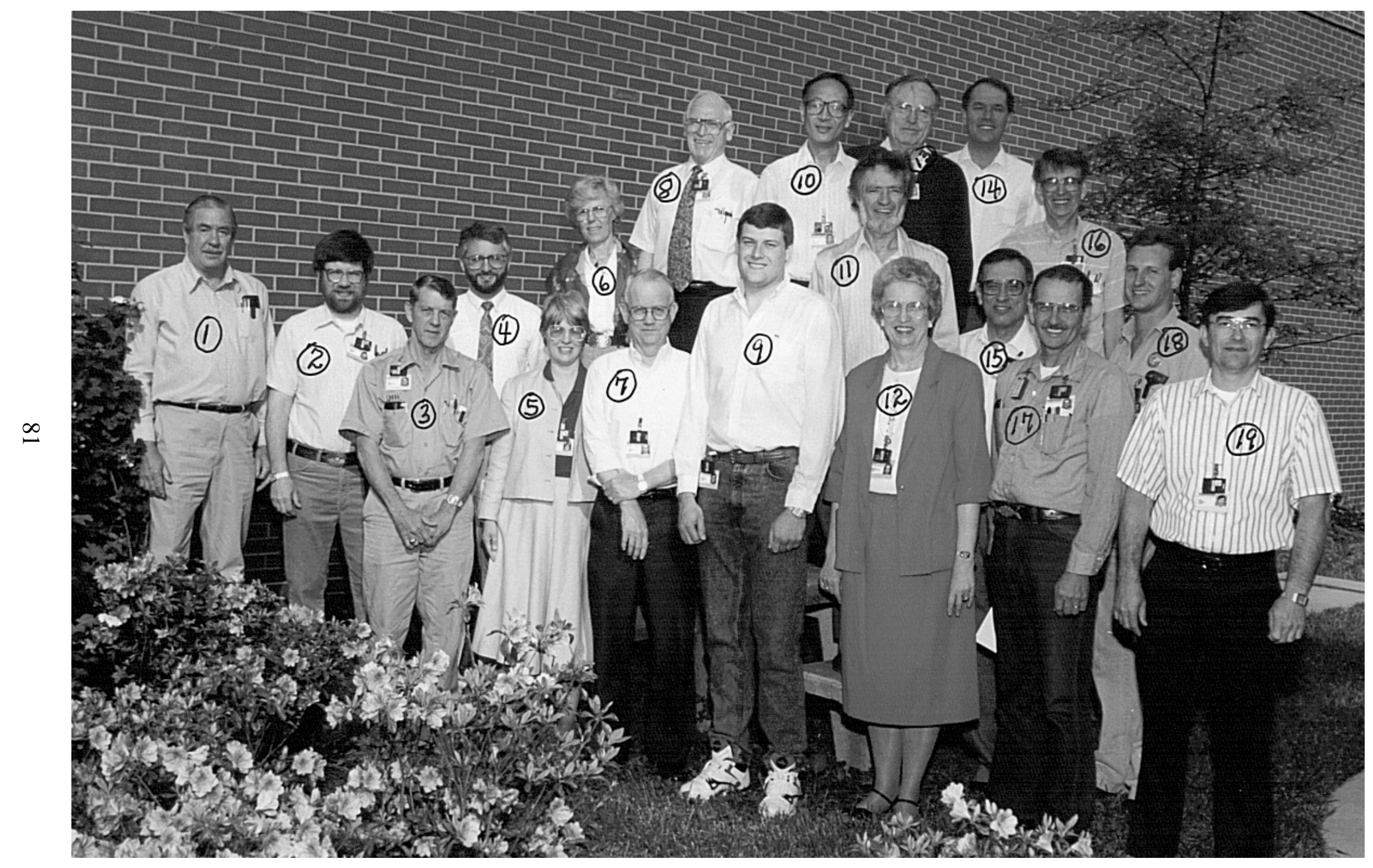

ORELA staff members give a warm "send-off" to Dale Hensley as he leaves the division in 1991: 1-J im Todd, 2-Duane Larson, 3-Ken Wallace (HPD), 4-Dave Hetrick, 5-Nancy Larson, 6-Claire Perey, 7-T. A. Lewis, 8-J ack Haney, 9-Dale Hensley, 10-Peter Fu, 11-Franc is Perey, 12-Sue Damewood, 13-Nat Hill, 14-J ack Craven, 15-Bob Peelle, 16-Rex Ingle, 17-Dick Green, 18-Wayne Finch and 19-Don Pierce. ORNL 3931-91 


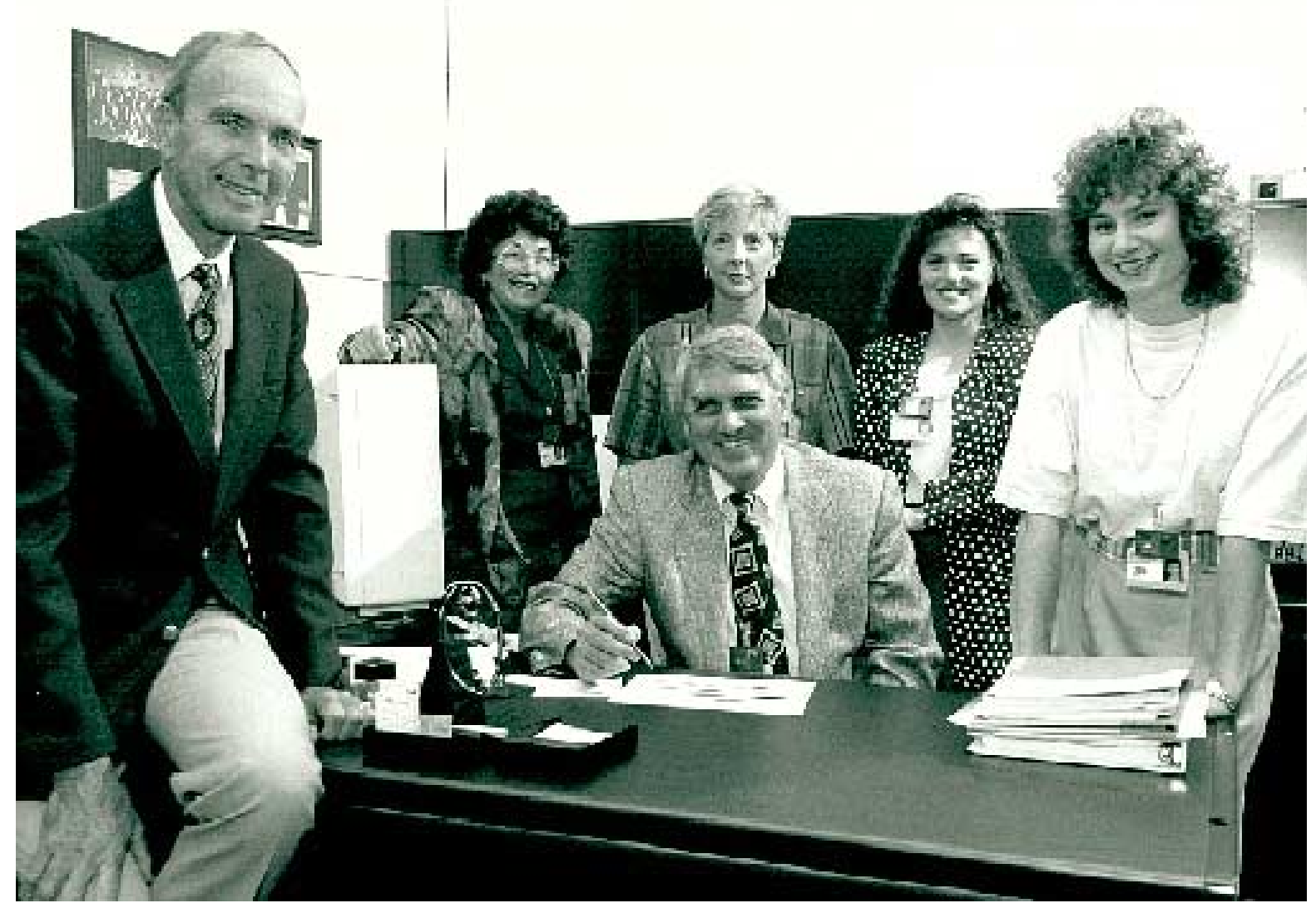

The EPMD Office staff takes time for a 1992 photo (from left, standing): Donna R. Burton (division sec retary), Stephanie A. Raby (public a tions), Kimberly D. Bames (finance offic er), and Tamara $\mathbf{R}$ Henson (operations secretary: (sea ted, from left) Cloyd O. Beasley (operations mana ger), and EPMD Director, Robert C. Ward. ORNL 6461-92

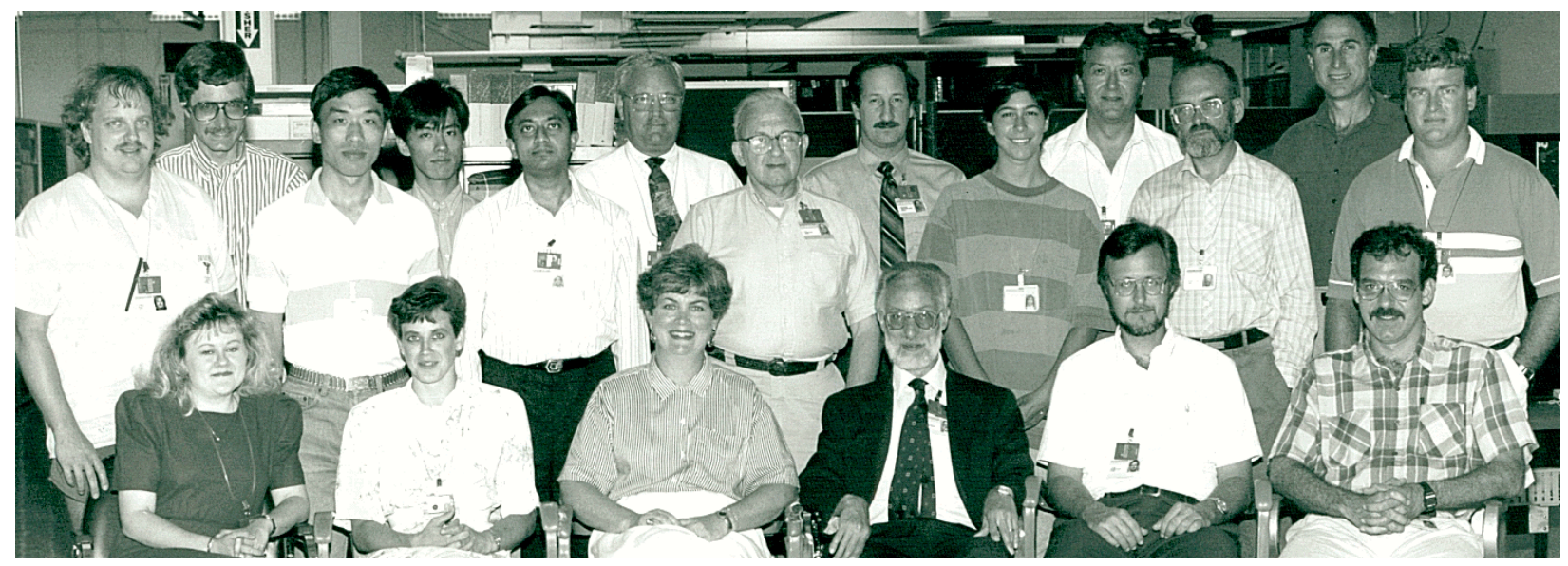

The Intelligent Systems Section sits for a portra it, circa 1992. Front row from the left, Karen S. Harber, Anita J. Alton, Susan L Rider, Martin Beckeman, J ack C. Schryver, J udson P. Jones Sec ond row, James E Baker, Xiaojun Guan, Manesh B. Shah, J. Ralph Enstein, Michelle Moulton, Sergei Petrov, Charles W. Glover, third row, Michael A. Unseren, Yutaka Watanabe, Philip F. Spelt, Edward C. Uberbacher, Reinhold C. Mann, Edward M. Oblow. ORNL-6364-92 


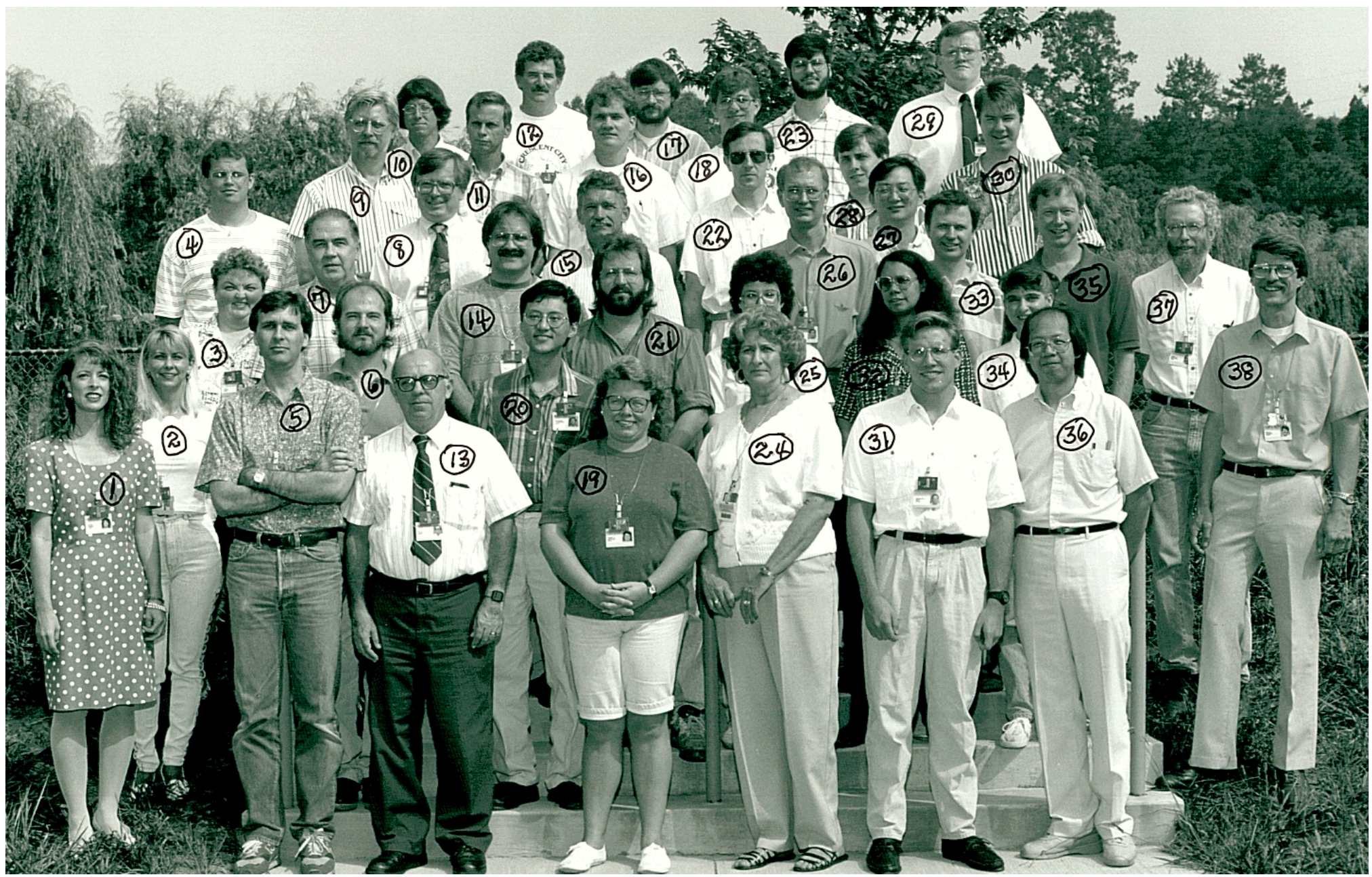

The Mathematical Sciences Section. In numeric al order. 1-Dawn Human, 2-Marjorie Hamis, 3-J udy Green, 4-?, 5-Dave Semeraro, 6Patrick Worley, 7-Emon Leach, 8-Rich Sincovec, 9-Gary Hartman, 10-Rick Schmoyer, 11-Tom Dunigan, 12-Len Gray, 13-Bill Lever, 14-Bill Shelton, 15-Daryl Downing, 16-Chuck Romine, 17-Tom Rowan, 18-Mark Dewing, 19-Tammy Darland, 20-Eduardo D'Azevedo, 21-Ray Fanery, 22-David Walker, 23-Ken Bateman, 24-J anice Trent, 25-Debbie Fanagan, 26-Bamy Peyton, 27-J aeyoung Choi, 28Bruce Lowekamp, 29-Charles Leete, 30-Nick Van Goor, 31-Doug Sept, 32-J une Donato, 33-George Ostrouchov, 34-Carol San Soucie, 35-J ohn Drake, 36-Esmond Ng, 37-Toby Mitchell, 38-Max Momis. ORNL 5817-92 


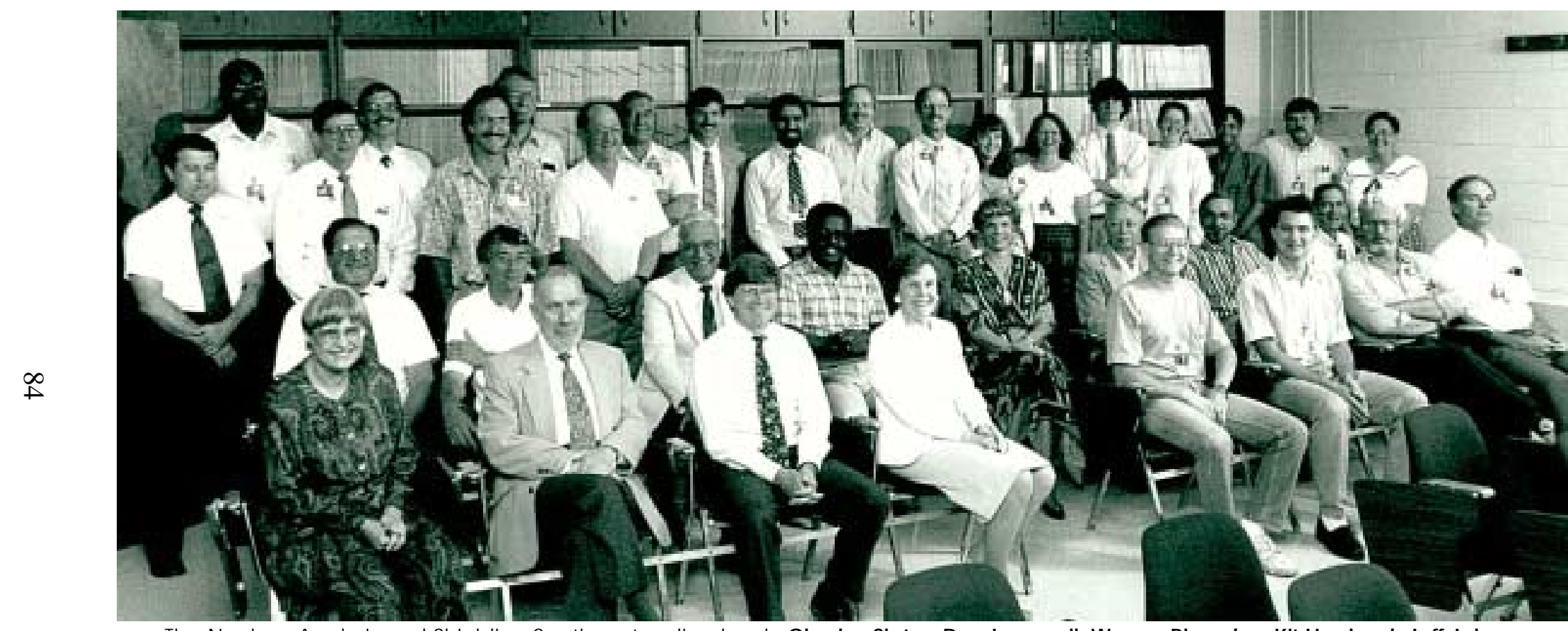

The Nuclear Analysis a nd Shield ing Section: sta nding ba ck: Charles Sater, Dan Ingersoll, Wayne Rhoades, Kit Haaland, Jeff J ohnson, Yousry Azmy, Trent Primm, Mark Smith, Christine Parks, Barbara Bishop, Robert Mc Nees, Sally Gaff, Shree Whitaker, Lamy Williams, Angie Alford: standing front; J im Bucholz, J oe Pace, Hamilton Hunter, Bob Spencer, sea ted ba ck: Tony Gabriel, Dick Lillie, Bob Santoro, J ohn Bames, Sue Shriner, Dick Maerker, Vladimir Protopopesc u, J im Drisc hler, seated front; Fran Alsmiller, Tut Alsmiller, Brian Worley, Peggy Emmett, Patrick Brantley, Alan Smith, Tom Bums, Ward Engle. ORNL 5450-92 


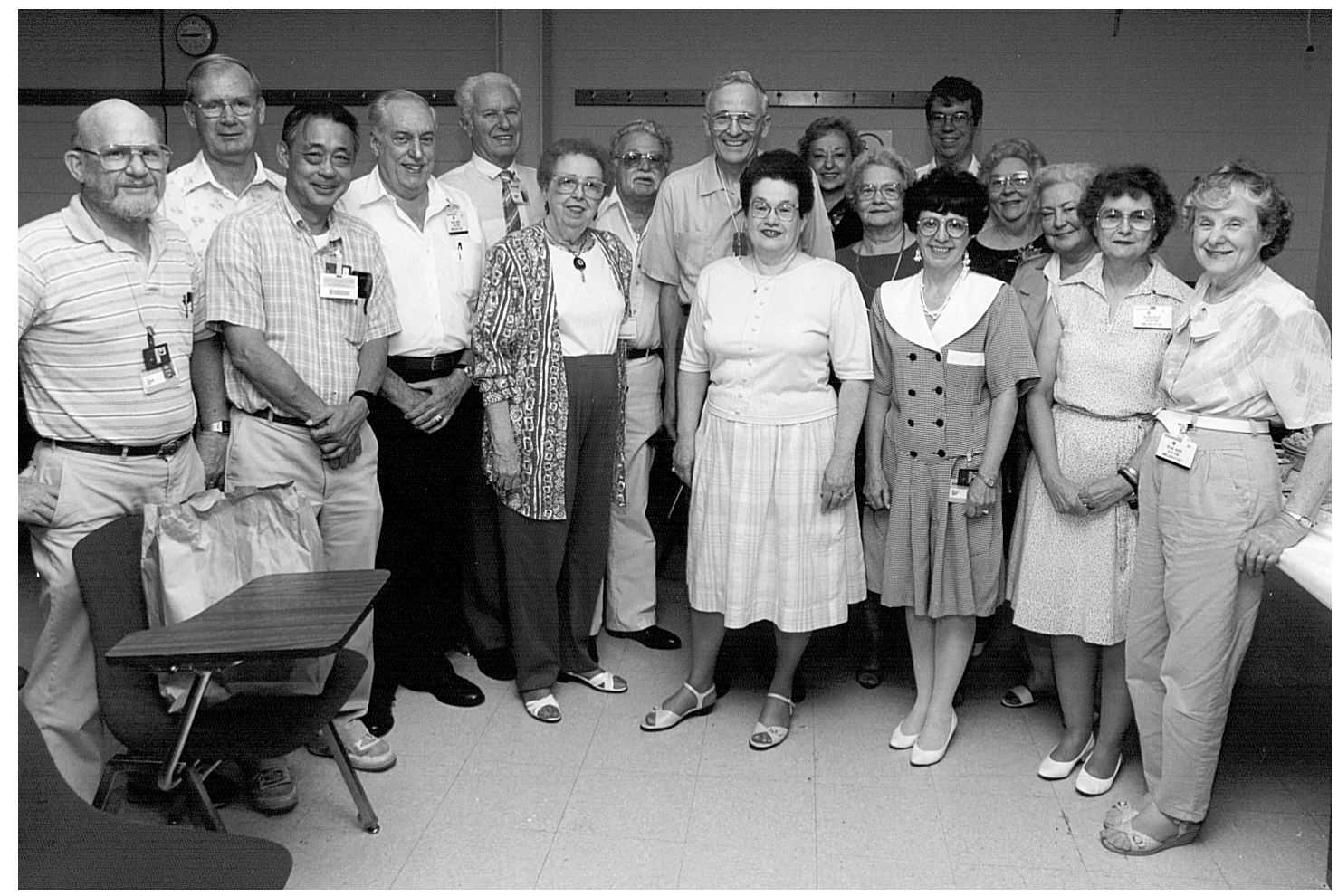

Giving Trubey a sendoff upon his retirement (from the left) Pemy Gouge, J ohn Miller, Lincoln J ung, J ack Taylor, Francois Kertesz, Rebecca Rickman, Hary Maggart, Trubey, Lomaine Abbott, Vivian Jacobs, Ann Gustin, Betty Clack, Van Baxter, Hennietta Hendrickson, Jane Gumey, J uanita Wright, and Mildred Landay. ORNL 4772-92

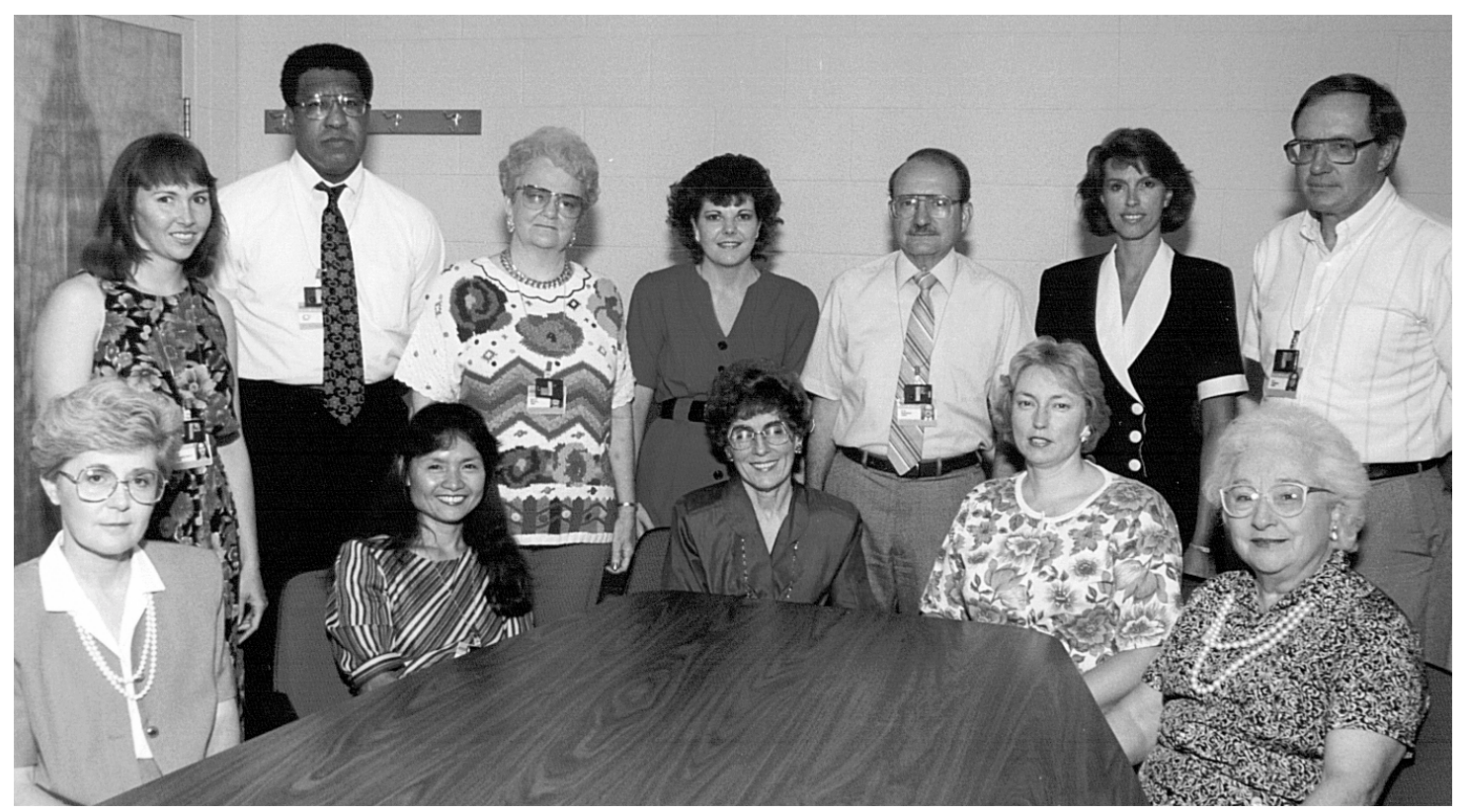

RSIC aga in celebratesa milestone year, its 30th a nniversa ry, in 1992. From left stand ing, J ennifer B. Mannesc hmidt, J ohn E. White, Betty L Mc Gill, Barbara J. Snow, Robert W. Roussin, Sheila V. Taylor, S. Noel Cramer, seated from left, Nancy A. Hatmaker, Bemadette L Kirk, Carol P. Coker, Alice F. Rice, and Betty F. Maskewitz (consultant). ORNL 5734-92 


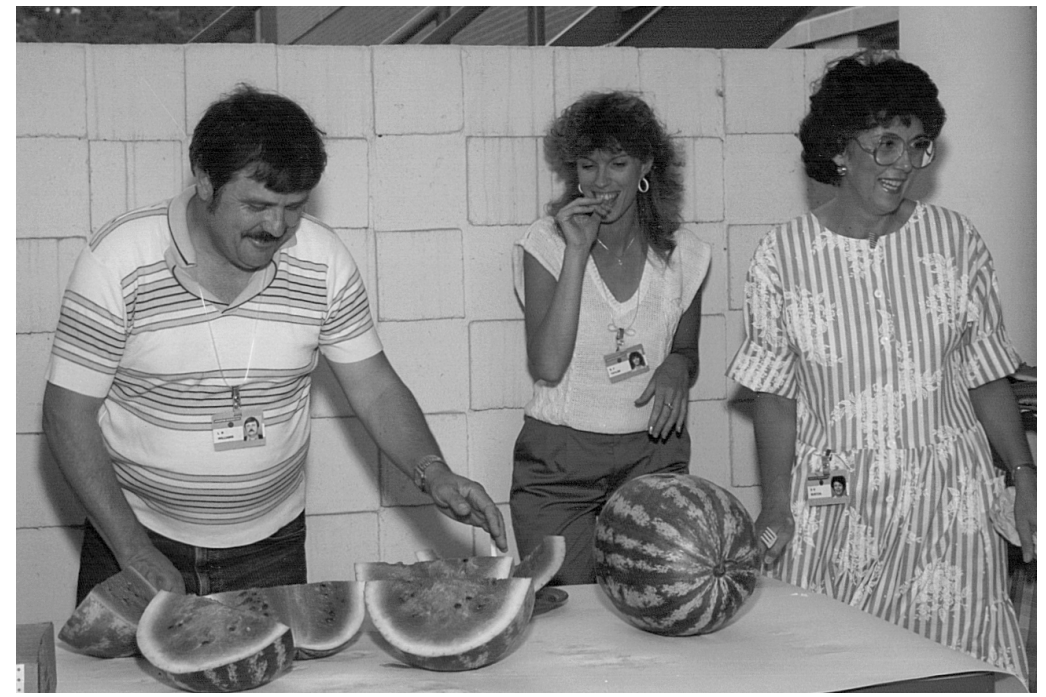

A welc ome watermelon feast relieves a hot summer day in 1992 and leads to a high level of camaraderie with the division. Lany Williams serves, assisted by Sheila Taylor, and Donna Burton.

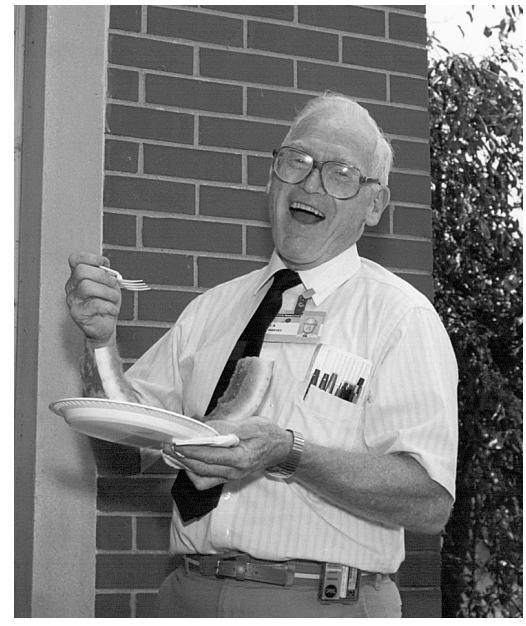

J ack Hawey a p preciates a slice of cold watemelon on a summer's day.

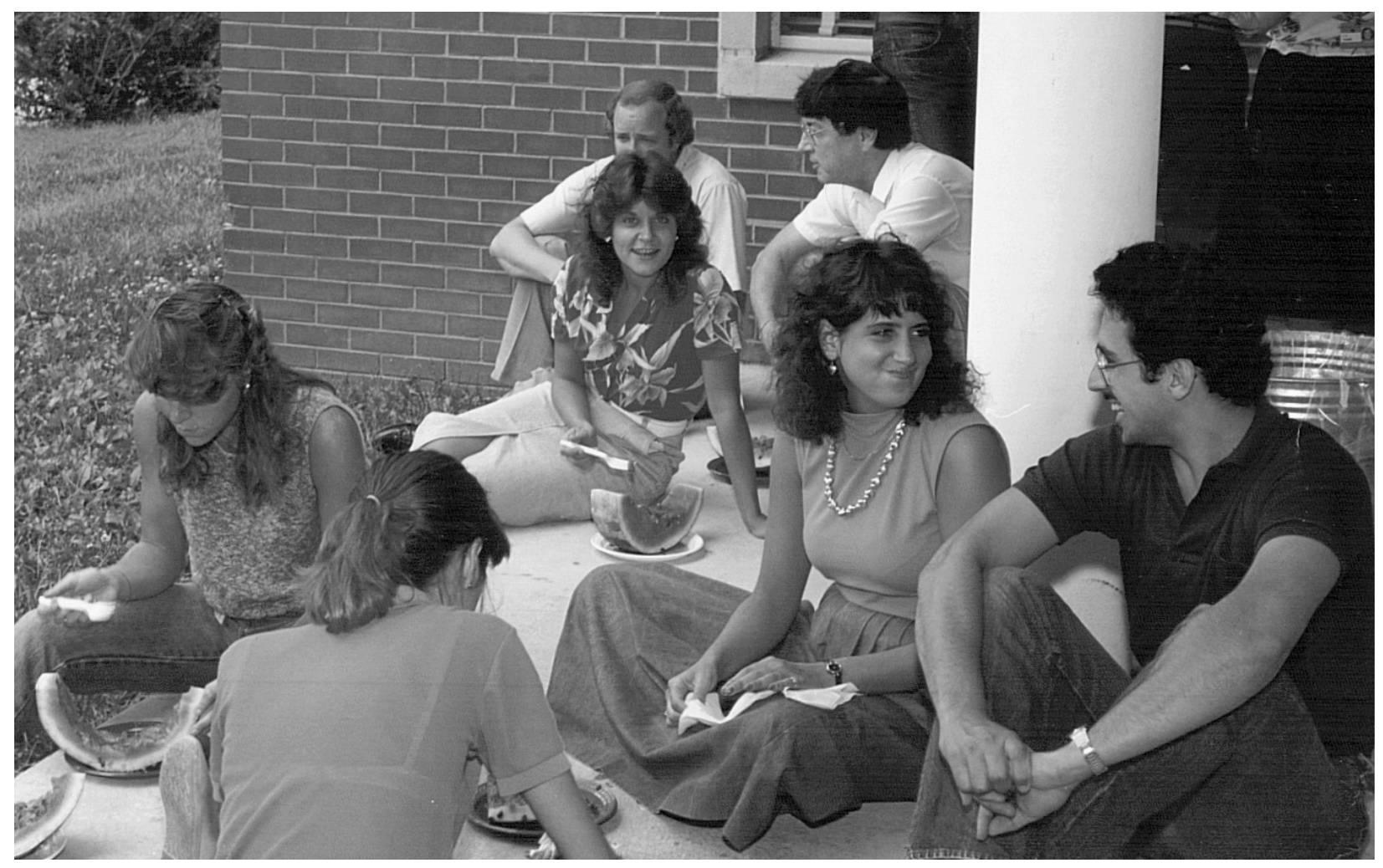

Staff members and students enjoy a summer treat. 


\section{REFERENCES}

1. Applied Nuclear Physics Division Annual Report for the Period Ending September 10, 1956, preface, ORNL-2081.

2. Lorraine S. Abbott, "The Origin of Shielding Research at ORNL," ORNL Review, 9:4, (53-55) Fall 1976.

3. Lorraine S. Abbott, "The Origin of Radiation Shielding Research: The Oak Ridge Perspective" Pages page 1-8 in Early Test Facilities and Analytic Methods for Radiation Shielding, Proceedings of a Special Session for the Radiation Protection and Shielding Division at the American Nuclear Society Winter Meeting, Chicago, Illinois, November 15-20, 1992, ORNL/RSIC-55 (November 1992).

4. A. Dixon Callihan, "Reminiscences on Critical Experiments," ORNL Review, 5:4 (1976), 98-99.

5. F. J. Muckenthaler, "Where Have the Neutrons Gone - A History of the Tower Shielding Facility," pages 33-46 in Early Test Facilities and Analytic Methods for Radiation Shielding, Proceedings of a Special Session for the Radiation Protection and Shielding Division at the American Nuclear Society Winter Meeting, Chicago, Illinois, November 15-20, 1992, ORNL/RSIC-55, (November 1992).

6. Francis J. Muckenthaler, The Tower Shielding Facility — It's Glorious Past, ORNL-12339, 1993.

7. Carolyn Krause, "Bulk Shielding Reactor Shut Down Permanently," ORNL Review, 25:1 (1992), 71.

8. A. M. Weinberg, "State of the Laboratory-1969," pp 1-14, ORNL Review, Winter 1970.

9. Engineering Physics and Mathematics Division Progress Report for the Period Ending June 30, 1985, ORNL-6214, preface. 


\section{APPENDICES}




\title{
APPENDIX A DIVISION RECIPIENTS OF HONORS AND AWARDS
}

\author{
Abbott, Lorraine S. \\ 1979 Society for Technical Communications, East TN Chapter - 2nd Place Prize, Annual Reports \\ 1979 Society for Technical Communications, East TN Chapter - 1st Place Prize, Technical News \\ Articles
}

Alsmiller, Rufard G., Jr.

1972 American Nuclear Society — Fellow

1979 American Nuclear Society Radiation Protection and Shielding Division — Best Paper Award

Azmy, Yousry Youssef

1986 American Nuclear Society — Mark M. Mills Memorial Award

Barhen, Jacob

1982 American Nuclear Society Reactor Physics Division — Best Paper Award

Barnes, John M.

1979 American Nuclear Society Radiation Protection and Shielding Division - Best Paper Award

Bartine, David E.

1978 American Nuclear Society Radiation Protection and Shielding Division — Outstanding Service Award

Beasley, Cloyd O., Jr.

1983 Union Carbide Corporation — Community Service Award

Blizard, Everitt P.

1960 American Nuclear Society — Editor of Nuclear Science and Engineering (NS\&E), 5-yr appointment

1961 American Nuclear Society - Fellow

1965 American Nuclear Society - Editor of NS\&E Special Service Award

1965 Ottawa University, Kansas - Honorary Doctorate

1966 Franklin Institute - Elliott Cresson Medal

1967 American Nuclear Society — NS\&E Memorial Issue, February 1967

1980 American Nuclear Society — 25th Anniversary Exceptional Service Award

Booth, Ray S.

1984 American Nuclear Society — Fellow

Bowman, Kimiko O.

1970 American Association for the Advancement of Science - Fellow

1976 American Statistical Association - Fellow

1978 International Statistical Institute - Ordinary Member

1978 Radford College, Virginia - Most Outstanding Alumnae

1988 Institute of Mathematical Statistics - Fellow

1988 Association for Women in Science, East TN Chapter - Award for Distinguished and Sustained Contributions to Science 
1989 Institute for Scientific Information - Citation Classic "Tables for Determining Statistical Significance of Mutation"

\section{Buhl, Anthony R.}

---- American Nuclear Society - Fellow

\section{Cacuci, Dan G.}

1984 American Nuclear Society - Fellow

1984 American Nuclear Society — Associate Editor of Nuclear Science and Engineering,

1986 American Nuclear Society — Editor of Nuclear Science and Engineering, indefinite appointment

\section{Callihan, A. Dixon}

1958 American Physical Society — Fellow

1960 American Nuclear Society — Fellow

1964 Marshall University, West Virginia - Honorary Doctorate

1965 American Nuclear Society — Editor of Nuclear Science and Engineering (indefinite appointment)

1967 American Nuclear Society - David V.P. Williams Memorial Award

1980 American Nuclear Society - 25th Anniversary Exceptional Service Award

1983 American Nuclear Society — Distinguished Service Award

1988 American Nuclear Society — Standards Service Award

\section{Carter, R. J.}

1991 Human Factors Society — Bulletin Editor

\section{Clifford, Charles E.}

1972 American Nuclear Society — Fellow

\section{Currence, Nancy S.}

1979 Professional Secretaries International - Certified Professional Secretary

\section{Dabbs, John W.T.}

1957 American Physical Society — Fellow

\section{de Saussure, Gerard}

1971 American Nuclear Society - Fellow

1974 American Nuclear Society Reactor Physics Division — Executive Committee

1975 American Nuclear Society Reactor Physics Division — Best Paper Award

1982 American Nuclear Society Reactor Physics Division — Best Paper Award

\section{Difilippo, Felix C.}

1988 American Nuclear Society — Fellow

\section{Drake, J. B.}

1988 American Society for Mechanical Engineers Solar Energy Division — Best Paper

1990 American Society for Mechanical Engineers — Best Paper

\section{Dresner, Lawrence}

1973 Fulbright-Hays Award - Fellowship 


\section{Engle, Ward W.}

1979 American Nuclear Society Radiation Protection and Shielding Division — Technical Achievement Award

1988 American Nuclear Society — Fellow

Flanagan, George F.

1987 American Nuclear Society — Board of Directors (3 yr)

Fontana, Mario H.

1977 Society for Technical Communications, East TN Chapter — 2nd Place, Technical Journal Articles

1981 American Nuclear Society — Fellow

Gabriel, T. A.

1985 American Nuclear Society Radiation Protection and Shielding Division — Professional Excellence Award

1991 American Physical Society - Fellow

Geist, G. A.

1990 International Business Machines Supercomputing Competition — First Place in Distributive and Cooperative Processing

1990 Cray Research, Inc. - Gigaflop Performance Award

1991 Institute of Electrical \& Electronic Engineers, Inc. — Gordon Bell Prize Winner

\section{Gosslee, David G.}

1976 American Statistical Association - Fellow

1977 American Association for the Advancement of Science — Fellow

\section{Halbert, Edith C.}

1972 American Physical Society — Fellow

\section{Hanauer, Stephen $\mathbf{H}$.}

1965 NRC - Advisory Committee on Reactor Safeguards (4 yrs)

\section{Harvey, John A.}

1957 American Physical Society - Fellow

1992 Martin Marietta Energy Systems — Two Technical Achievement Awards

Hebble, Thomas L.

1986 American Welding Society — W. H. Hobart Memorial Award

Human, Dawn C.

1990 Martin Marietta Energy Systems Engineering Physics and Mathematics Division Distinguished Secretarial Support

1992 Professional Secretaries International - Certified Professional Secretary

\section{Ingersoll, Dan T.}

1983 American Nuclear Society Radiation Protection and Shielding Division - Best Paper Award

1991 American Nuclear Society Radiation Protection and Shielding Division — Chairman 
1992 American Nuclear Society Radiation Protection and Shielding Division — Distinguished Service Award

Johnson, Elizabeth B.

1975 American National Standards Institute - Citation for Contributions to the Field of Nuclear Criticality Safety

1982 American Nuclear Society — Fellow

Kam, Frank

1980 American Society for Testing and Materials — E-10 Award of Merit

Kirk, Bernadette L.

1970 Fulbright-Hays Award - Fellowship

1992 American Nuclear Society Radiation Protection and Shielding — Executive Committee

Knee, H. E.

1991 American Nuclear Society Human Factors Division — Executive Committee

Larson, Duane C.

1982 Union Carbide Corporation — Community Service Award

Lillie, Richard A.

1979 American Nuclear Society Radiation Protection and Shielding Division - Best Paper Award

Macklin, Richard L.

1967 American Association for the Advancement of Science — Fellow

1968 American Physical Society - Fellow

Maienschein, Fred C.

1971 American Nuclear Society — Fellow

Mann, Reinhold C.

1992 R\&D Magazine — R\&D 100 Award

\section{March-Leuba, Jose A.}

1986 American Nuclear Society — Mark Mills Award (Thesis co-directed by D. Cacuci and R. B. Perez)

Maskewitz, Betty F.

1974 American Nuclear Society Shielding and Dosimetry Division — Executive Committee

1975 American Nuclear Society Radiation Protection and Shielding Division — Outstanding Service Award

1980 American Nuclear Society - Certificate of Governance, Board of Directors (3 yrs), Executive Committee (2 yrs)

1980 American Nuclear Society — 25th Anniversary Exceptional Service Award

1982 American Nuclear Society - Fellow

1991 Association for Women in Science, East TN Chapter - Award for Distinguished and Sustained Contributions to Science 
Mihalczo, John T.

American Nuclear Society - Fellow

\section{Mitchell, Toby J.}

1978 American Statistical Association and the Biometric Society - George W. Snedecor Memorial Award

1979 American Statistical Association - Fellow

1989 Martin Marietta Corporation — Jefferson Cup Award

Moses, David L.

1987 State of Tennessee - Certified/Registered Professional Engineer

Muckenthaler, Francis J.

1980 American Nuclear Society Radiation Protection and Shielding Division - Technical Achievement Award

\section{Mynatt, Frederick R.}

1978 American Nuclear Society — Fellow

1979 American Nuclear Society Radiation Protection and Shielding Division — Technical Achievement Award

1982 USDOE Ernest O. Lawrence Memorial Award

\section{Otaduy, Pedro J.}

1981 ORNL — Eugene P. Wigner Fellowship

Peelle, Robert W.

1978 American Nuclear Society — Fellow

1989 International Atomic Energy Agency — USDOE Appointment/U.S. Representative on International Nuclear Data Committee

Perey, Francis G.

1969 American Physical Society - Fellow

1979 Union Carbide Corporation - Corporate Fellow (Research)

Perez, Rafael B.

1975 American Nuclear Society Reactor Physics Division — Best Paper Award

1978 American Nuclear Society — Fellow

1982 American Nuclear Society Reactor Physics Division — Best Paper Award

\section{Peyton, Barry}

1989 IEEE Software Journal — Gordon Prize Winner

Pin, Francois G.

1991 International Journal of Robotics and Mechatronics — Editorial Board

1991 Computers and Electrical Engineering Journal — Guest Editor

1991 Japanese Journal of Advanced Automation Technology — Editorial Board

1992 Intelligent and Fuzzy Systems Journal — Board of Associate Editors, appointment 
Protopopescu, V. A.

1990 Martin Marietta Corporation — Special Achievement Award

1991 Journal of Transport Theory and Statistical Physics - Editorial Board

1991 Journal of Mathematical Models and Methods in Applied Sciences — Editorial Board

\section{Radiation Shielding Information Center (RSIC)}

1987 American Nuclear Society Radiation Protection and Shielding Division - Professional Excellence Award

\section{Reister, D. B.}

1991 International ENERGY Journal — Associate Editor

\section{Rhoades, Wayne A.}

1981 American Nuclear Society Radiation Protection and Shielding Division — Technical Achievement Award

\section{Rickman, Rebecca}

1955 Professional Secretaries International, Oak Ridge Chapter - Margaret R. Stewart Cup, Member of the Year

\section{Roussin, Robert W.}

1986 American Nuclear Society Radiation Protection and Shielding Division — Chairman

1990 American Nuclear Society Radiation Protection and Shielding Division — Professional Excellence Award

\section{Santoro, Robert T.}

1979 American Nuclear Society Radiation Protection and Shielding Division - Best Paper Award

1986 American Nuclear Society — Fellow

1991 American Nuclear Society Radiation Protection and Shielding Division — Executive Committee

\section{Selby, Douglas L.}

1983 American Nuclear Society Oak Ridge/Knoxville Section — Outstanding Member of the Year

\section{Silver, Ernest G.}

1975 American Nuclear Society Reactor Physics Division — Best Paper Award

1984 ORNL Nuclear Safety Journal — Editor

1985 American Nuclear Society — Fellow

\section{Simon, Albert}

1956 American Physical Society — Fellow

\section{Solomon, Alan}

1988 American Society for Mechanical Engineers Solar Energy Division - Best Paper

1990 American Society for Mechanical Engineers — Best Paper

\section{Straker, Edward A.}

1974 American Nuclear Society — Fellow 
Thomas, James (Joe) T.

1975 American Nuclear Society - Nuclear Criticality Safety Achievement Award

1986 American Nuclear Society — Fellow

\section{Trubey, David K.}

1974 American Nuclear Society Shielding and Dosimetry Division - Chairman

1976 American Nuclear Society — Fellow

1983 American Nuclear Society Radiation Protection and Shielding Division - Technical Achievement Award

1991 American Nuclear Society — Standards Service Award

1992 American Nuclear Society — Rockwell Award

Uberbacher, E. C.

1992 Human Genome Organization — Elected Member

1992 R\&D Magazine - R\&D 100 Award

\section{Uppuluri, V. R. Rao}

1967 UK Royal Statistical Society — Fellow

1971 American Statistical Association - Fellow

1975 International Statistical Institute — Ordinary Member

\section{Ward, Robert C.}

1986 American Association for Advancement of Science — Fellow

\section{Weaver, Hanover}

1975 American Nuclear Society Reactor Physics Division — Best Paper Award

\section{Weisbin, Charles R.}

1988 Society for Technical Communications, East TN Chapter - 3rd Place, Promotional Materials

\section{Wells, Virginia M.}

1960 Professional Secretaries International, Oak Ridge Chapter - Margaret Stewart Cup, Member of the Year

\section{Wright, Tommy}

1980 American Journal of Mathematical and Management Sciences - Editorial Board

1988 American Statistical Association Advisory Committee to the U.S. Census Bureau - Chairman

1990 National Statistical Institute — Elected Member 


\section{APPENDIX B \\ ANPD—NPD—EPD—EPMD ADVISORY COMMITTEES 1955-1992}

$\underline{\text { Advisor }}$

Francis L. Friedman (Massachusetts Institute of Technology)

Herbert Goldstein (Columbia University)

Henry Hurwitz, Jr. (General Electric Research)

L. W. Nordheim (General Atomic)

Robert R. Wilson (Cornell Syn)

(Harvard University)

R. F. Taschek (Los Alamos Scientific Laboratory)

P. F. Gast (General Electric)

T. J. Thompson (Massachusetts Institute of Technology)

R. A. Charpie (Oak Ridge National Laboratory)

Gale Young (Oak Ridge National Laboratory)

M. L. Goldberger (California Institute of Technology)

G. Dessauer (Savannah River Laboratory)

M. H. Kalos (New York University-Courant Institute)

L. V. Spencer (Nat'l Bureau of Standards/Kansas State Univ.)

B. C. Diven (Los Alamos Scientific Laboratory)

W. N. Hess (National Aeronautics \& Space Administration)

E. R. Cohen (Rockwell International)

Herman Feshbach (Massachusetts Institute of Technology)

C. R. Mehl (District of Columbia, Consultant)

H. T. Motz (Los Alamos Scientific Laboratory)

Paul F. Fox (Westinghouse)

W.W. Havens (New York University)

A. F. Henry (Massachusetts Institute of Technology)

R. E. Uhrig (Florida Power \& Light)

Paul Greebler (General Electric)

W. B. Loewenstein (Electric Power Research Institute)

H. J. C. Kouts (USNRC/Brookhaven National Laboratory)

P. W. Dickson, Jr. (Westinghouse)

Don Steiner (Rensselaer Polytechnic Institute)

R. M. Haralick (University of Washington)

G. H. Golub (Stanford University)

J. J. Dorning (University of Virginia)

J. E. Liess (National Bureau of Standards/Consultant)

Mary F. Wheeler (Rice University)

N. Moray (University of Illinois)

R. W. Brockett (Harvard University)

Donald J. Dudziak (North Carolina State University, Raleigh) $\underline{\text { Term of Service }}$

$1955-1958$

$1955-1961$

$1969-1972$

$1975-1980$

$1955-1958$

$1955-1961$

1955-1958

1978-1982

1959-1964

1960-1963

1960-1963

1961-1964

1961-1962

1962-1966

1964-1967

1965-1968

1965-1968

1965-1969

1967-1968

1968-1970

1969-1974

1970-1973

1971-1972

1973-1976

1974-1977

1974-1977

1975-1978

1977-1980

1978-1982

1980-1985

1982-1985

1983-1987

1985-1989

1987-1991

1987-1991

1989-1993

1989-1993

1989-1993

1991-1994

1993-1996 


\section{APPENDIX C \\ 1993 EPMD ORGANIZATION CHART}

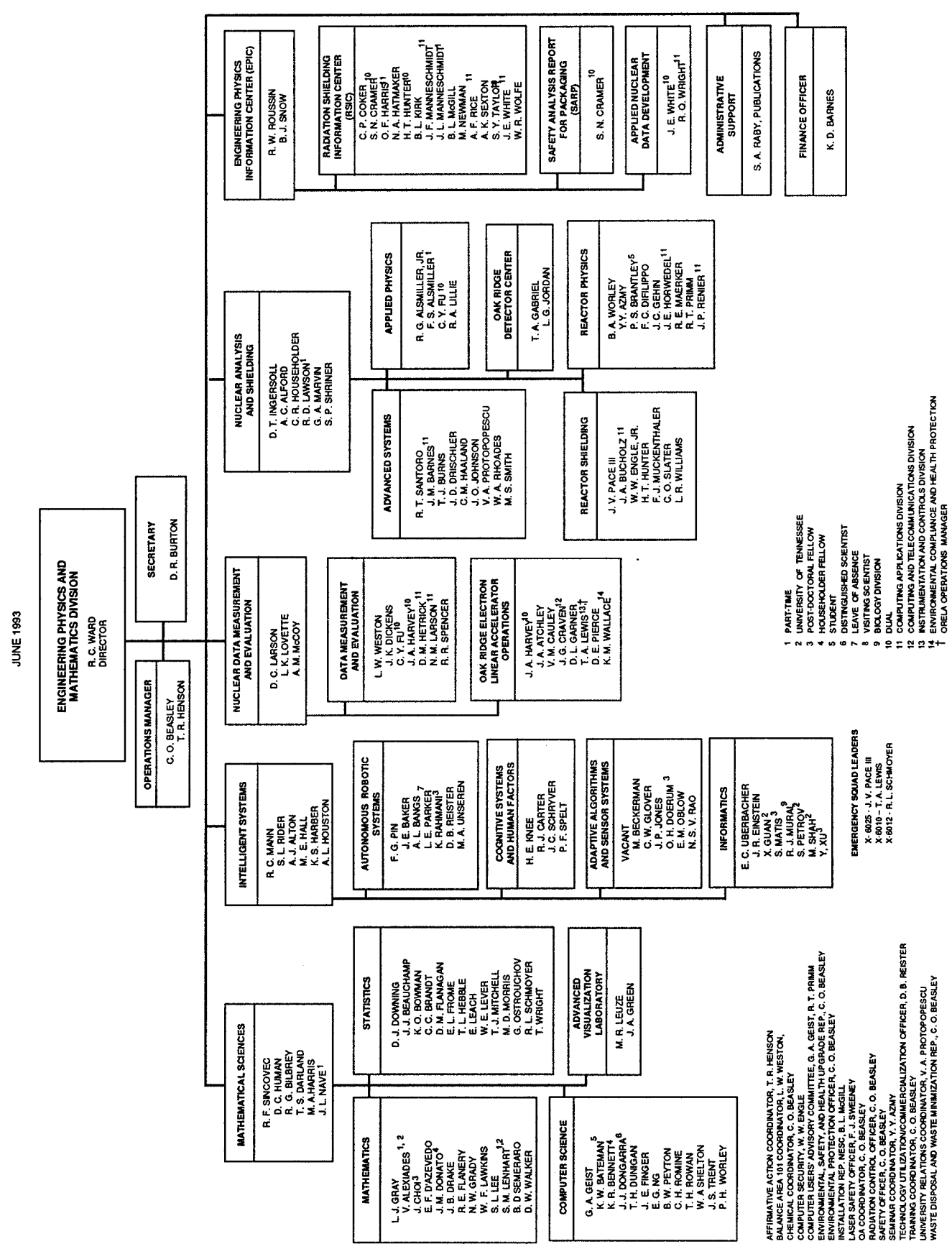




\section{INTERNAL DISTRIBUTION}

1-2. ORNL Laboratory Records-OSTI

3. ORNL Laboratory Records-RC

4. A. C. Alford

5. Yousry Y. Azmy

6. J. M. Barnes

7. Kimiko Bowman

8. Richard J. Carter

9. V. Mike Cauley

10. Justin Kirk Dickens

11. F. C. Difilippo

12. John B. Drake

13. J. D. Drischler

14. Margaret B. Emmett

15. Sheila Y. Finch

16. Raymond E. Flanery Jr.

17. E. L. Frome

18. Tony A. Gabriel

19. Daniel L. Garner

20. Nancy Wright Grady

21. N. M. Greene

22. William Ross Hamel

23. J. A. Harvey

24. Nancy A. Hatmaker

25. Hamilton T. Hunter

26. D. T. Ingersoll

27. Jeffrey O. Johnson

28. Ann G. Jordan

29. Bernadette L. Kirk
30. H. E. Knee

31. M. A. Kuliasha

32. Duane C. Larson

33. N. M. Larson

34. T. A. Lewis

35. Richard A. Lillie

36. Reinhold C. Mann

37. George Ostrouchov

38. J. V. Pace

39. Francis Georges Perey

40. Lester M. Petrie Jr.

41. Don Pierce

42. Francois G. Pin

43. R. Trenton Primm III

44. Vladimir A. Protopopescu

45. S. Raman

46. David B. Reister

47. J. P. Renier

48. Alice F. Rice

49. R. T. Santoro

50. Charles O. Slater

51. Philip F. Spelt

52. Edward C. Uberbacher

53. R. M. Westfall

54. J. E. White

55. Brian Addison Worley

56-60. RSICC

\section{EXTERNAL DISTRIBUTION}

61. Lorraine Abbott, 1303 Wilson Rd, Knoxville, TN 37912

62. Hugo W. Bertini, 915 West Outer Drive, Oak Ridge, TN 37830

63. Barbara L. Bishop, 7808 Luxmore Drive, Knoxville, TN 37919-6902

64. Donna Burton, 3351 Bird Road, Lenoir City, TN 37771-7359

65. V. R. Cain, 48 Brookside Drive, Oak Ridge, TN 37830-7670

66. Dixon Callihan, 400 Avinger Lane, Apt. \#404, Davidson, NC 28036

67. C. E. Clifford, 5304 Angeles Drive, Knoxville, TN 37918 
68. Carol Coker, 115 Independence Lane, Oak Ridge, TN 37831

69. Hemma Comolander, 157 S Purdue Avenue, Oak Ridge, TN 37830-7524

70. Ward W. Engle, 1151 Foster Drive, Lenoir City, TN 37772-5917

71. W. E. Ford, 11500 Kingston Pike, Farragut, TN

72. Janet P. Friedman, P.O. Box 455, Buckeystown, MD 21717-0455

73. Ann B. Gustin, 104 Norwood Lane, Oak Ridge, TN 37830-5236

74. R. Gwin, 218 Wakefield Road, Knoxville, TN 37922-2036

75. William H. Hannum, 213 Arlington Avenue, Naperville, IL 60565

76. Phillip B. Hemmig, 604 E Lynfield Drive, Rockville, MD 20852-1037

77. Henrietta Hendrickson, 3321 West Gallaher Ferry Road, Knoxville, TN 37932

78. L. Holland, 107 Carnegie Drive, Oak Ridge, TN 37830-7735

79. Vivian Jacobs, 100 Wilderness Lane, Oak Ridge, TN 37830

80. Miriam Kertesz, 360 Laboratory Road, Oak Ridge, TN 37830

81. Lawanda Klobe, 106 Brockton Lane, Oak Ridge, TN 37830

82. Mildred Landay, 122 Euclid Circle, Oak Ridge, TN 37830-4100

83. Joseph Lewin, 32508 W. Golf Ct., Pennbrooke, Leesburg, FL 34748

84. R. L. Macklin, 225 Outer Drive, Oak Ridge, TN 37830-3810

85. Richard Maerker, 724 Bristol Circle, Knoxville, TN 37923

86. Fred Maienschein, 838 W Outer Drive, Oak Ridge, TN 37830-8402

87-91. Betty F. Maskewitz, 112 Artesia Drive, Oak Ridge, TN 37830-7817

92. Betty McGill, 101 Plymouth Circle, Oak Ridge, TN 37830

93. Francis J. Muckenthaler, 117 Underwood Road, Oak Ridge, TN 37830-5247

94. E. M. Oblow, 21132 Berrywood Drive, Knoxville, TN 37932

95. Robert Peelle, 130 Oklahoma Avenue, Oak Ridge, TN 37830-8604

96. S. K. Penny, 4717 Guinn Rd., Knoxville, TN 37931

97. W. A. Rhoades, 110 Netherlands Road, Oak Ridge, TN 37830-8105

98. Rebecca Rickman, 118 East Pasadena Rd, Oak Ridge, TN 37830

99. R. W. Roussin, 101 Newcrest Lane, Oak Ridge, TN 37830

100. Thomas H. Rowan, 107 Haven Hill Lane, Oak Ridge, TN 37830-7941

101. Dr. Richard F. Sincovec, Director, Division of Computer Science, The University of Texas at San Antonio, 6900 North Loop 1604, San Antonio, Texas 78249-0667

102. E. A. Straker, SAIC, 10010 Campus Point Drive, San Diego, CA 92121

103. Jane Gurney Teasley, 109 Tucker Road, Oak Ridge TN 37830-5569

104. Dr. David K. Trubey, 3993 Clubhouse Ct, Apt 1E, High Point, NC 27265

105. Dave Vondy, 5200 Hickory Creek Road, Lenoir City, TN 37771-6908

106. Robert C. Ward, The University of Tennessee, Computer Science, 203 Claxton Complex, Knoxville, TN 37996

107. Alvin Weinberg, 111 Moylan Lane, Oak Ridge, TN 37830-5351

108. Charles Weisbin, 775 Starlight Heights Drive, La Canada Flintridge, CA 91011-1854

109. Larry Weston, 109 Wade Lane, Oak Ridge, TN 37830

110. R. Q. Wright, 41 Montclair Road, Oak Ridge, TN 37830-8333

111. Walter Zobel, 110 Stanton Lane, Oak Ridge, TN 37830-8408 